\title{
Periodicals and Serials Received in the Library of the National Bureau of Standards As of October 1965
}

United States Department of Commerce

National Bureau of Standards

Miscellaneous Publication 274 


\section{THE NATIONAL BUREAU OF STANDARDS}

The National Bureau of Standards is a principal focal point in the Federal Government for assuring maximum application of the physical and engineering sciences to the advancement of technology in industry and commerce. Its responsibilities include development and maintenance of the national standards of measurement, and the provisions of means for making measurements consistent with those standards; determination of physical constants and properties of materials; development of methods for testing materials, mechanisms, and structures, and making such tests as may be necessary, particularly for government agencies; cooperation in the establishment of standard practices for incorporation in codes and specifications; advisory service to government agencies on scientific and technical problems; invention and development of devices to serve special needs of the Government; assistance to industry, business, and consumers in the development and acceptance of commercial standards and simplified trade practice recommendations; administration of programs in cooperation with United States business groups and standards organizations for the development of international standards of practice; and maintenance of a clearinghouse for the collection and dissemination of scientific, technical, and engineering information. The scope of the Bureau's activities is suggested in the following listing of its three Institutes and their organizational units.

Institute for Basic Standards. Applied Mathematics. Electricity. Metrology. Mechanics. Heat. Atomic Physics. Physical Chemistry. Laboratory Astrophysics.* Radiation Physics. Radio Standards Laboratory:* Radio Standards Physics; Radio Standards Engineering. Office of Standard Reference Data.

Institute for Materials Research. Analytical Chemistry. Polymers. Metallurgy. Inorganic Materials. Reactor Radiations. Cryogenics." Materials Evaluation Laboratory. Office of Standard Reference Materials.

Institute for Applied Technology. Building Research. Information Technology. Performance Test Development. Electronic Instrumentation. Textile and Apparel Technology Center. Technical Analysis. Office of Weights and Measures. Office of Engineering Standards. Office of Invention and Innovation. Office of Technical Resources. Clearinghouse for Federal Scientific and Technical Information.**

\footnotetext{
*Located at Boulder, Colorado, 80301.

**Located at 5285 Port Royal Road, Springfield, Virginia, 22151.
} 
UNITED STATES DEPARTMENT OF COMMERCE - John T. Connor, Secretary NATIONAL BUREAU OF STANDARDS - A. V. Astin, Director

\section{Periodicals and Serials Received in the \\ Library of the National Bureau of Standards As of October 1965}

Natalie J. Hopper

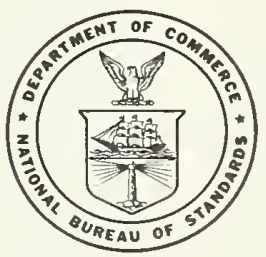

National Bureau of Standards Miscellaneous Publication 274 Issued July 1, 1966

(Supersedes NBS Monograph 57) 


\section{Contents}

1. Introduction _...

2. Alphabetical list _._- 1

3. Location of volumes -

List of periodicals and serials _-_-_- 3 


\title{
Periodicals and Serials Received in the Library of the National Bureau of Standards as of October 1965
}

\begin{abstract}
Natalie J. Hopper
This publication (which is a revision of the NBS Monograph 57) lists alphabetically the periodicals and serials, both American and foreign, that are currently being received in the Library of the National Bureau of Standards. Approximately 2,400 titles are cited, together with call numbers indicating the location of bound volumes in the Library. Although this information was compiled primarily for the use of the Bureau's scientific staff, it is also of value to libraries, scientific and technical organizations, and research workers.
\end{abstract}

Key words: Libraries, indexes (locators), translations, books, periodicals, bibliographies.

\section{Introduction}

The National Bureau of Standards was established in 1901 to provide technical assistance to industry, Government, and educational institutions. This assistance involves the development, maintenance, and dissemination of fundamental standards of physical measurement, and the systematic and accurate determination of physical constants and important properties of matter and materials. Early in 1964 the National Bureau of Standards was designated by the Secretary of Commerce to serve as the focal point in the Federal Government for assuring maximum application of the physical and engineering sciences to the advancement of technology in industry and commerce. To accomplish this objective, the Bureau is now organized into three institutes covering broad program areas of research and services: The Institute for Basic Standards, The Institute for Materials Research, and The Institute for Applied Technology.

To effectively conduct a technical program of this scope, the Bureau's scientific staff must have ready access to a good technical library. The NBS Library has a collection of over 100,000 bound volumes, including periodicals and books for loan and reference, and receives about 2400 different periodicals and serials. Although the listing that follows has been compiled primarily to inform the Bureau staff of currently received periodicals and serials, it is believed that the references given will be useful to librarians and research workers.

\section{Alphabetical List}

The titles are arranged in one alphabetical list, including Russian and translations which are indicated by an asterisk.

The arrangement of the titles is the same as the entries in the main catalog for bound volumes. For example:

1. Proceedings, transactions, journals, etc. of associations, societies, and academies are listed under the name of the organization-

American Chemical Society.

Journal

2. Publications of universities are under the name of the university or its location-

Harvard University. Cruft Memorial Laboratory. Progress report

Michigan. University. Engineering Experiment Station. Bulletin

3. Public institutions are listed by country if national, and by city if local-

Great Britain. Department of Scientific and Industrial Research. Building Research. Building science abstracts

Madrid. Laboratorio Central de Ensayo de Materiales de Construccion. Publicaciones 


\section{Location of Volumes}

The call number preceding the title indicates the shelf location of the bound volumes. The call number is added to the shelf tag of the current issues when the first volume is bound and classified.

A volume followed by "inc." indicates that some parts are missing. Consult the card catalog or a member of the Library staff for more detailed information.

"Ref." has been added to the call number when the set is shelved in the reference collection and is not circulated.

This publication also lists titles of "serial" publications not included in earlier editions. These are usually bound volumes of collected papers on a specific subject, such as "ADVANCES IN ELECTRONICS AND ELECTRON PHYSICS", published in a series at irregular intervals. They are classified and shelved with other bound volumes and are distinguished in the list by the symbol "\#". 


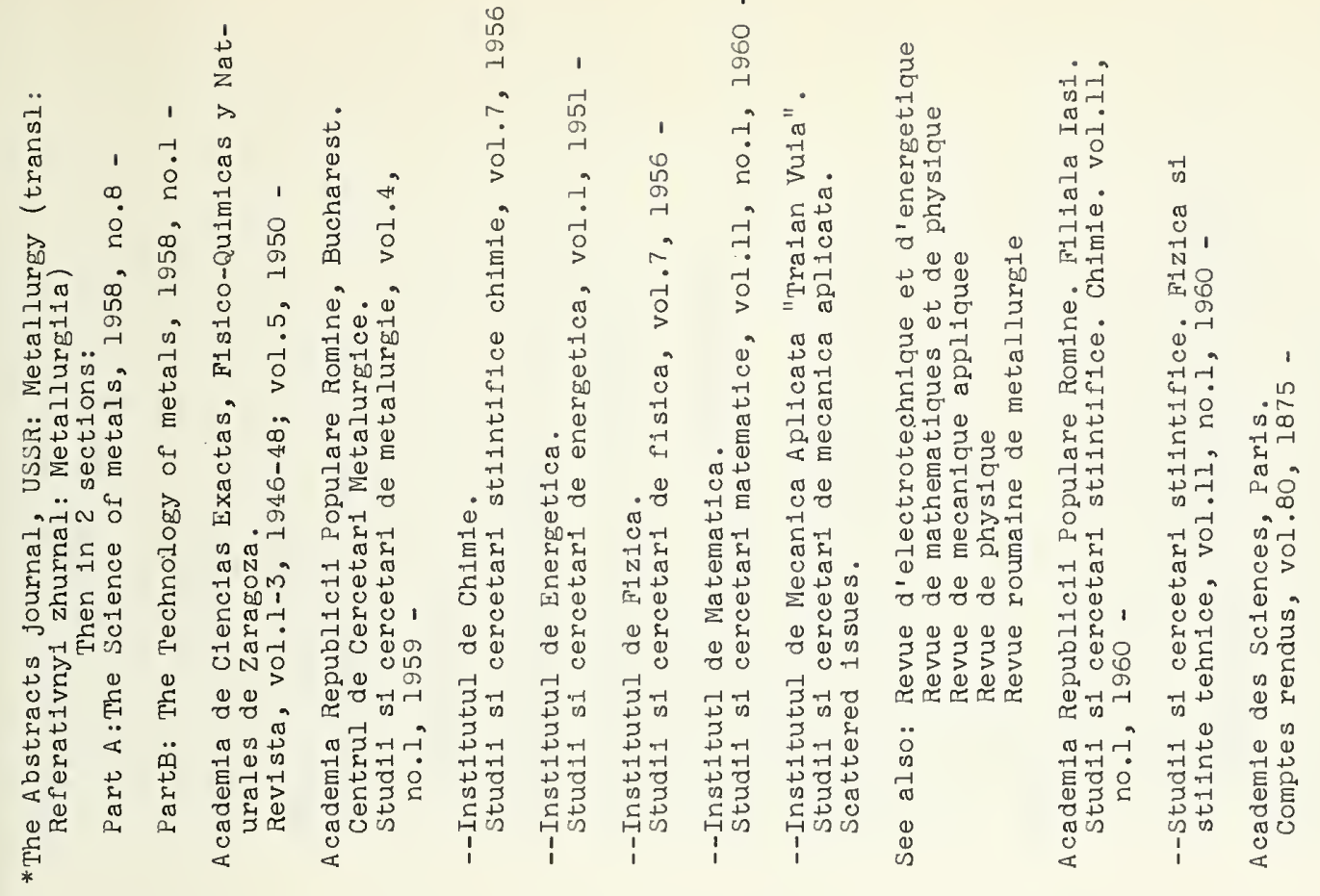

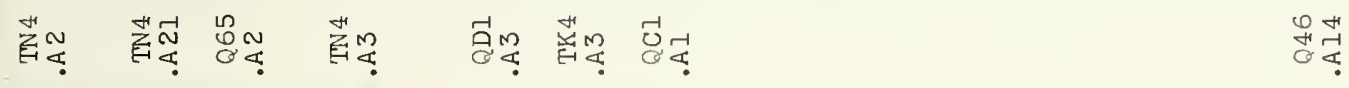

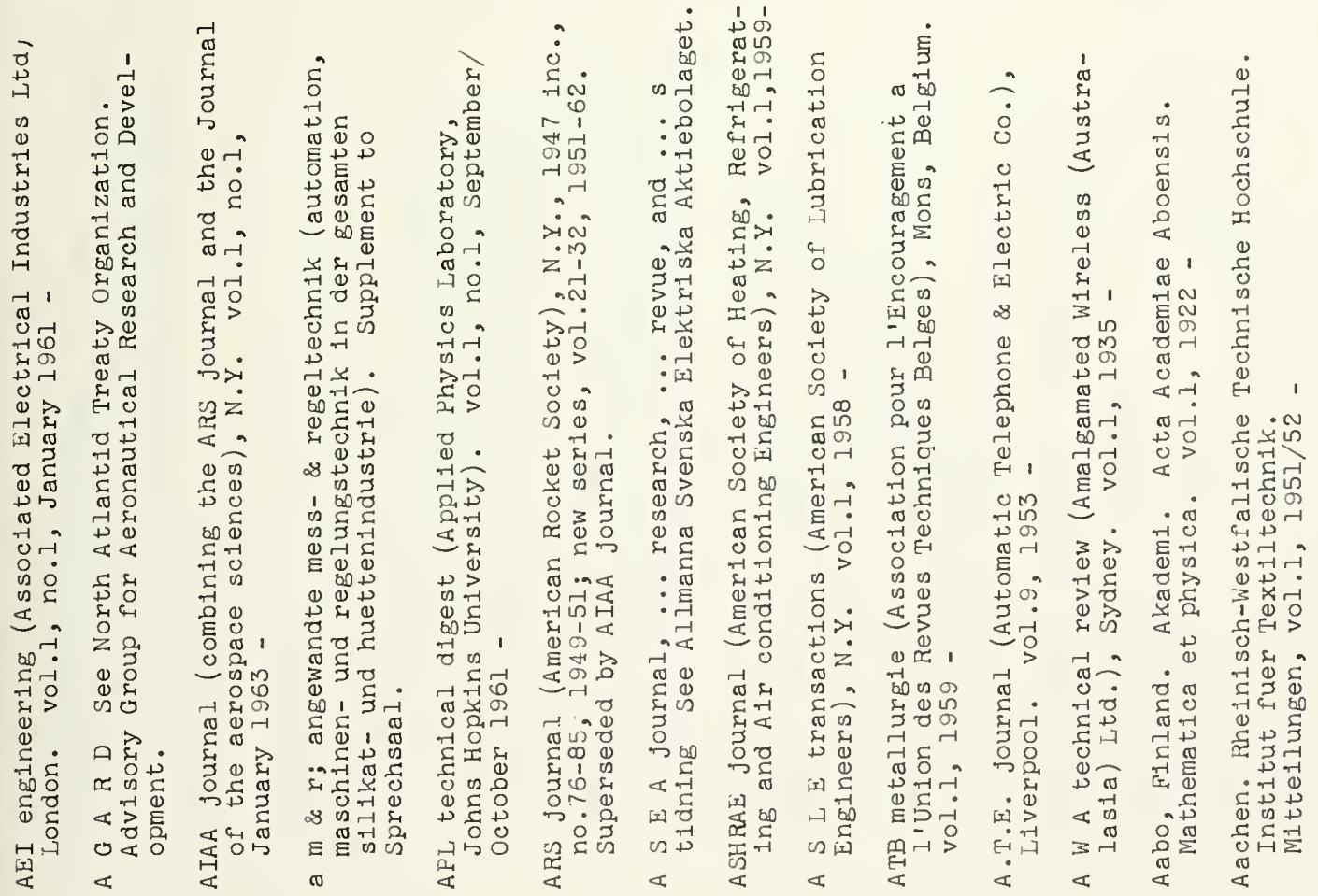

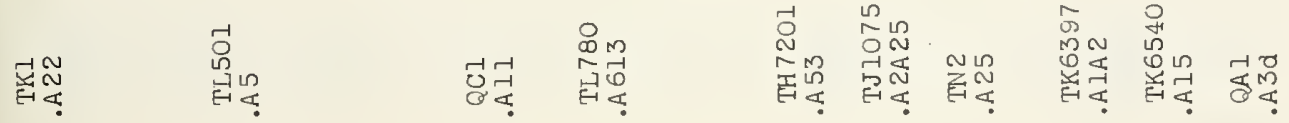




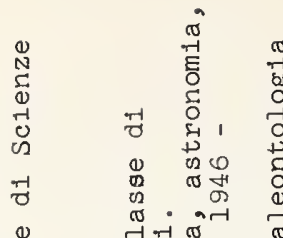

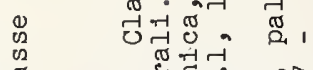

तु

‥

0ं क्ष

तन

वृ,

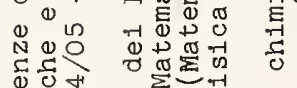

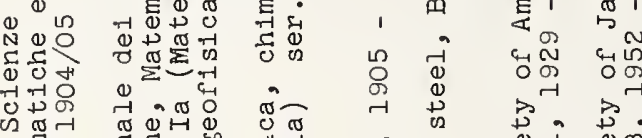

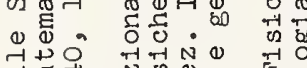

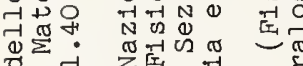

क

敢,

ब्र

का

Uफ\&

हों 1 तो

出-

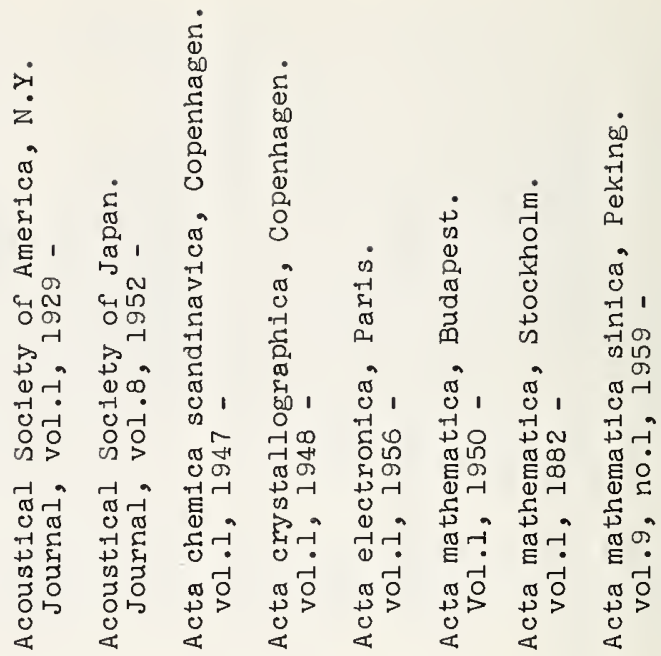

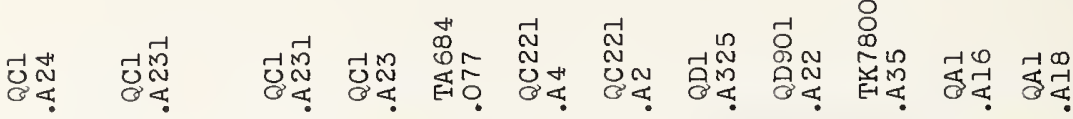

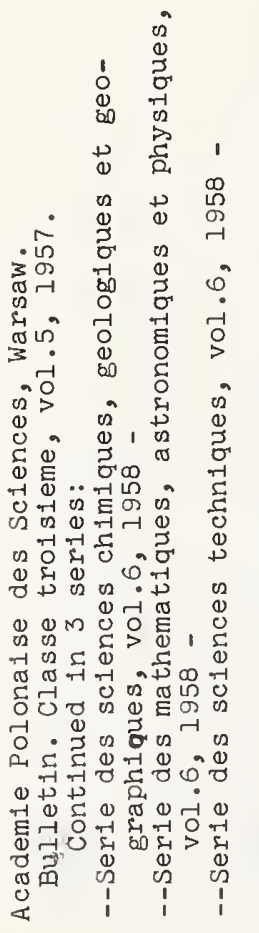

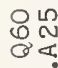

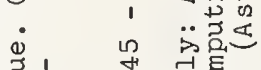

$\overbrace{\substack{1 \\ 1}} 1$

대요

๓ंन

$ช \stackrel{\infty}{0}$

مे का द्वि

ब -1 -

(⿻)

o.

我

굽

ฮั

ฮู

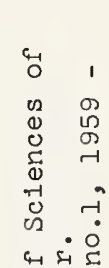

出兵

窟它

बू

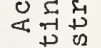

更

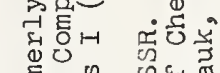

हैं एक

$\sum_{\substack{0 \\ \infty}}^{\infty} \sum_{5}^{-1}$

in $\left.{ }_{0}^{\infty}\right)_{-1}^{\pi}$

बंग्न

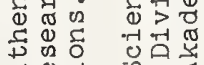

《这

4-

要

焉要

0
0

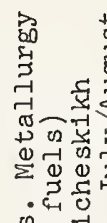

का a

ญृ듀

东政 ।

ن

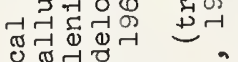

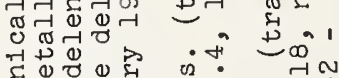

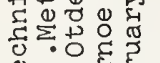

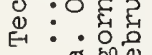

क . . .

पिन्त

ᄃㄷำ

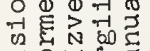

구에

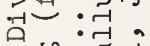

60.

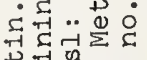

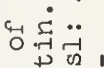

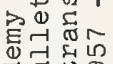

近

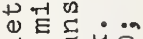

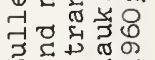

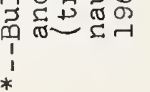

每 N

柋 


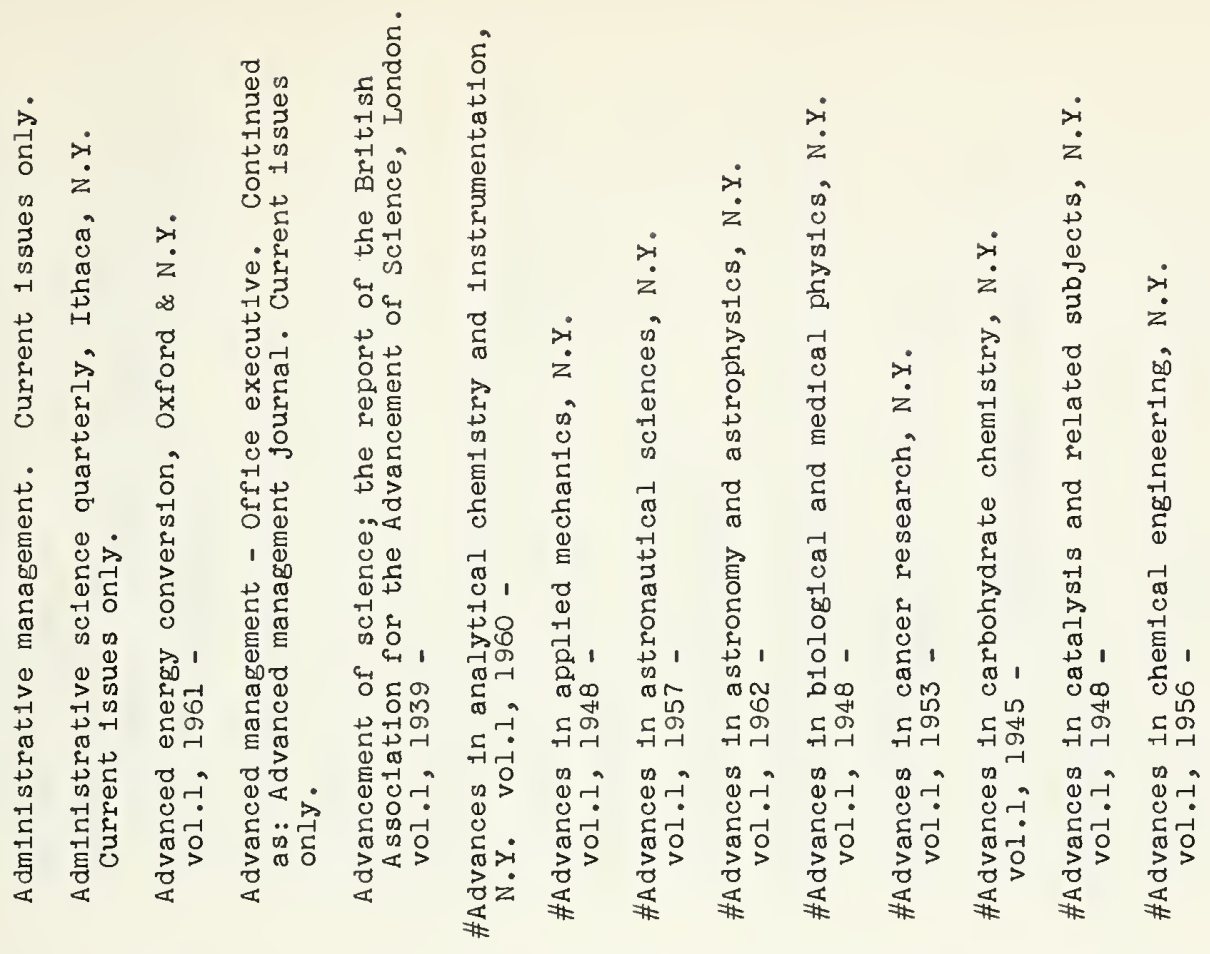

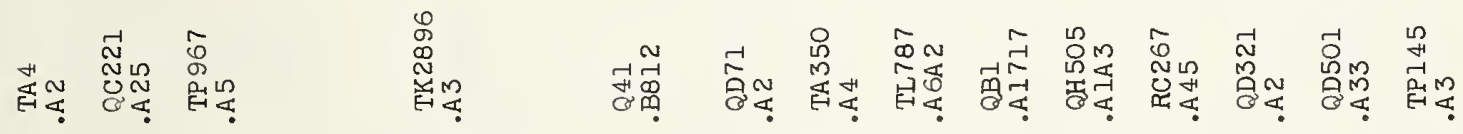

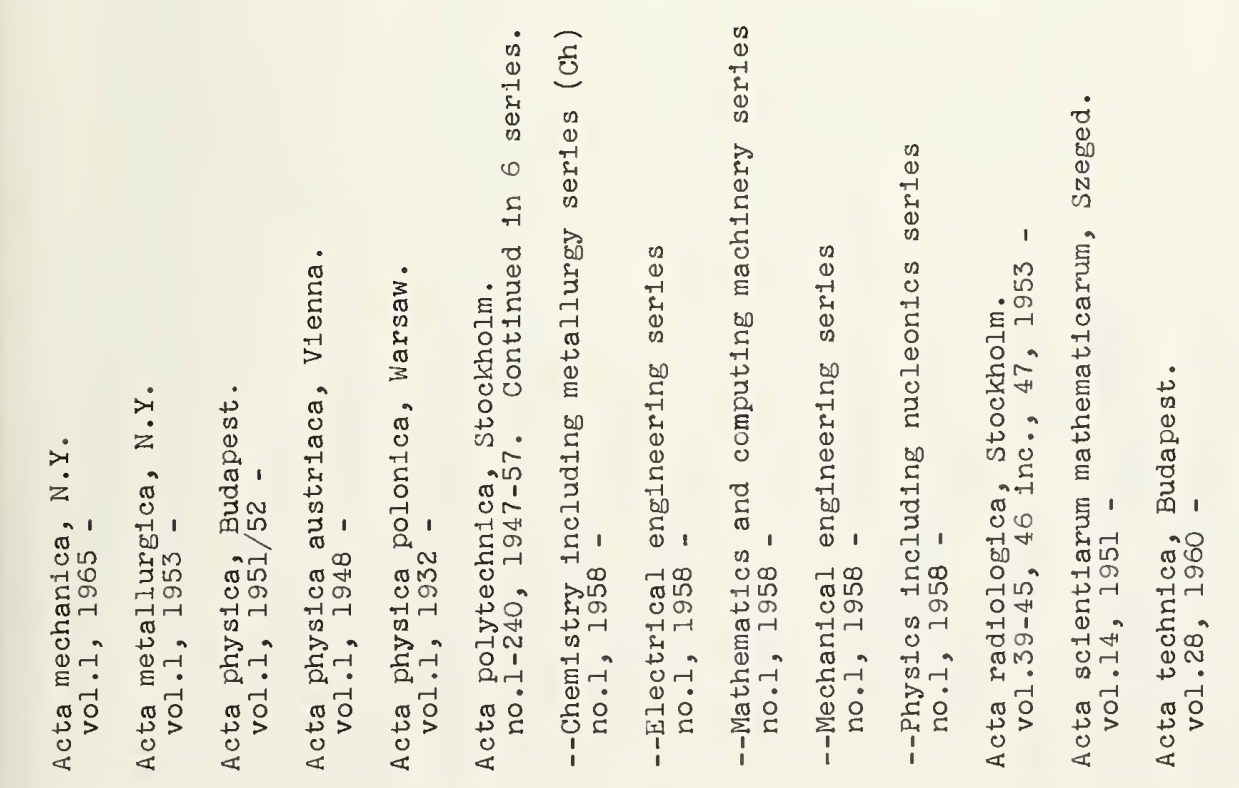

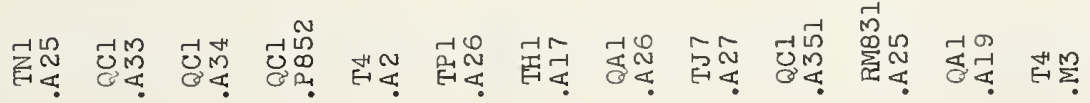



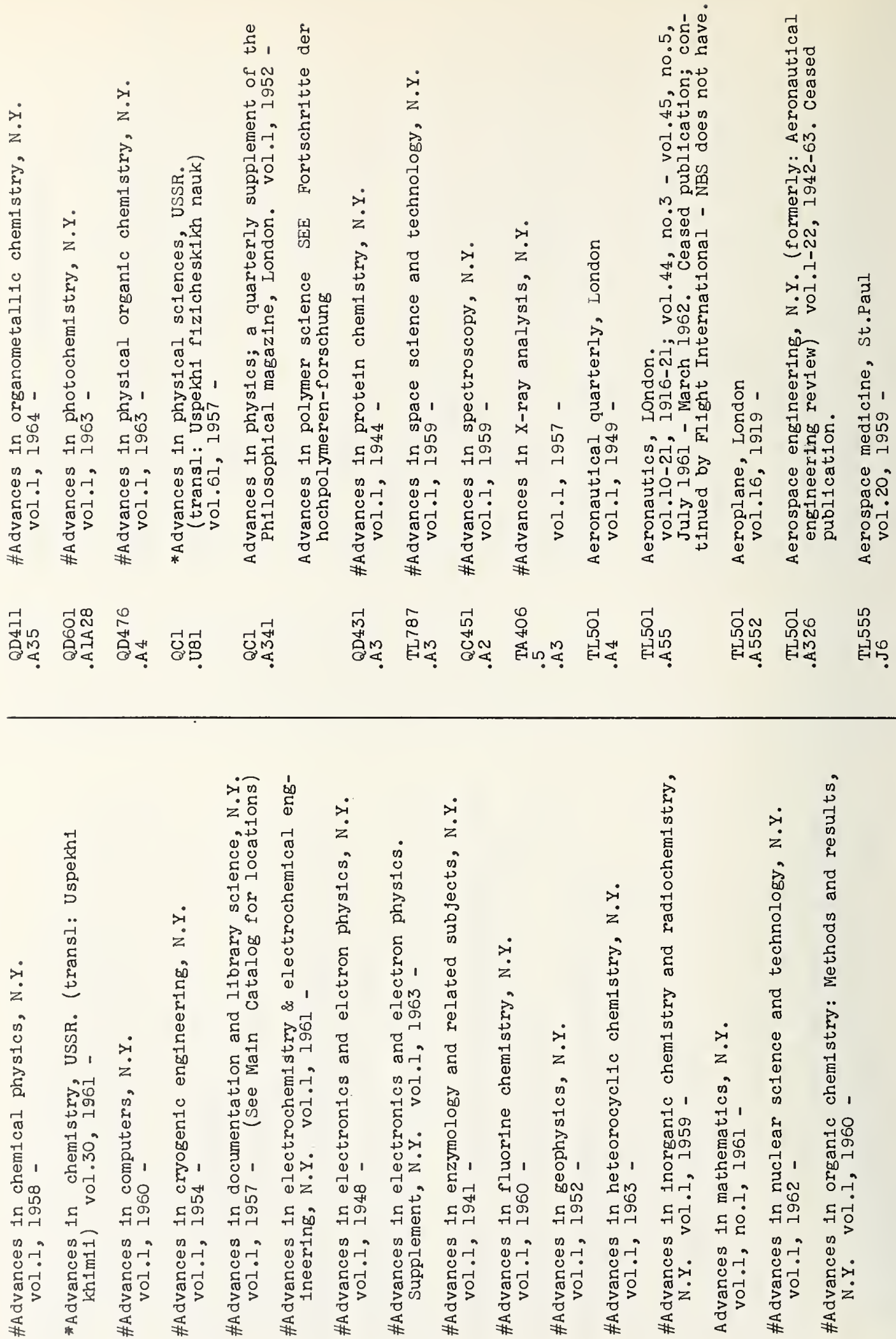

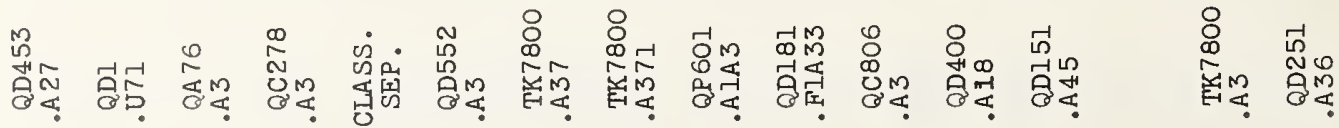




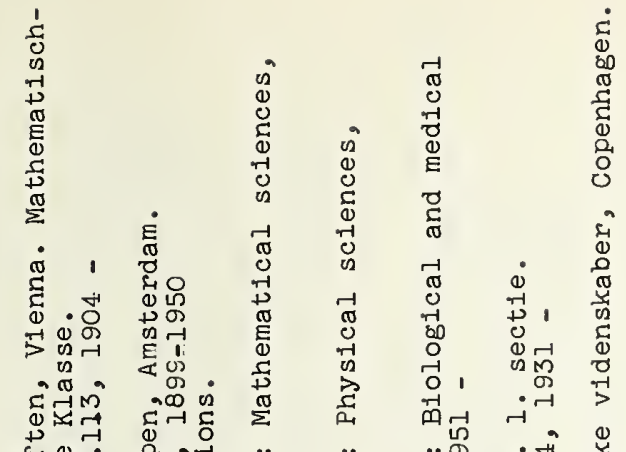

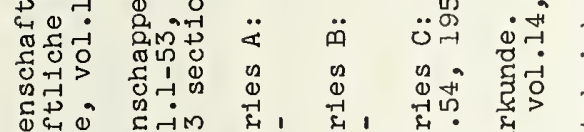

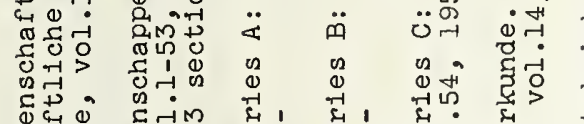

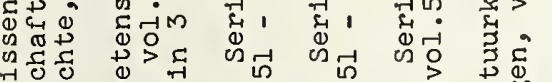

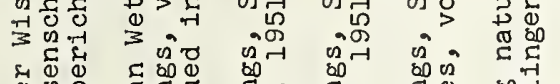

की

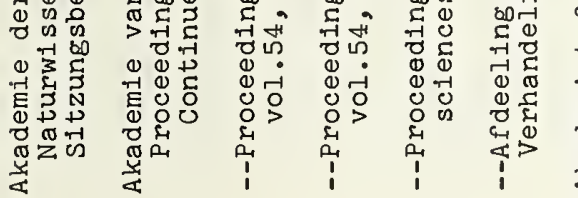

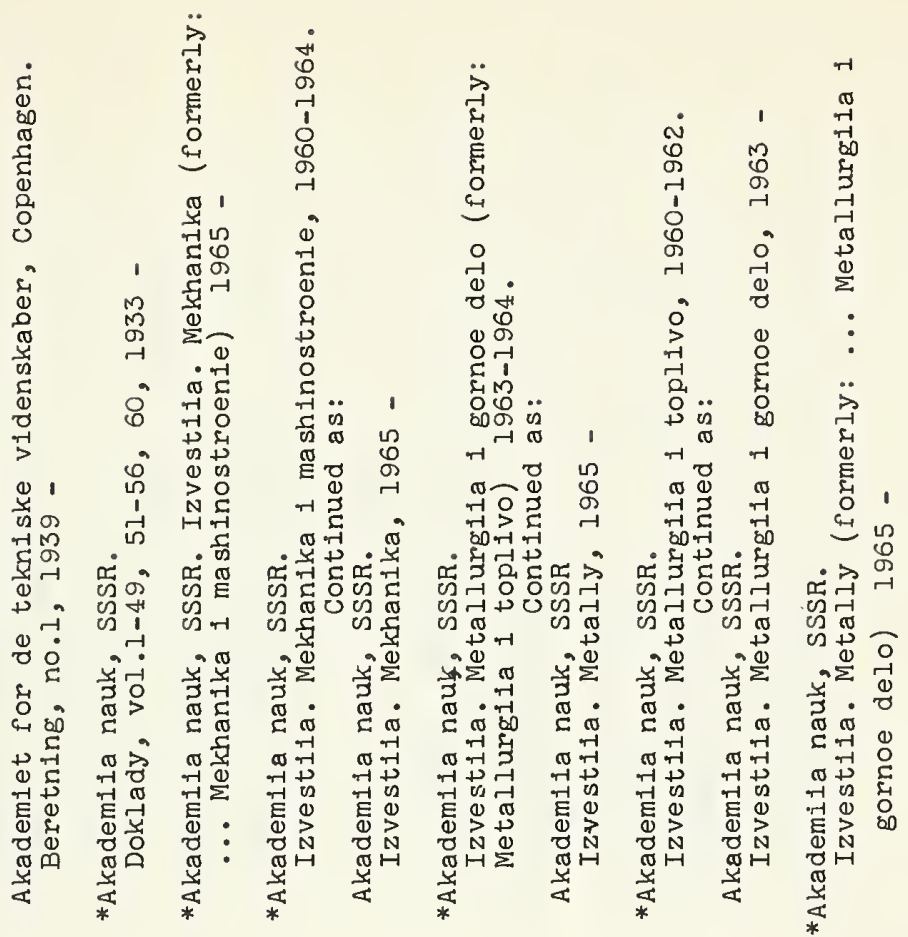

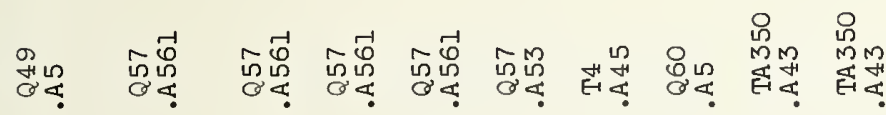

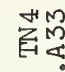

总舀
草怘

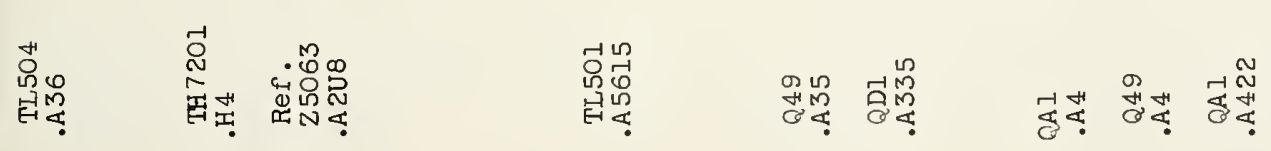




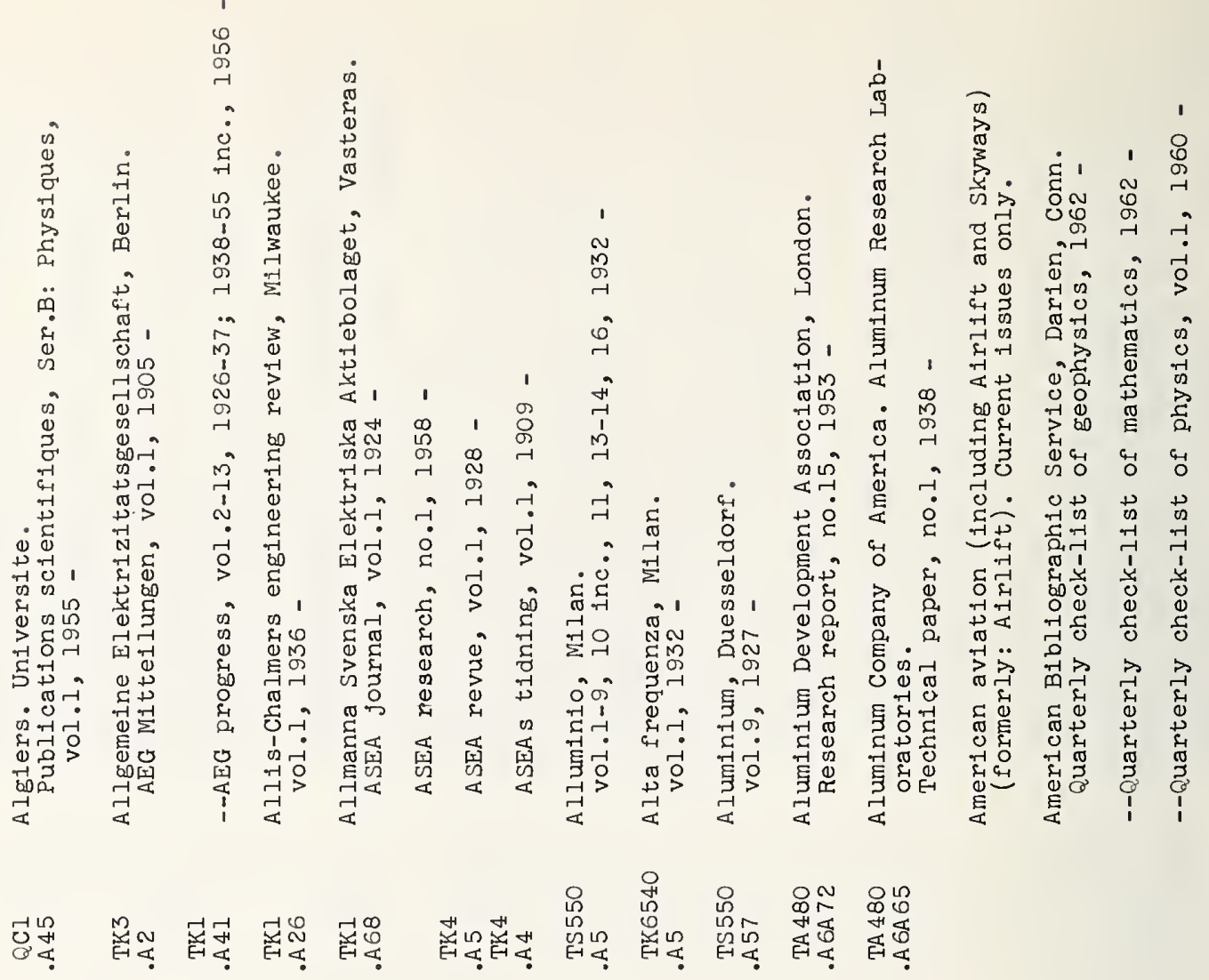

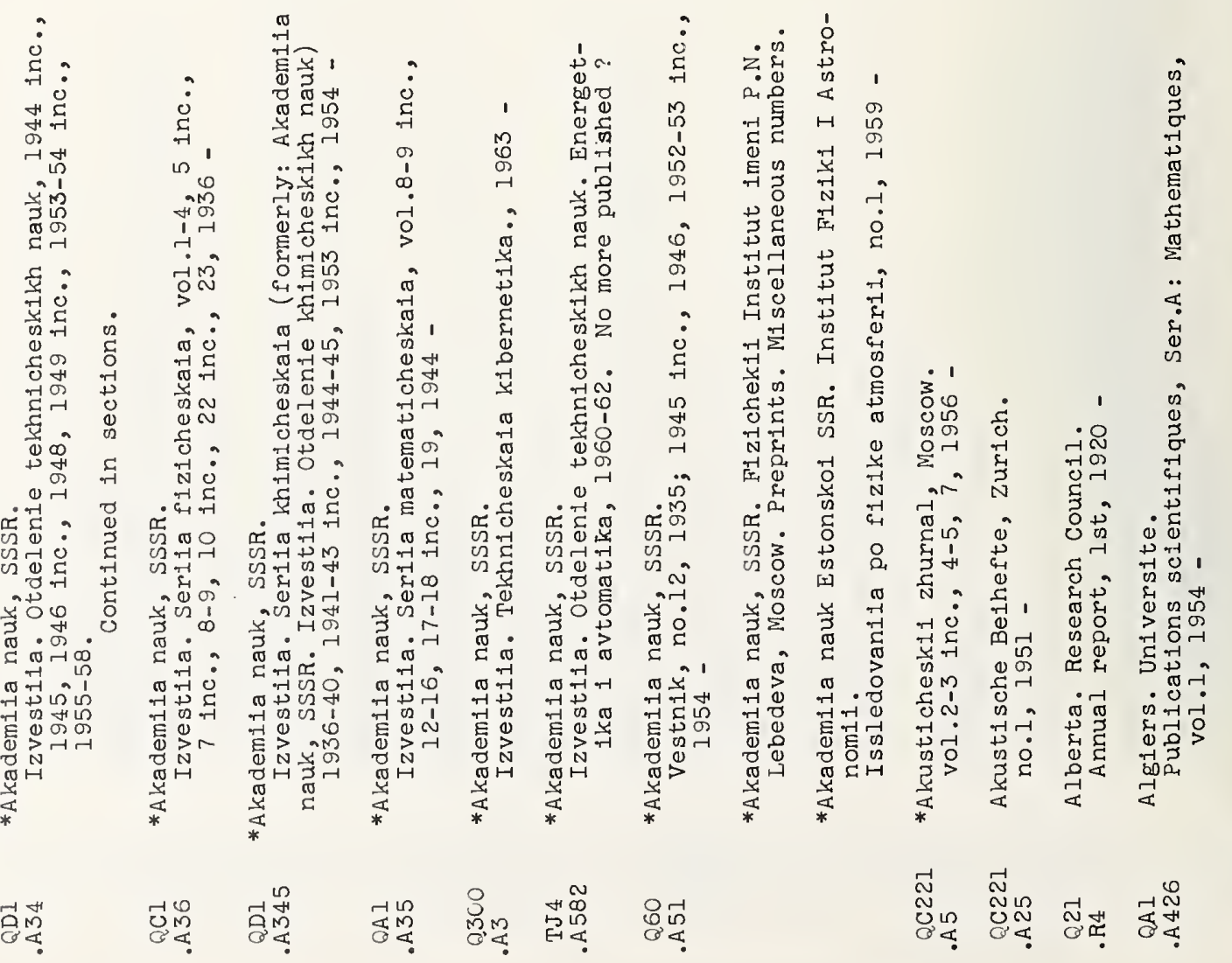



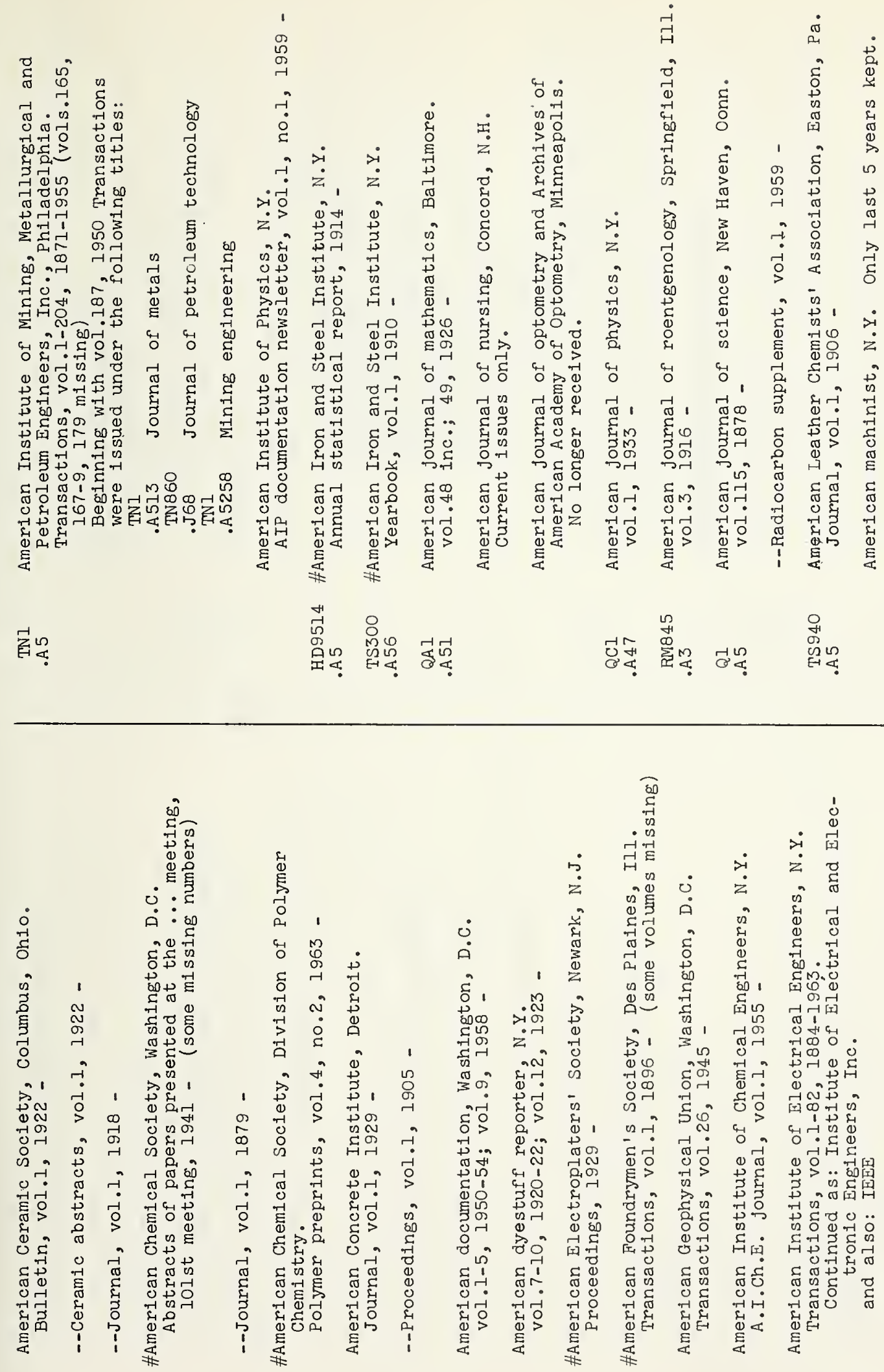

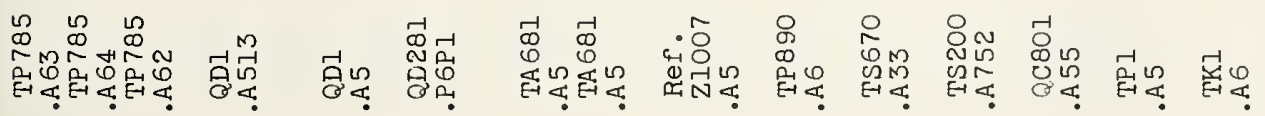




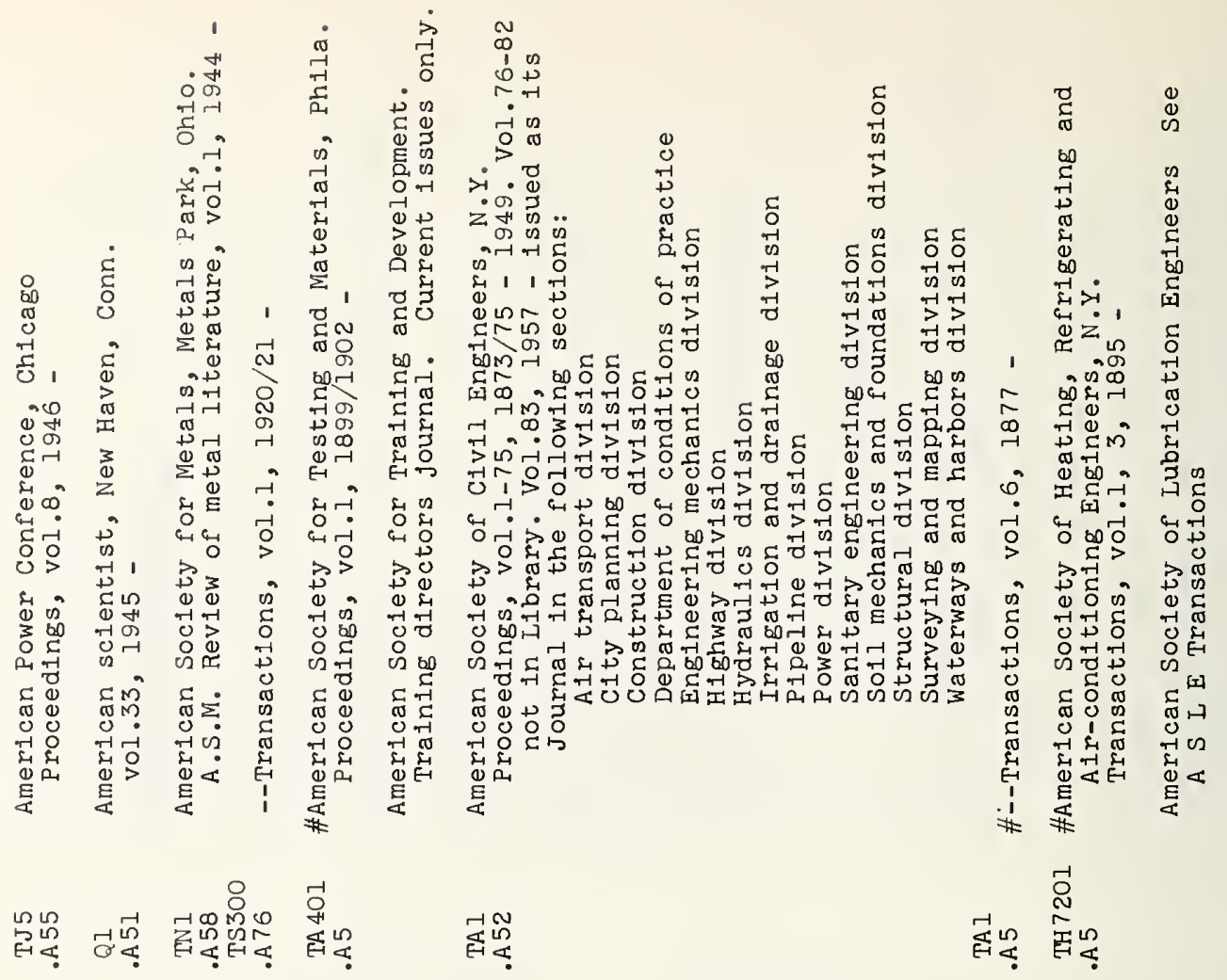

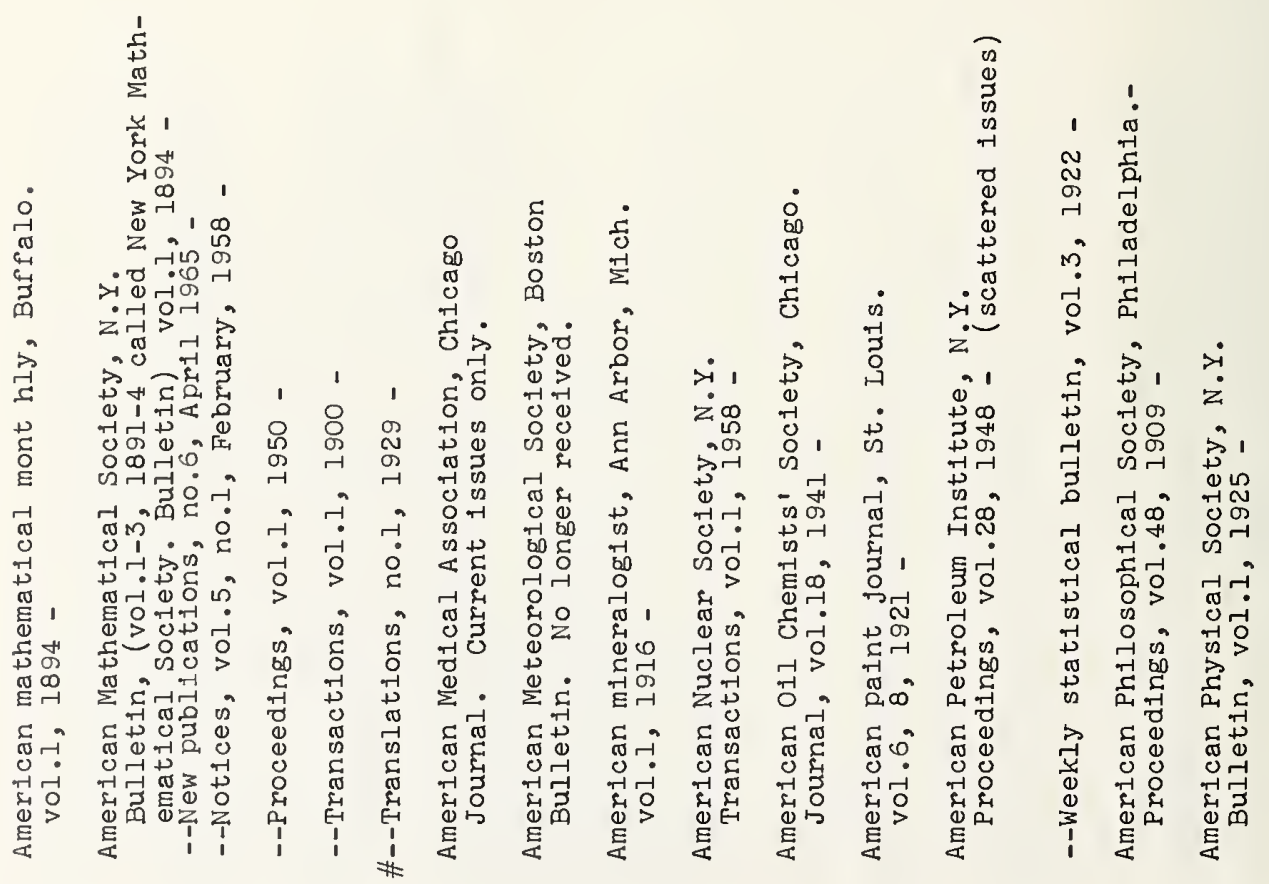

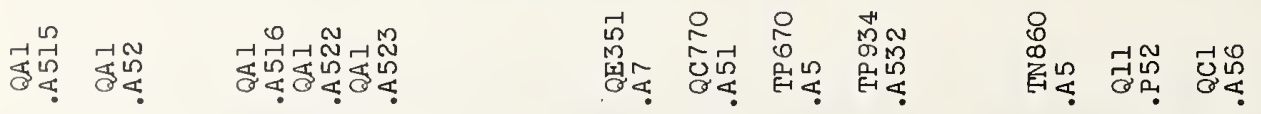


.

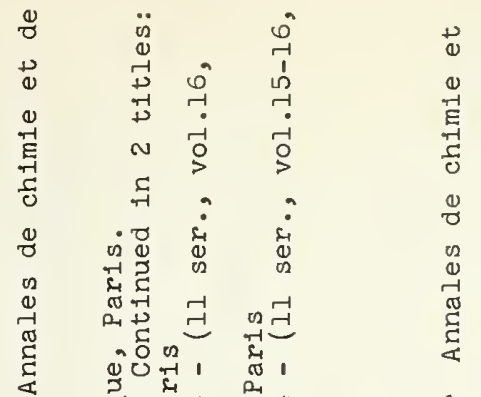

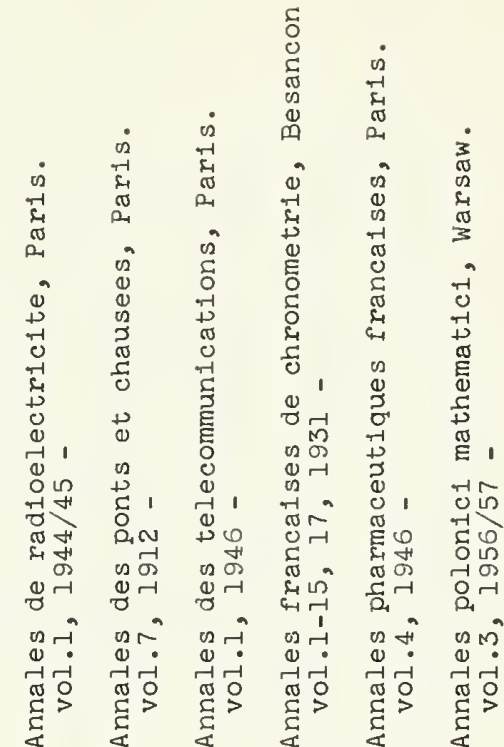

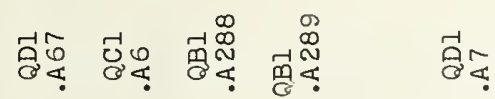

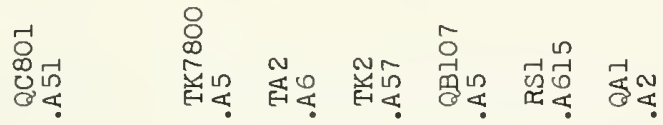

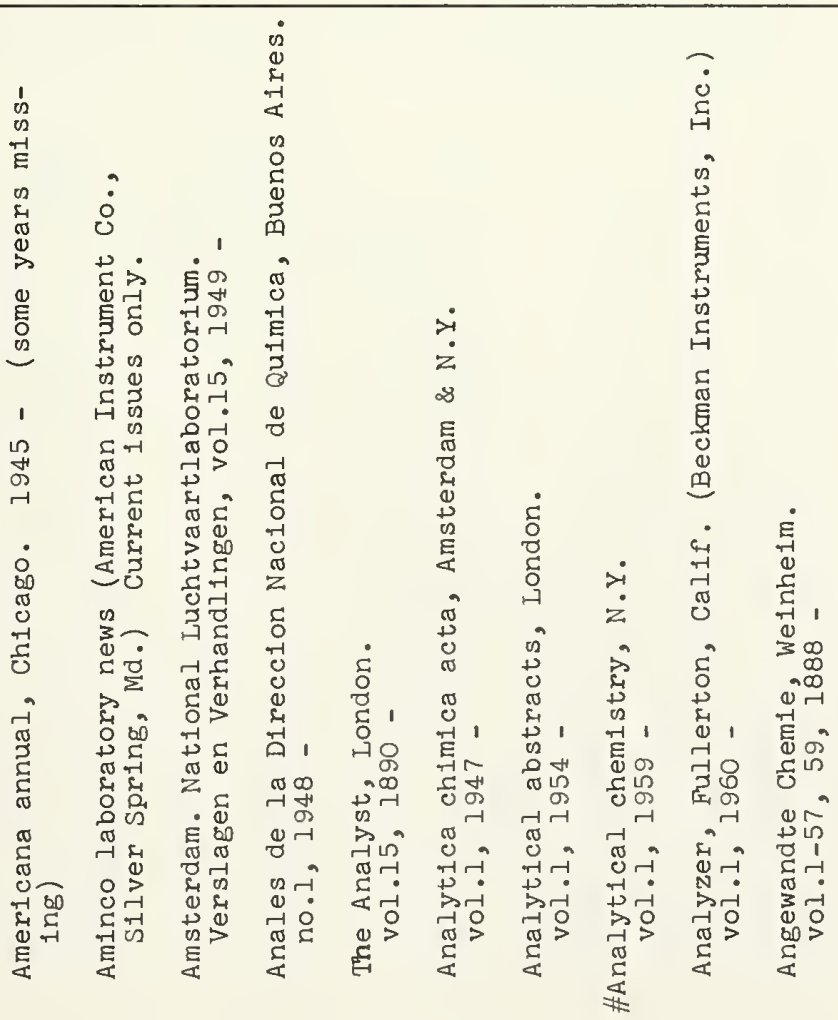

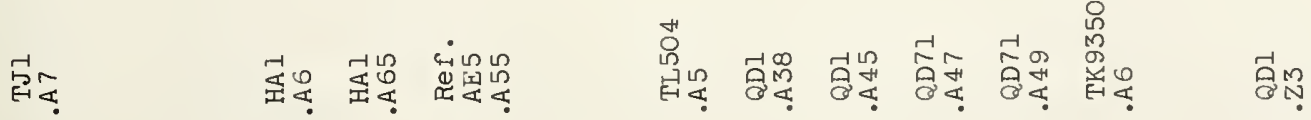




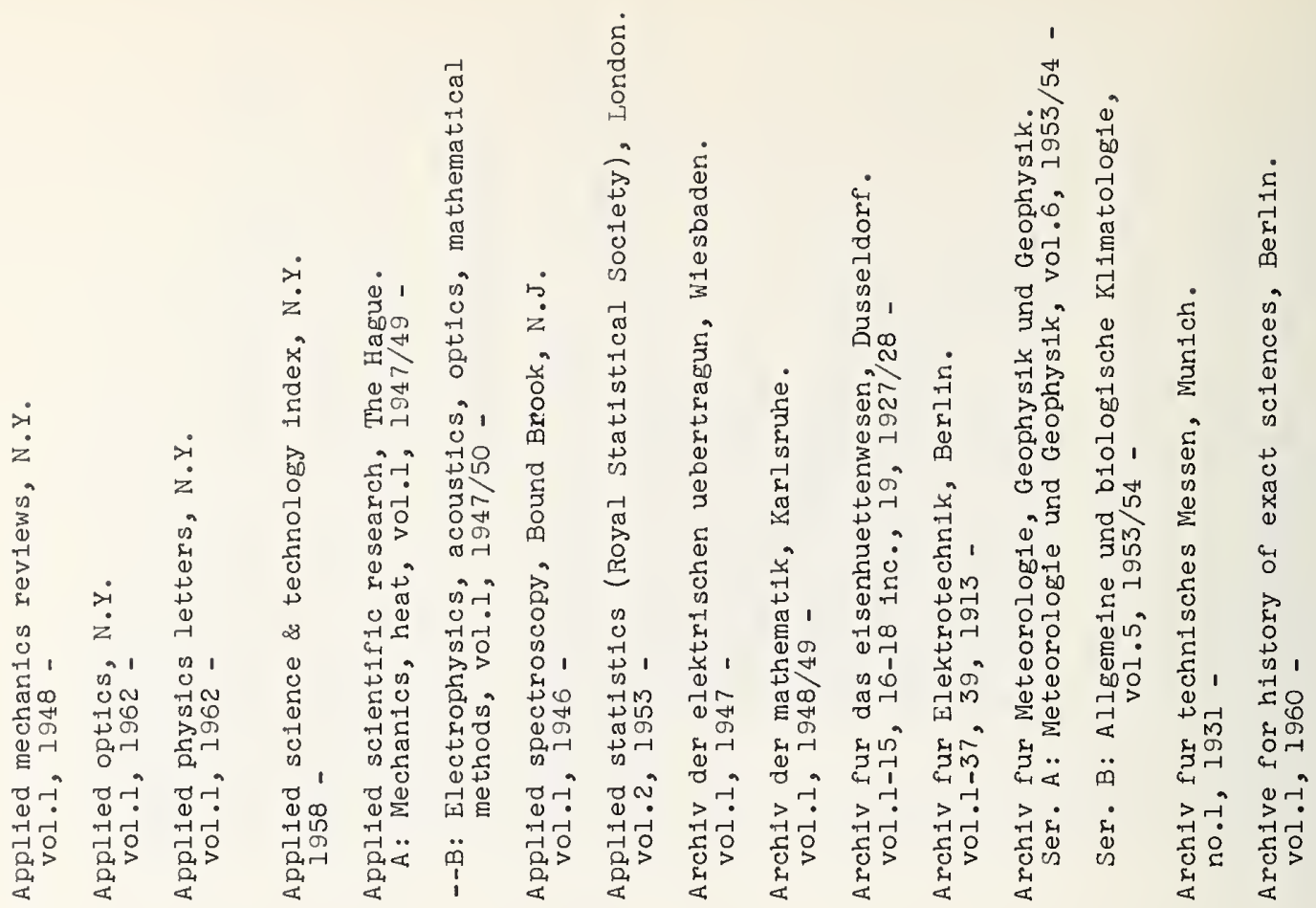

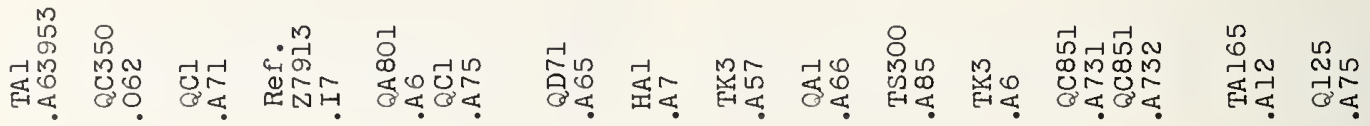

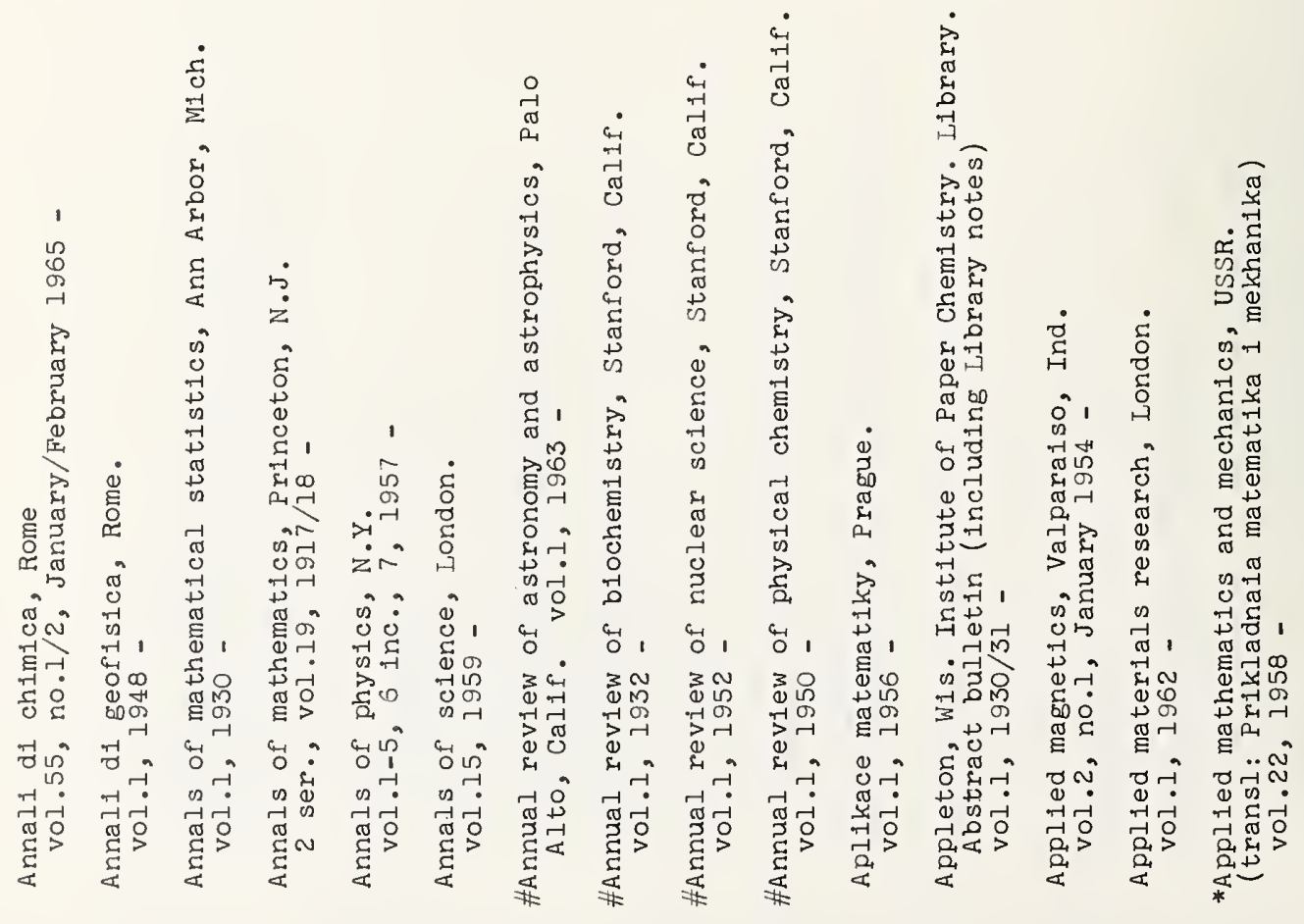

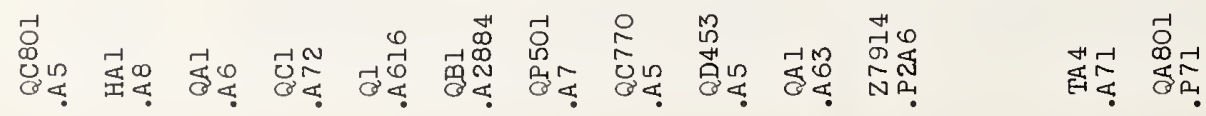




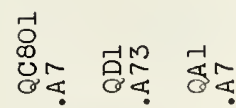

总密

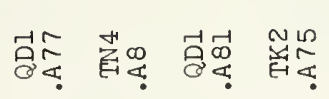

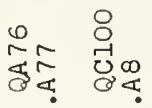

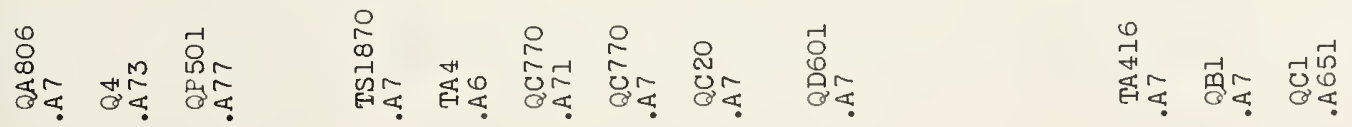




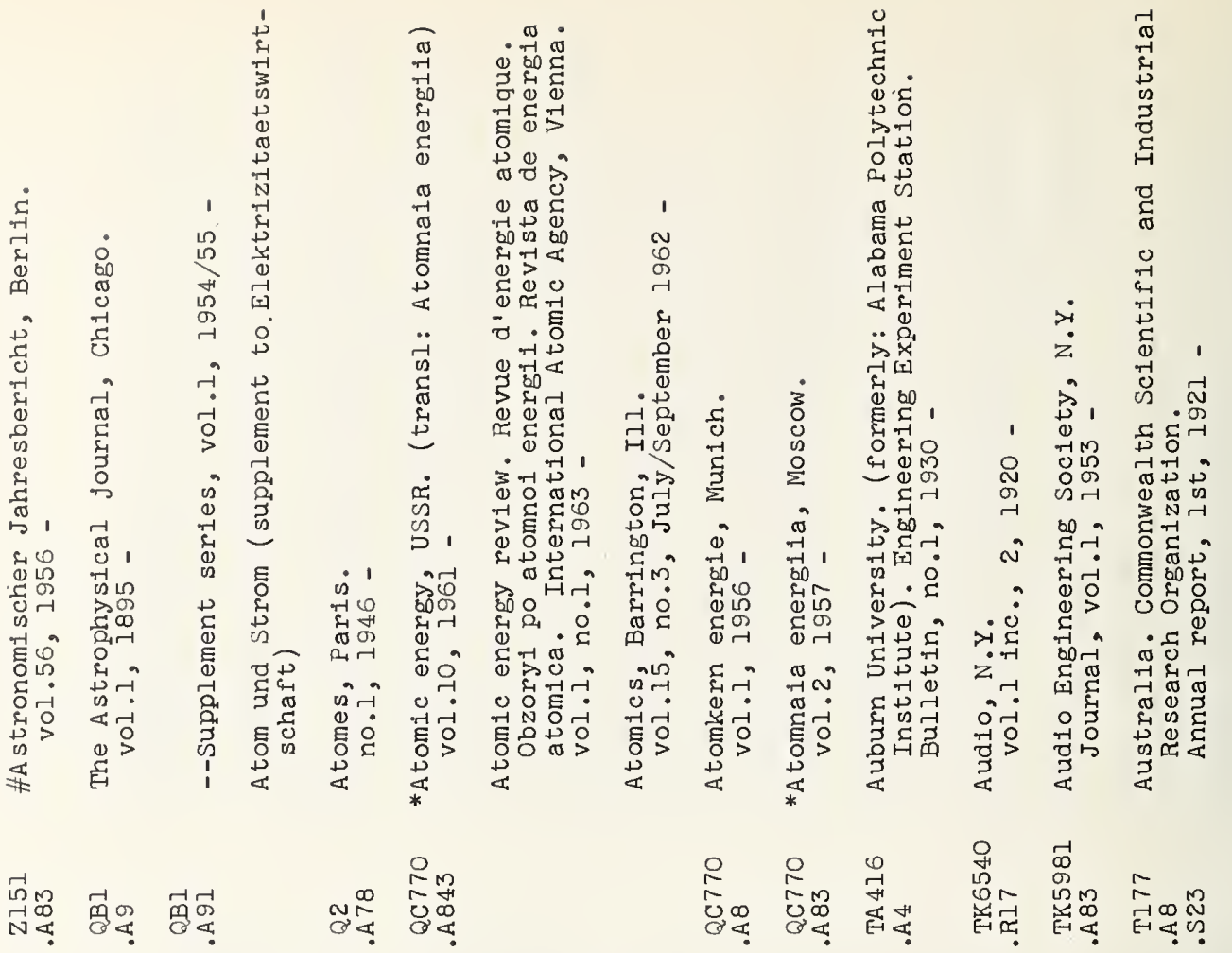

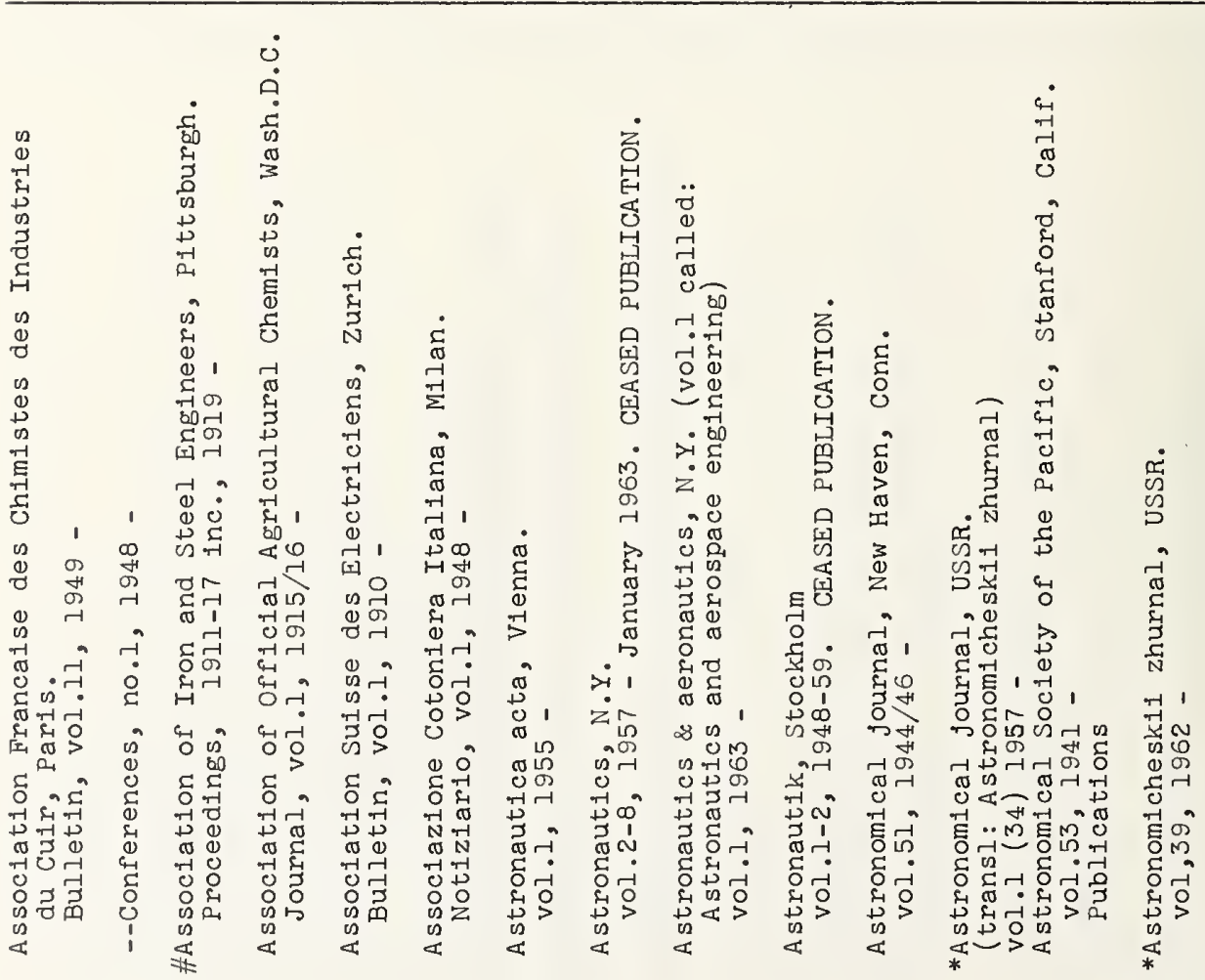

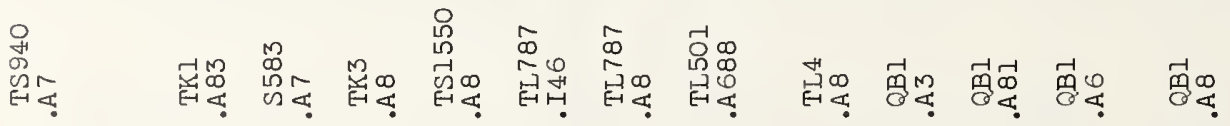




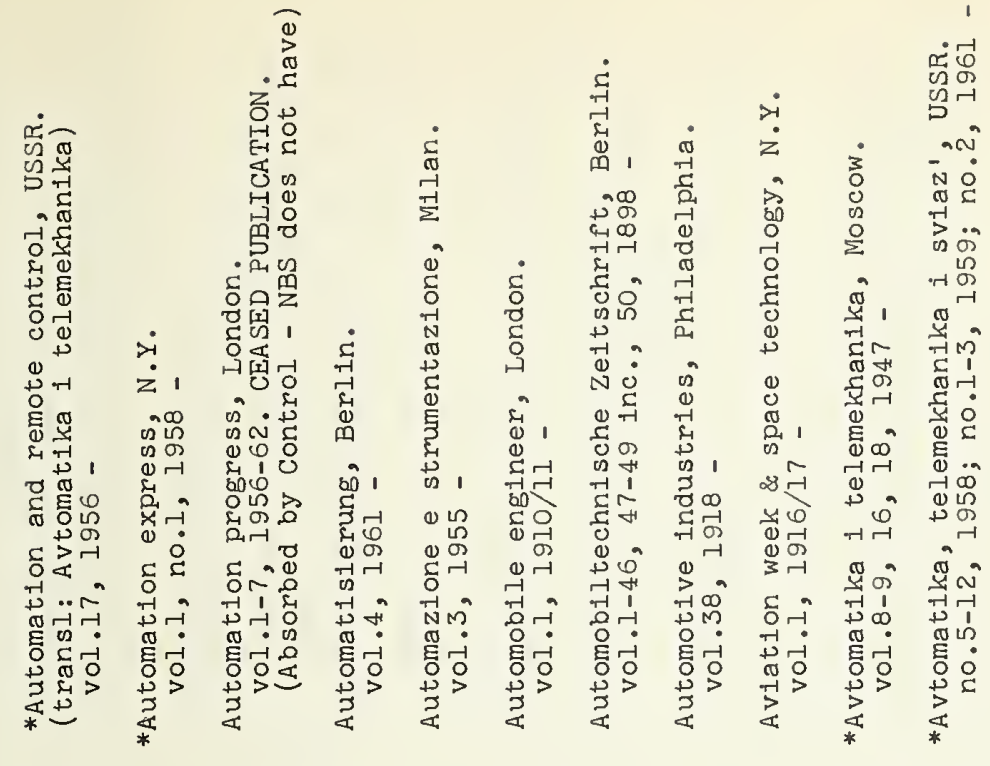

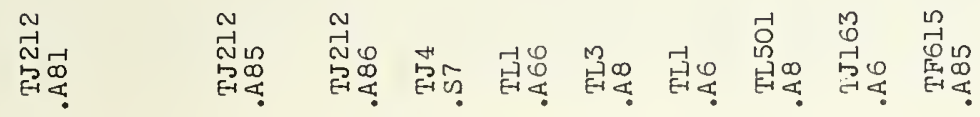

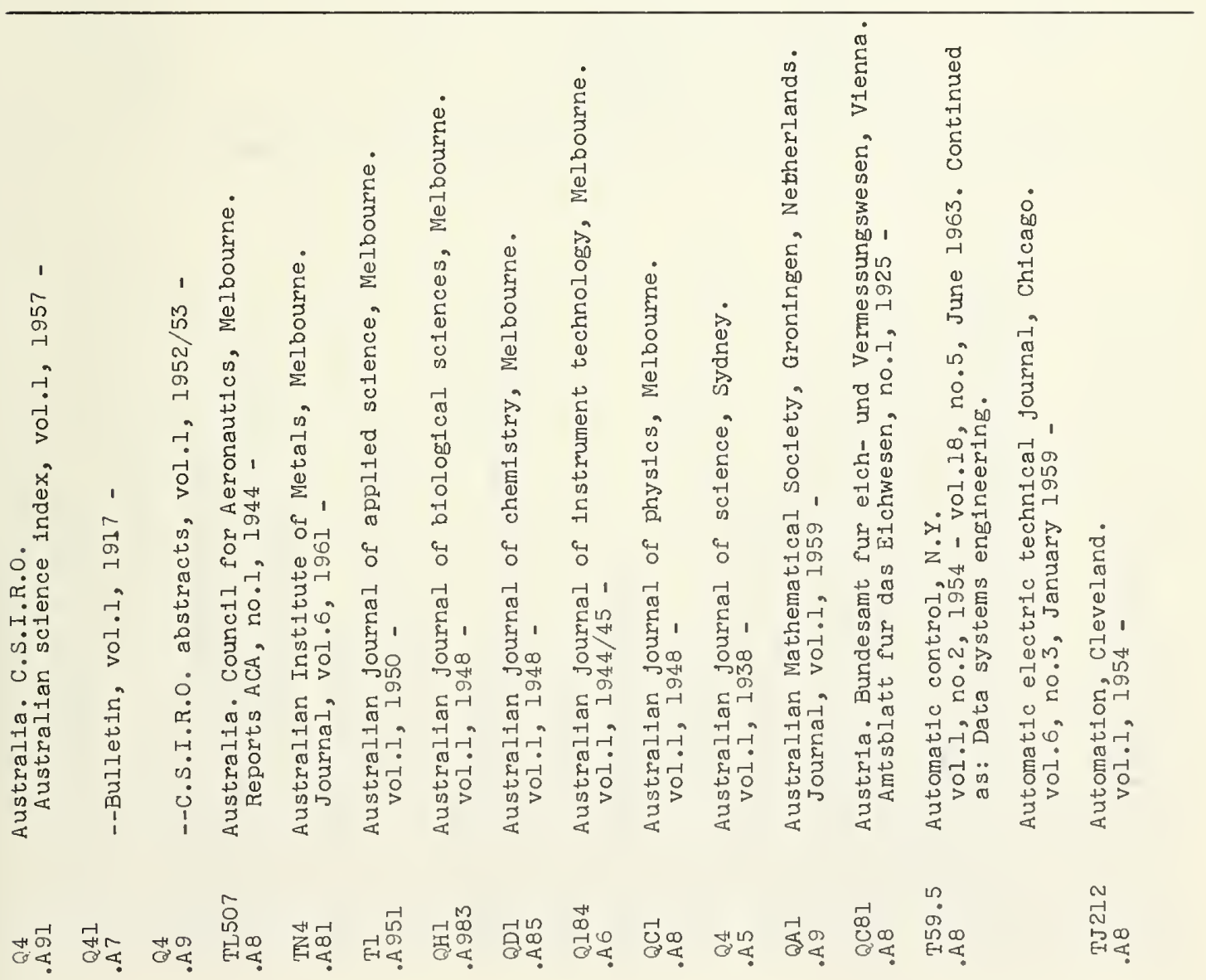


$\stackrel{0}{\stackrel{0}{0}}$

•. 요

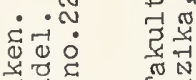

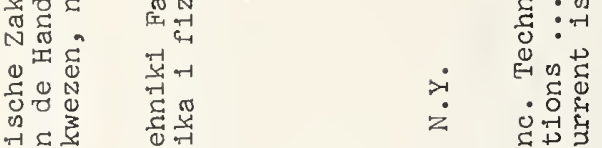

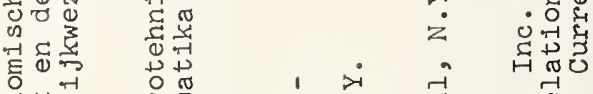

द्व

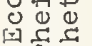

द्व

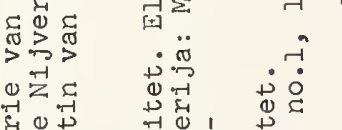

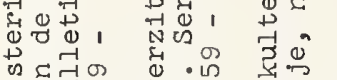

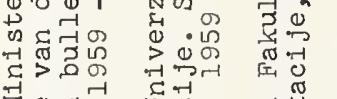

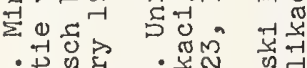

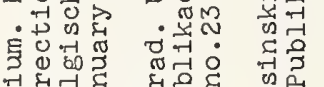

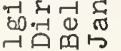

๓๐
焉

골

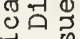

:

政

त्ञ

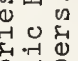



द्वित

०.

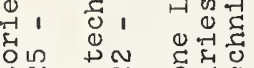

+N $N$ N

닥-

तु-!

-1

ज小

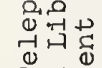

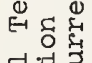

这

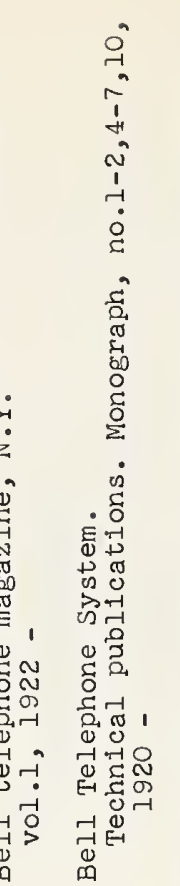

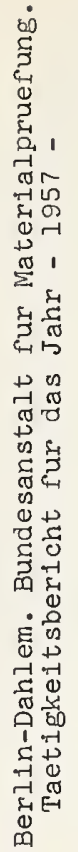

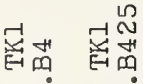

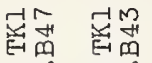

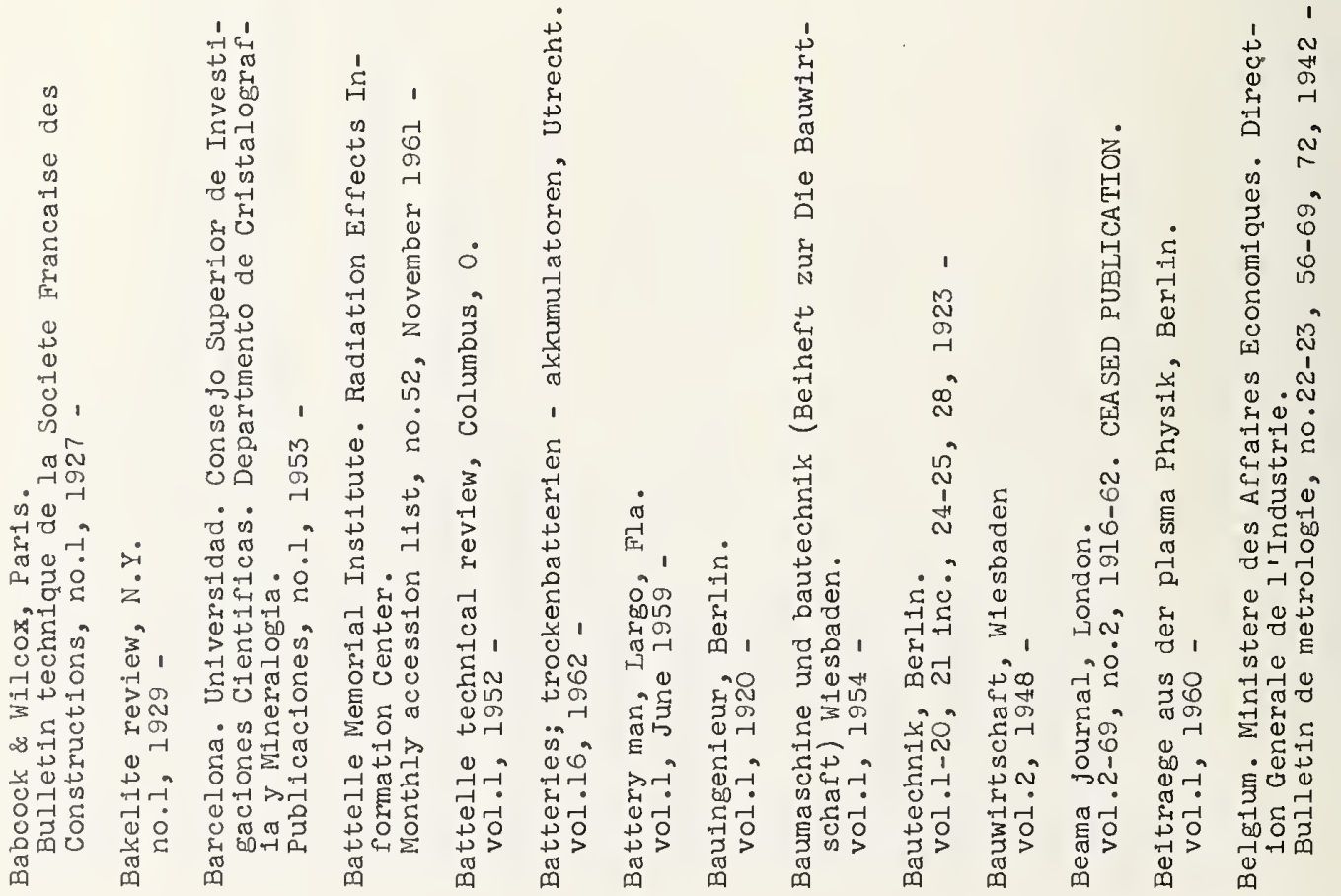

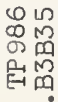

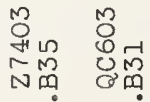

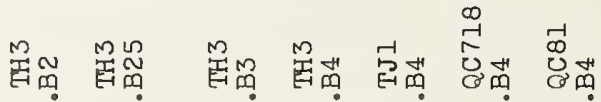




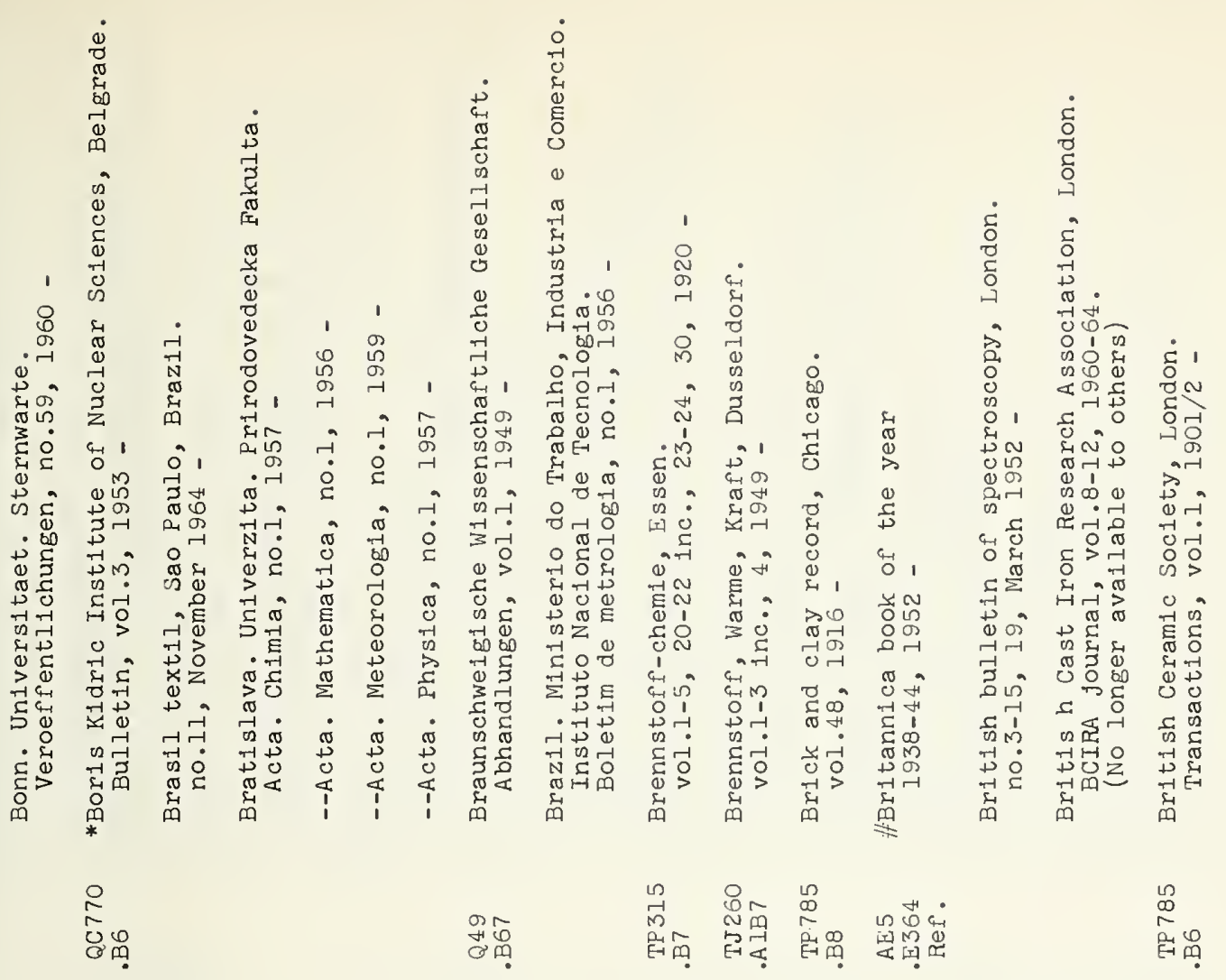

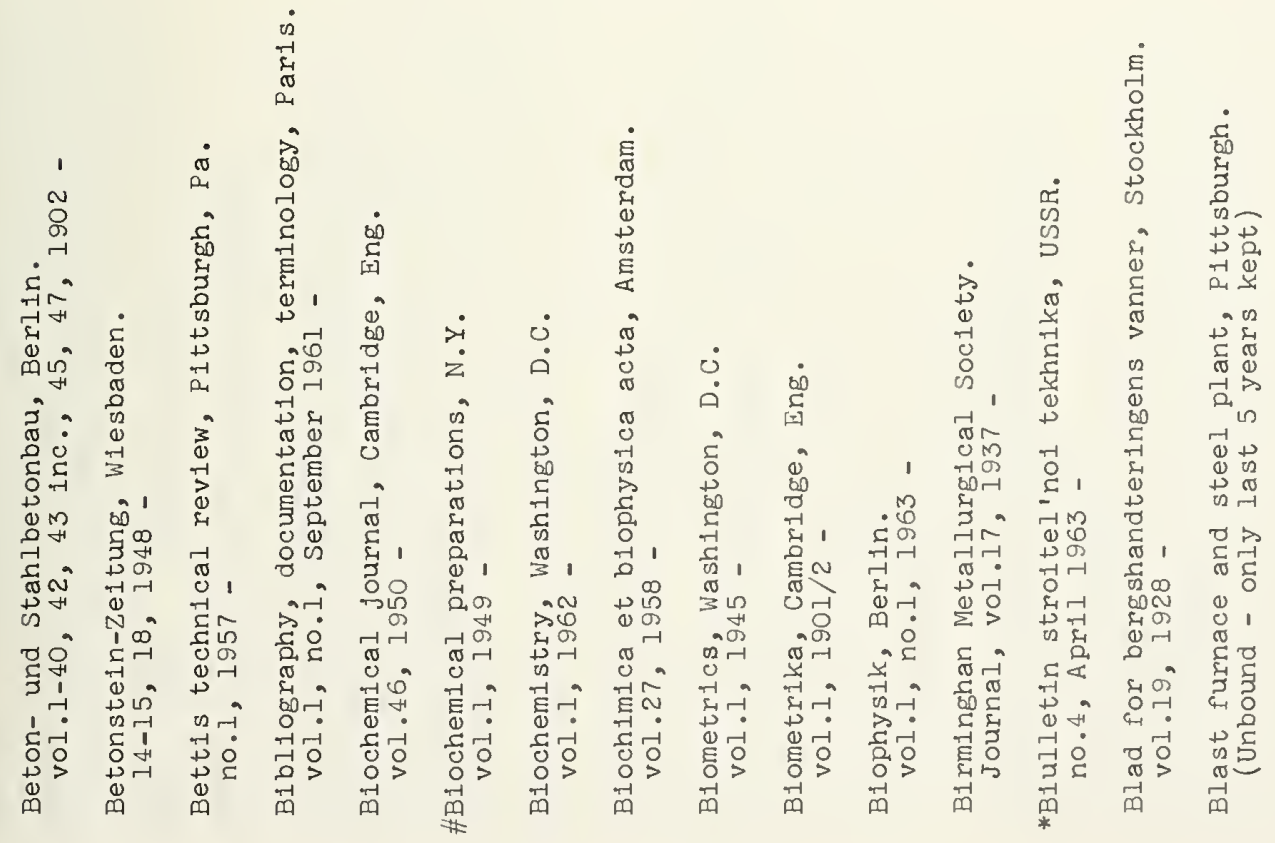

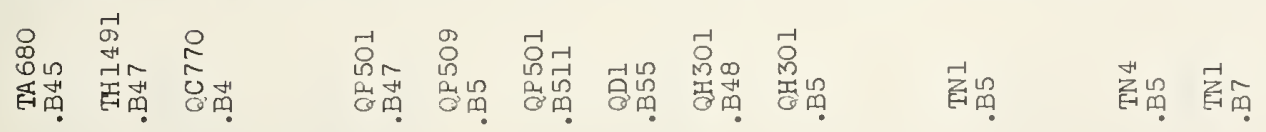




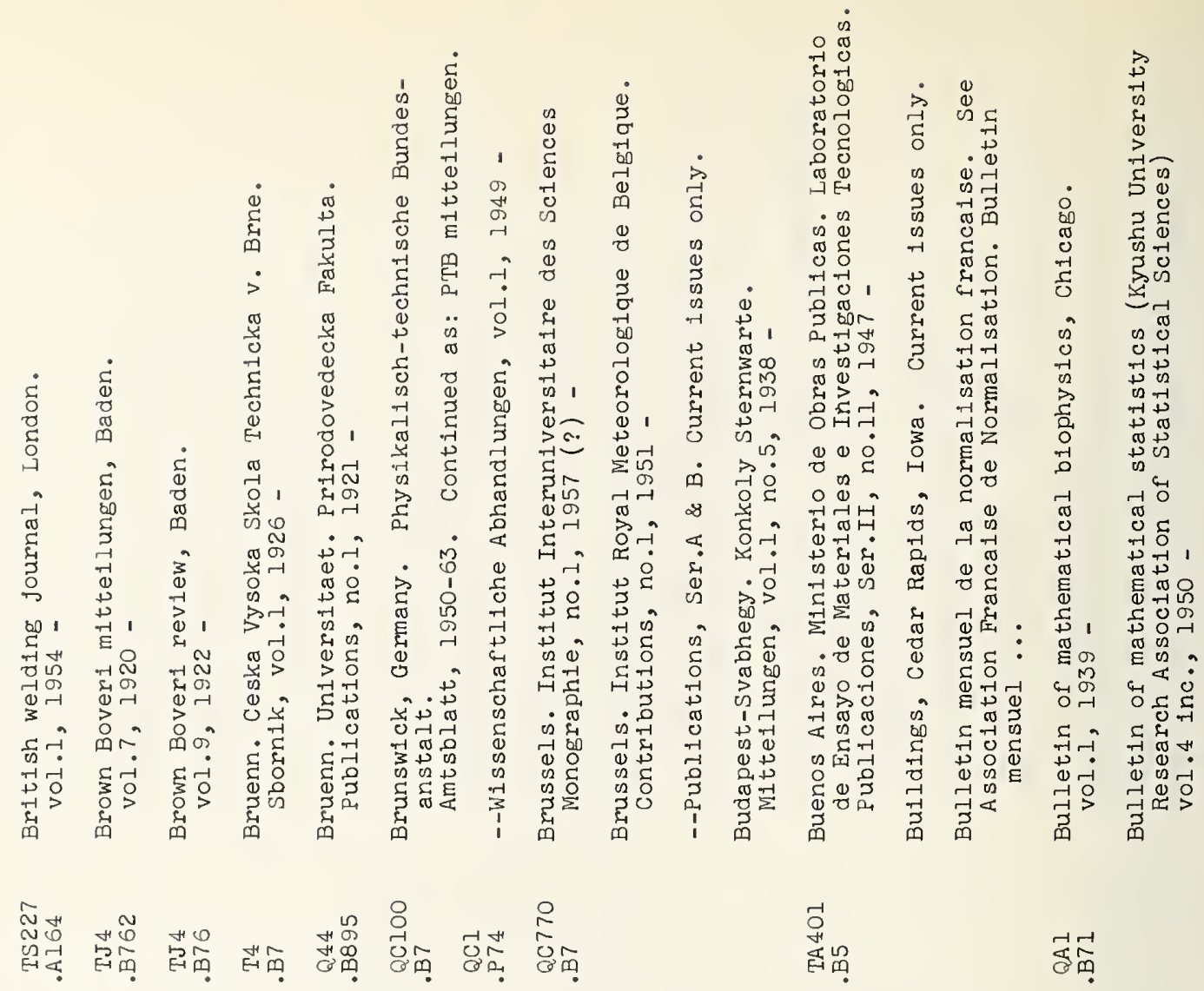




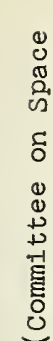

吾

วิ

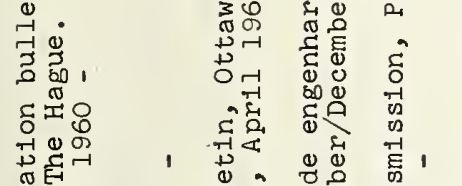

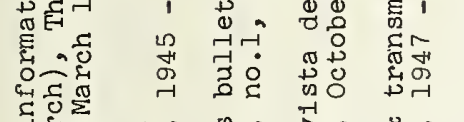

ชั

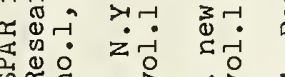

岁证
के
家

\% 1

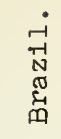

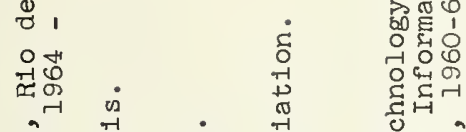

近

क्षिठ

约依

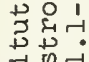

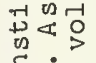

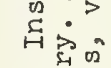

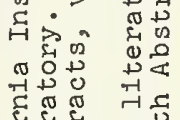

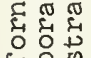

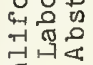

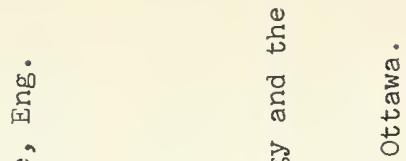

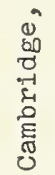
i.

की

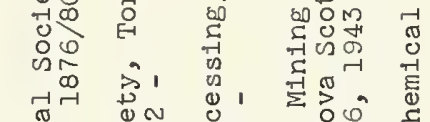

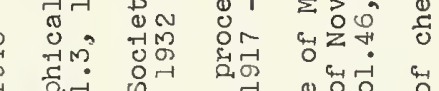
क्षि की न

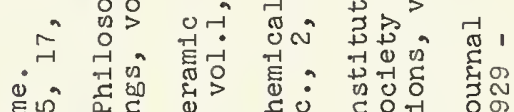
हैंत ऽ热

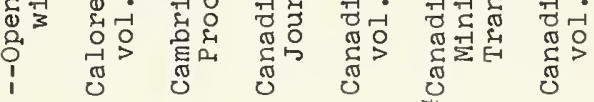

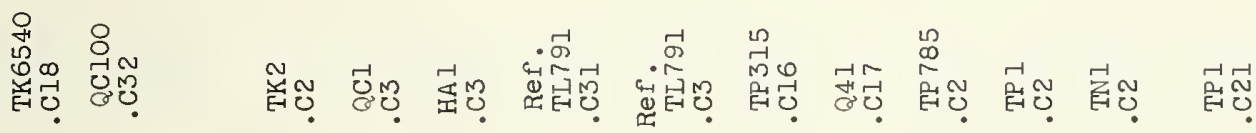

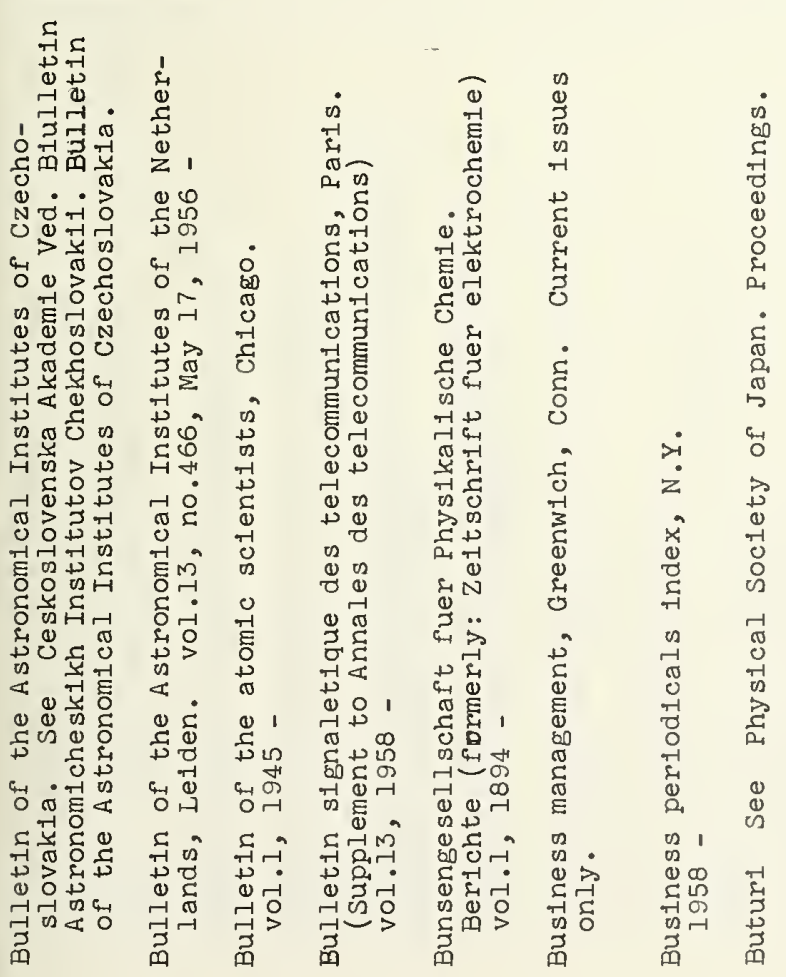

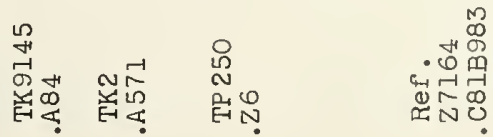




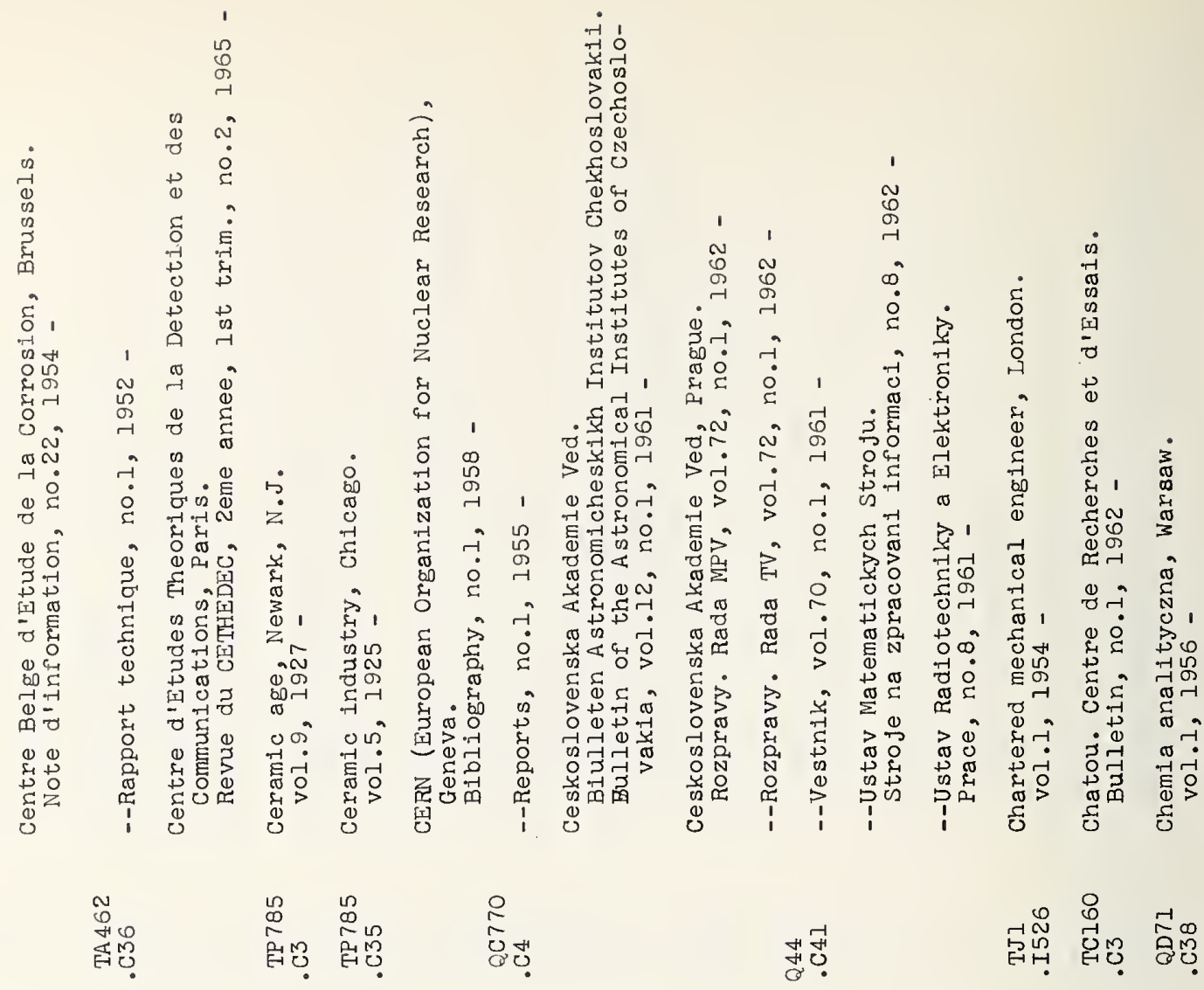

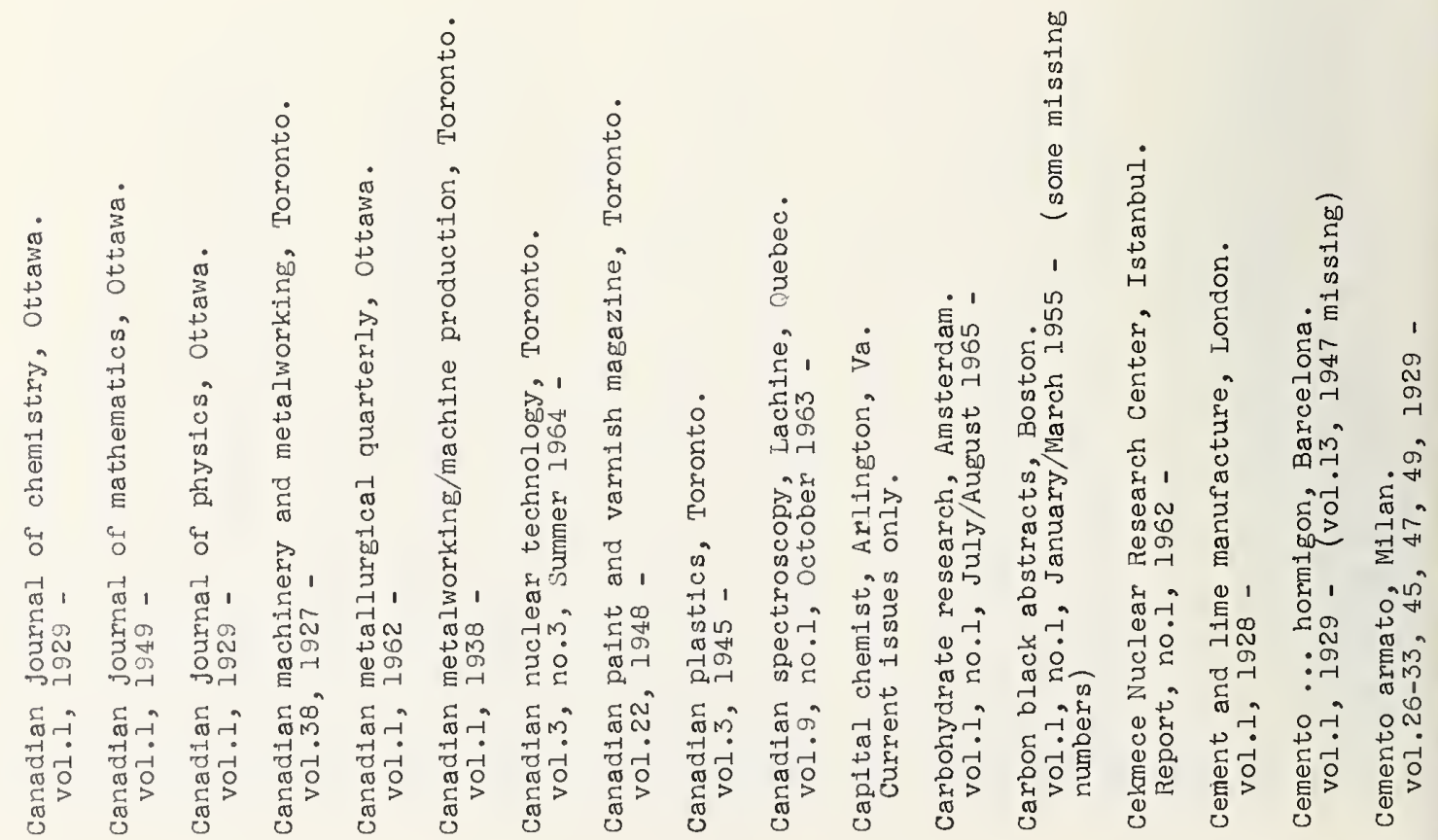

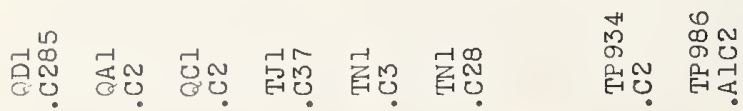

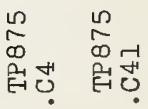




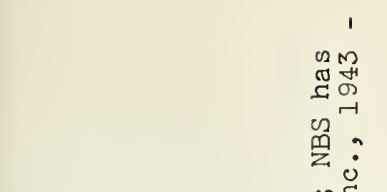

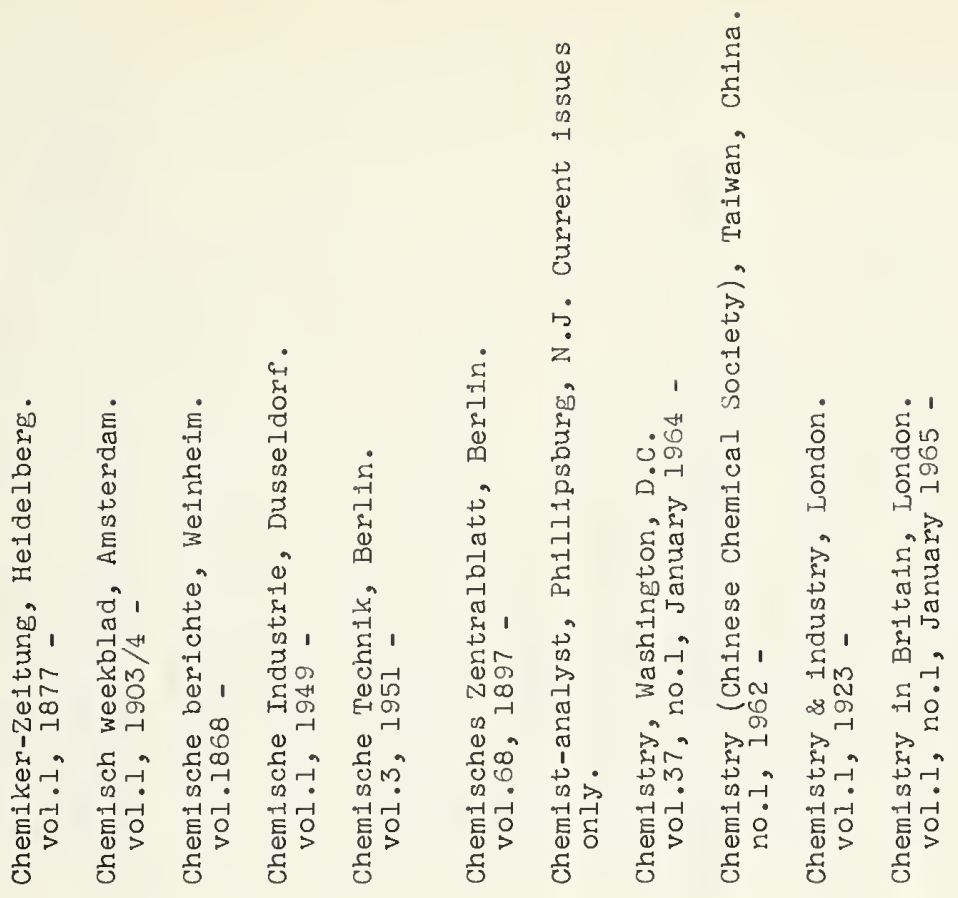

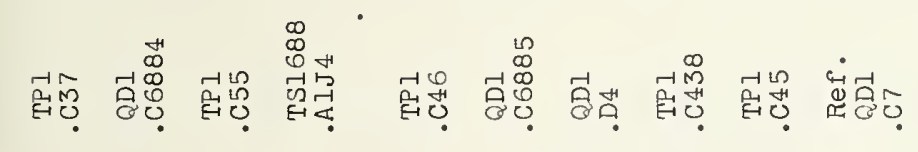

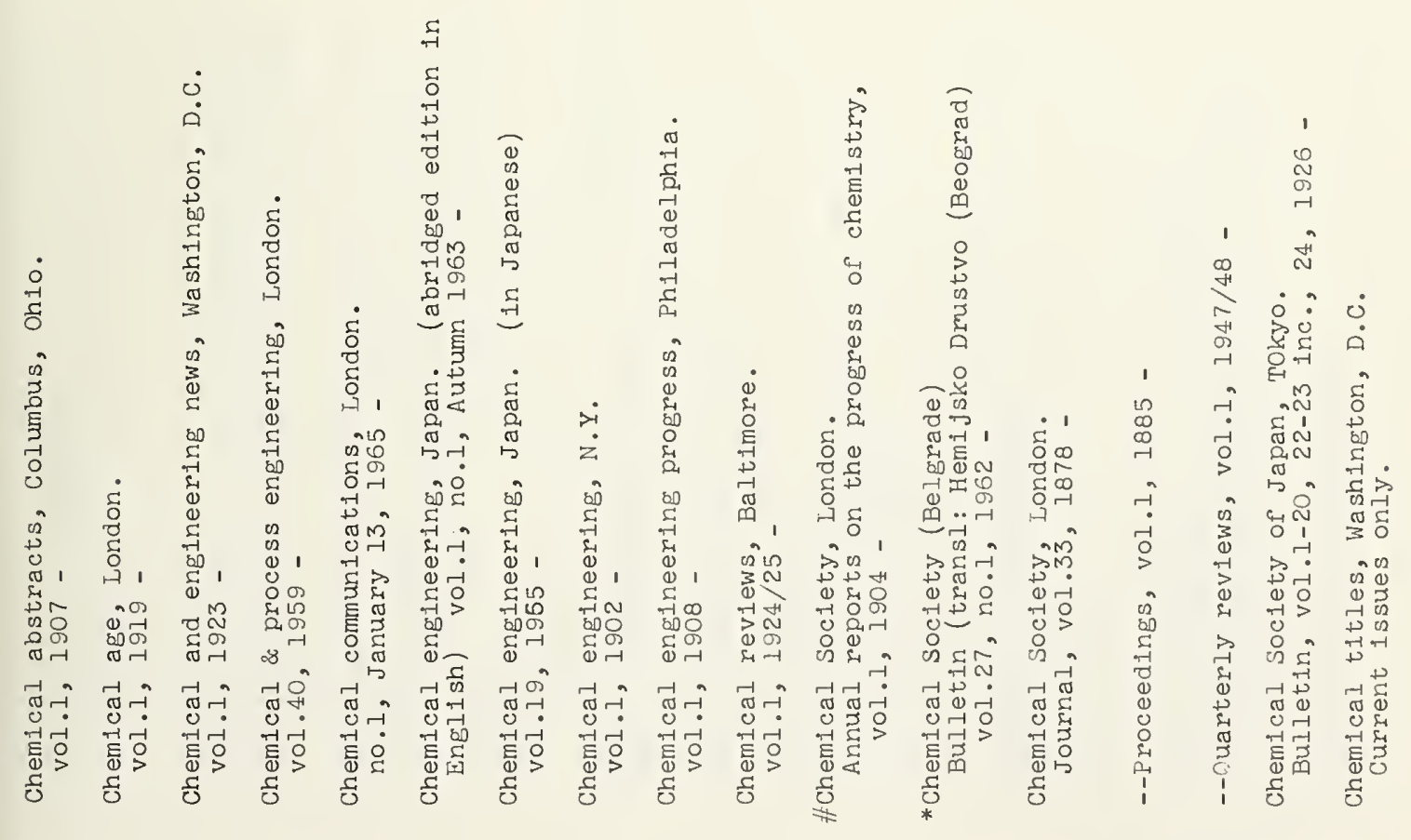

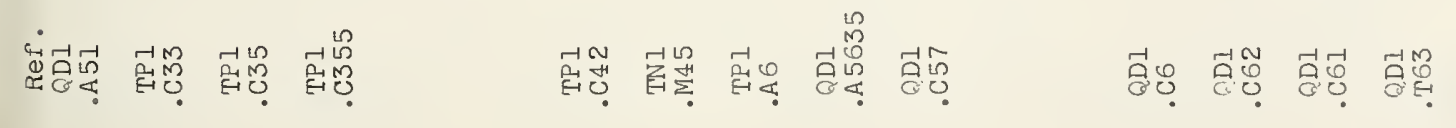




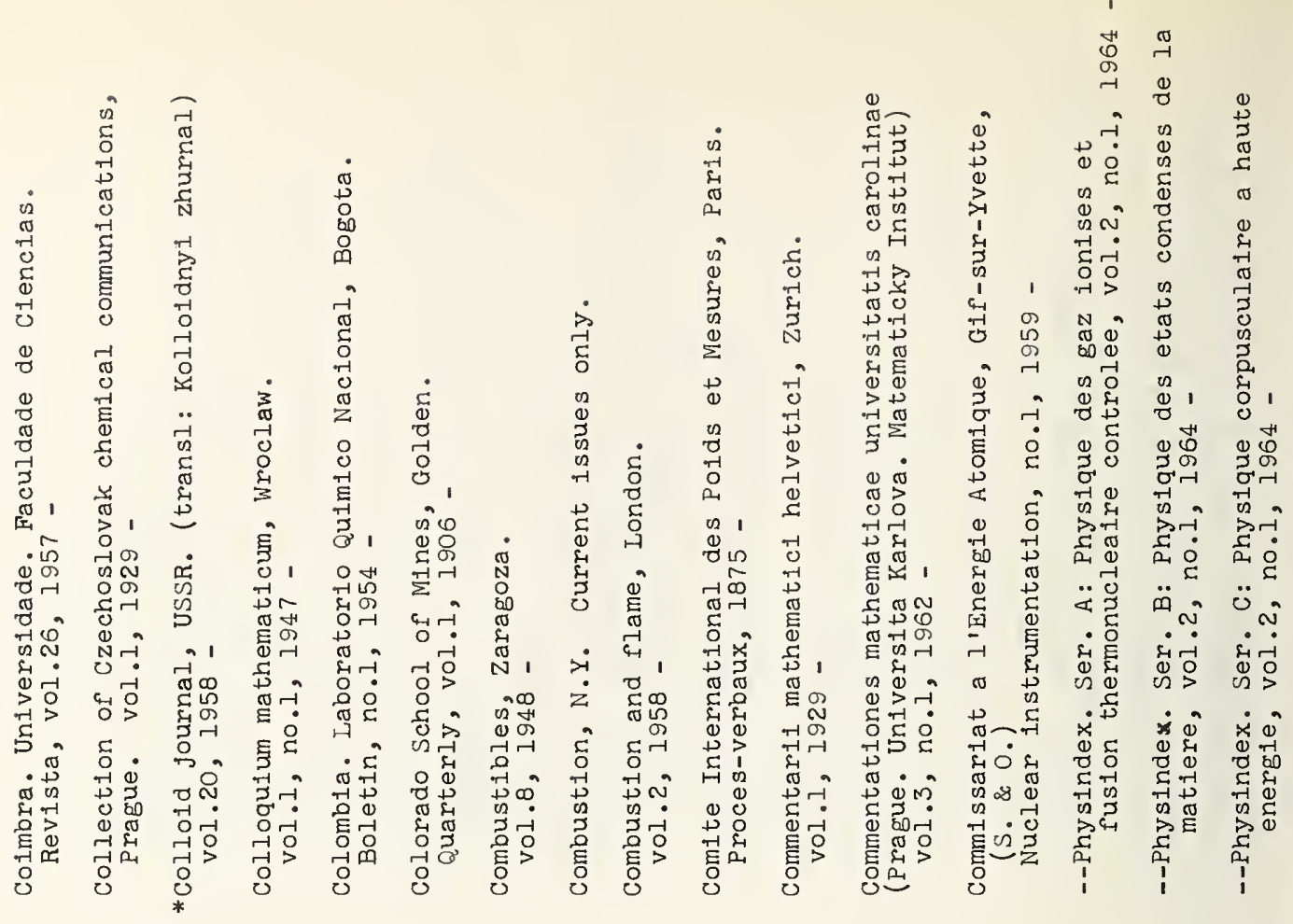

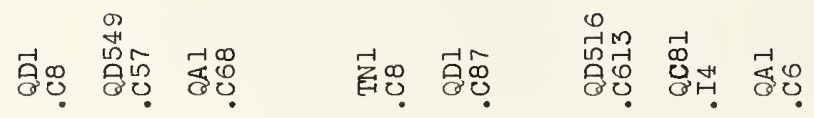

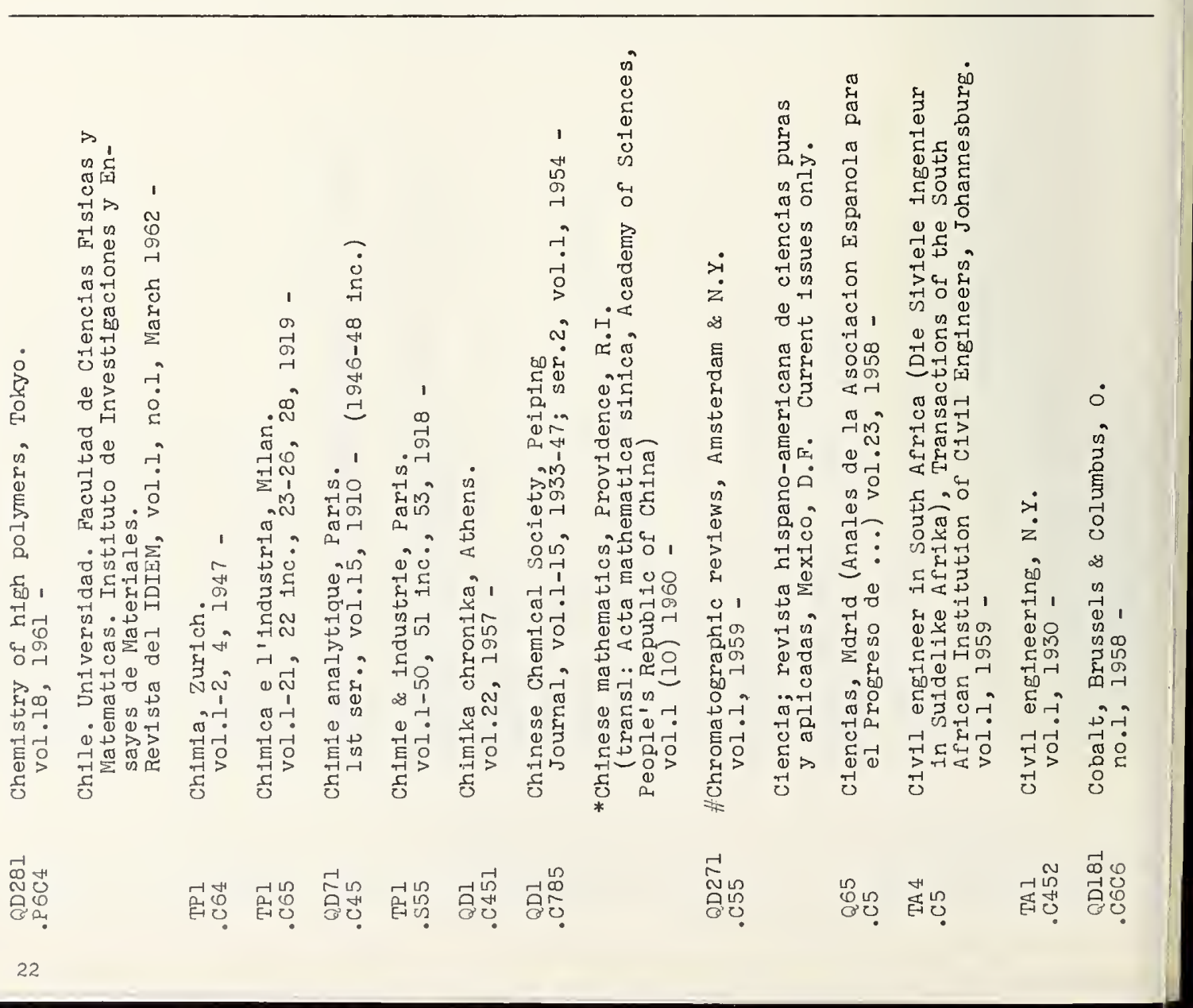




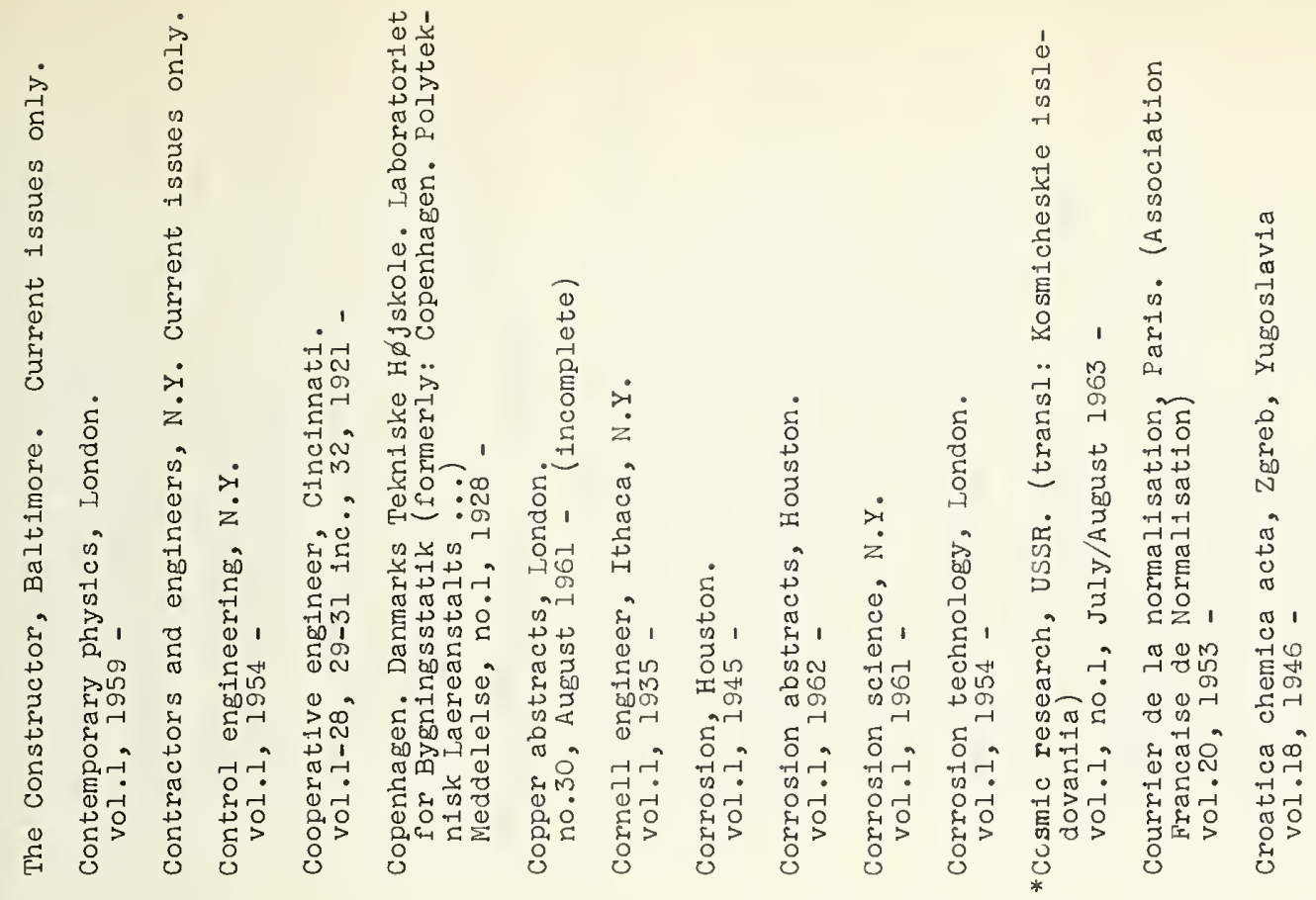

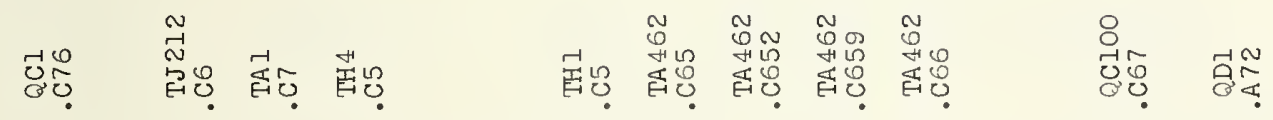

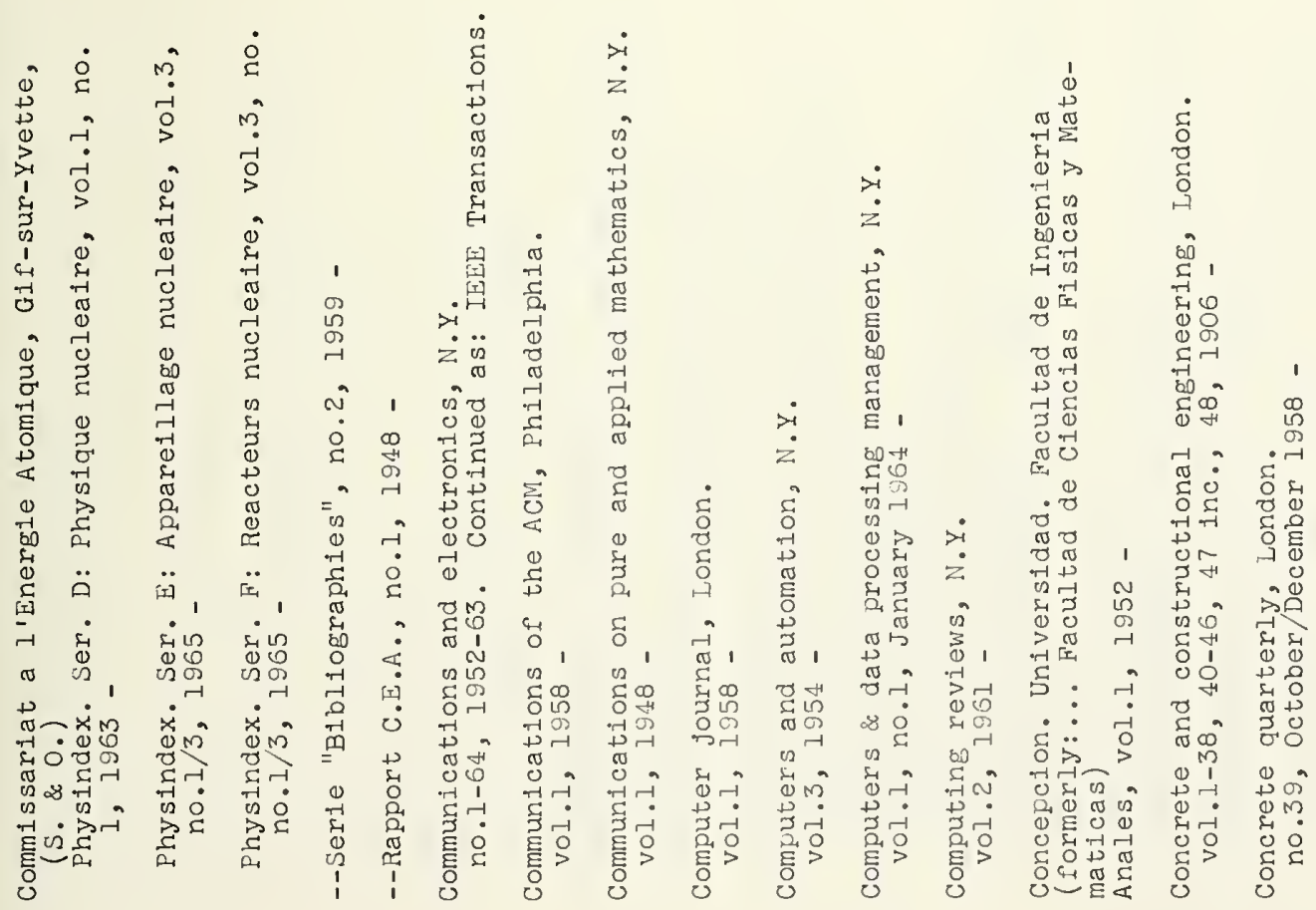

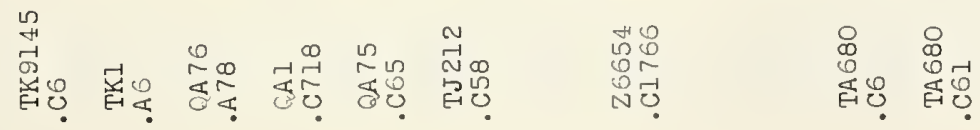



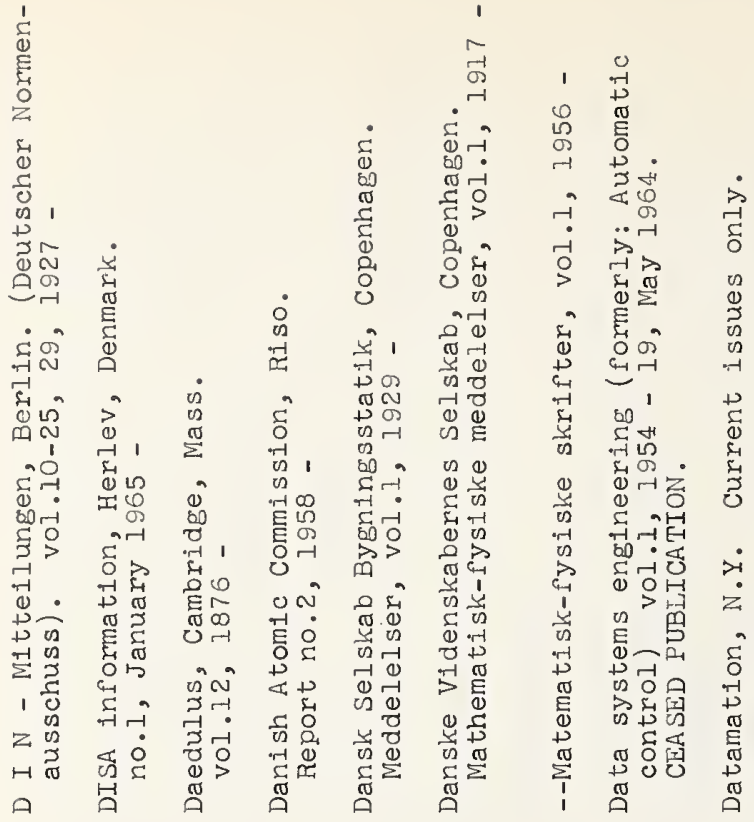

ฮ్ర

口

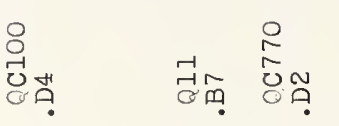
芸

踏

就

总

รă

窝苞萖菂

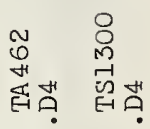

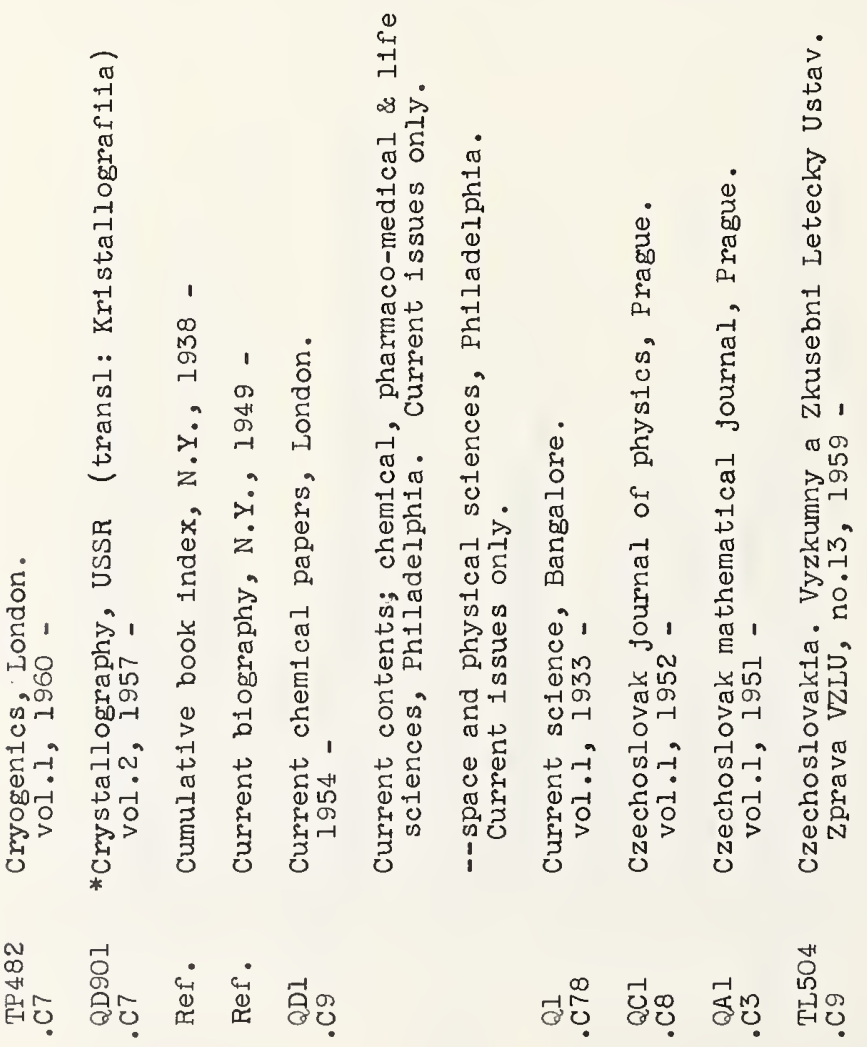




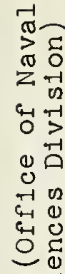

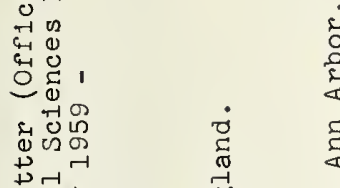

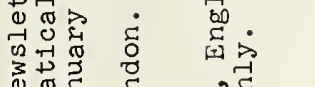

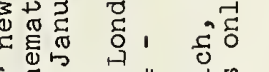

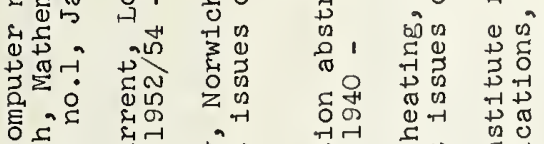

ठ

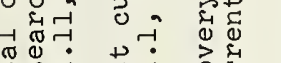

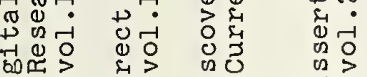

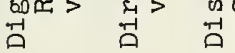

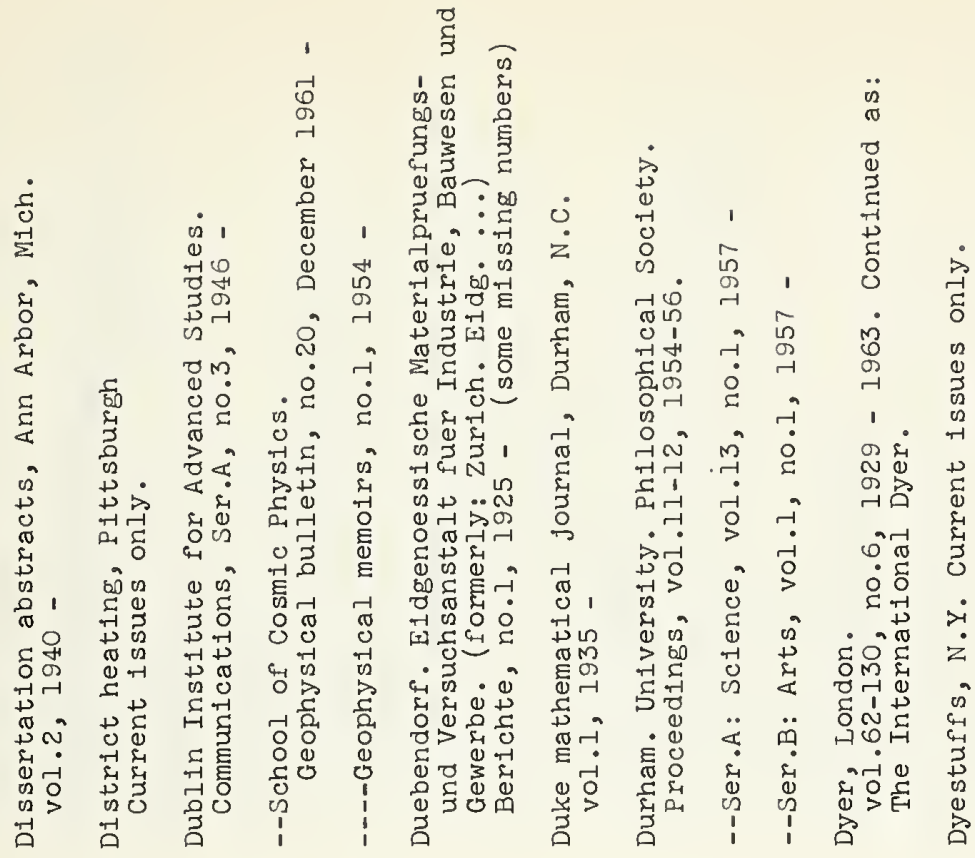

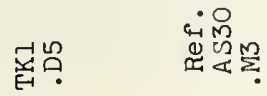

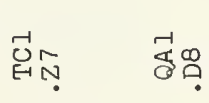

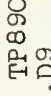

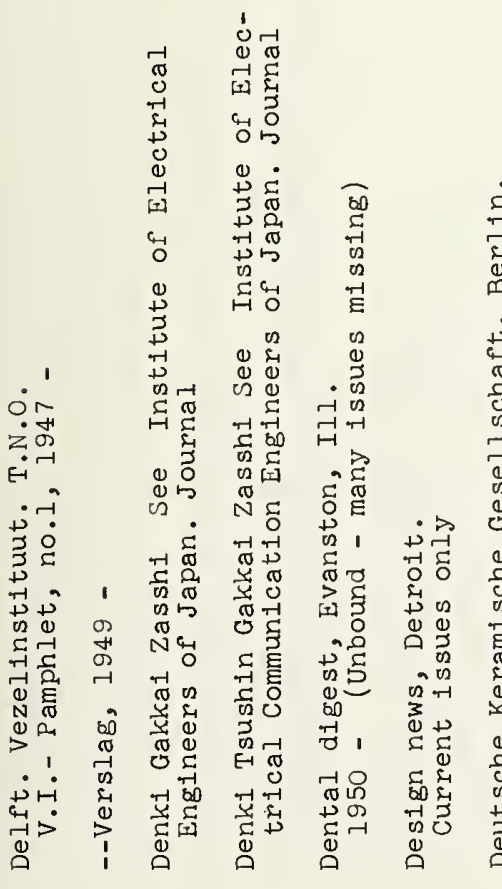

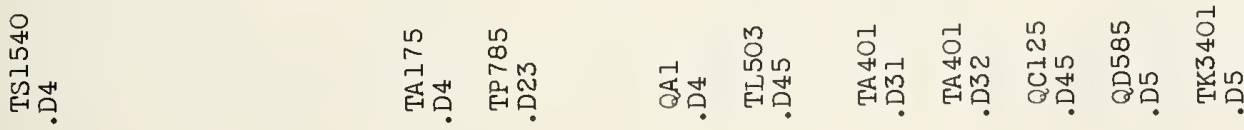



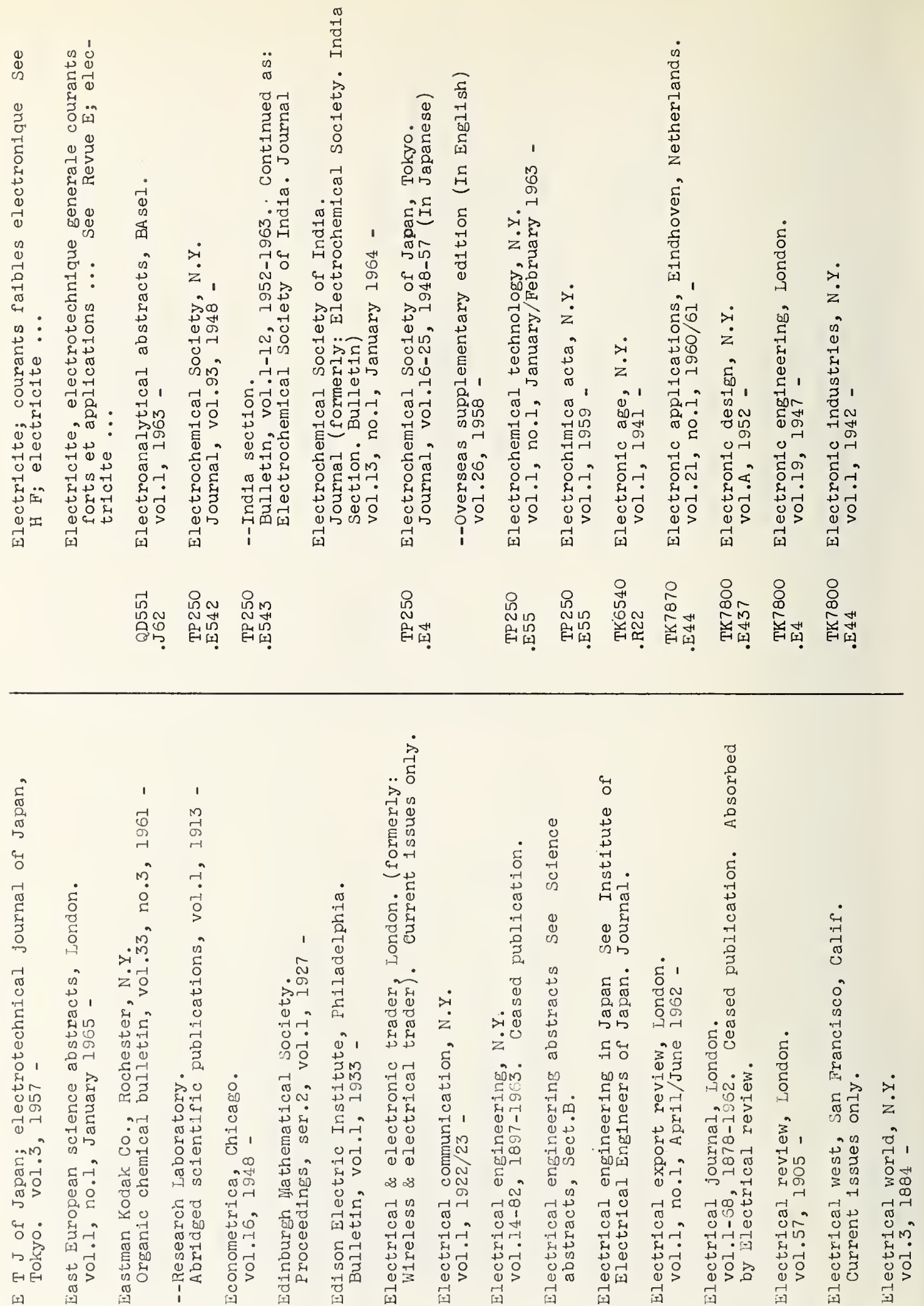

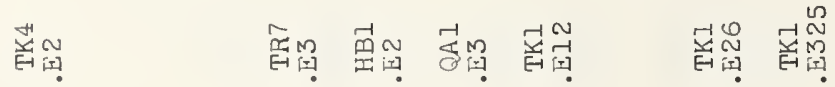

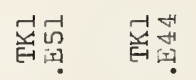

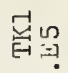




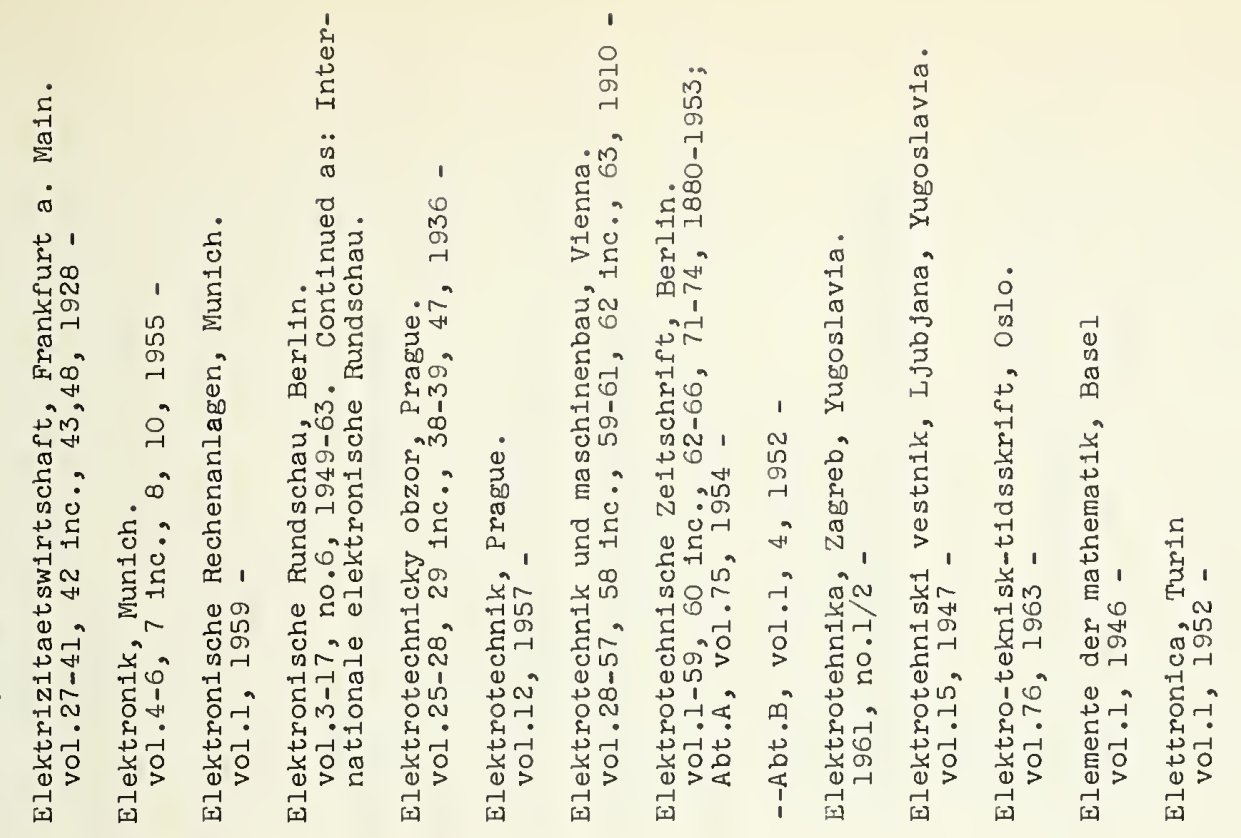

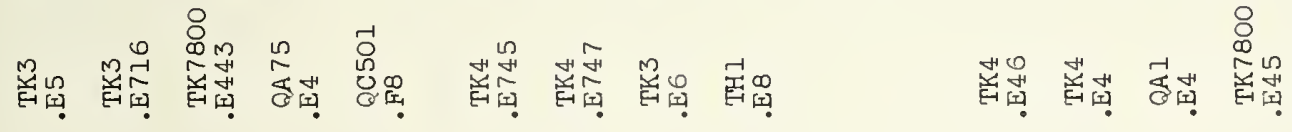

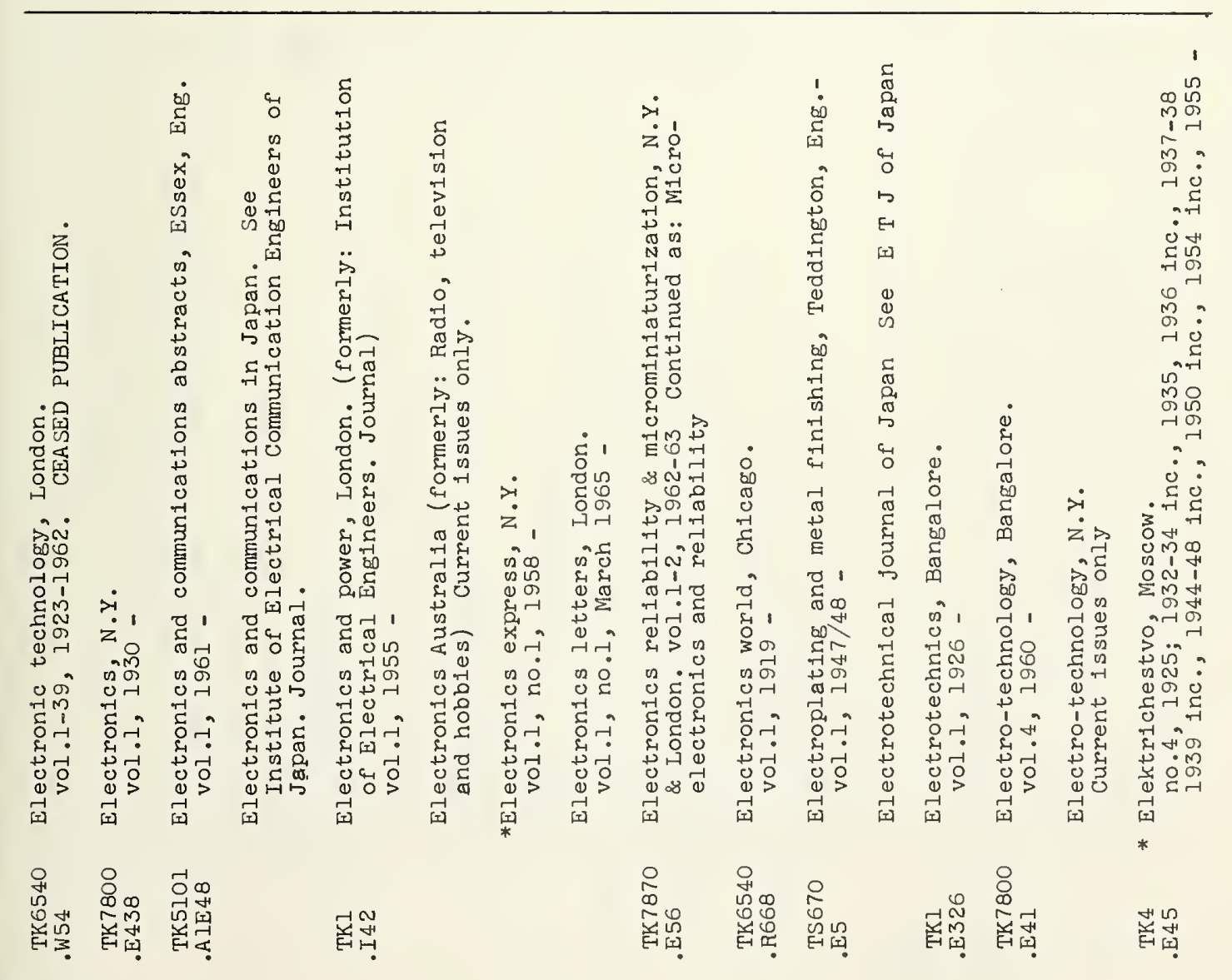




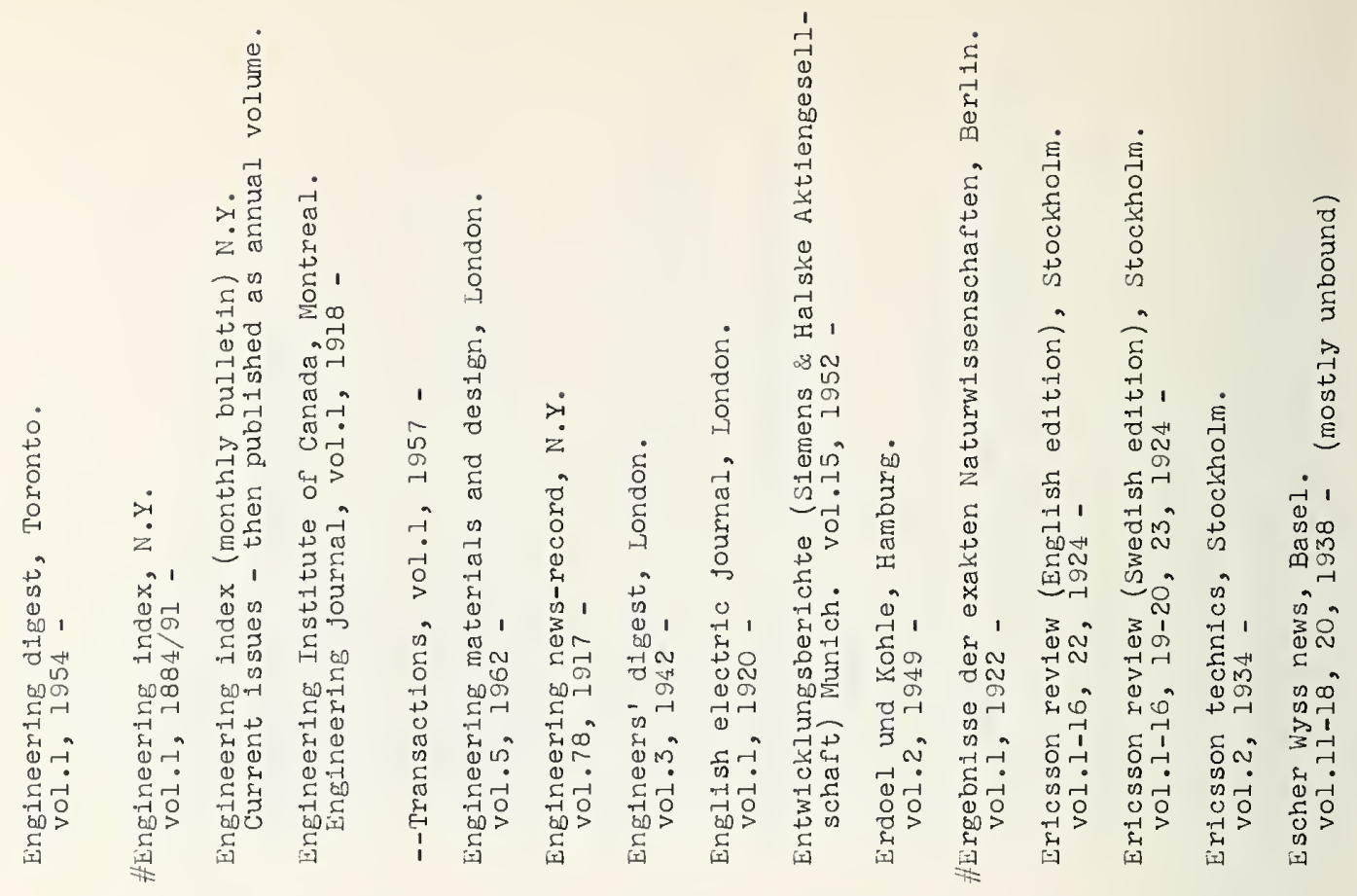

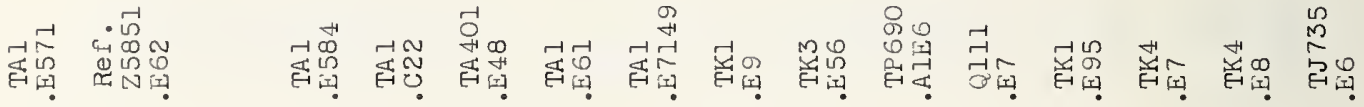

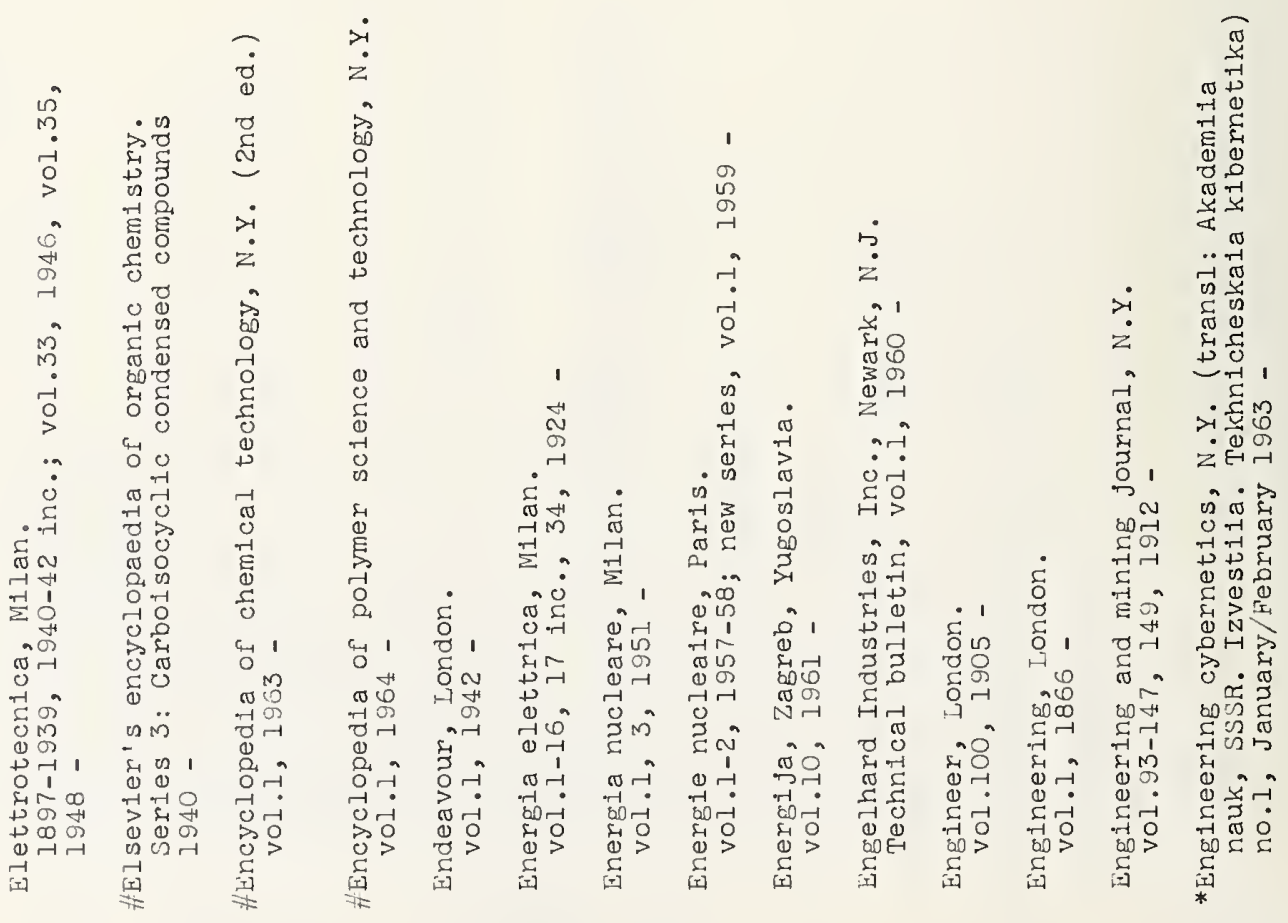

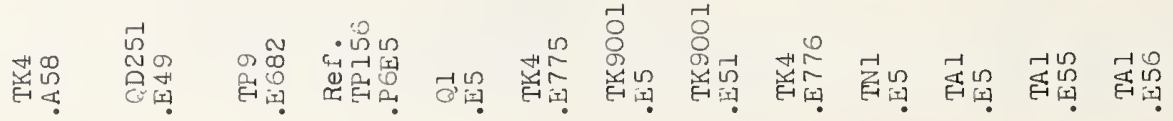



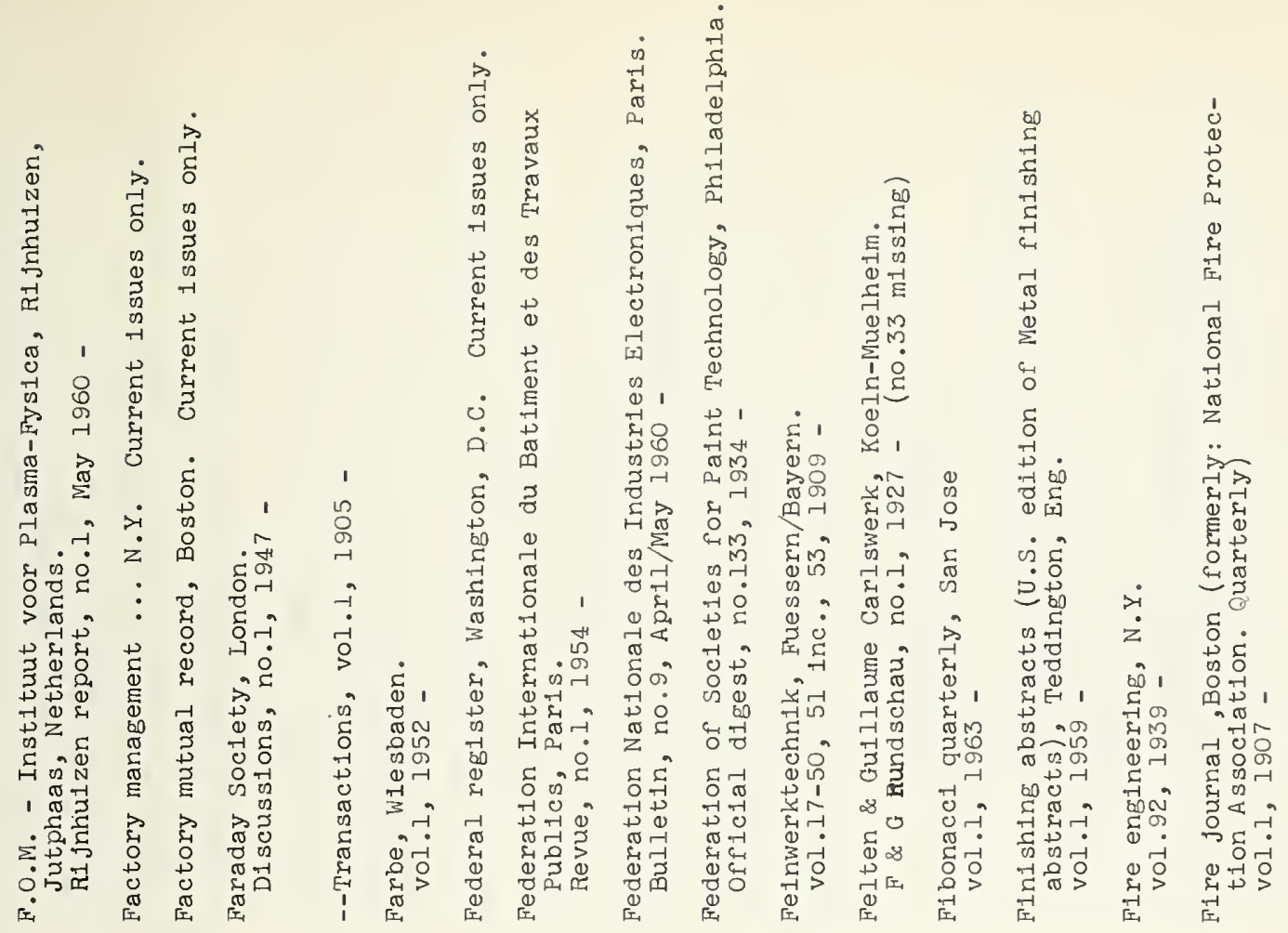

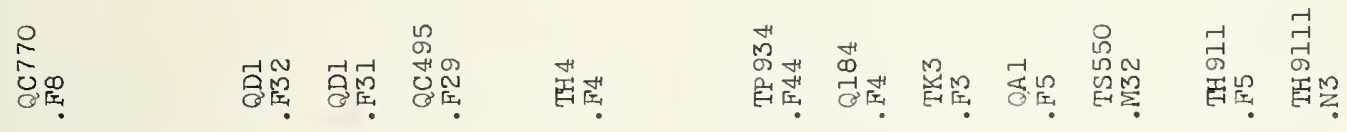

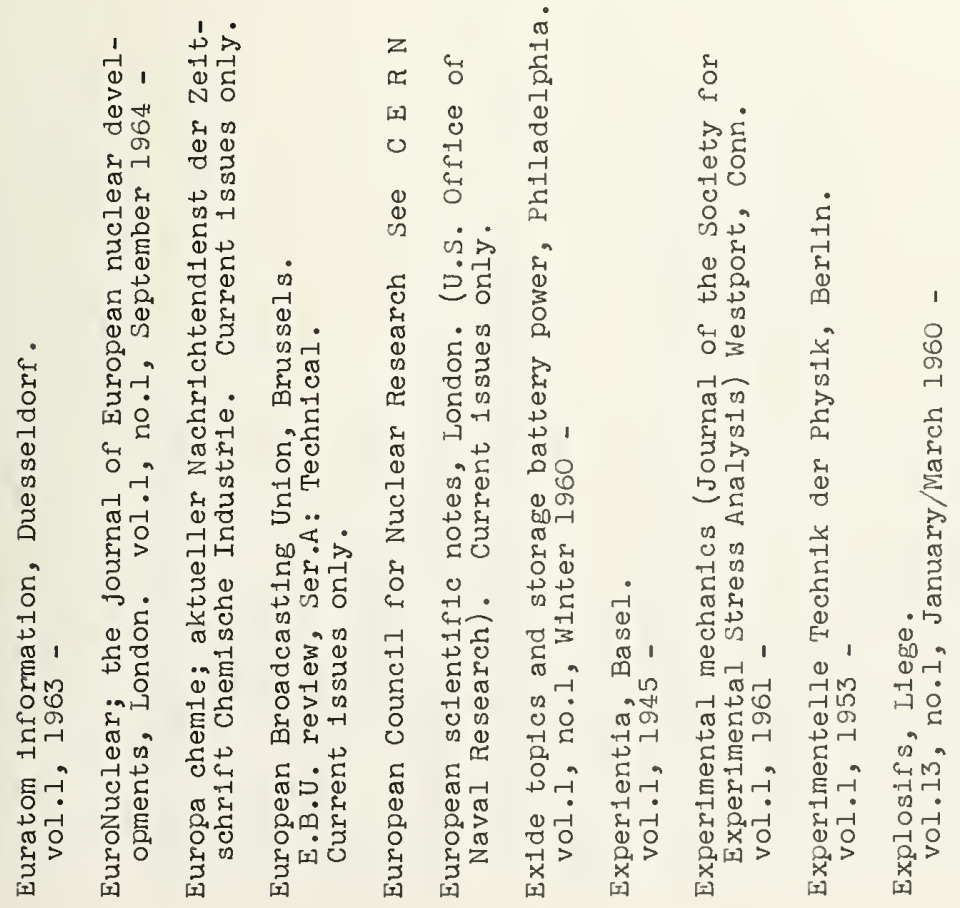

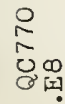

क्ञ 


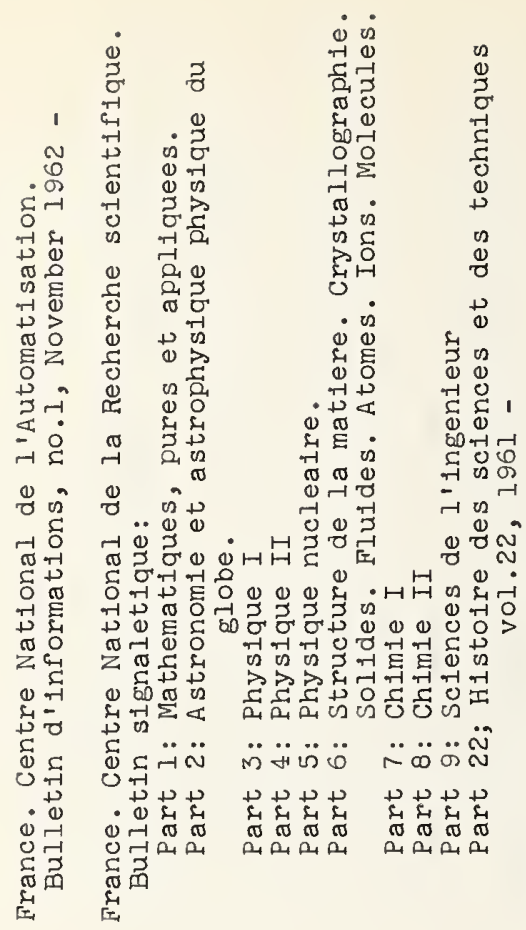

总的
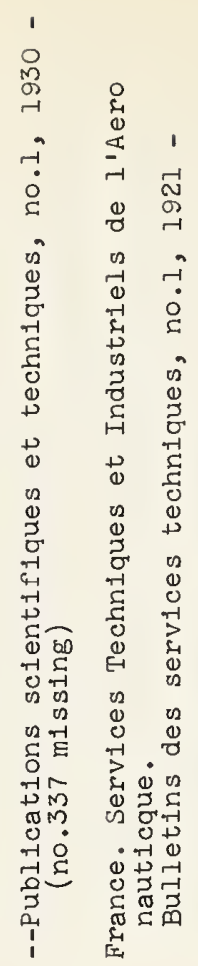

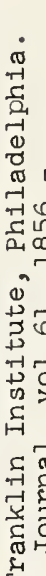

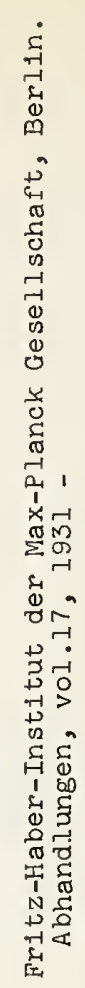

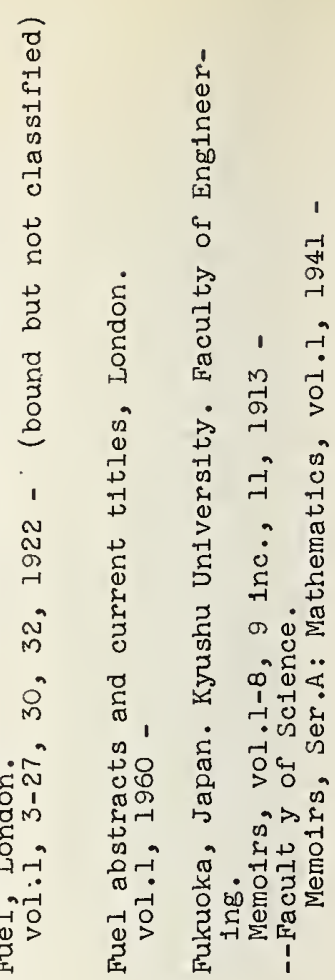

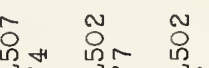

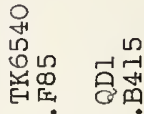

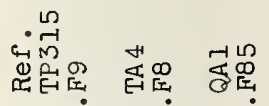
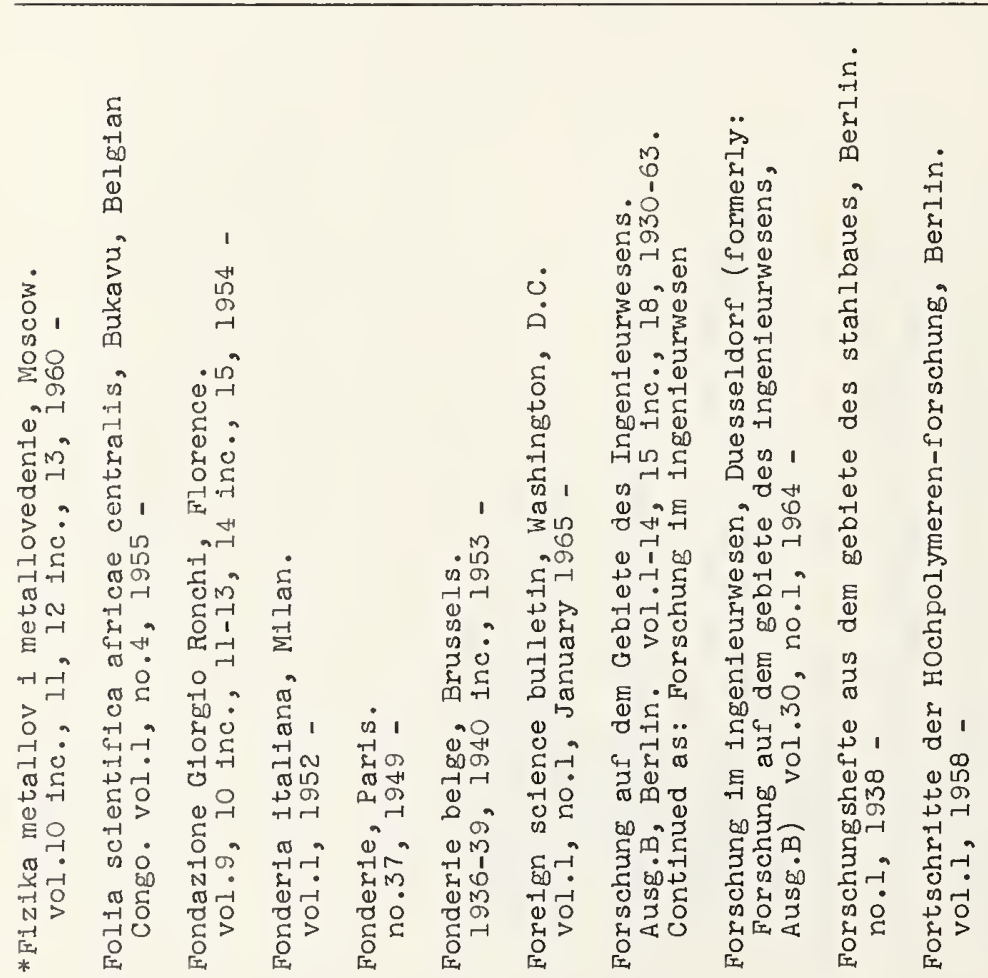

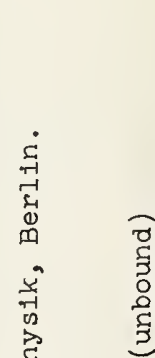

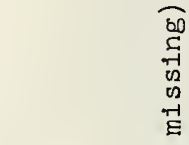

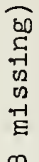

¿ัฒ

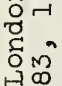

a

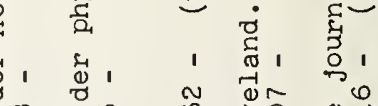

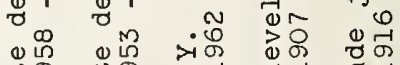

मु ग्न

द्र

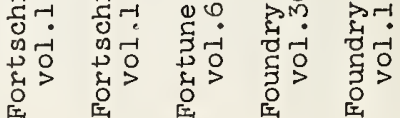

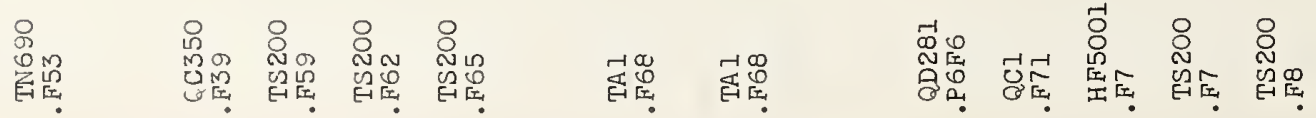




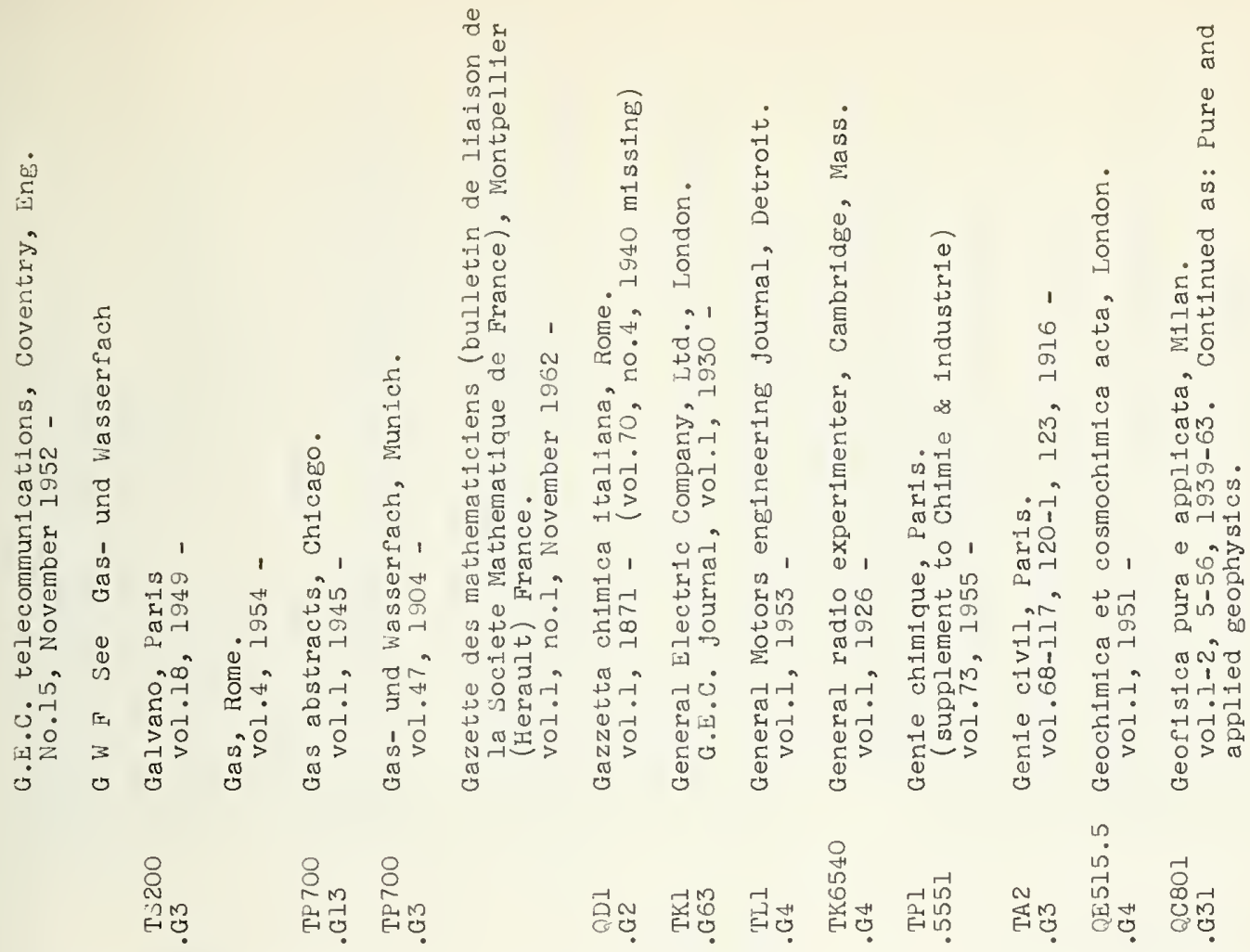

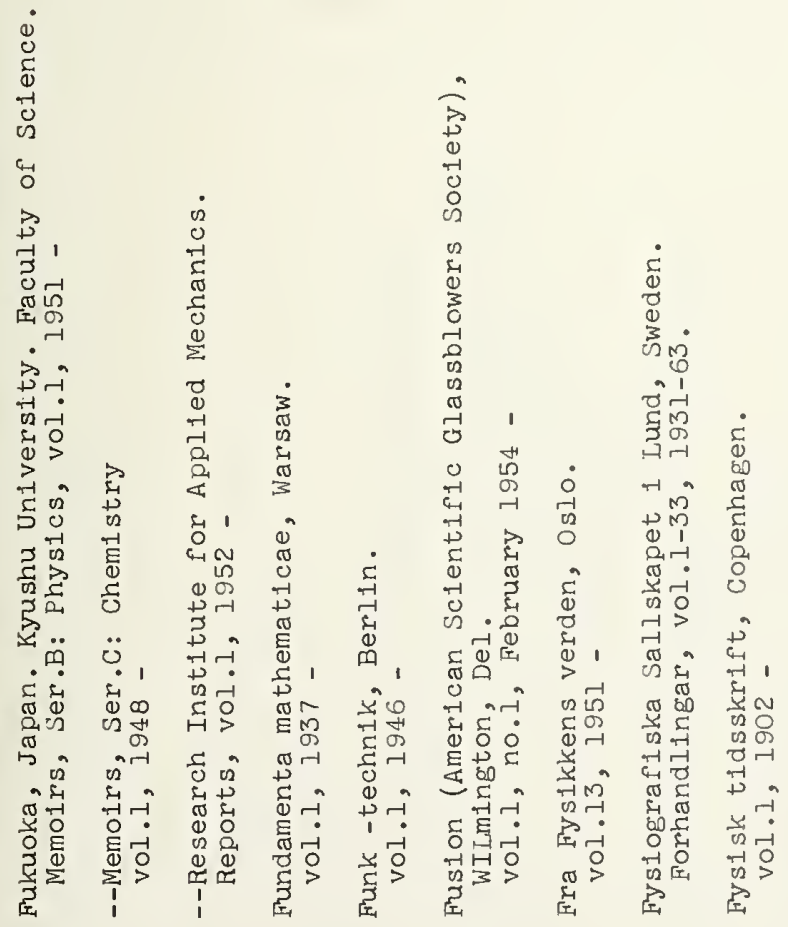

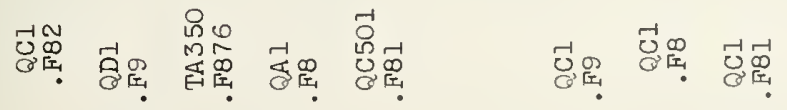




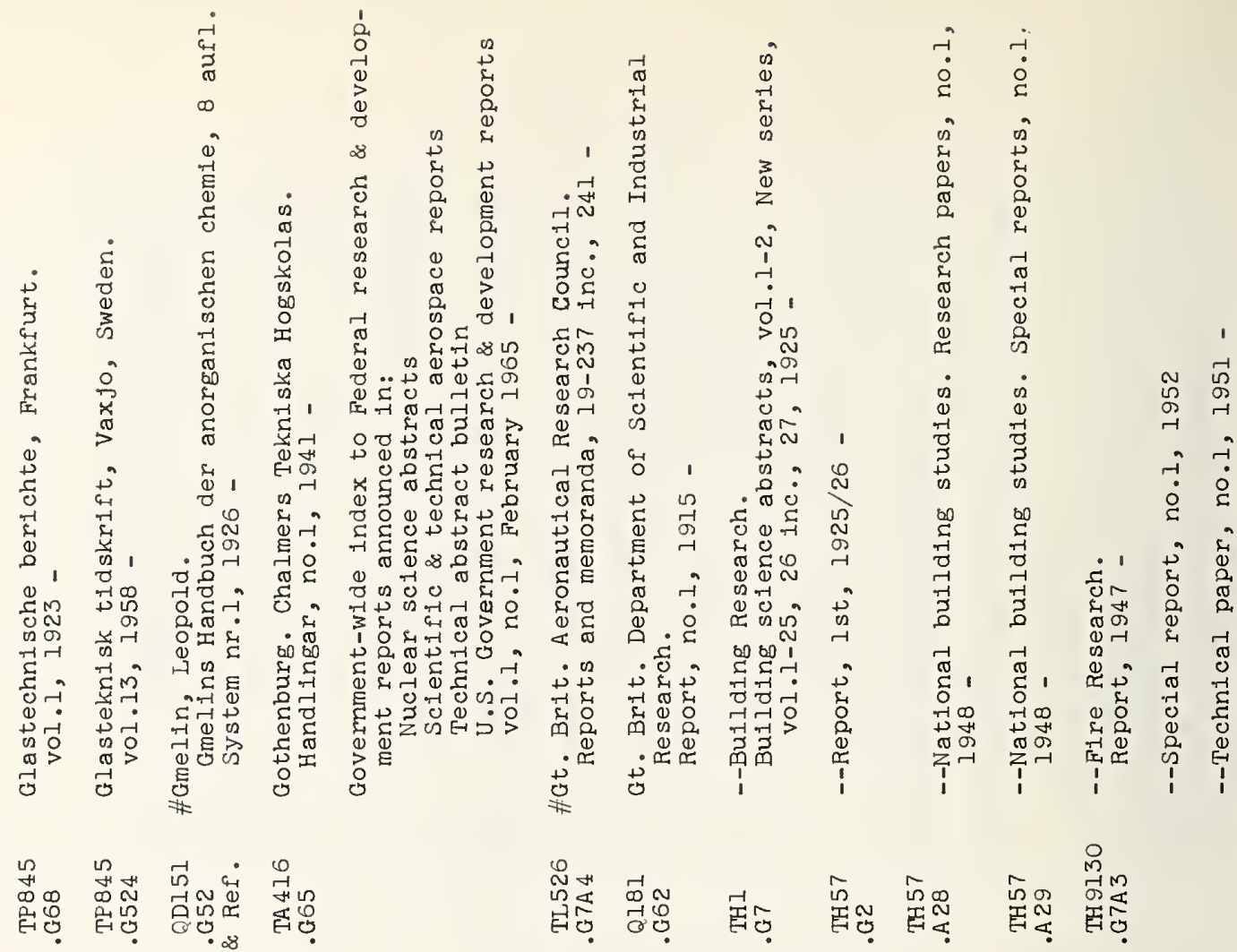

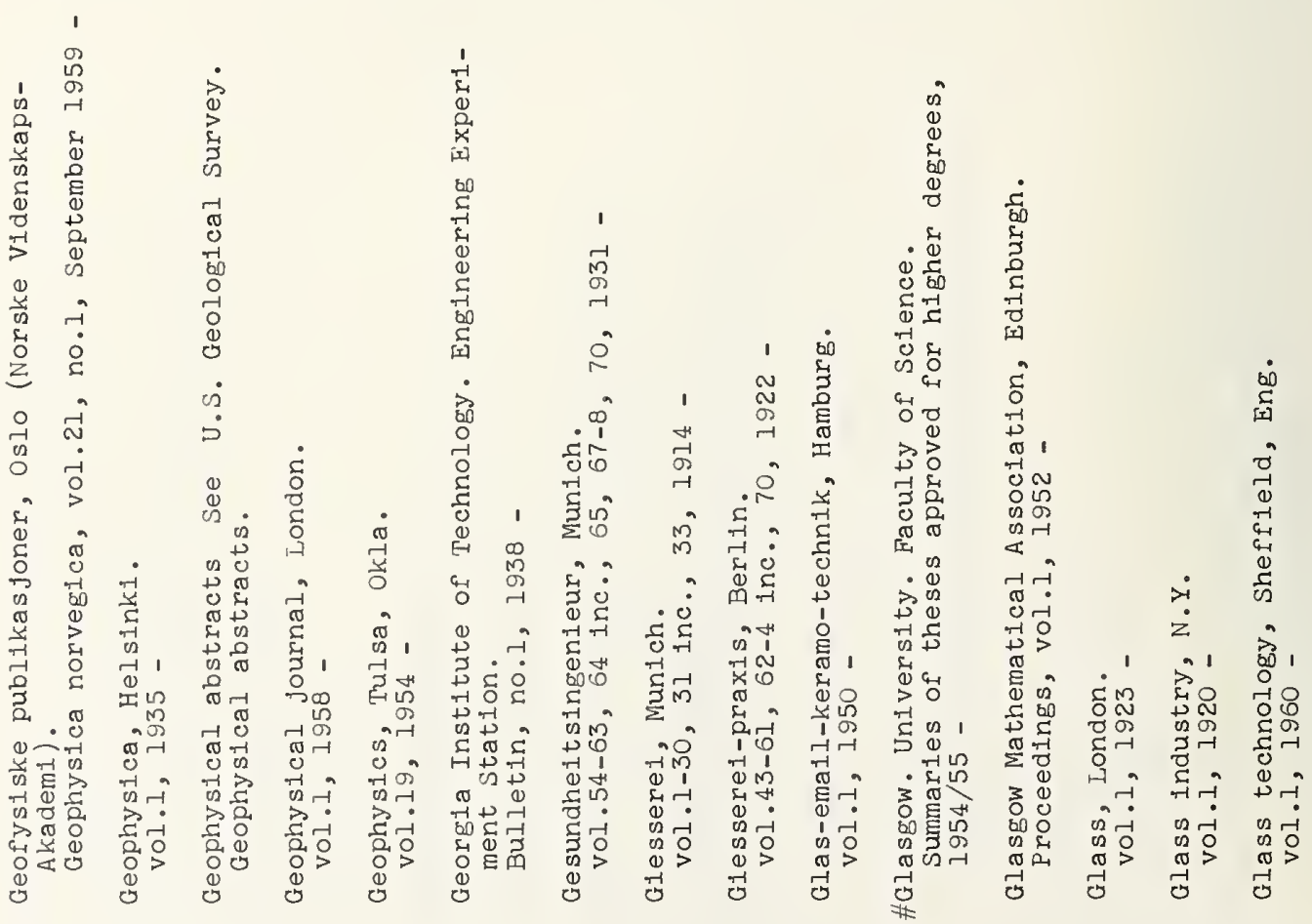

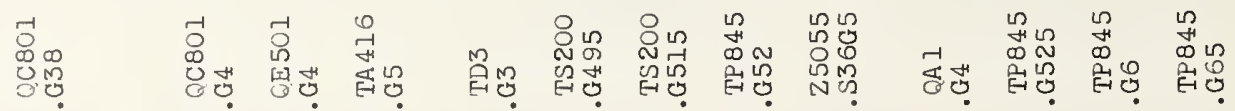




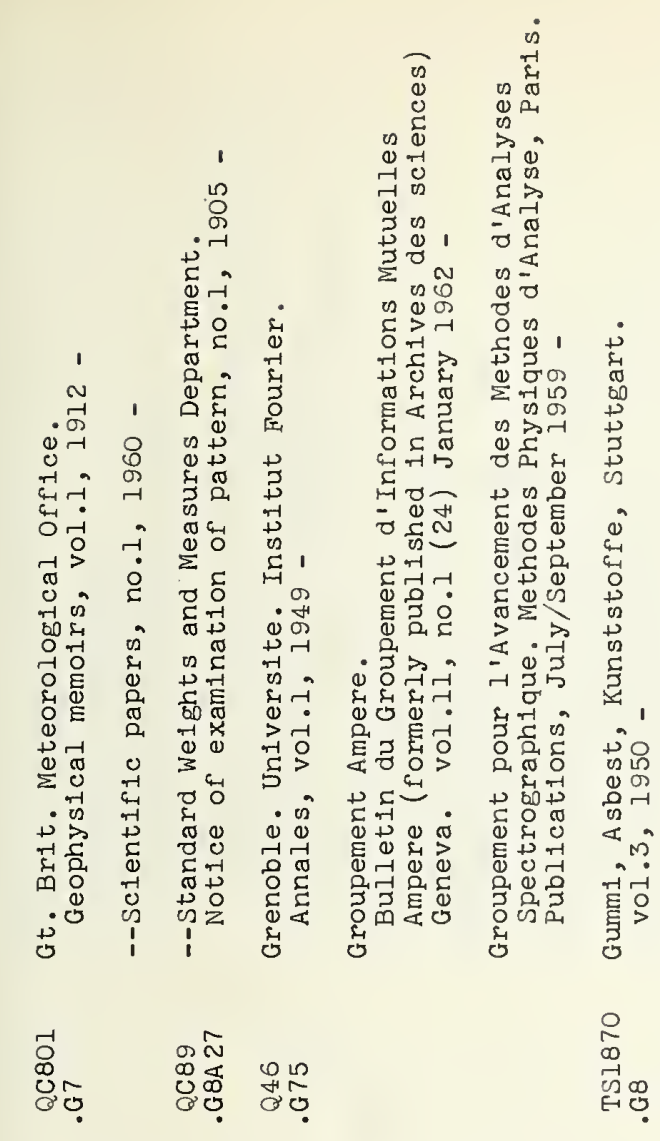

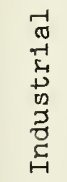

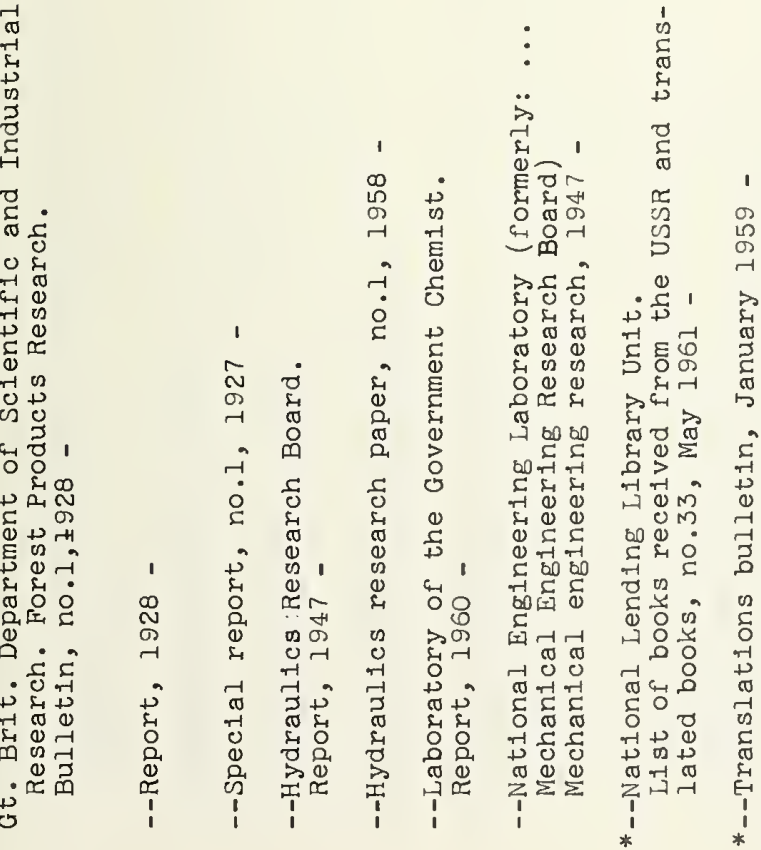

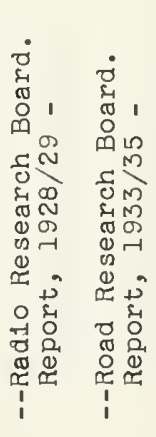

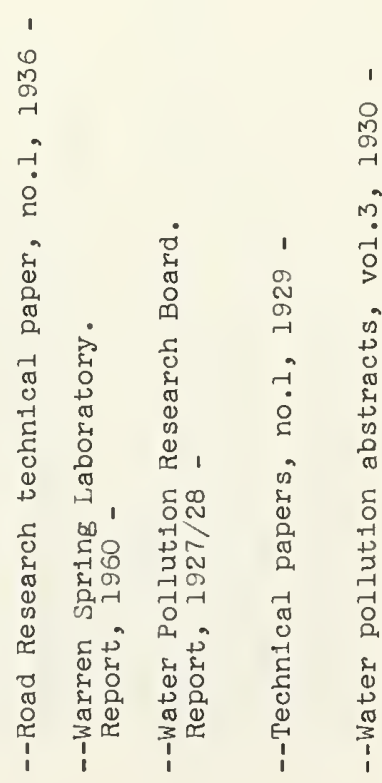

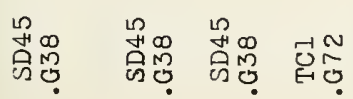

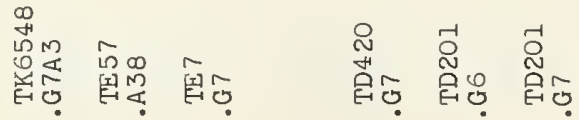



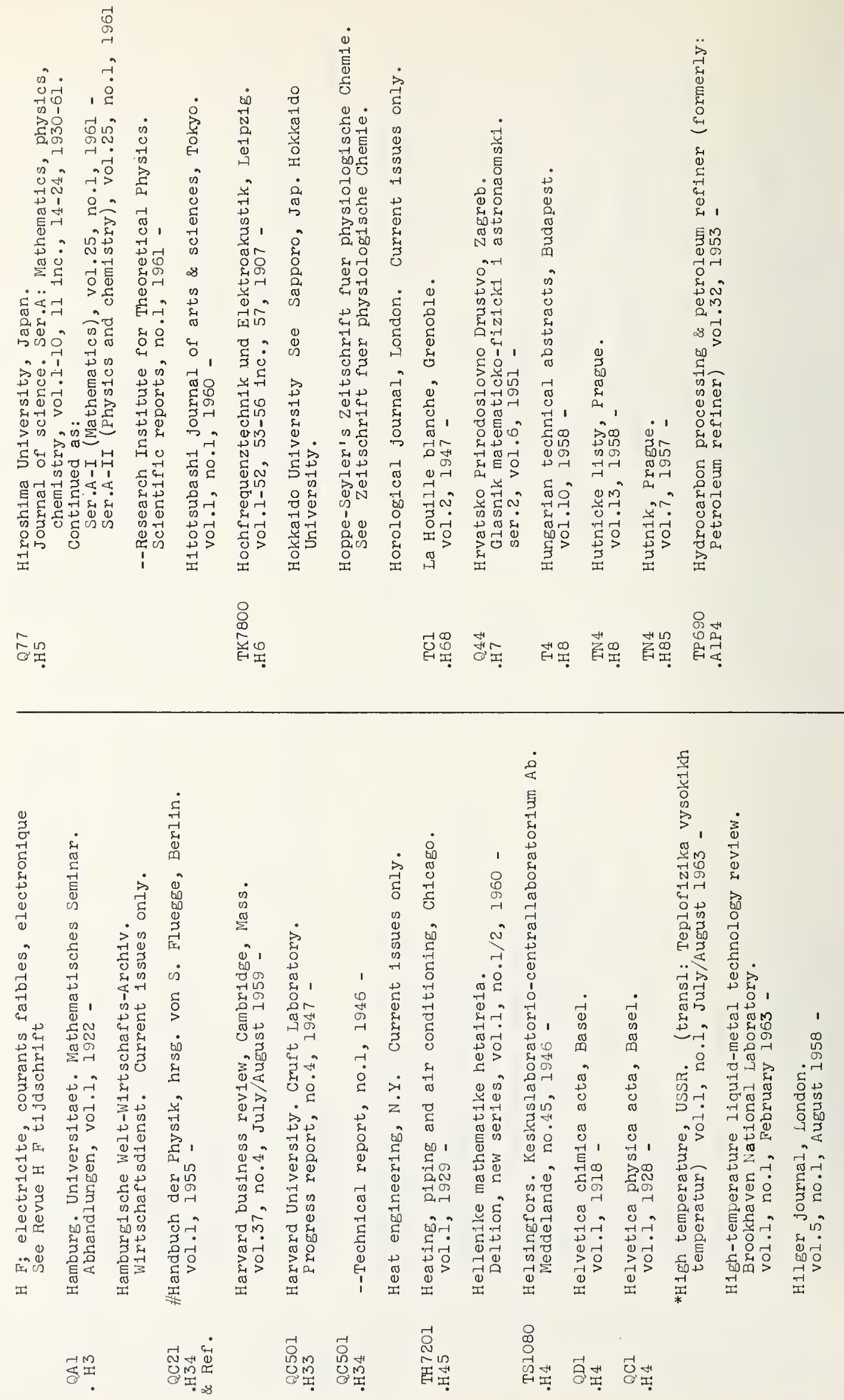


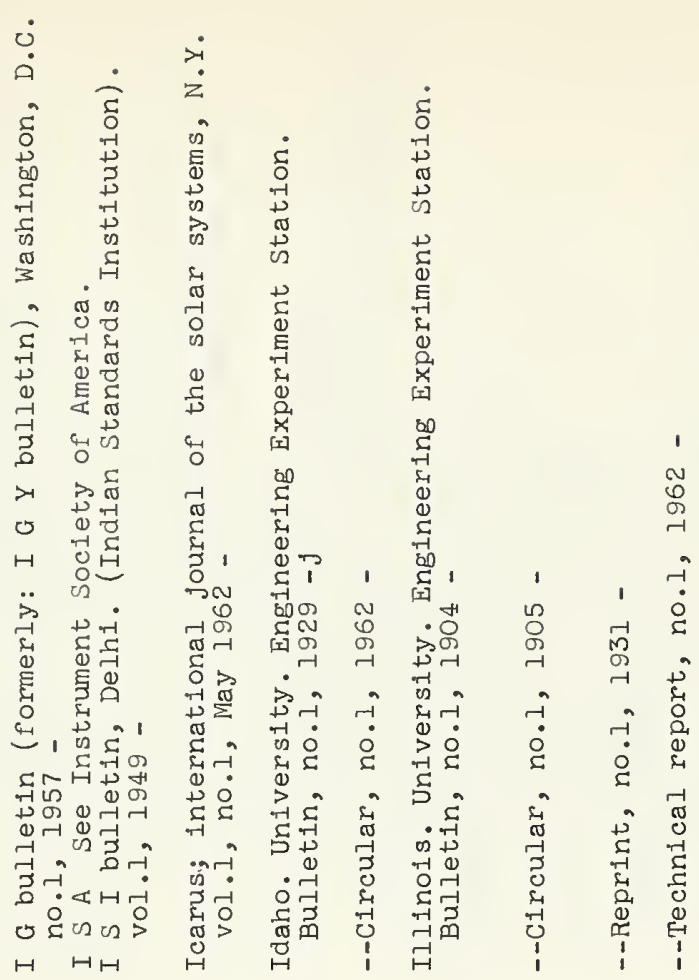

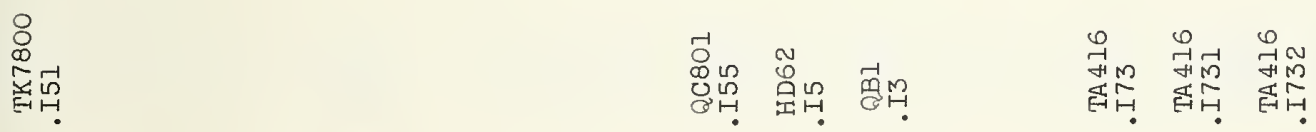

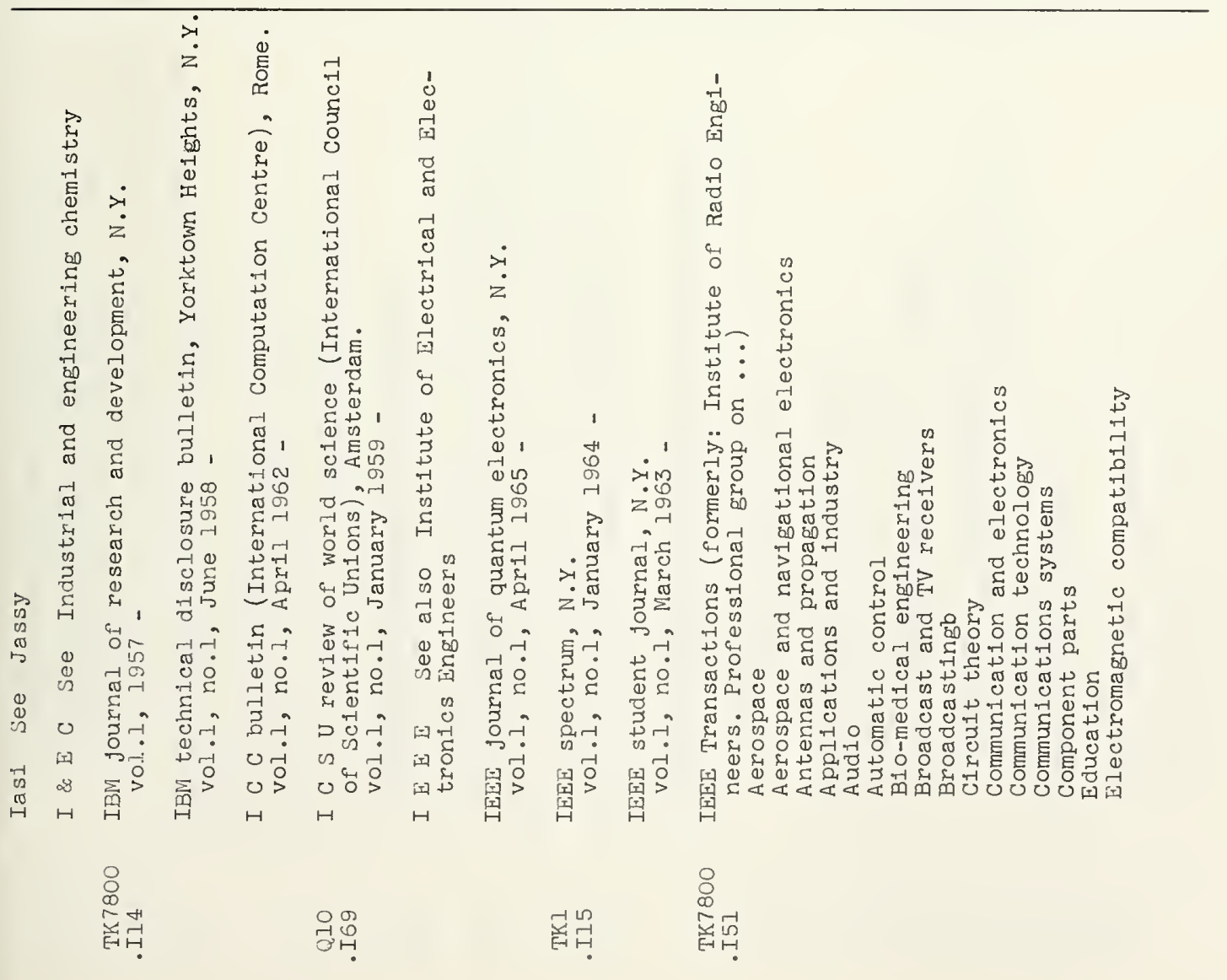




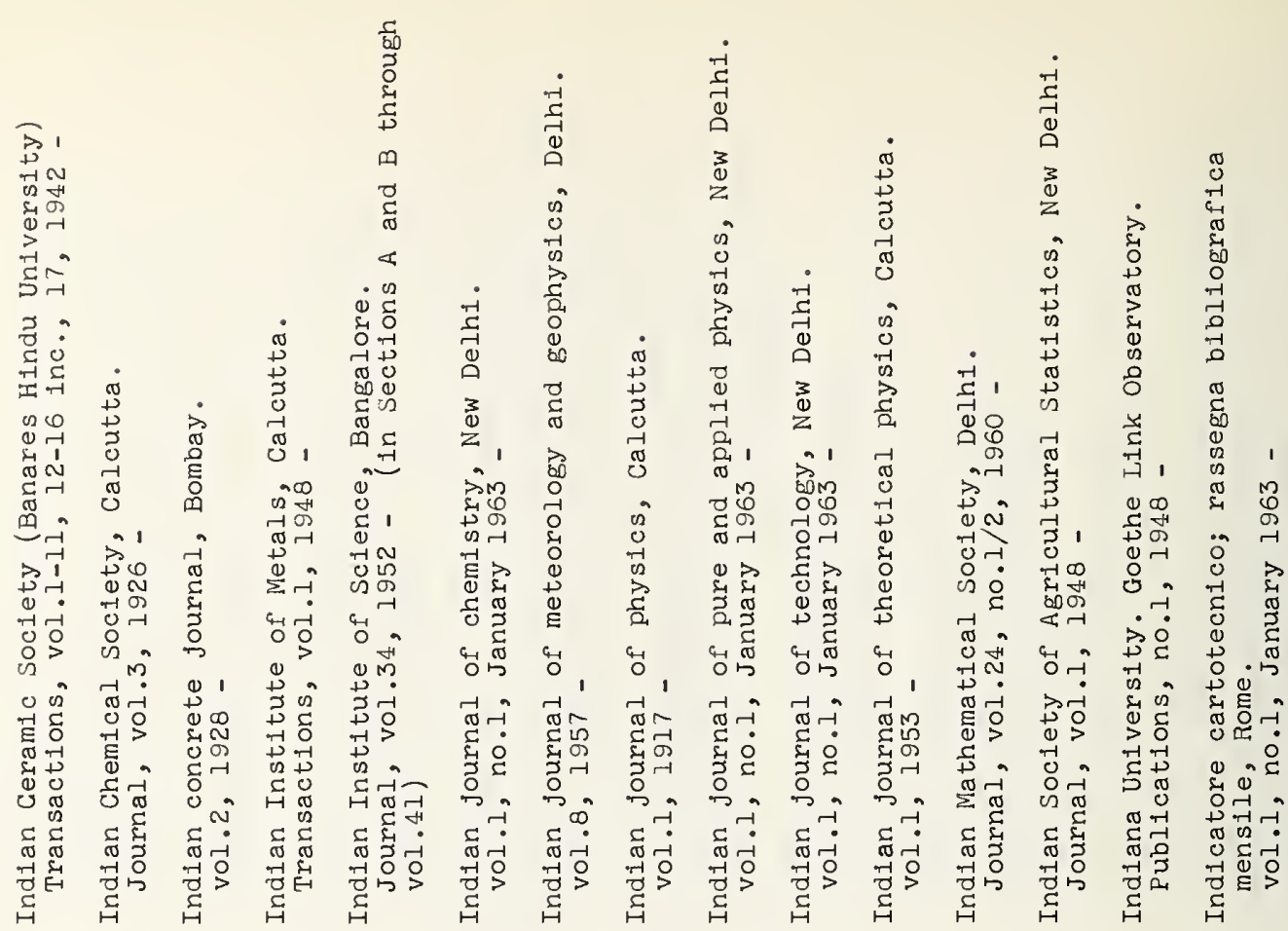

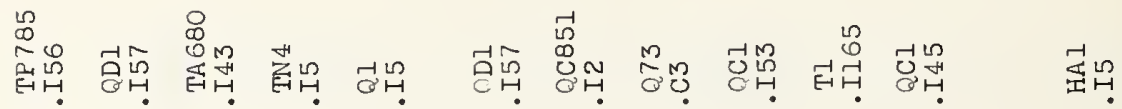

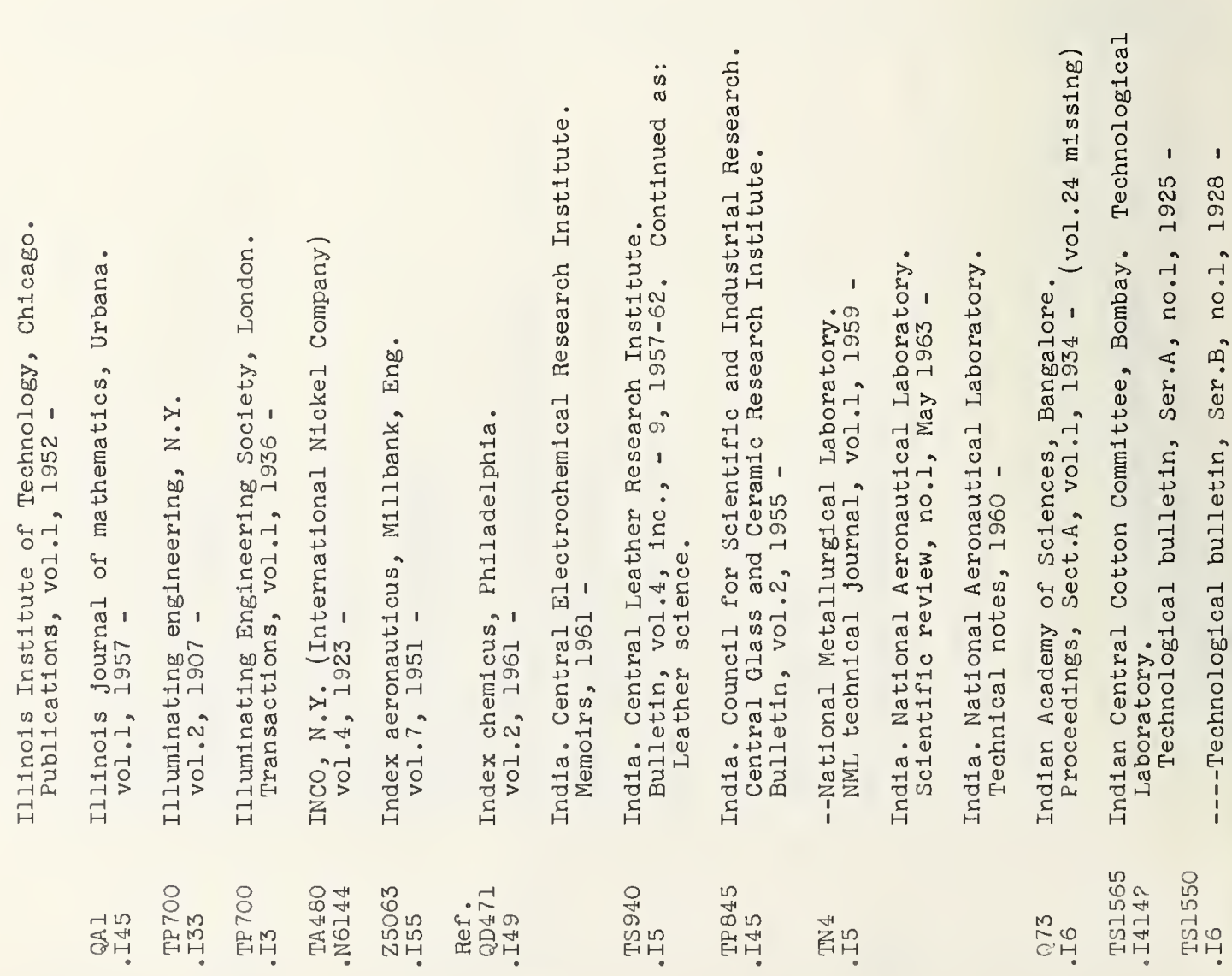




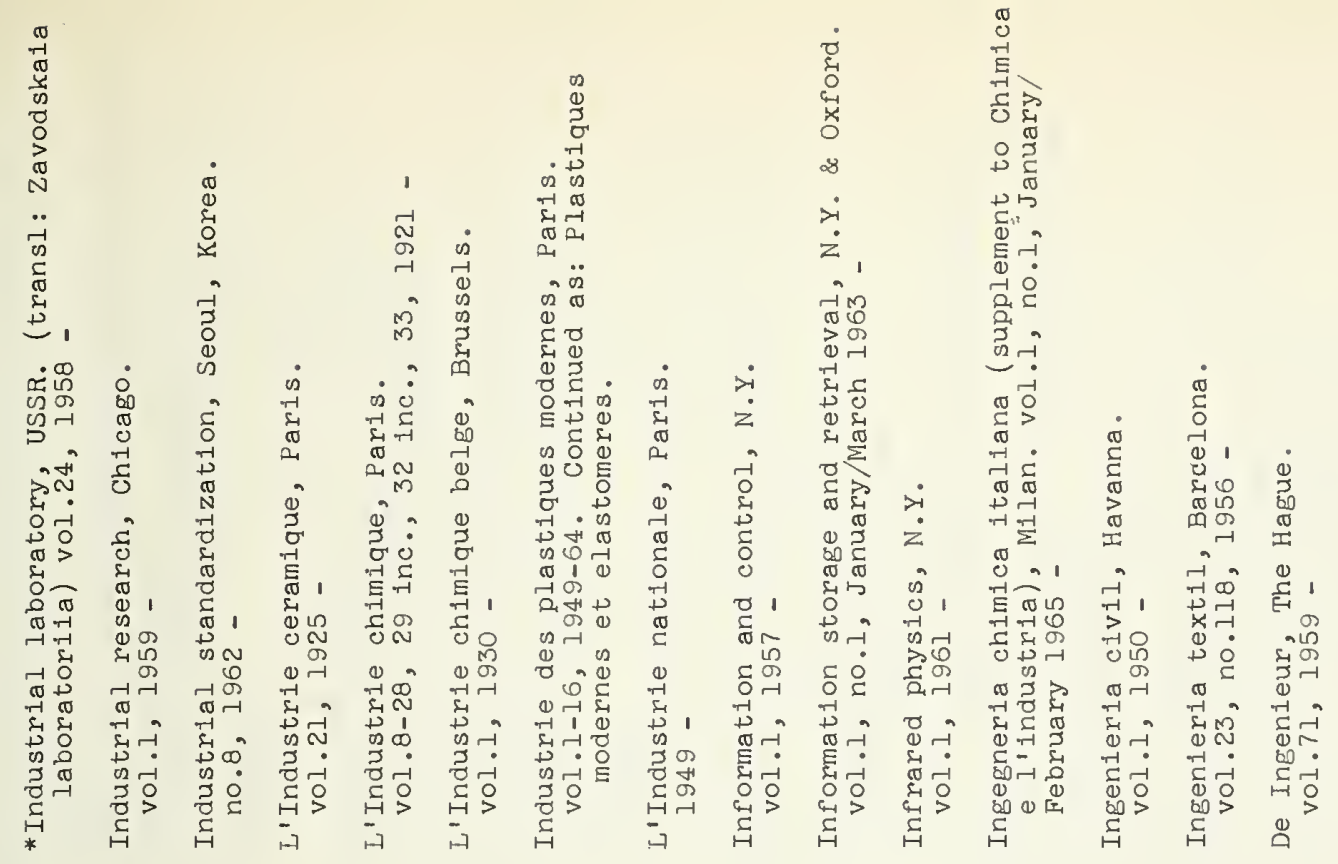

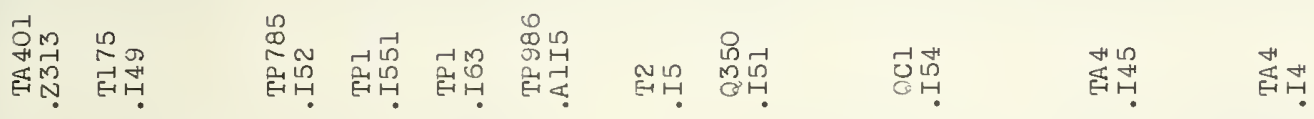

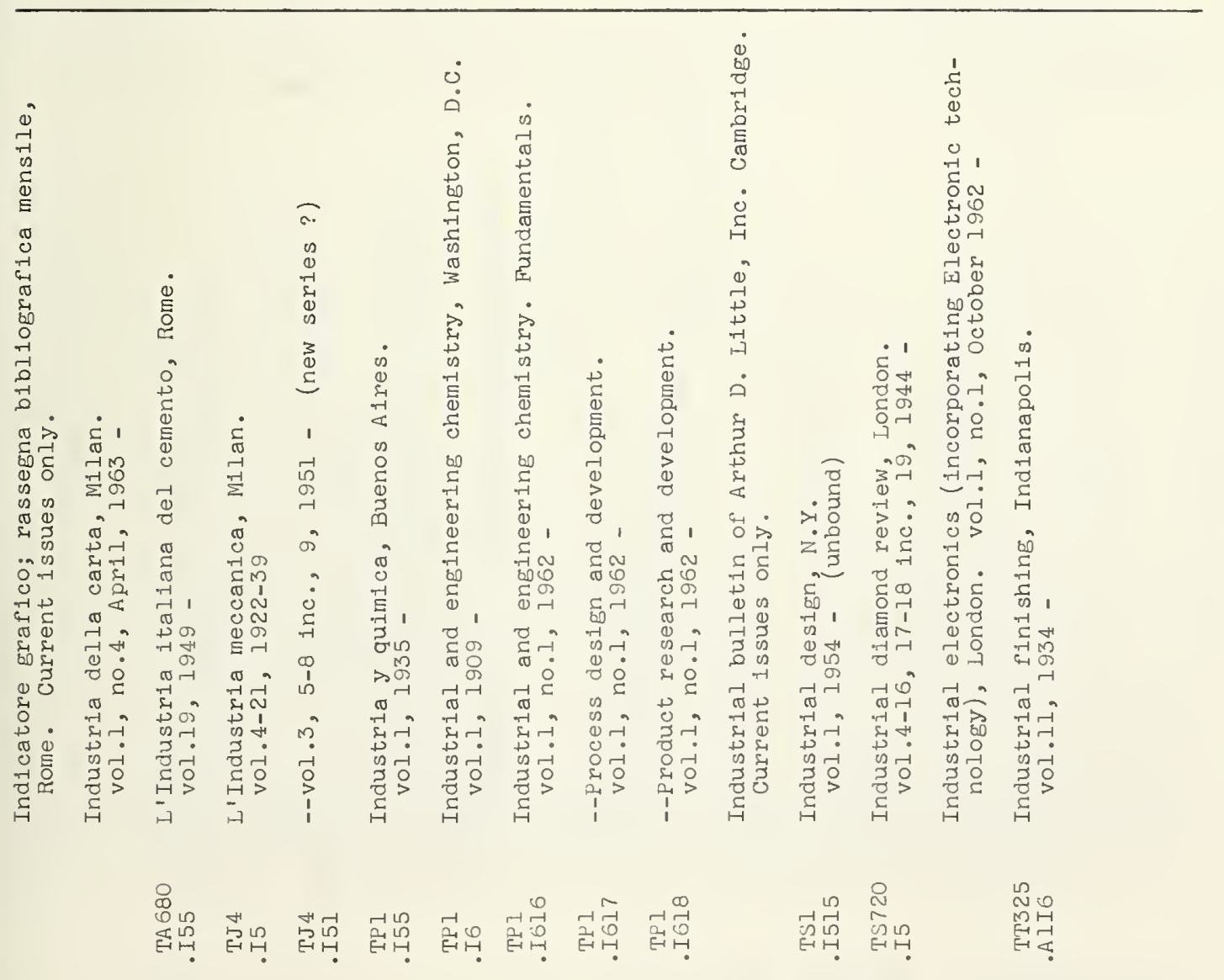




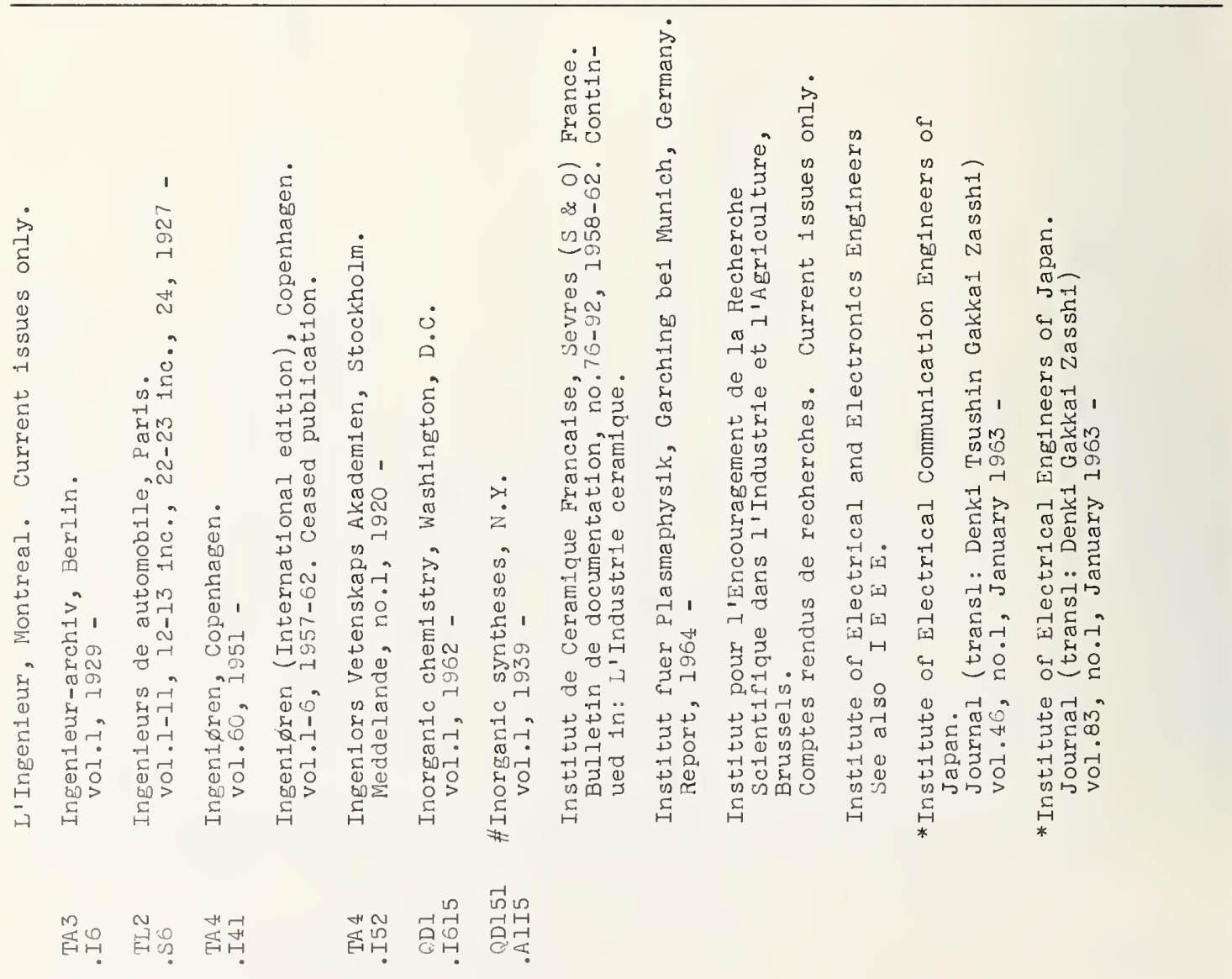




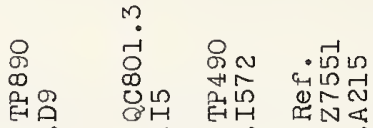

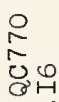
足

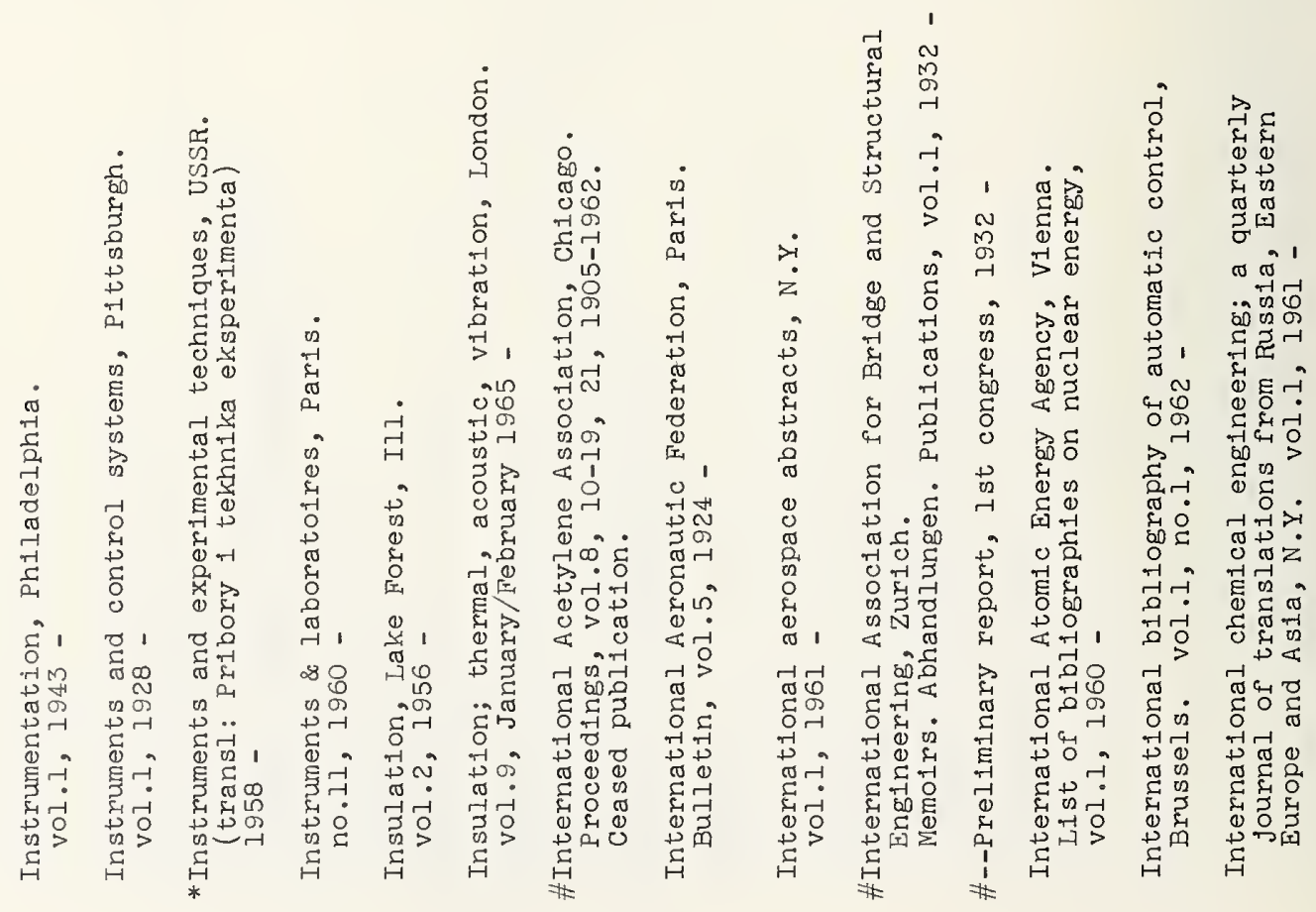

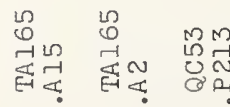

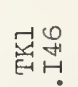

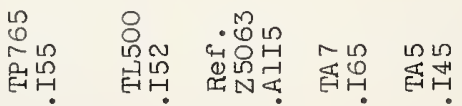

究踏 


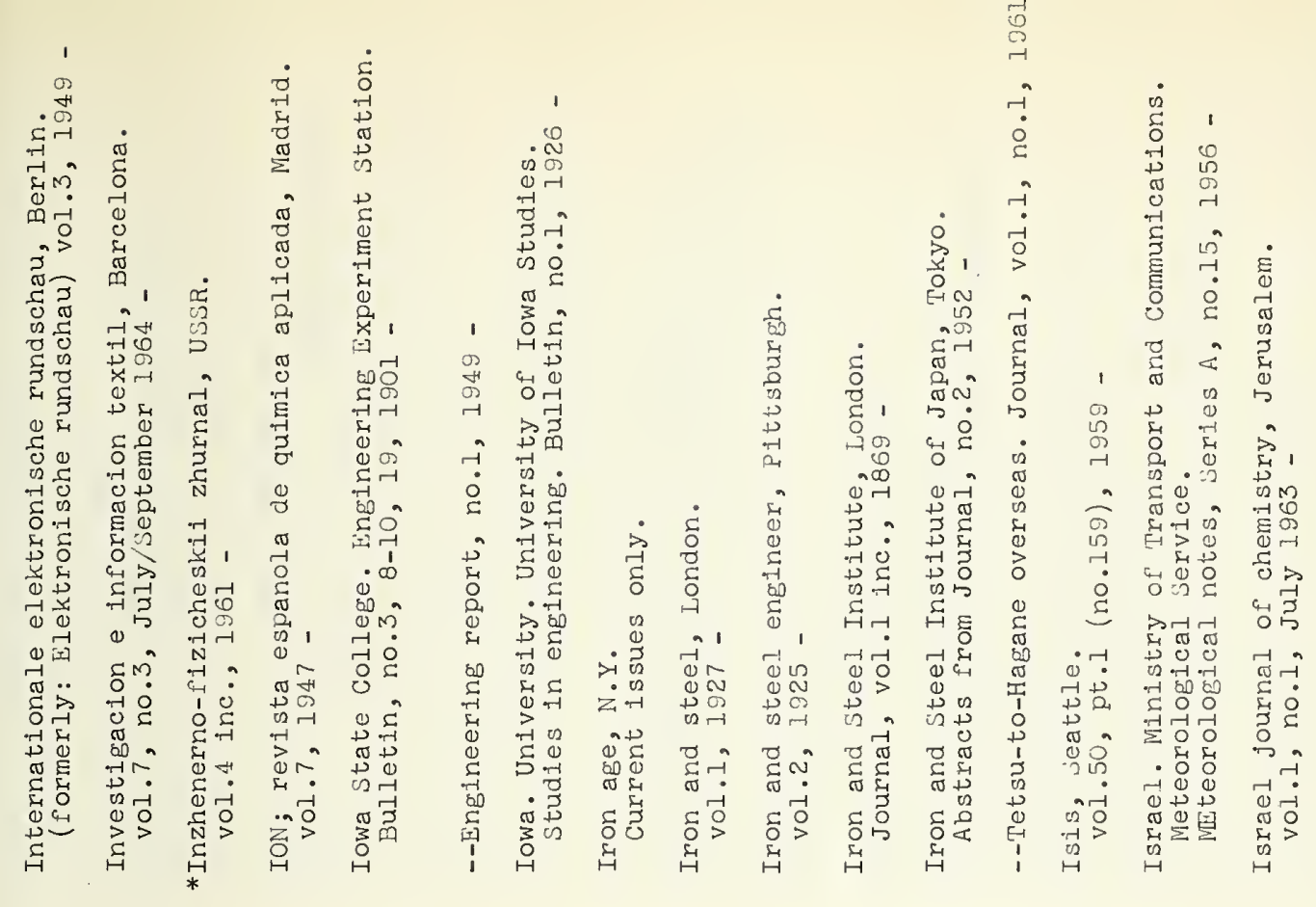

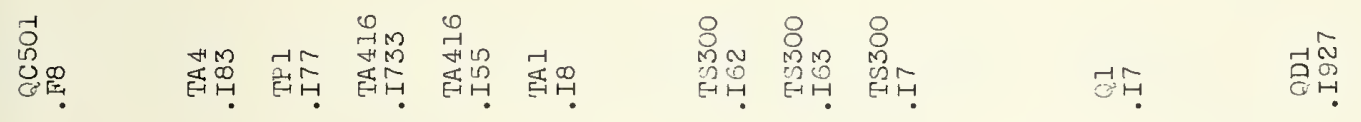

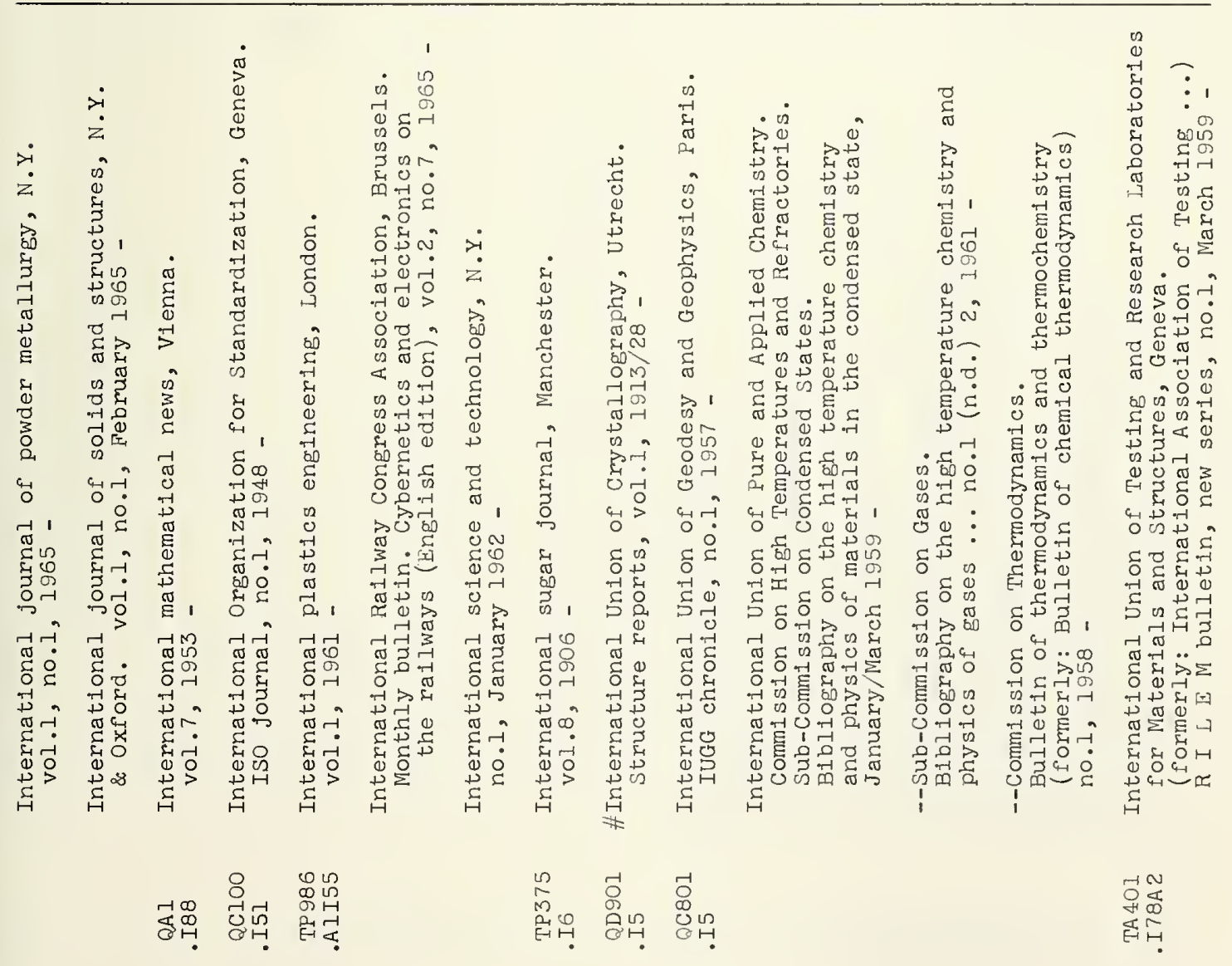




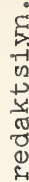

12

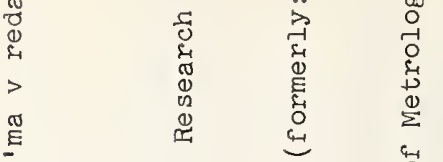

E
in
and
0

嘼

离.

. I 号

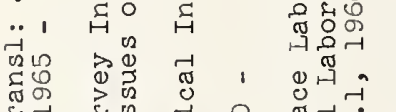

क्षे क्षूथ

त्न कू कू

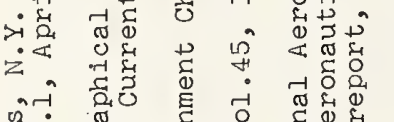

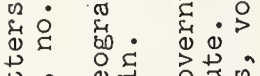

嵅

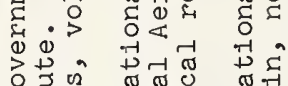

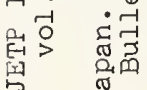

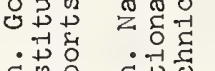

$z+\infty$

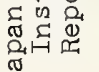

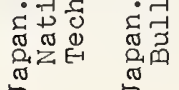

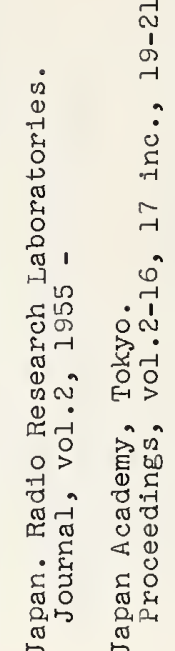

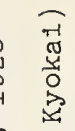

$\begin{array}{cc}0 & 0 \\ N & 2 \\ 0 & 0 \\ 1 & 1\end{array}$

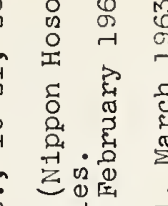

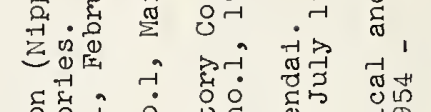

पुत्र

गुर

पूँ "

\&

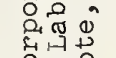

of

bo:

पू

क्षित्र

का

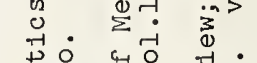

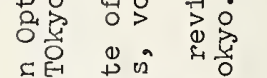

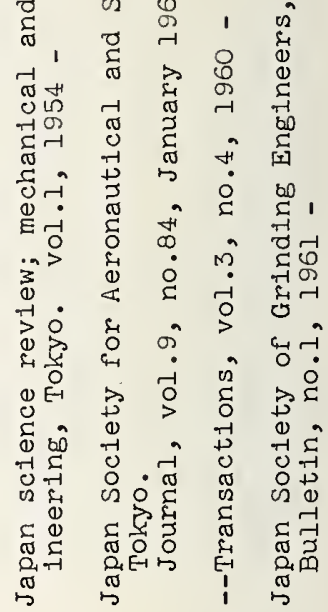

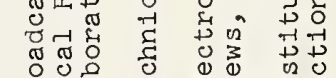

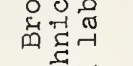

这

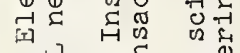

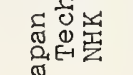

造号

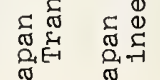

$\begin{array}{lll}0 & & \\ 0 & & \\ 0 & & \\ 0 & & \\ 0 & & 0 \\ 0 & & 0 \\ 0 & & 0 \\ 0 & 1 & 0\end{array}$

$\sum_{0}^{0}$

วิ้อ

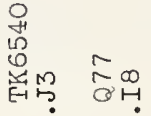

苾思

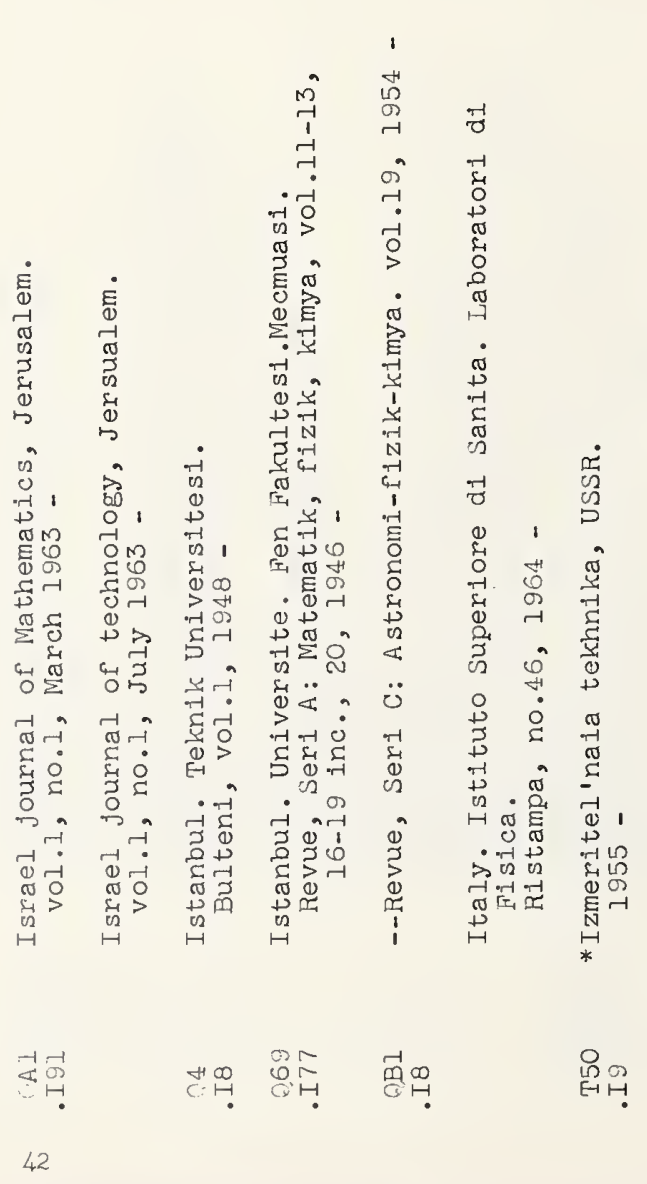




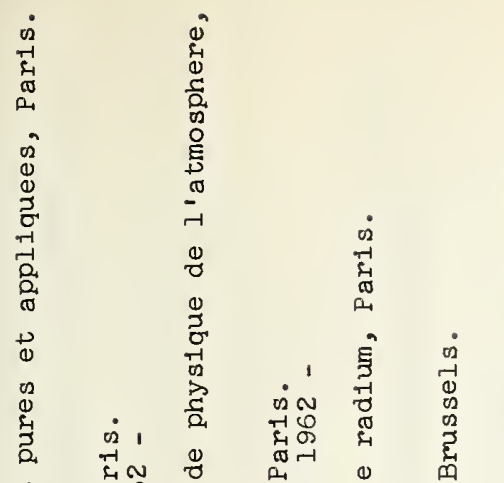

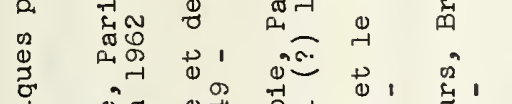

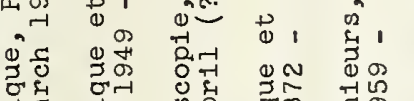

T.

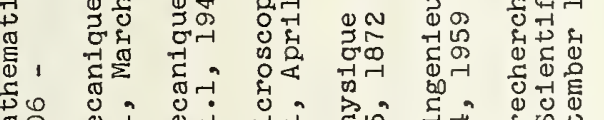

ठठ

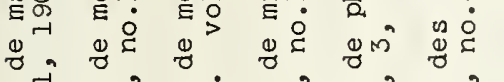

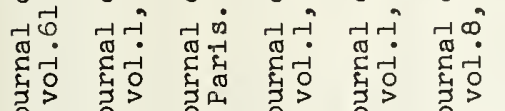

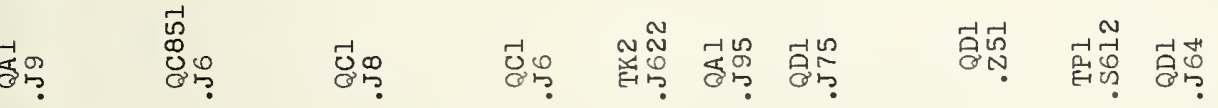

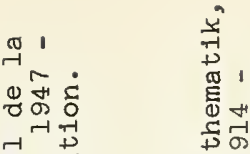

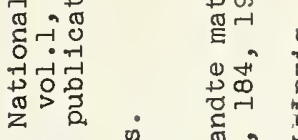

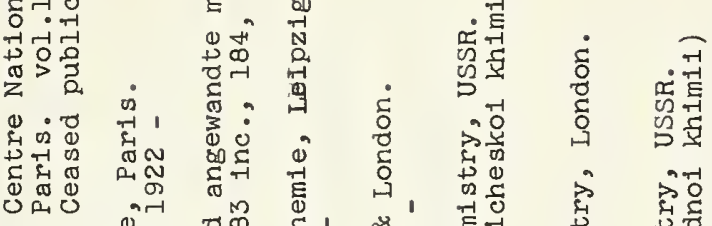

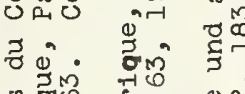

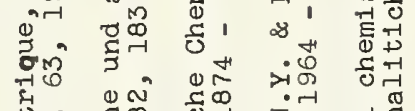

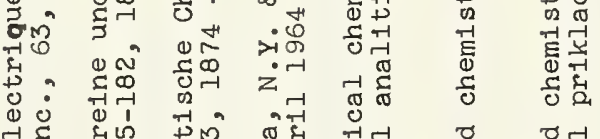

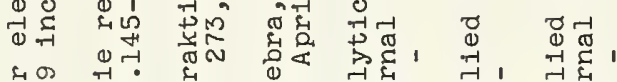

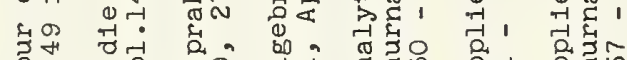

4i

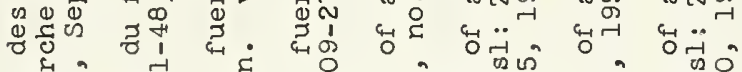

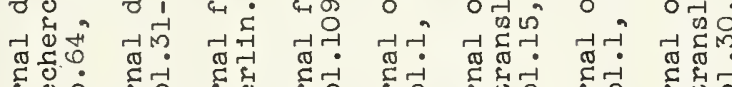

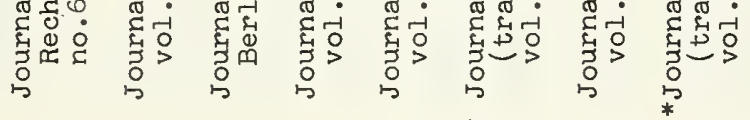

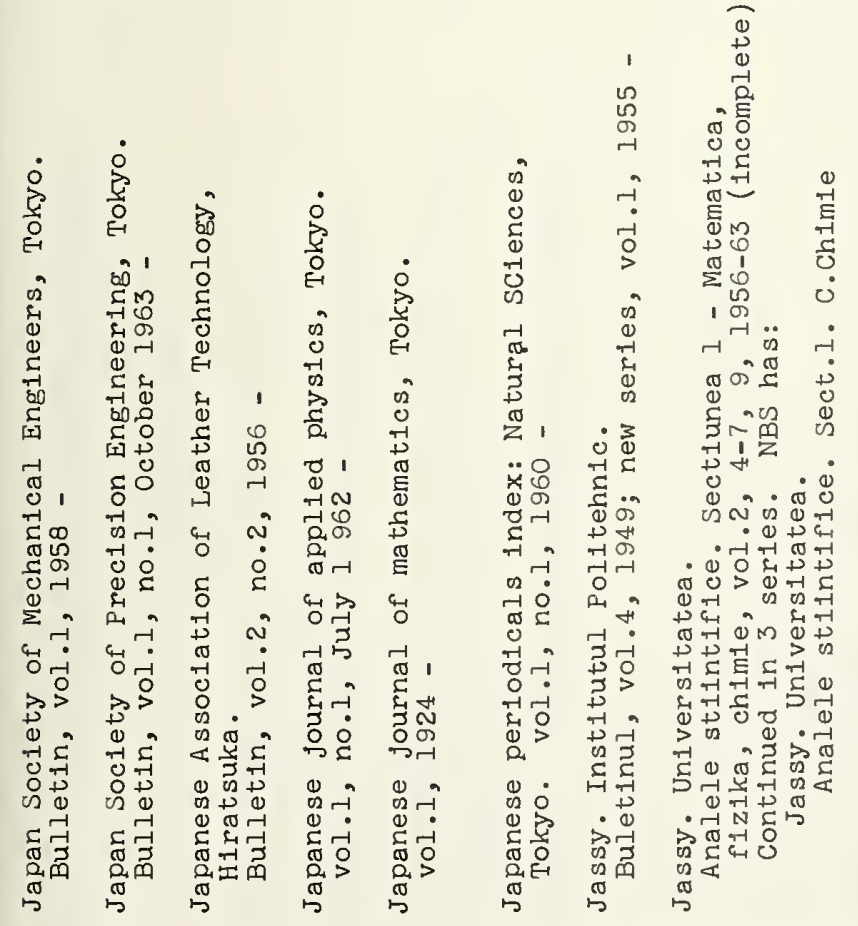
草?

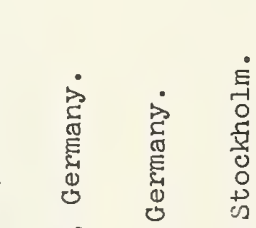

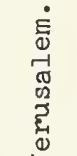

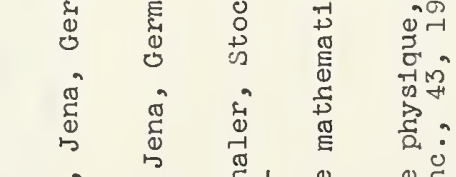

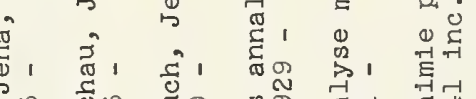

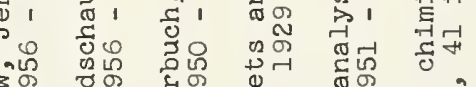

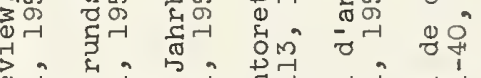

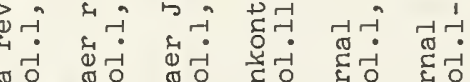

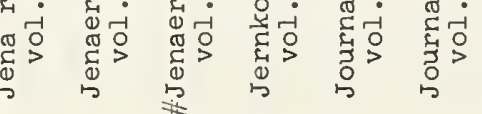

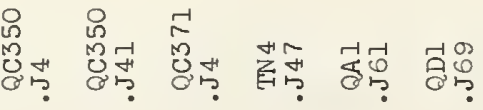



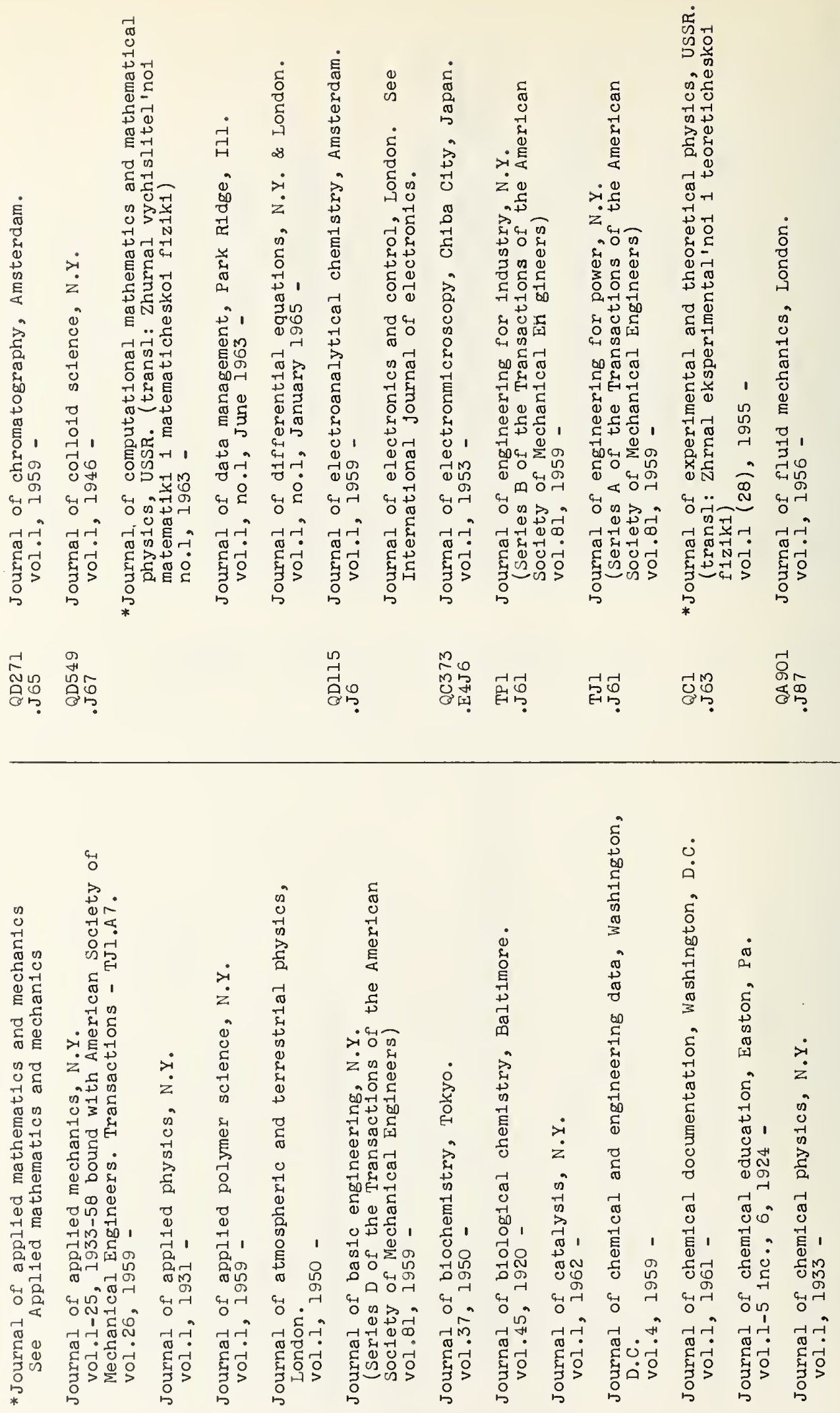

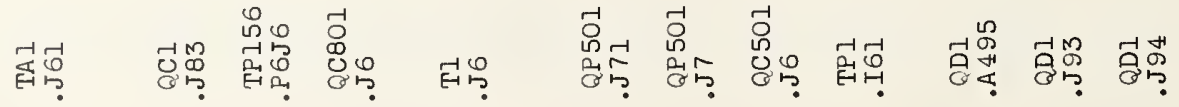


$\dot{0}$

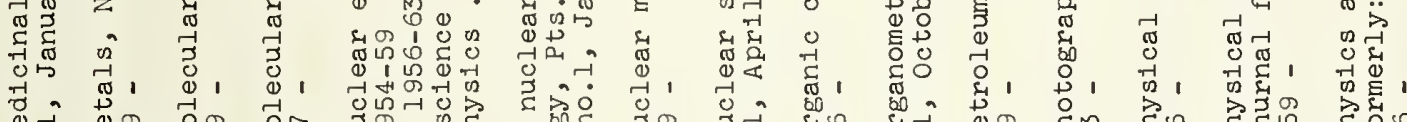

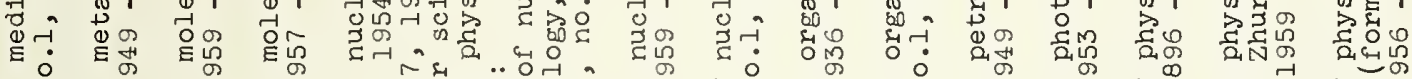

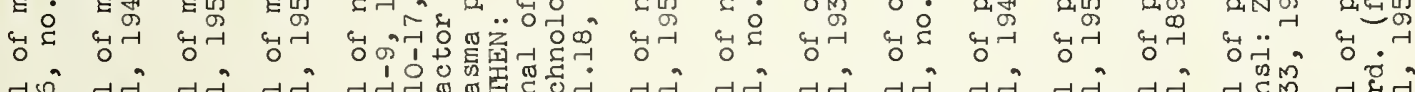

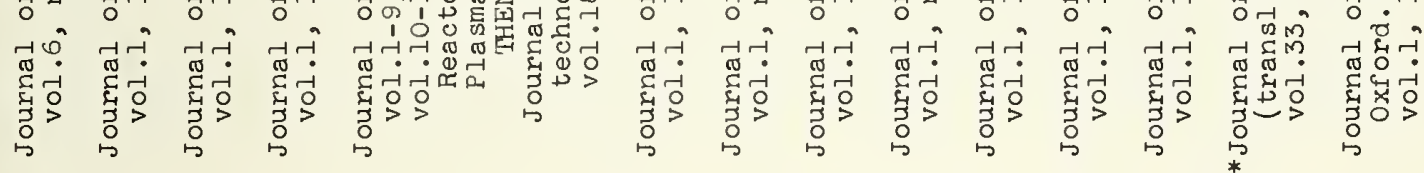

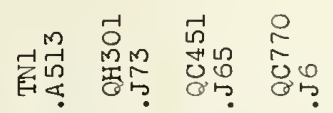

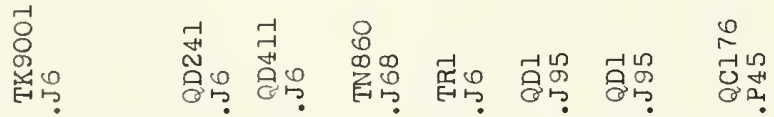

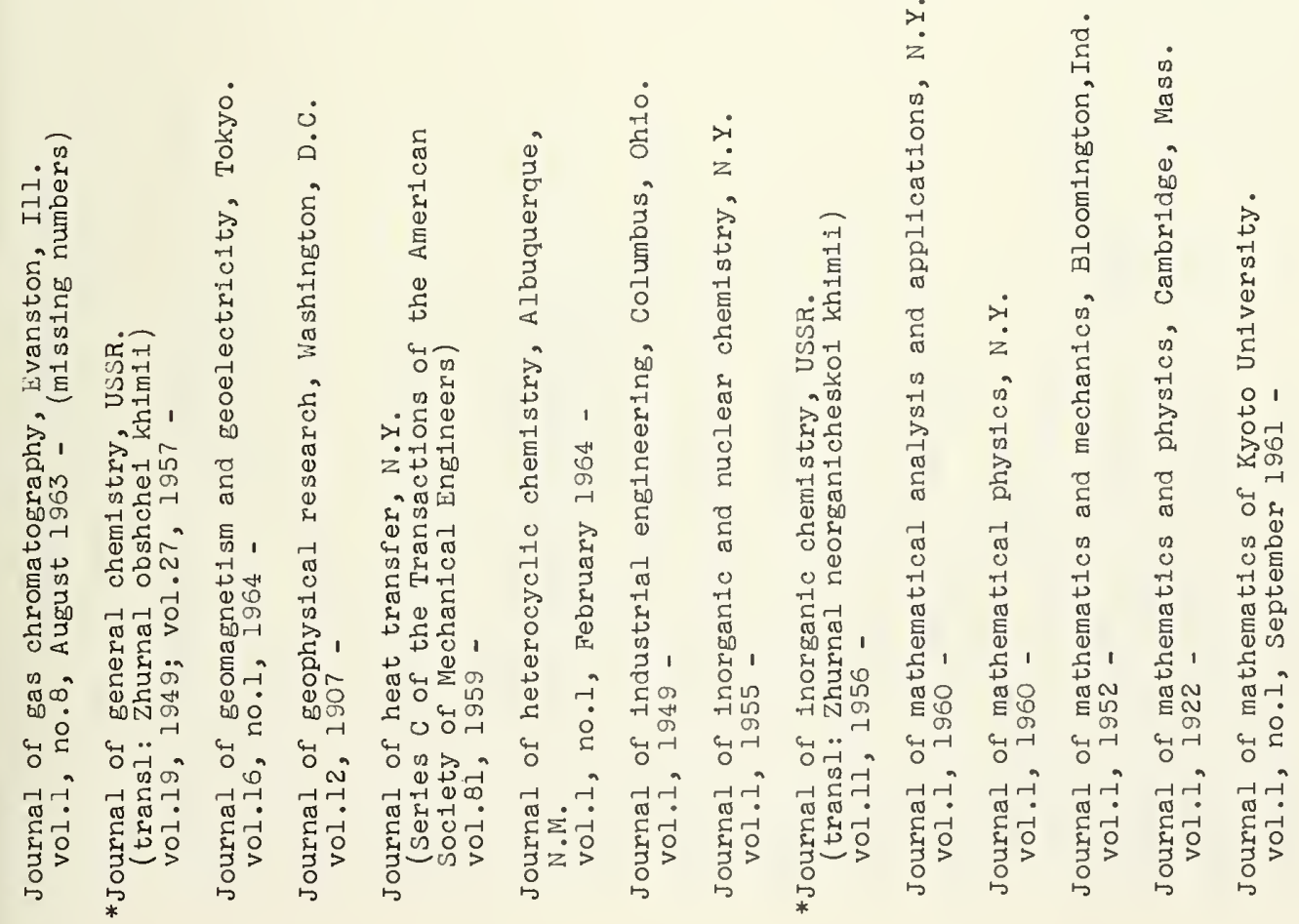

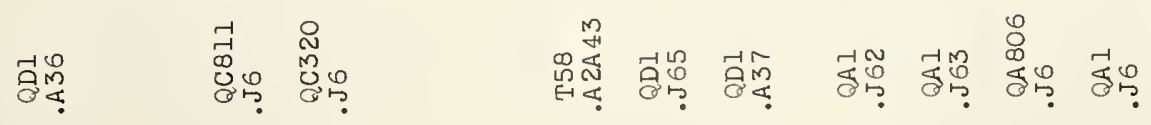




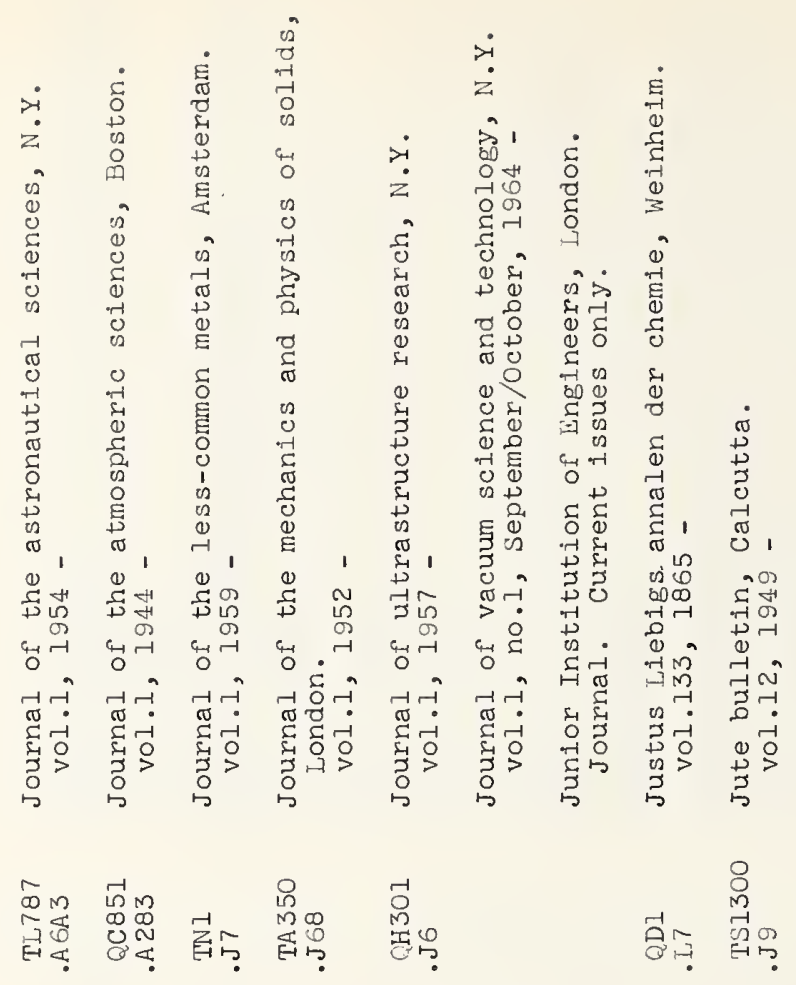

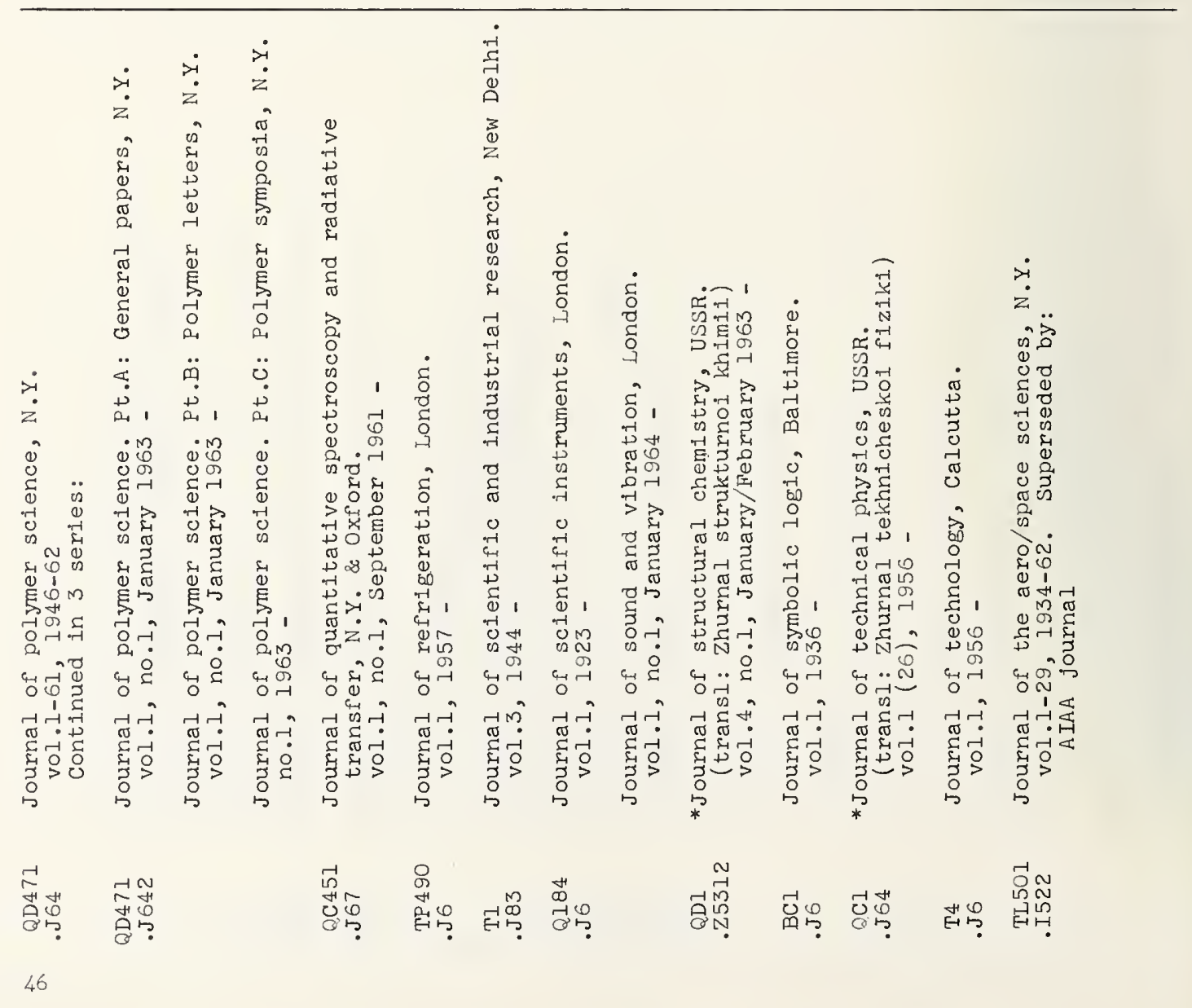




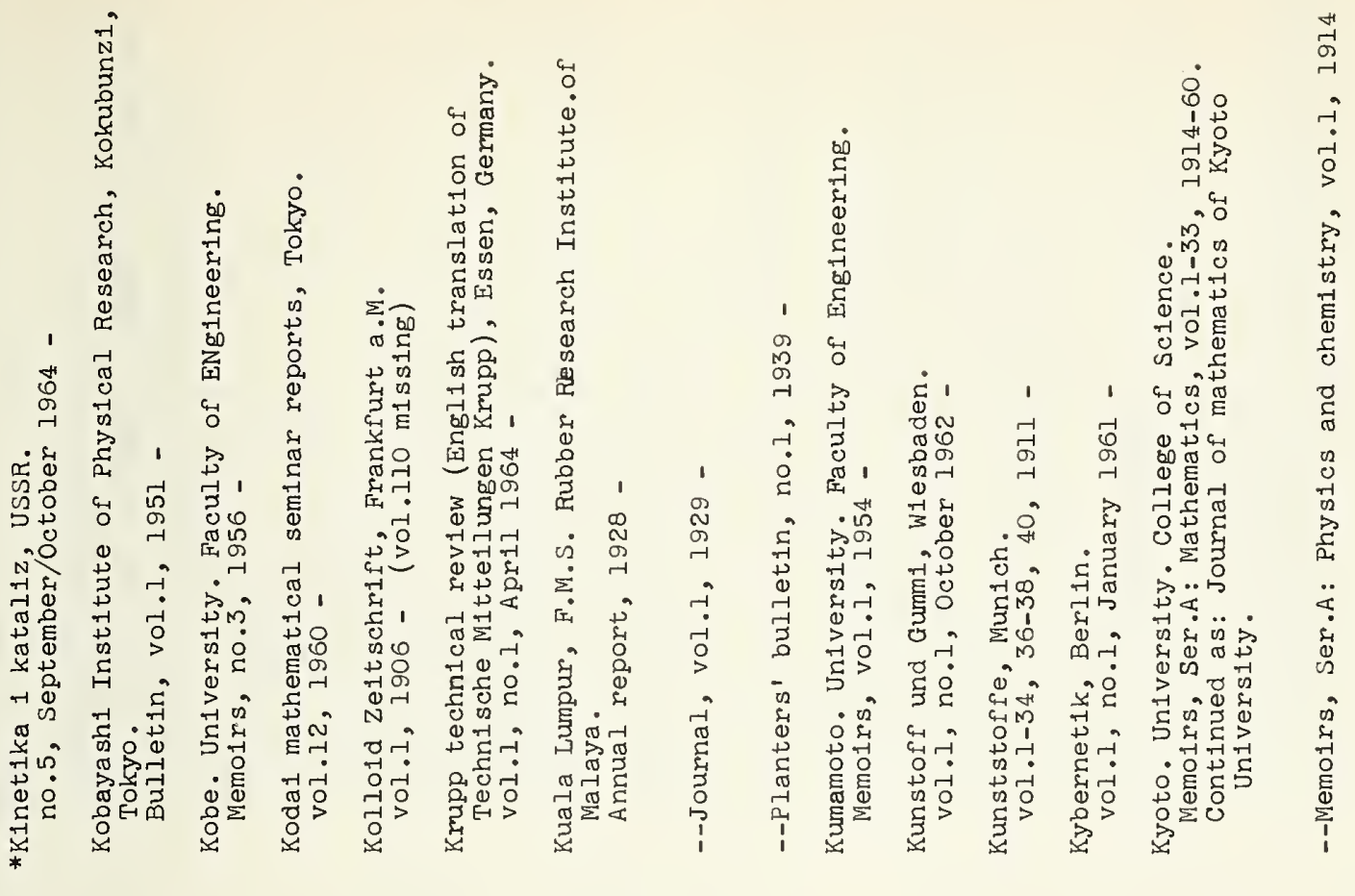

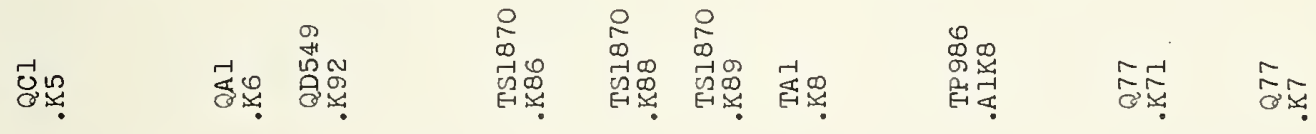

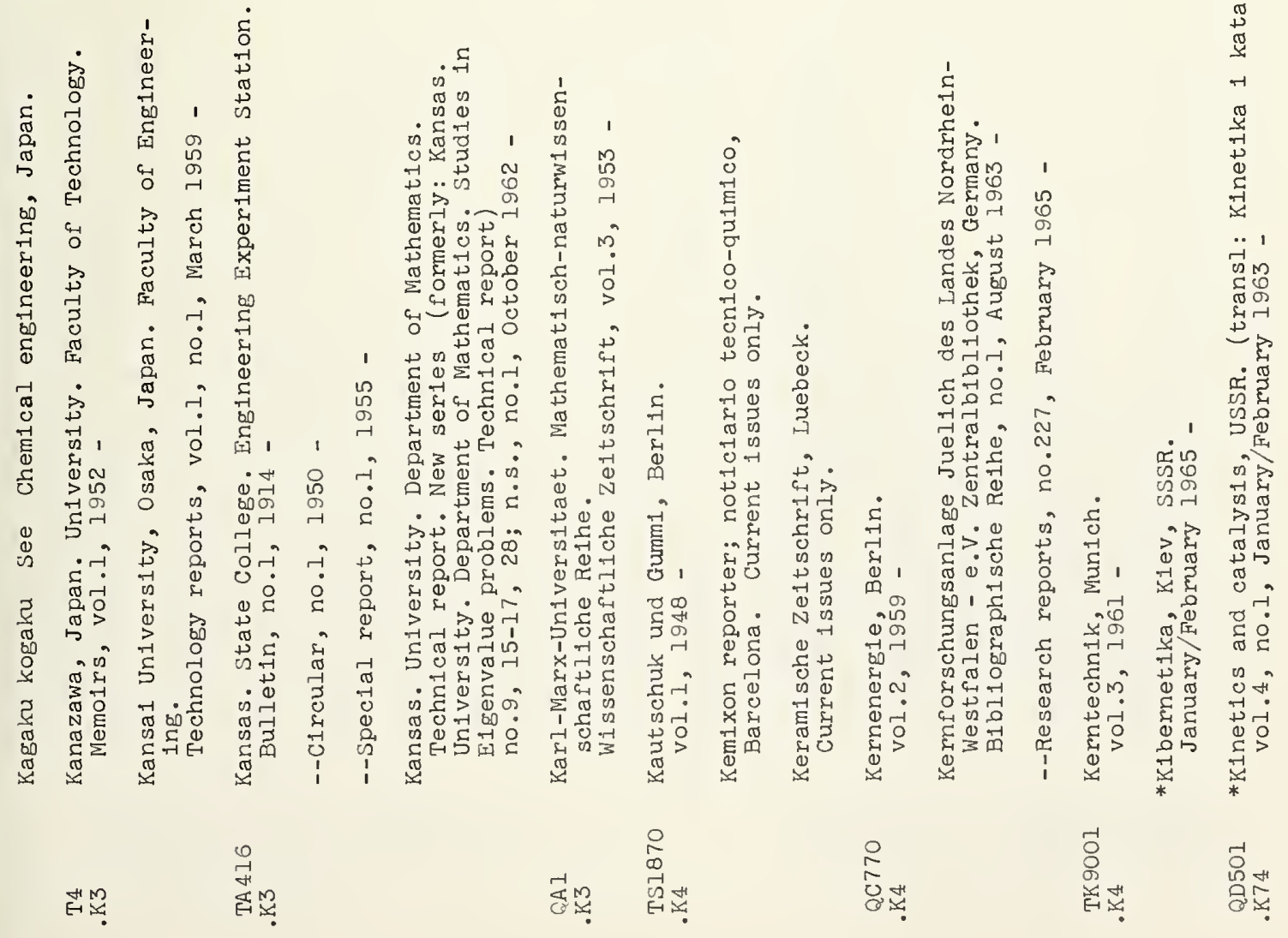




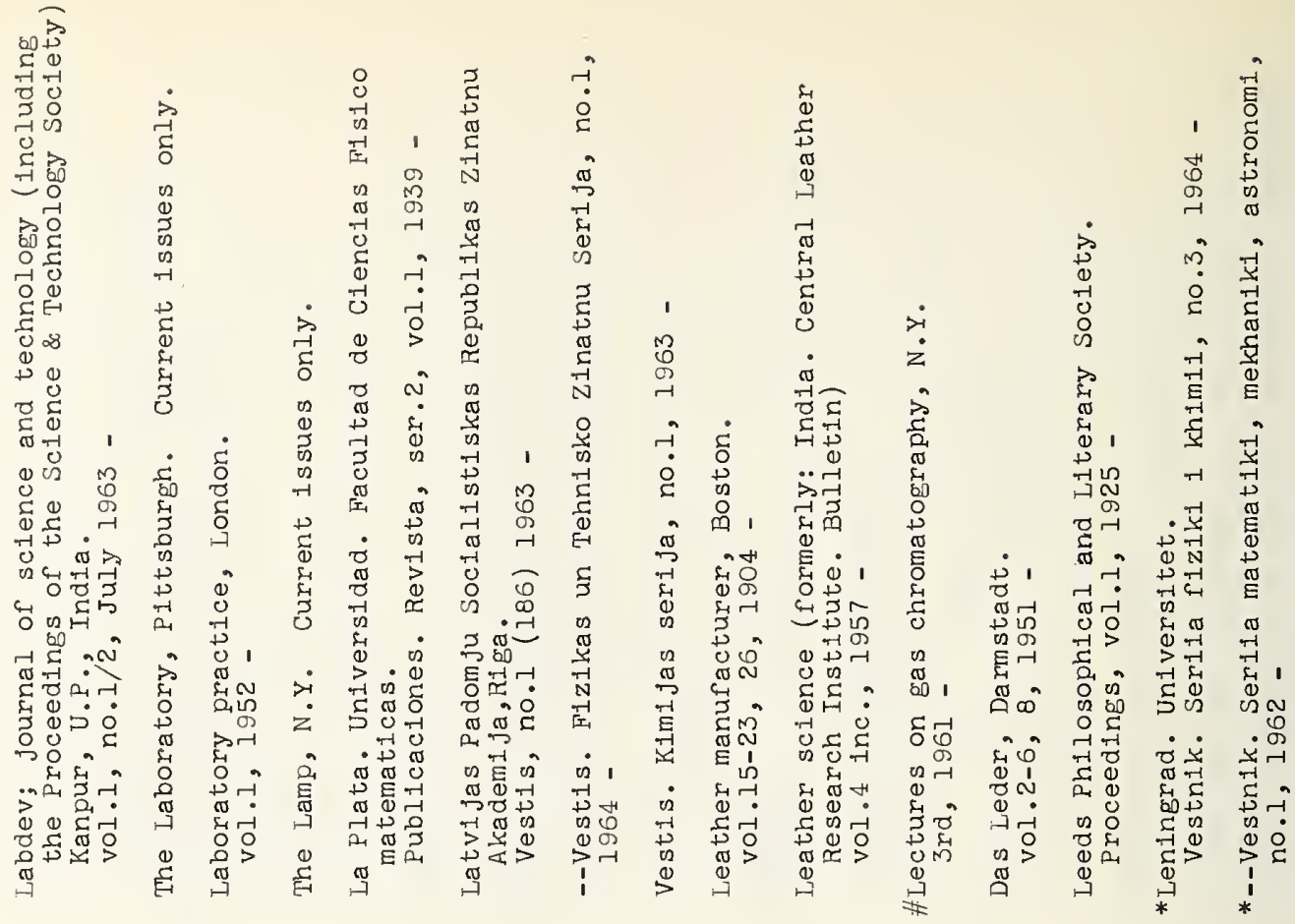

每

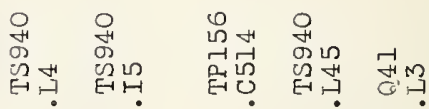

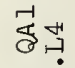

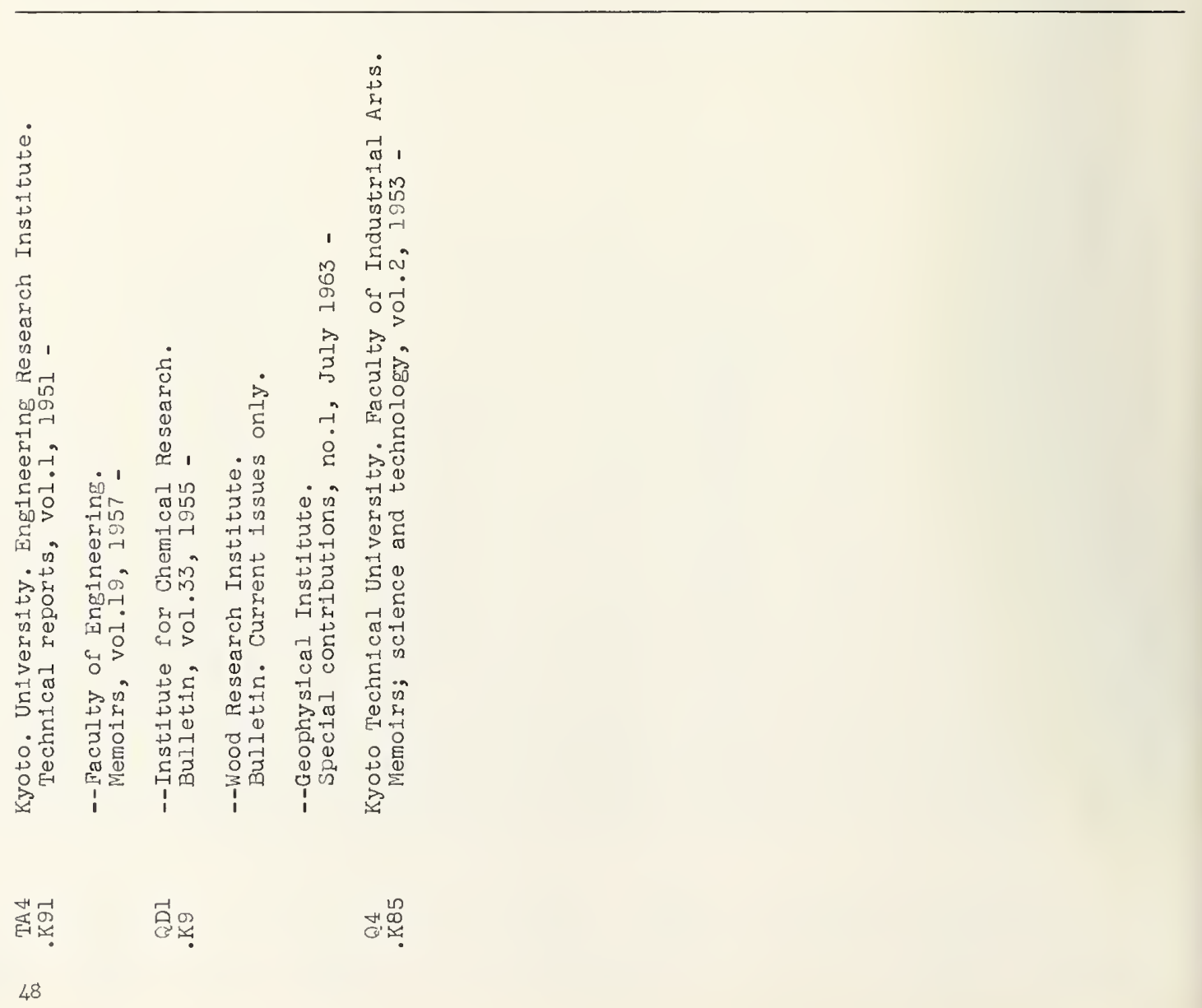




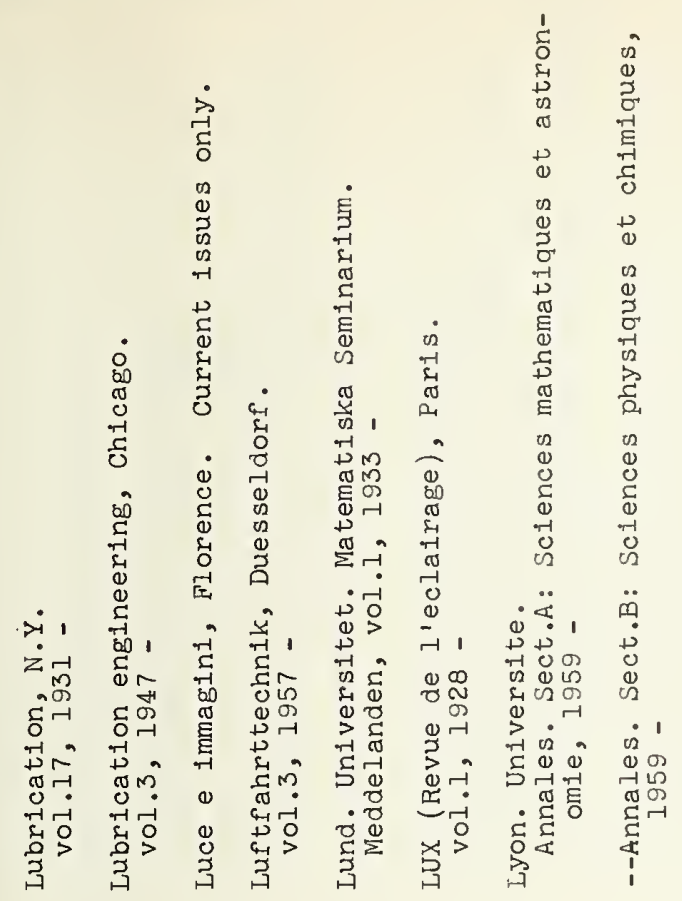

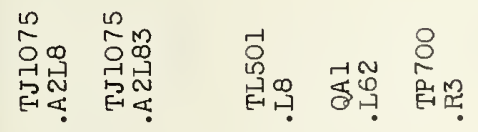

竞

(1)

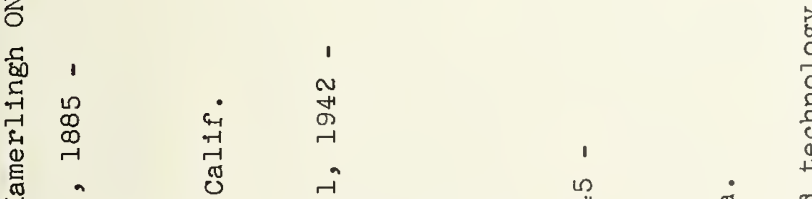

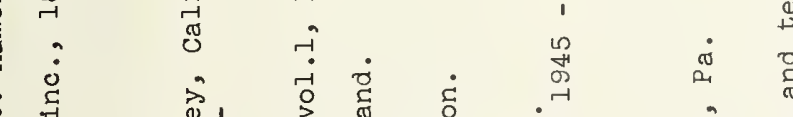

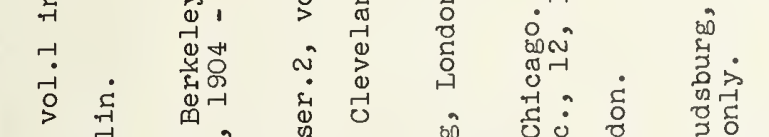

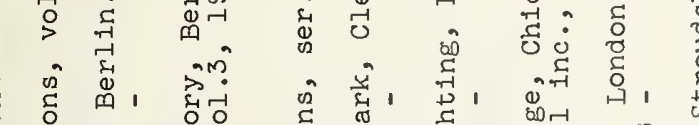

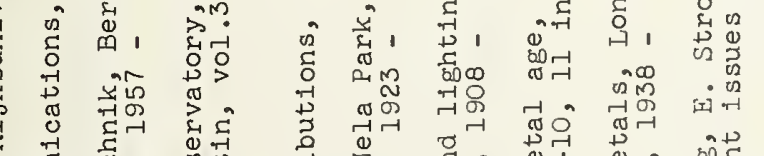

宊

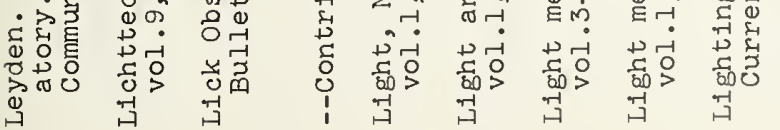

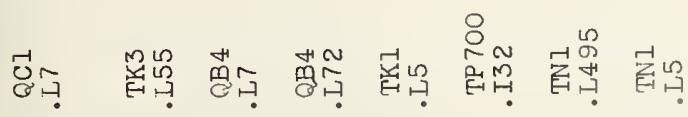

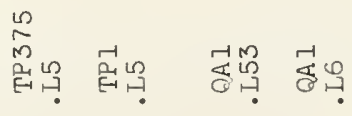




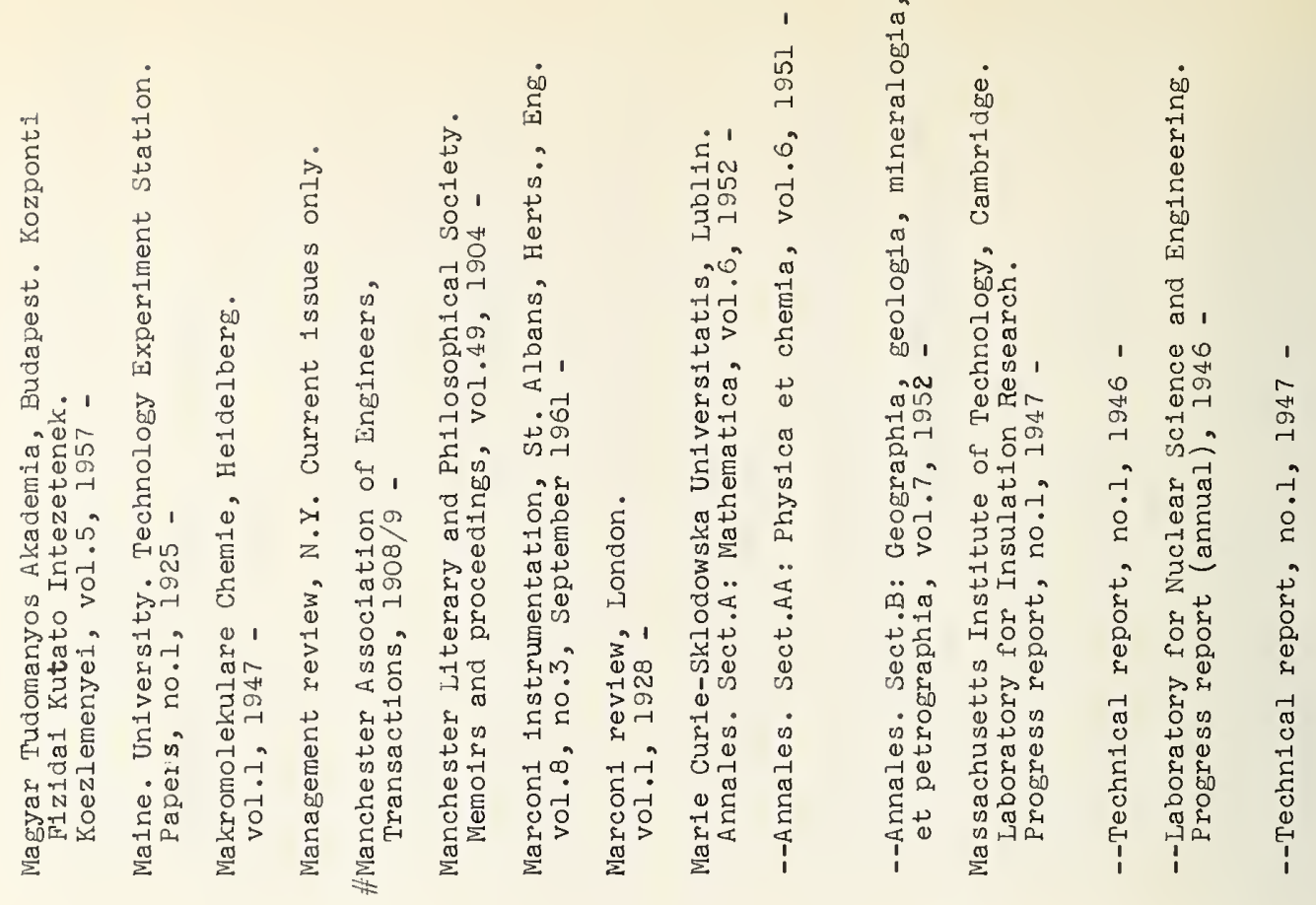

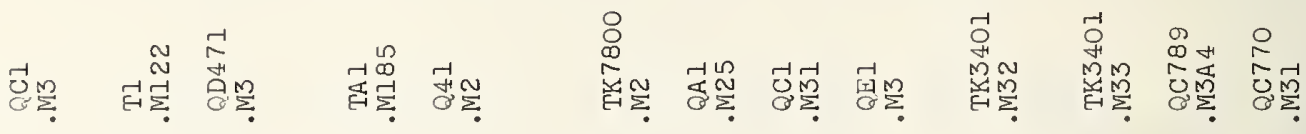

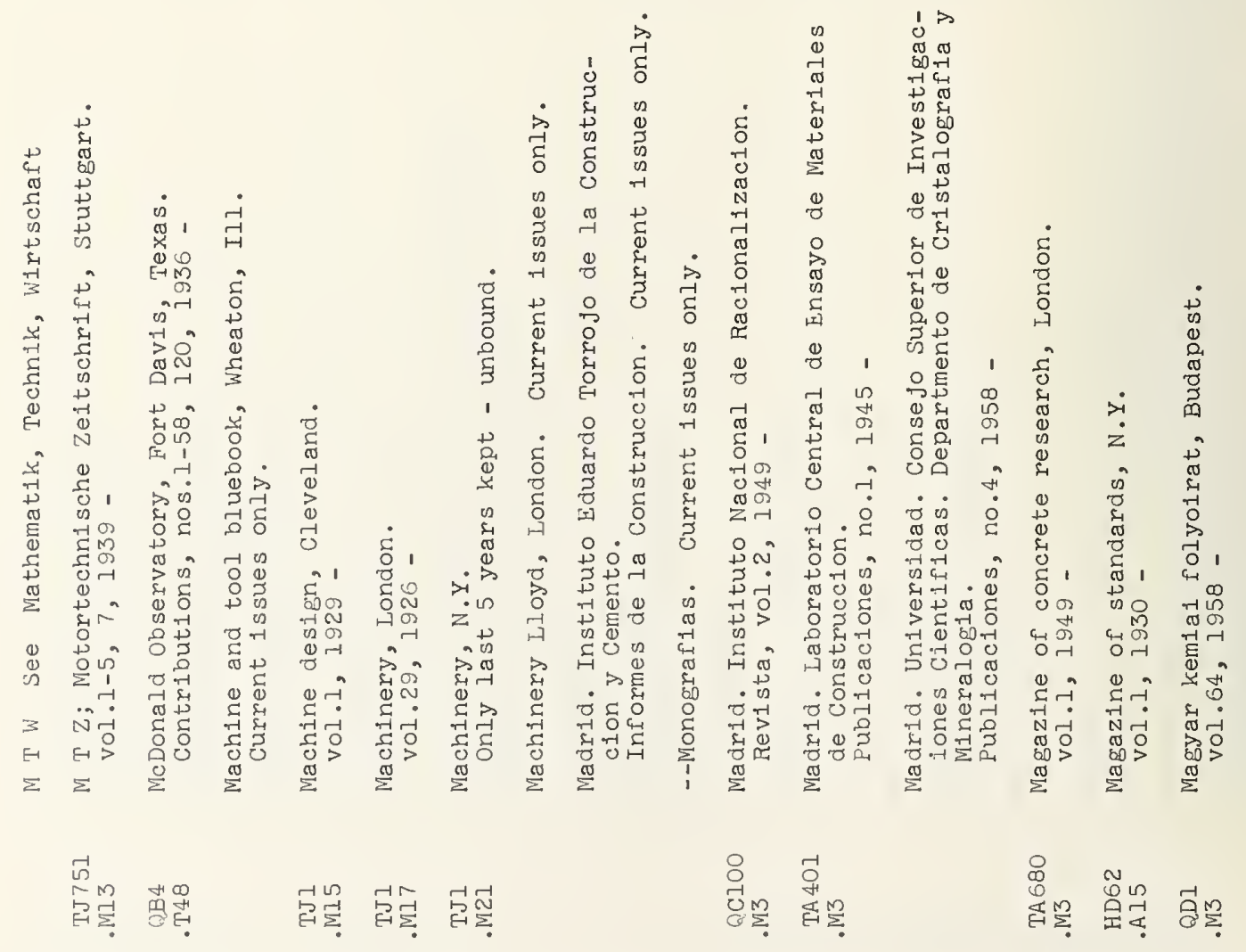



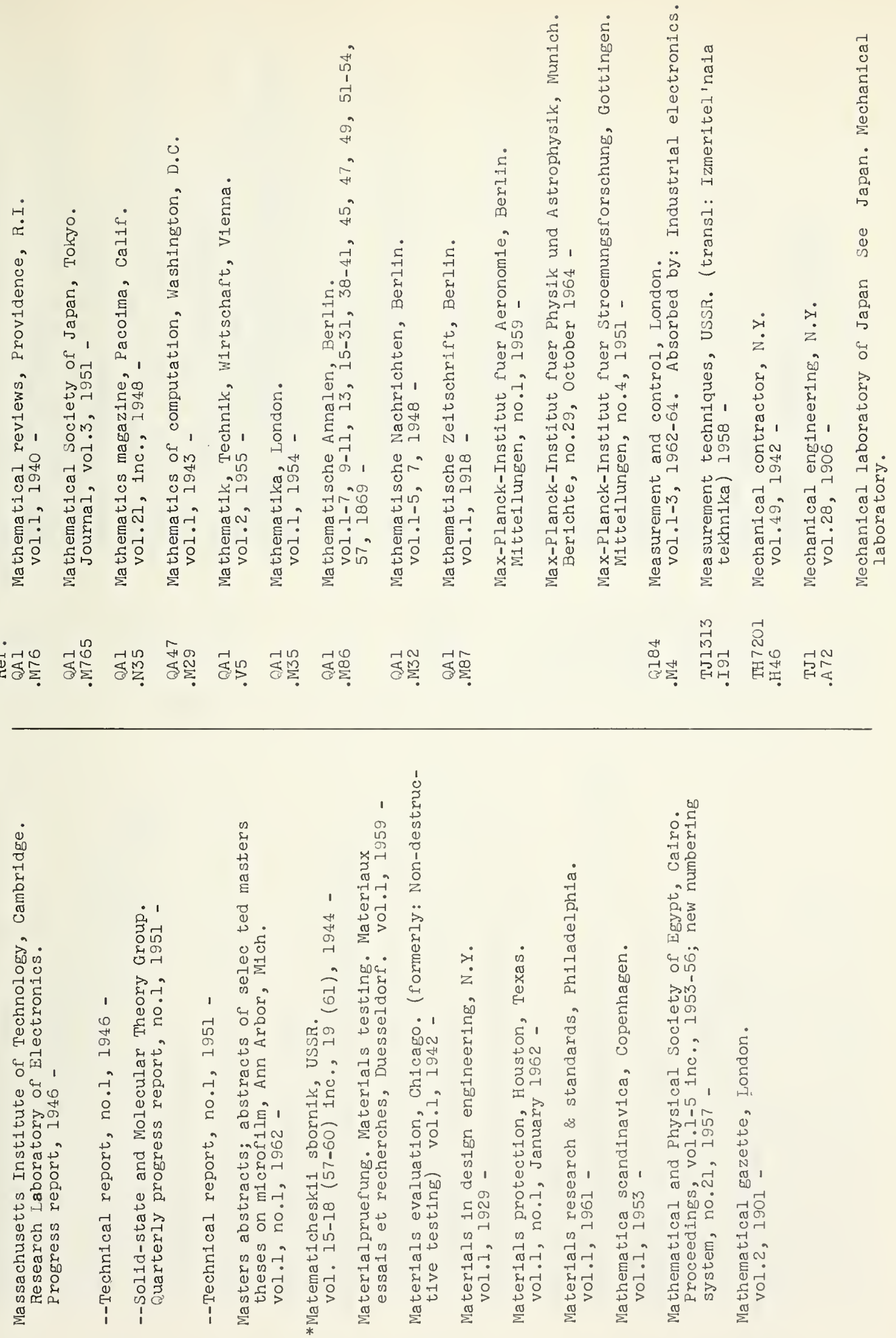

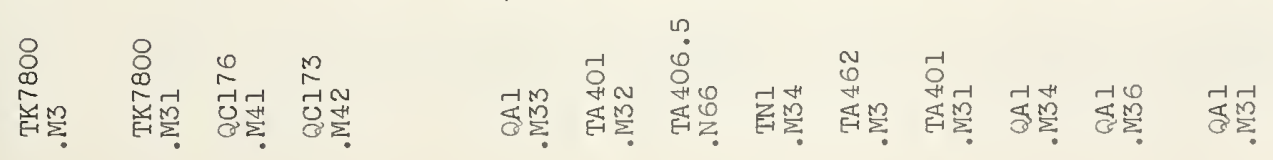



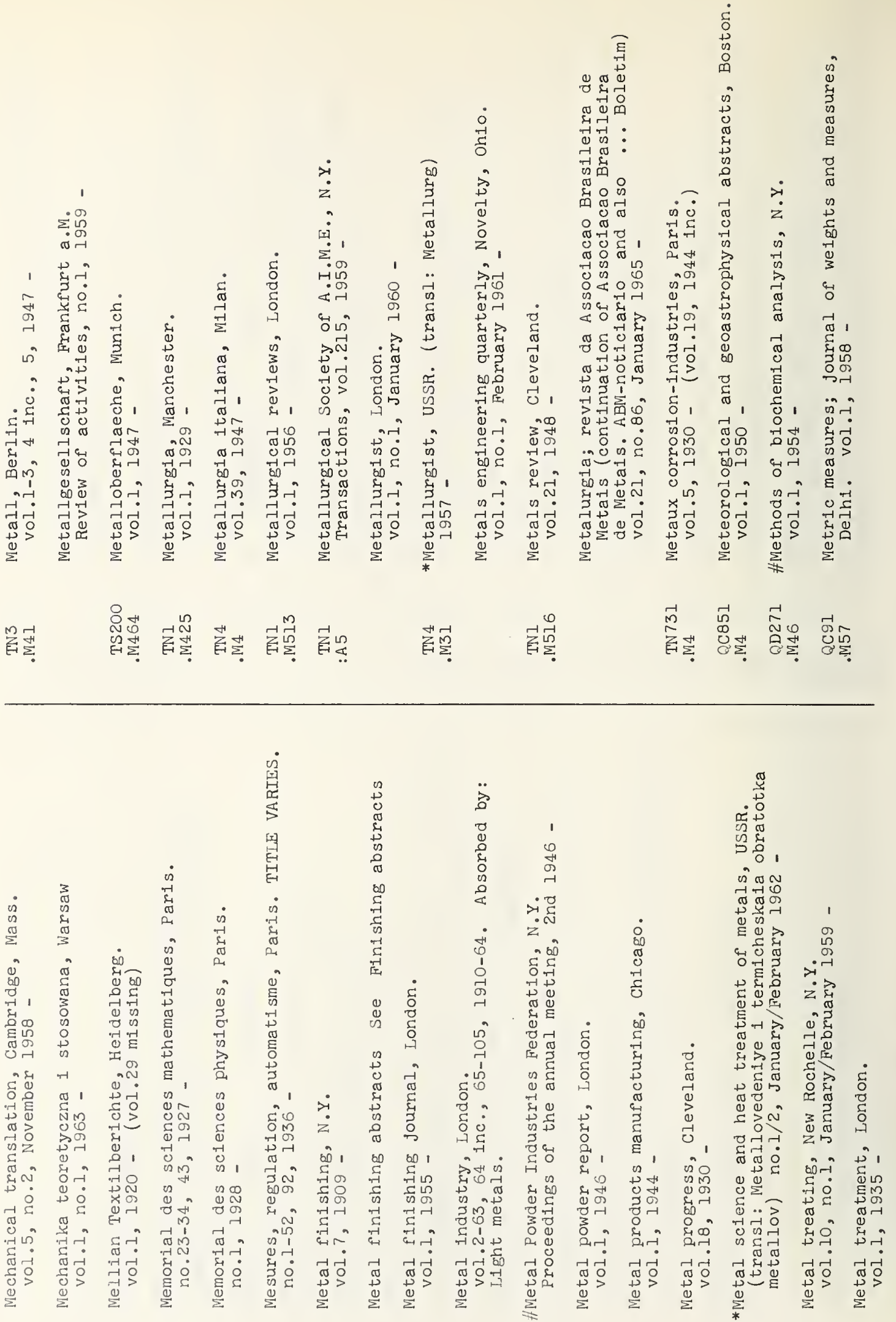

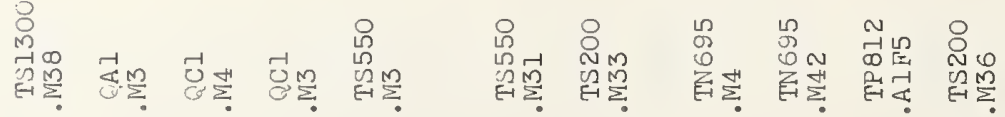




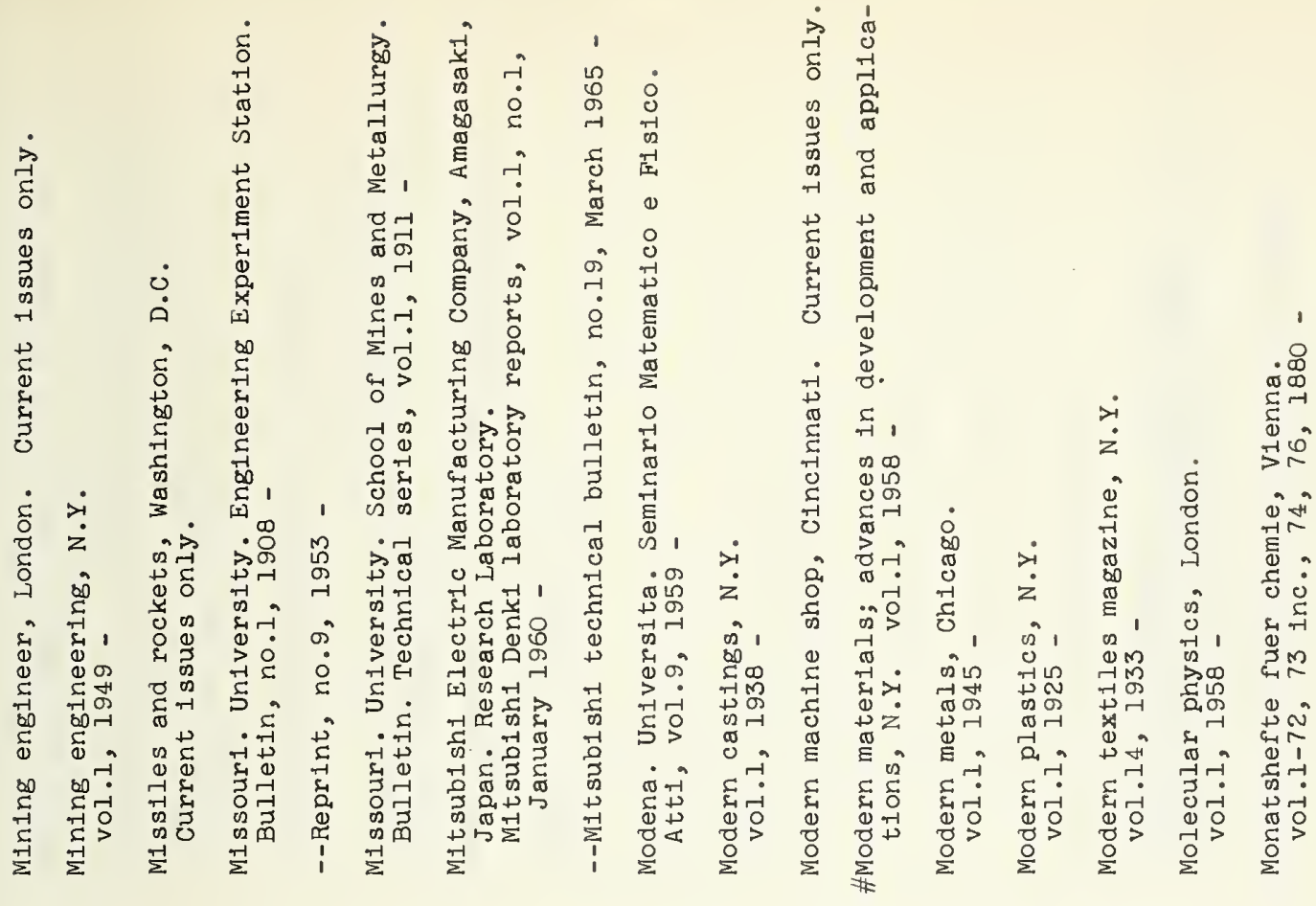

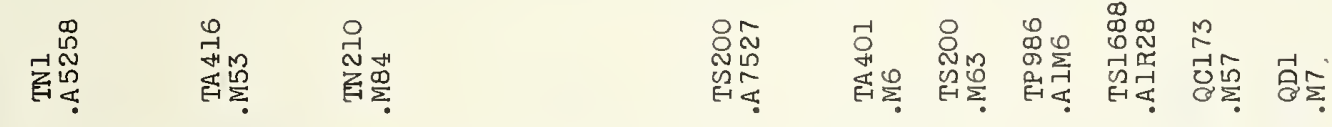

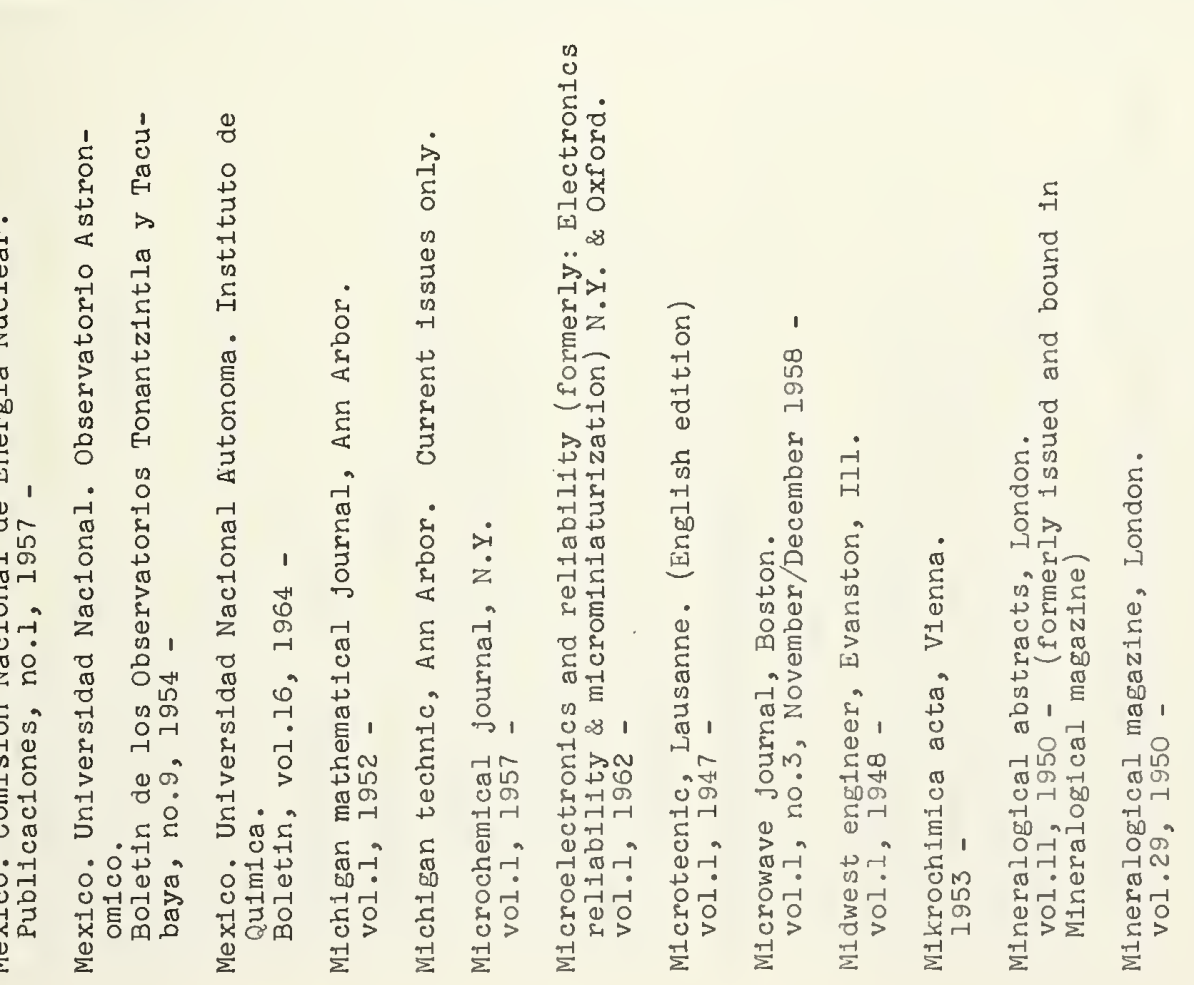

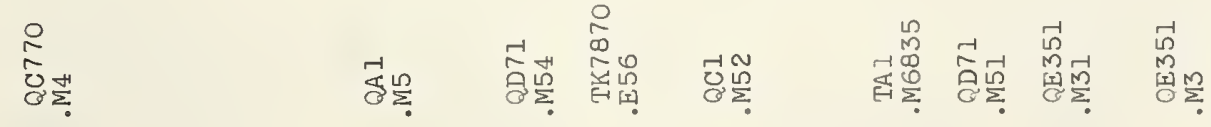




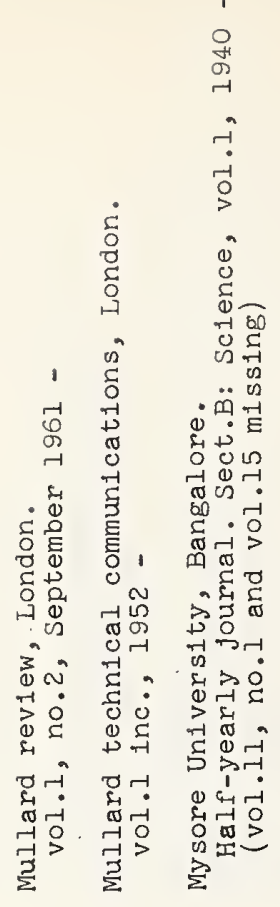

8

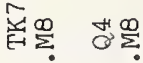

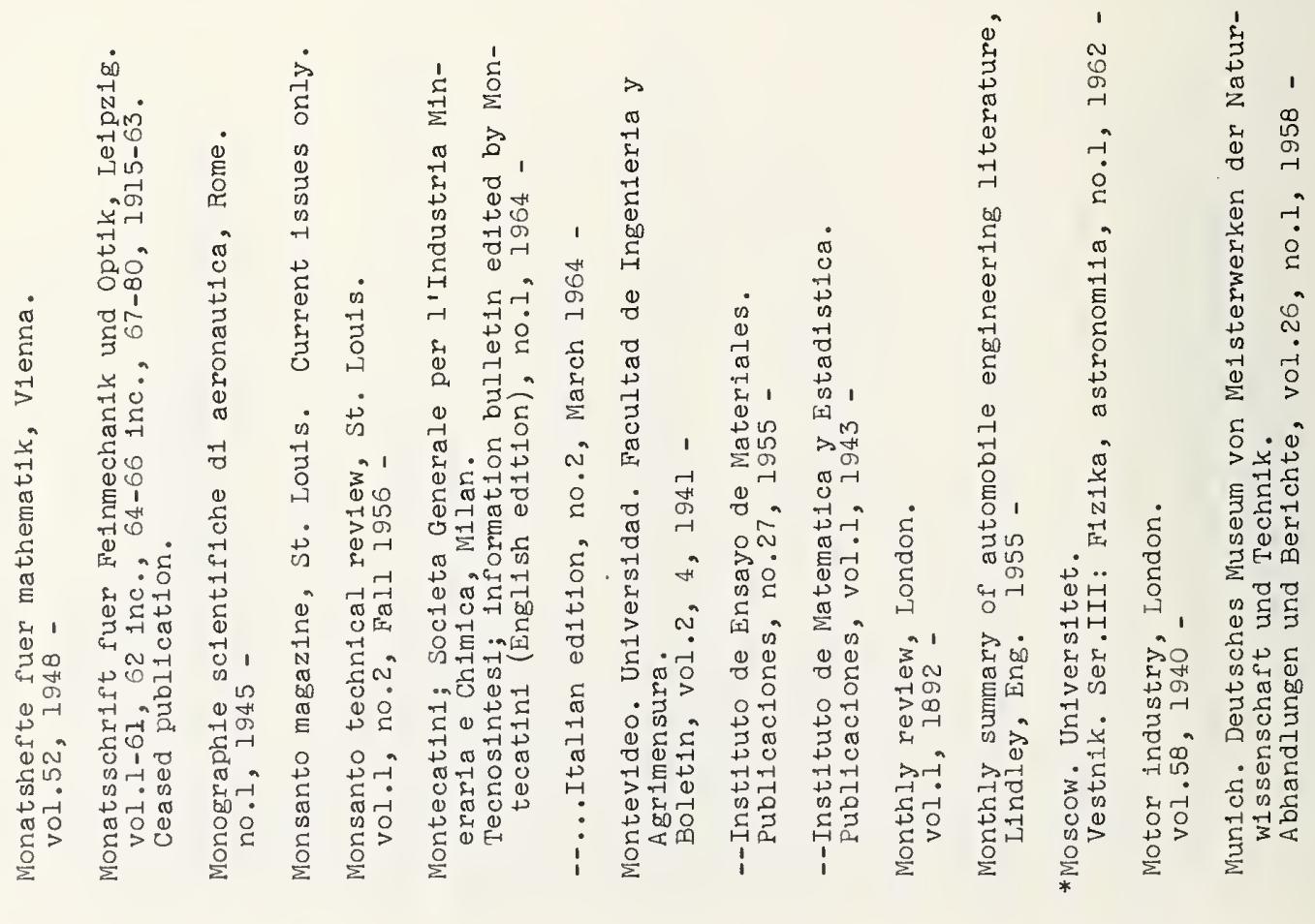

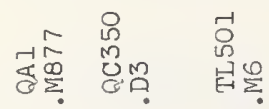

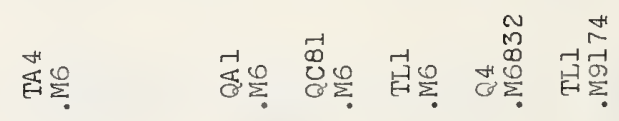


离

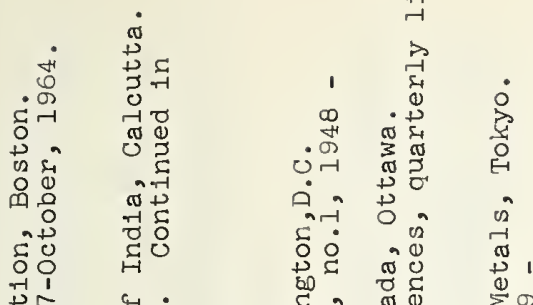

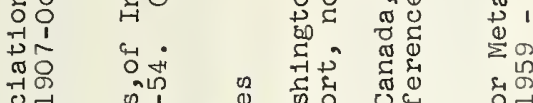

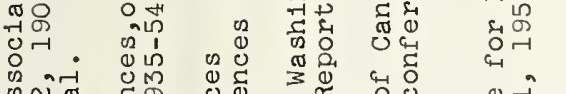

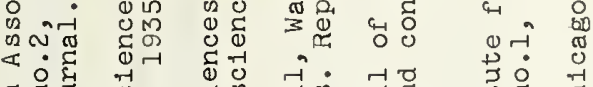

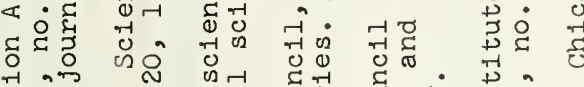

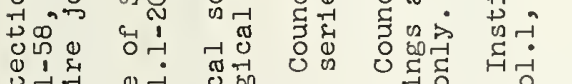

等

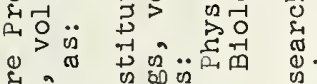

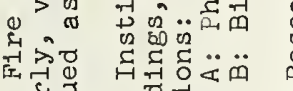

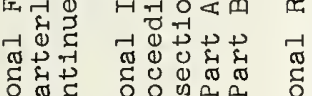

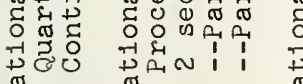

我

F

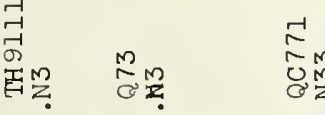

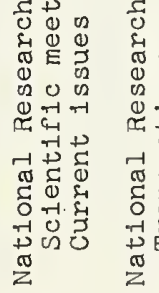

8

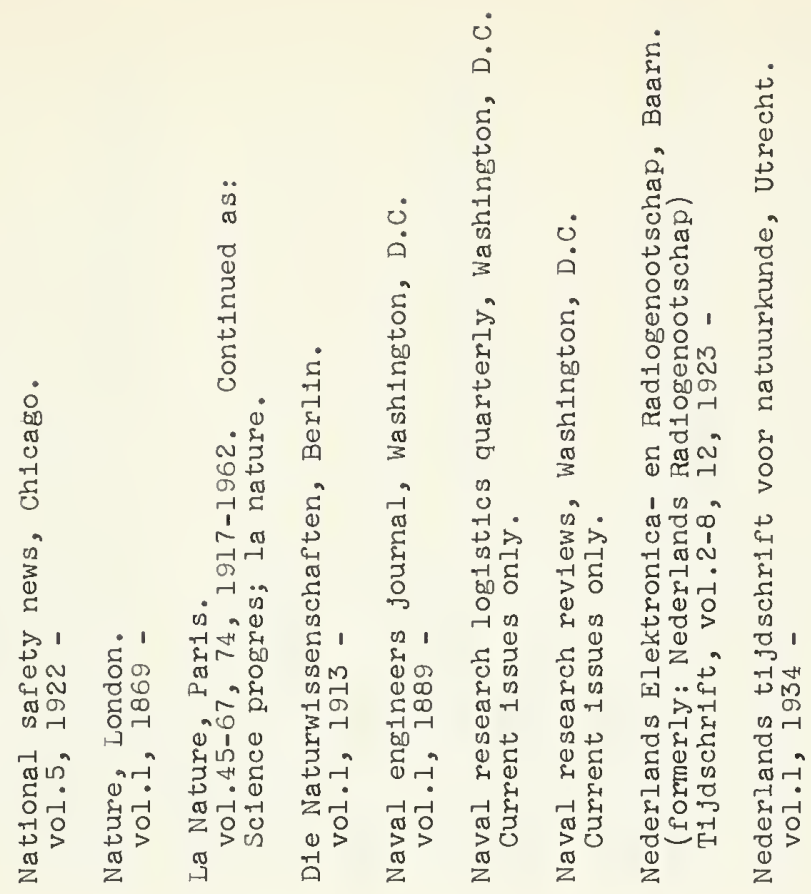
翼

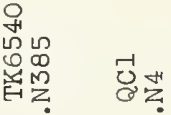

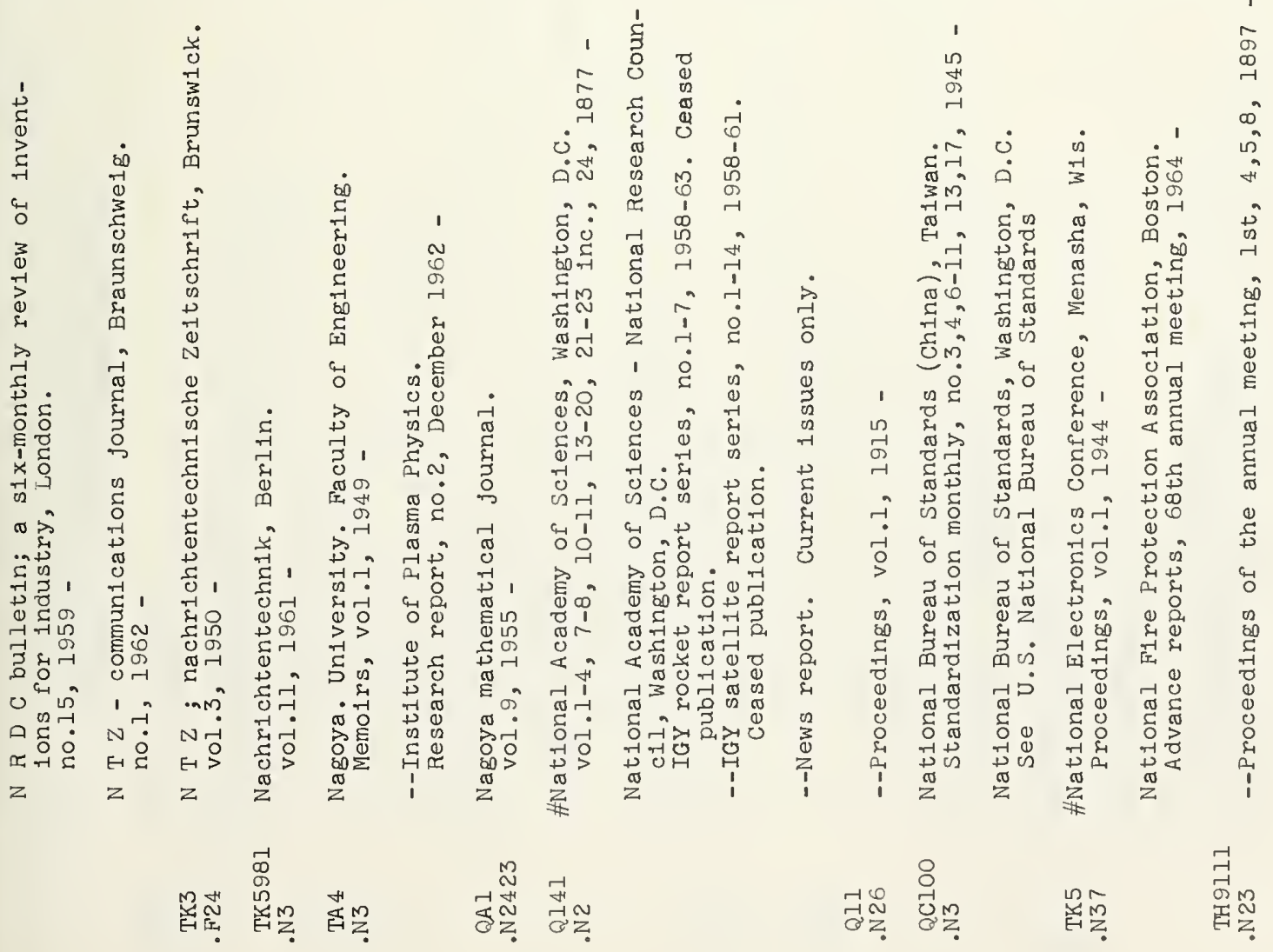




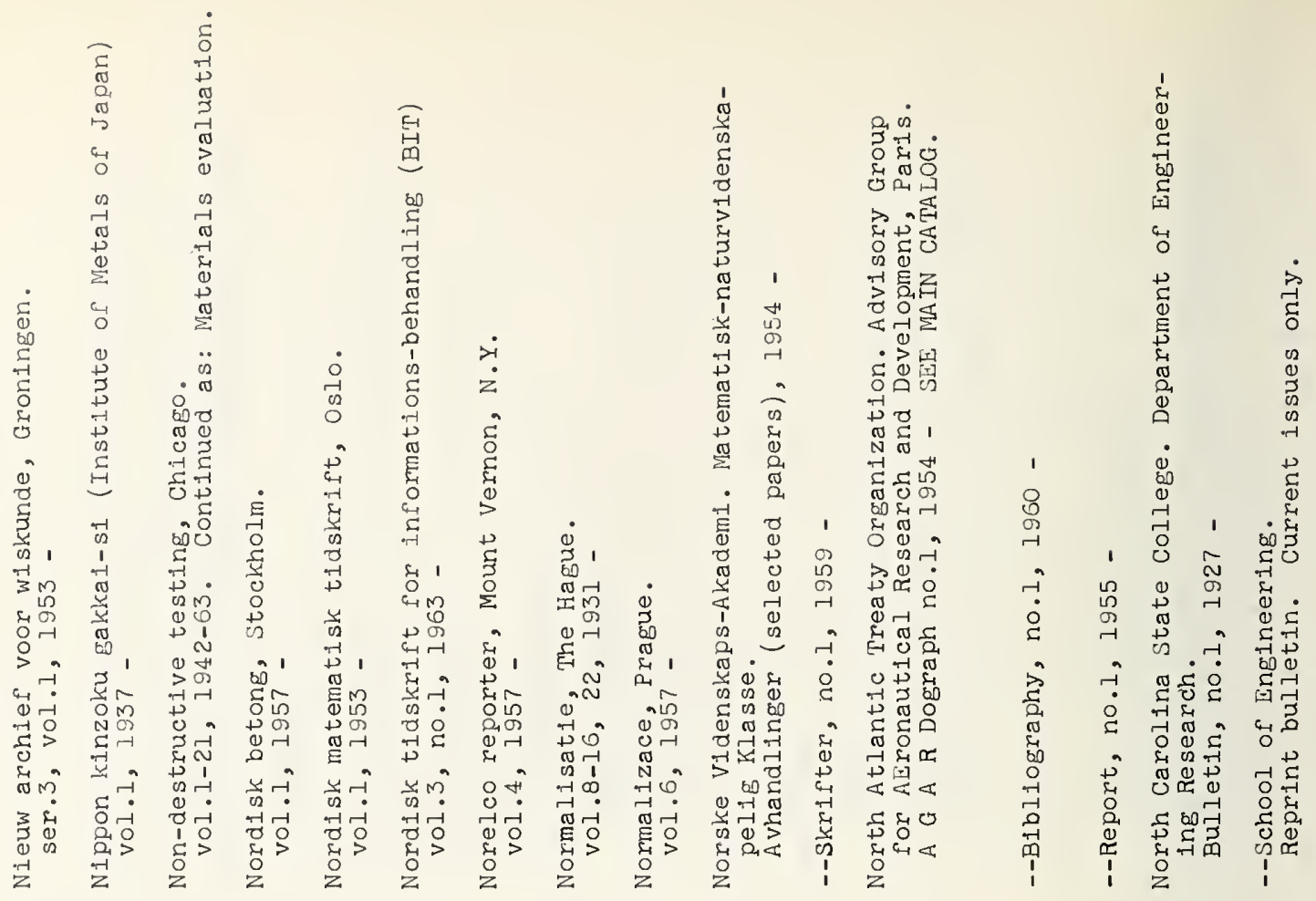

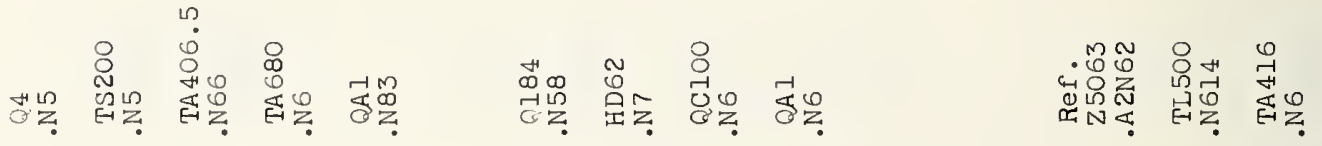

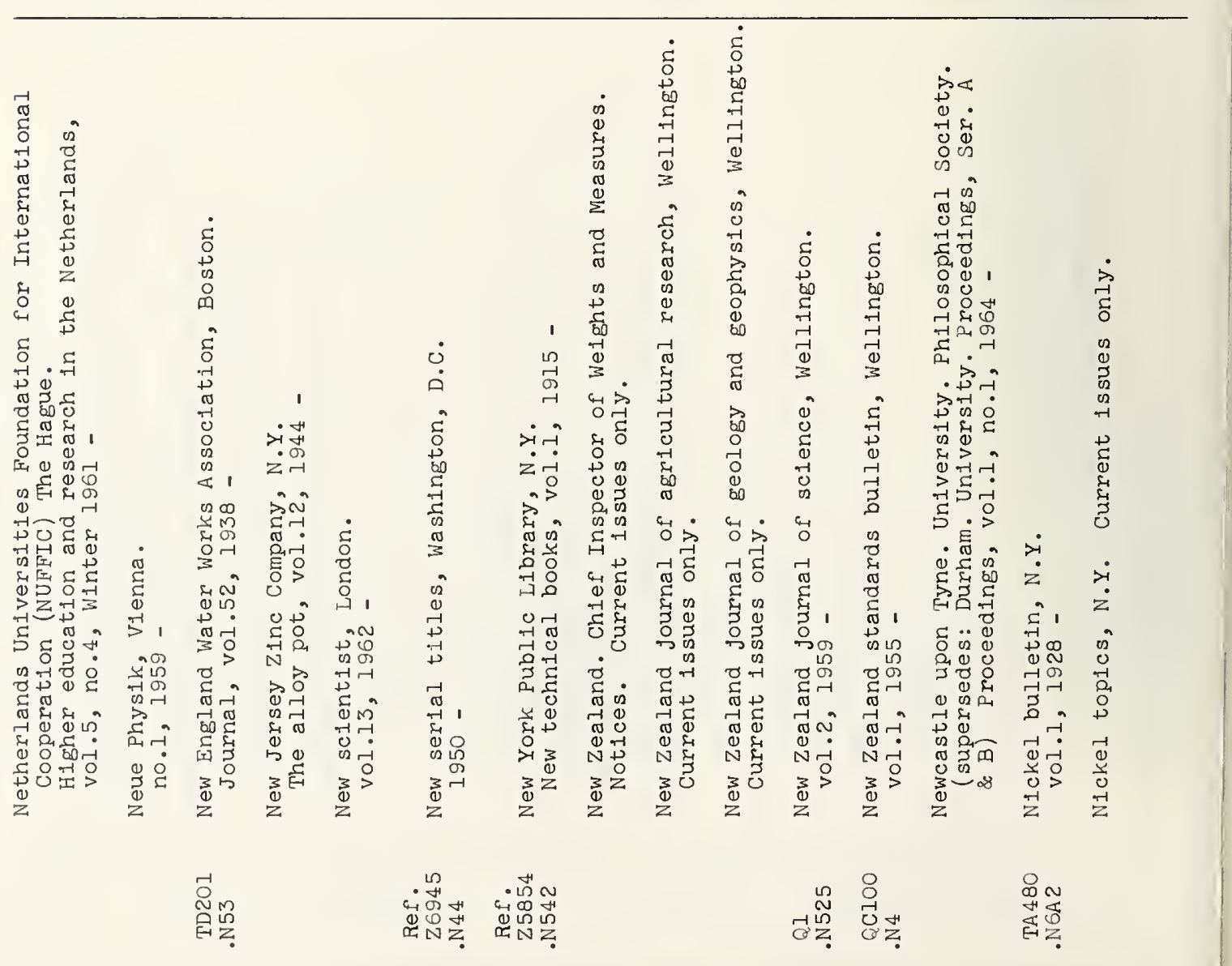




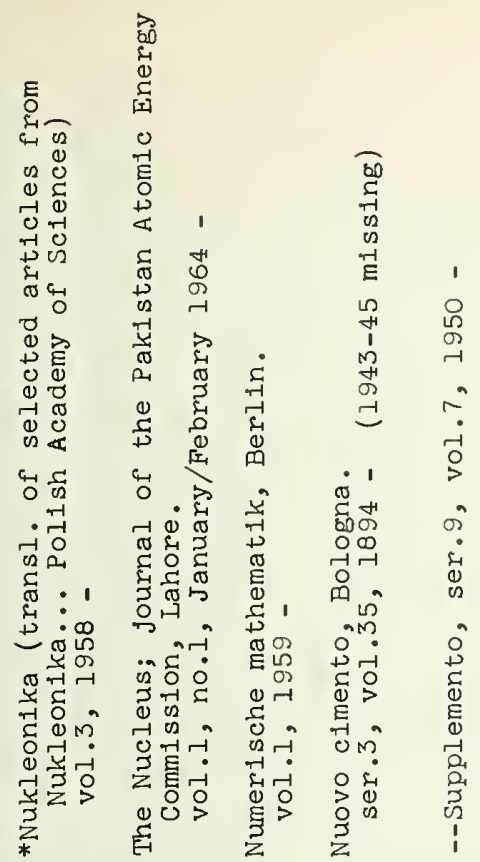

8

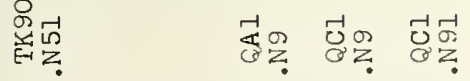
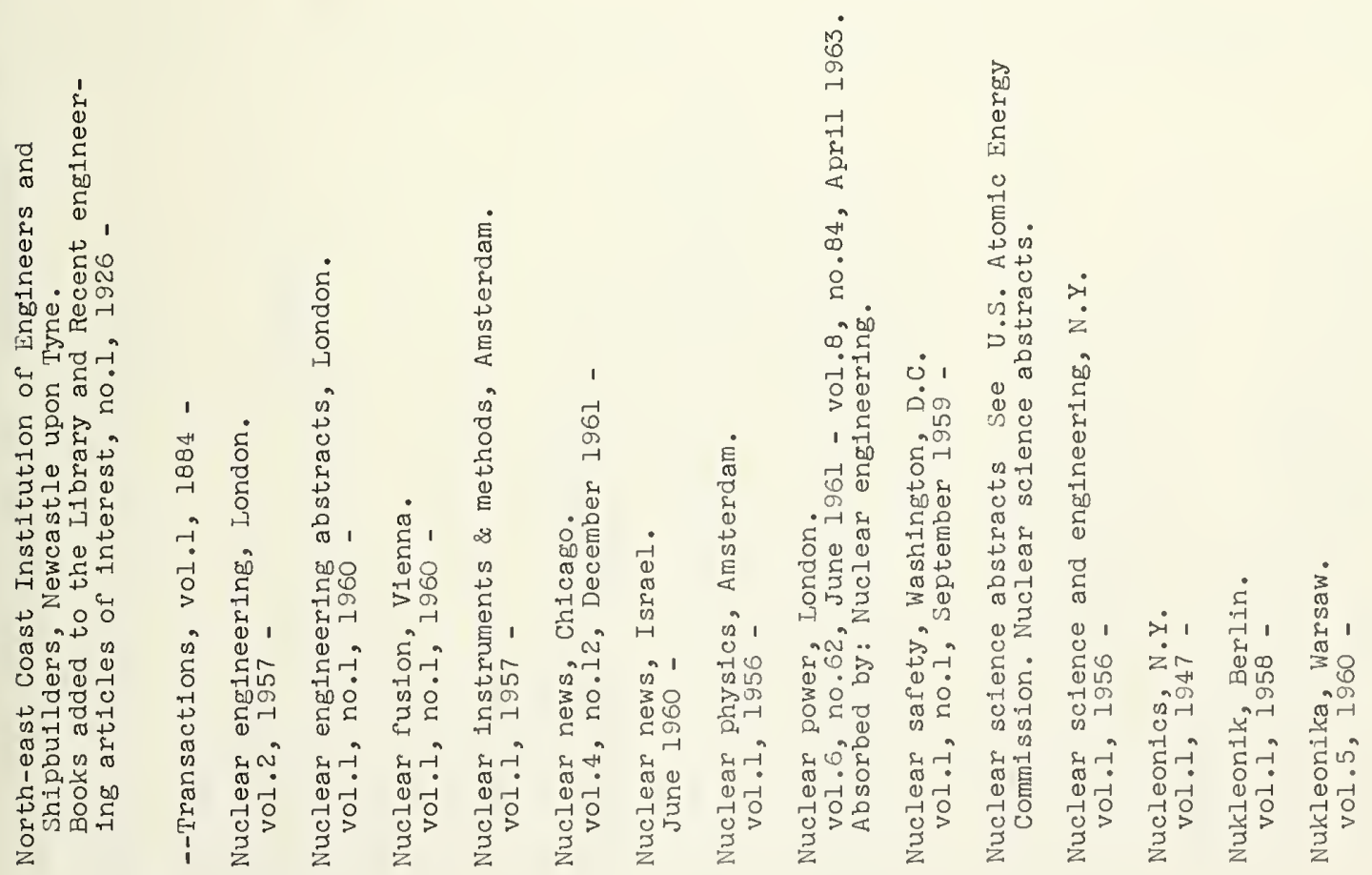

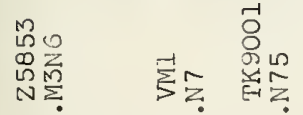
品品

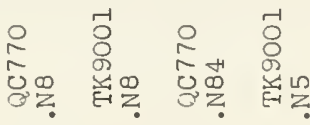




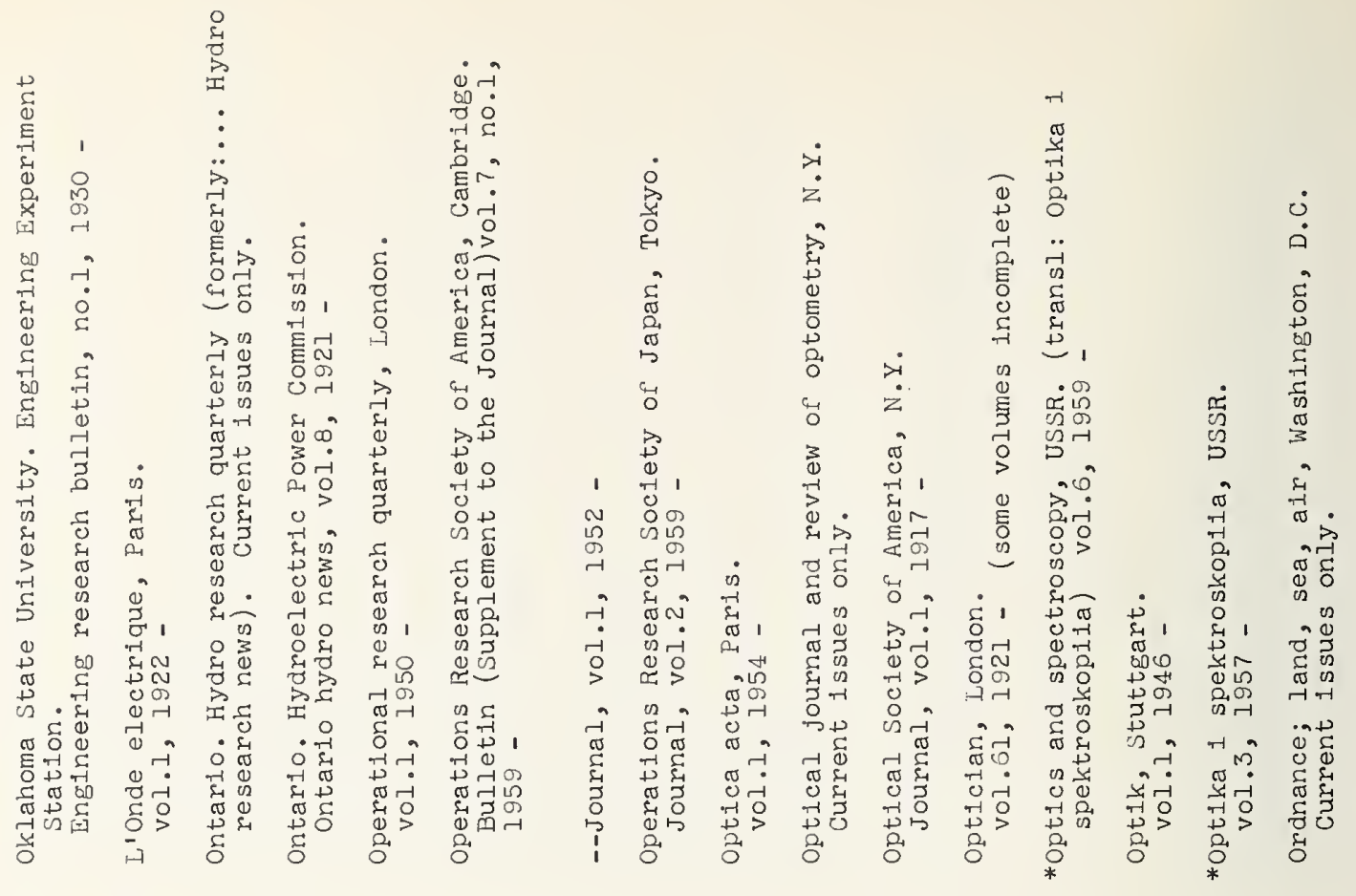

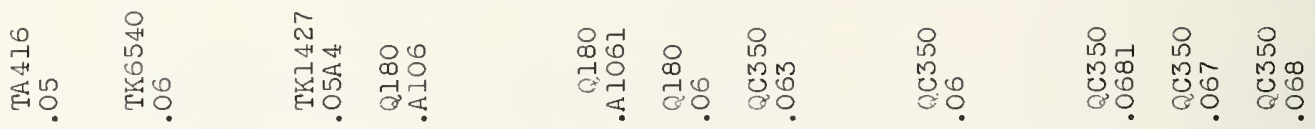

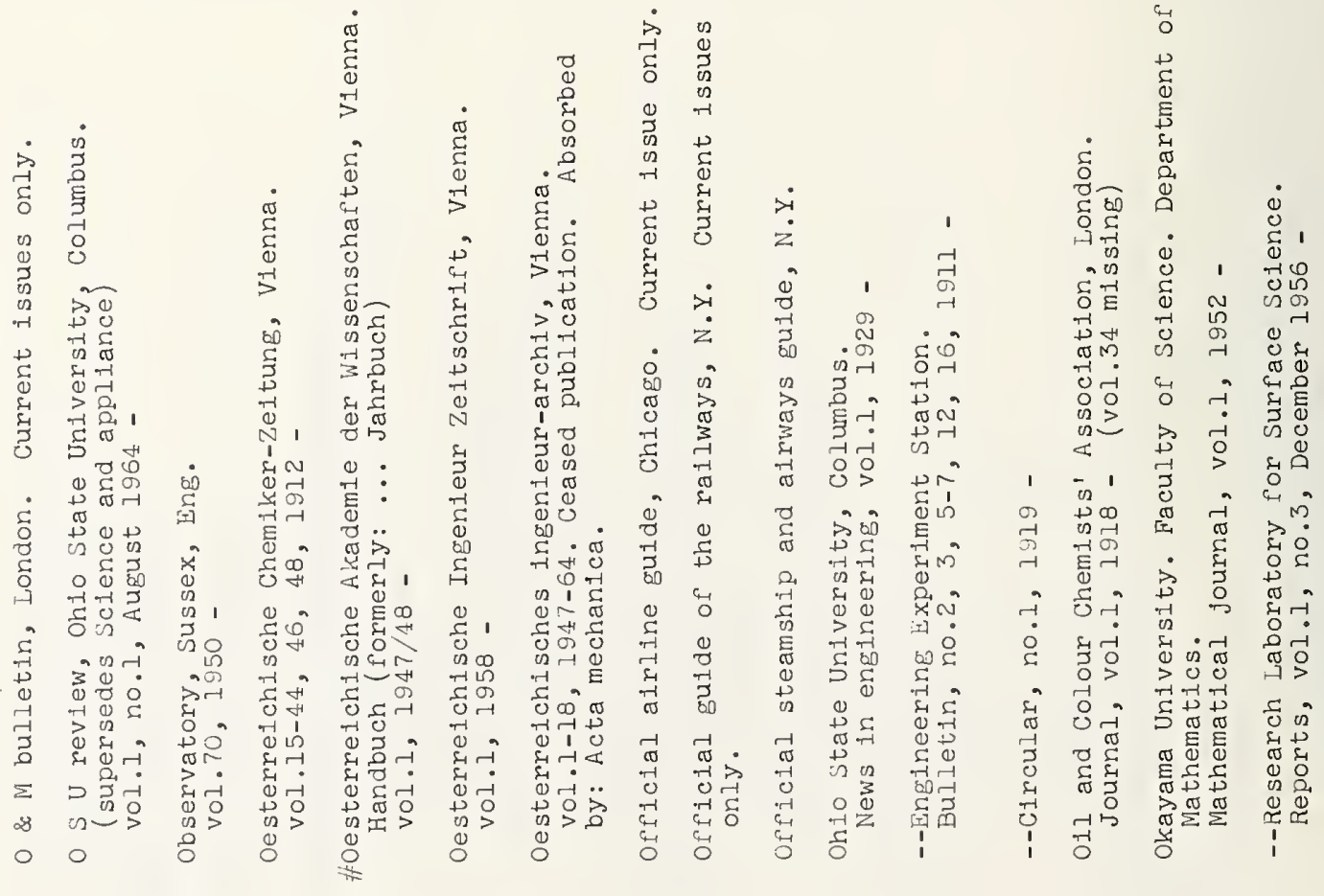

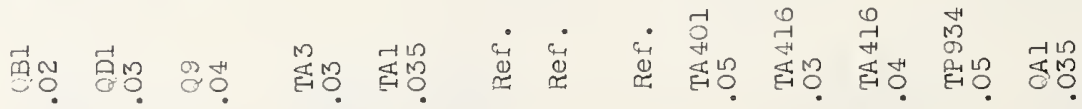




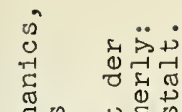

记

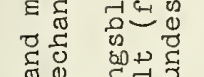

盛:

ต

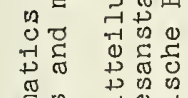

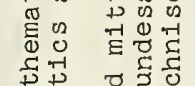

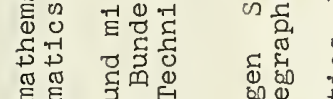

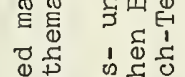

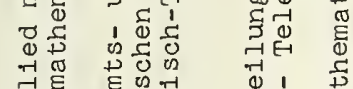

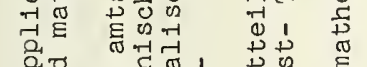

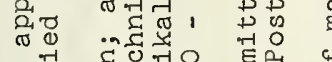

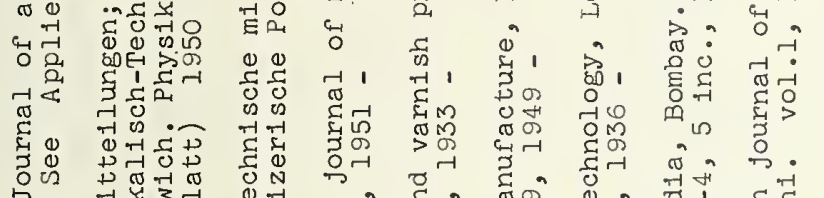

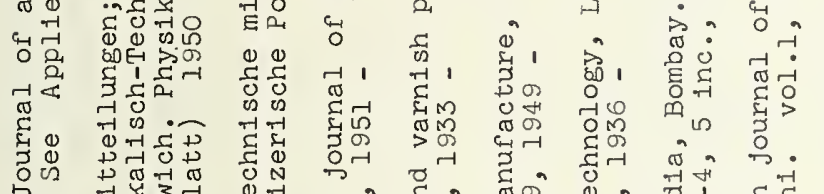

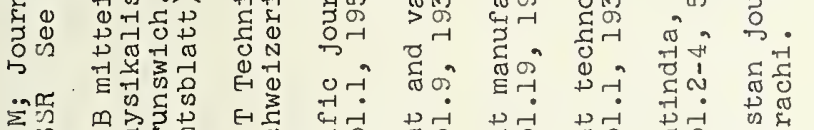

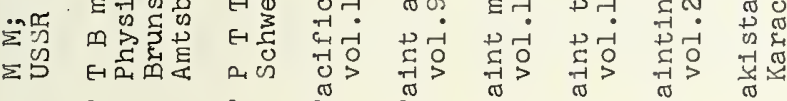

a $\square$

a.

3
2
$z$
$\vdots$
0
-1
1
0
0
0
0
0
0

⿷匚 $\quad$,

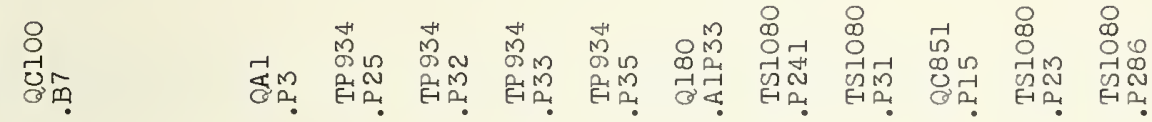

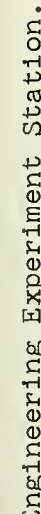

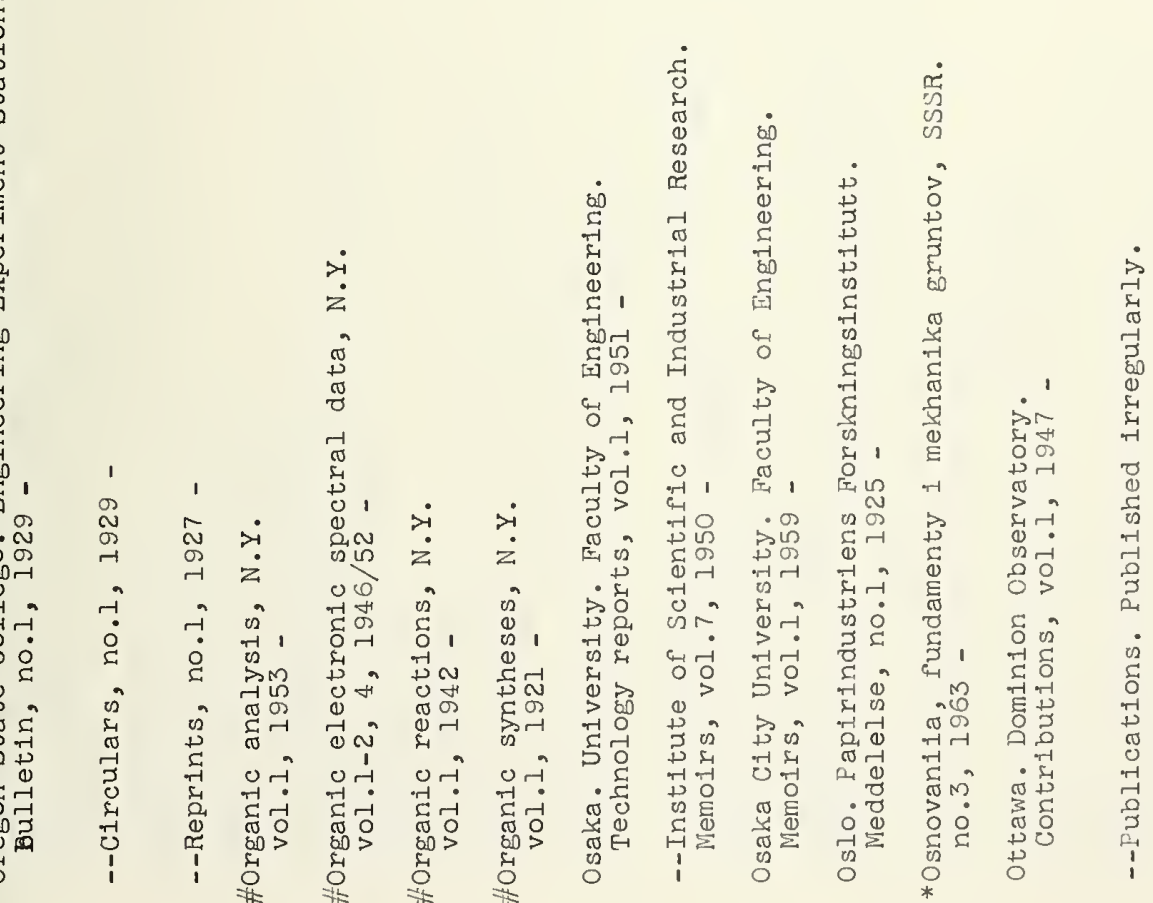

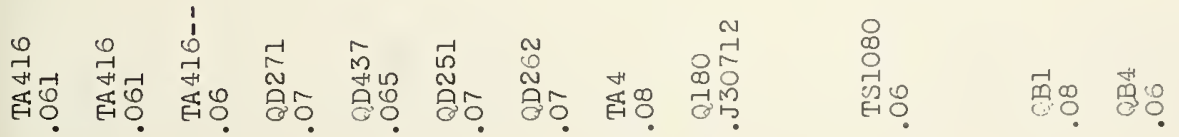




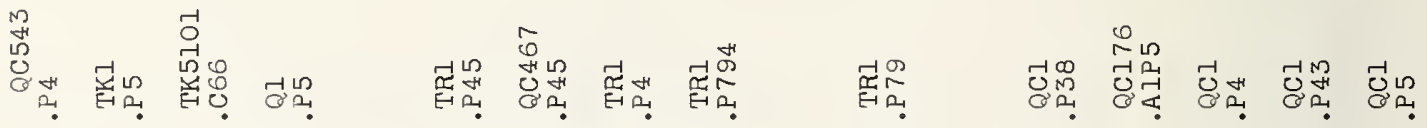

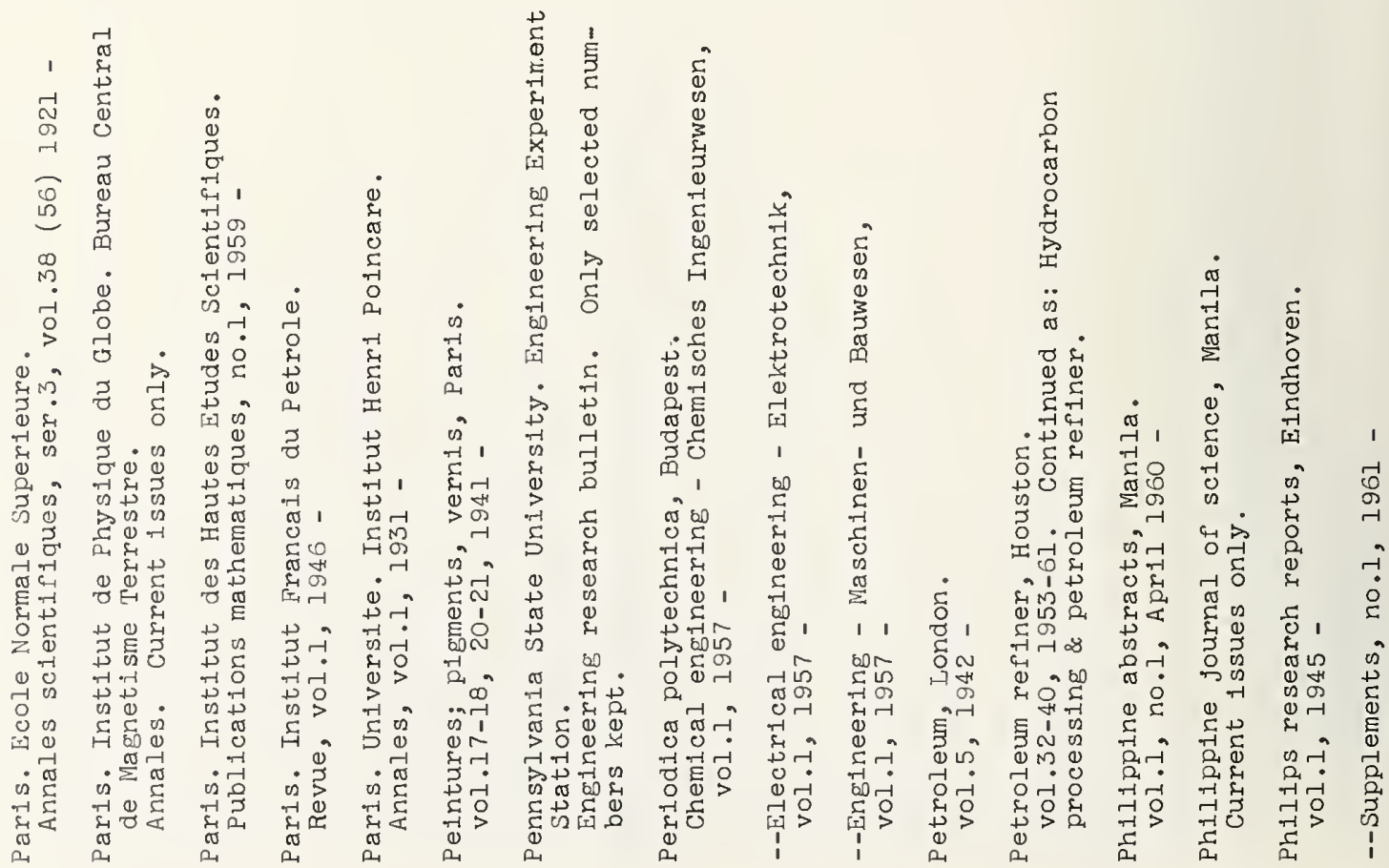




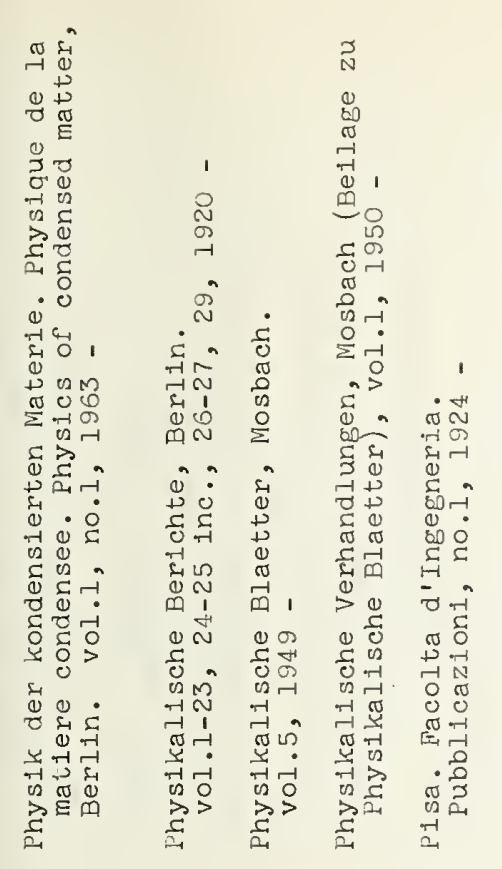

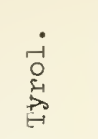

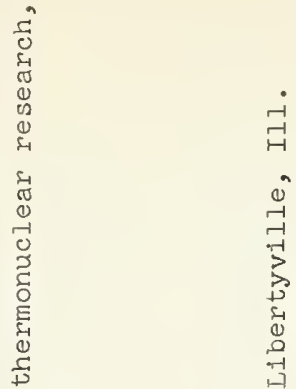

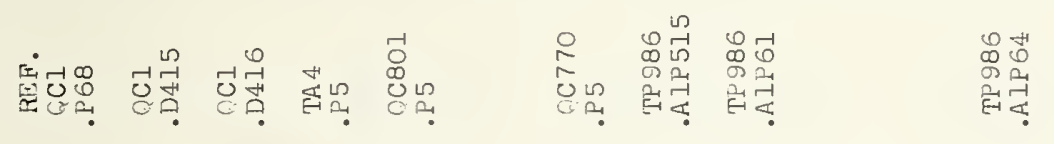

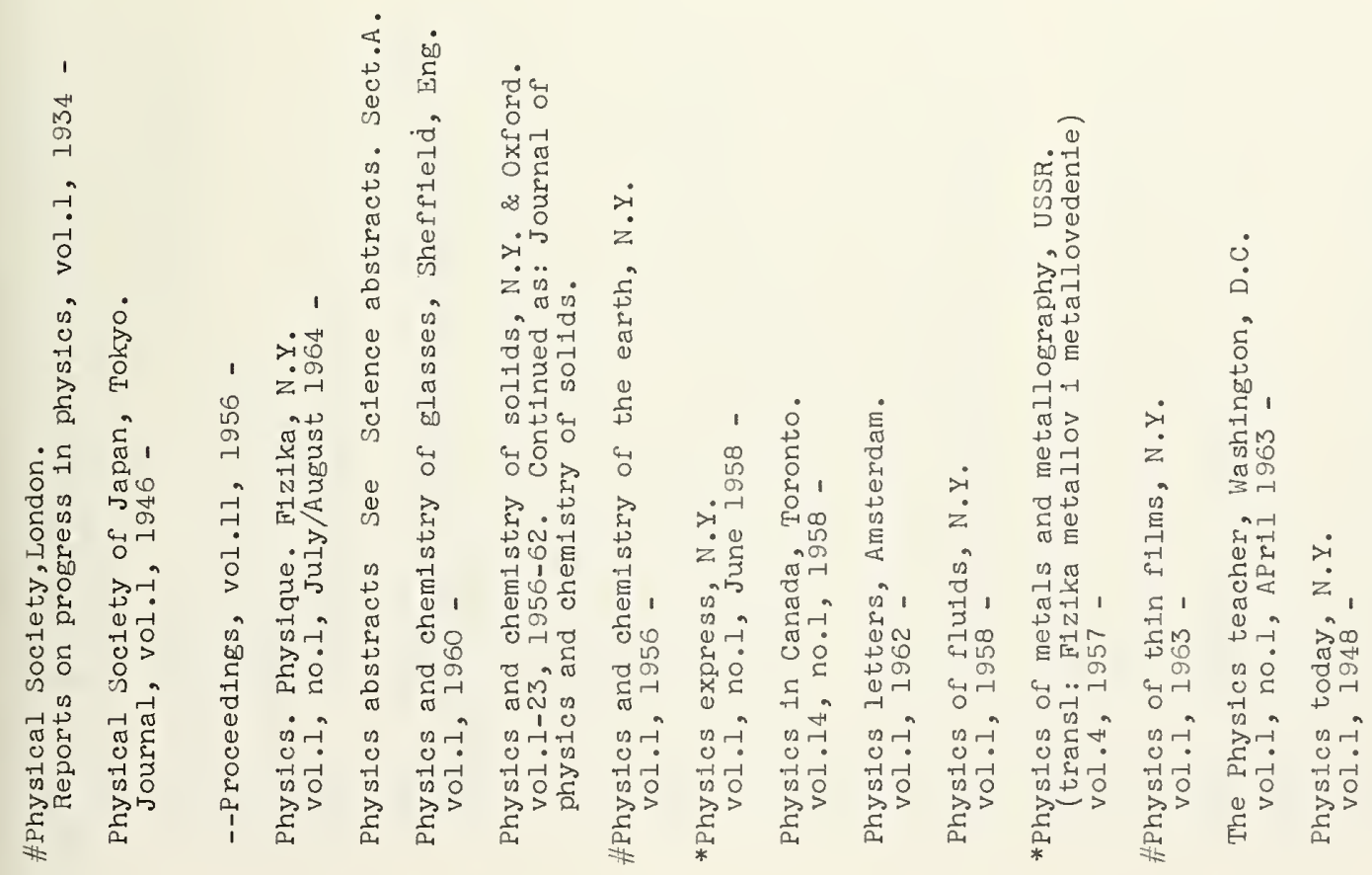

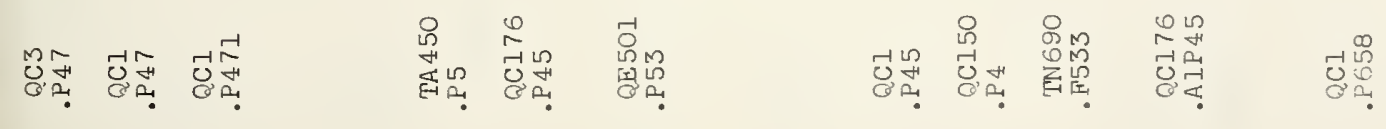



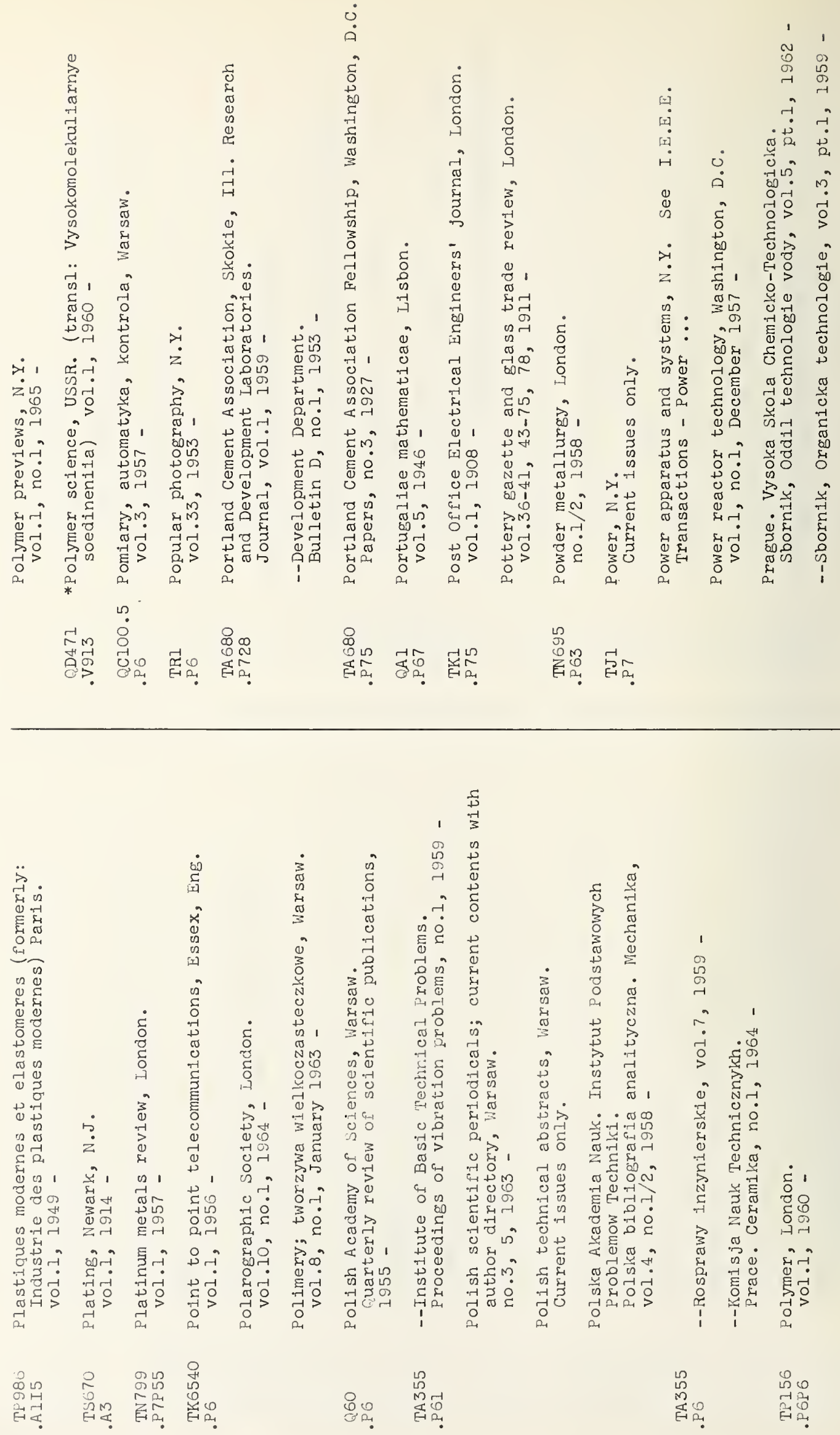


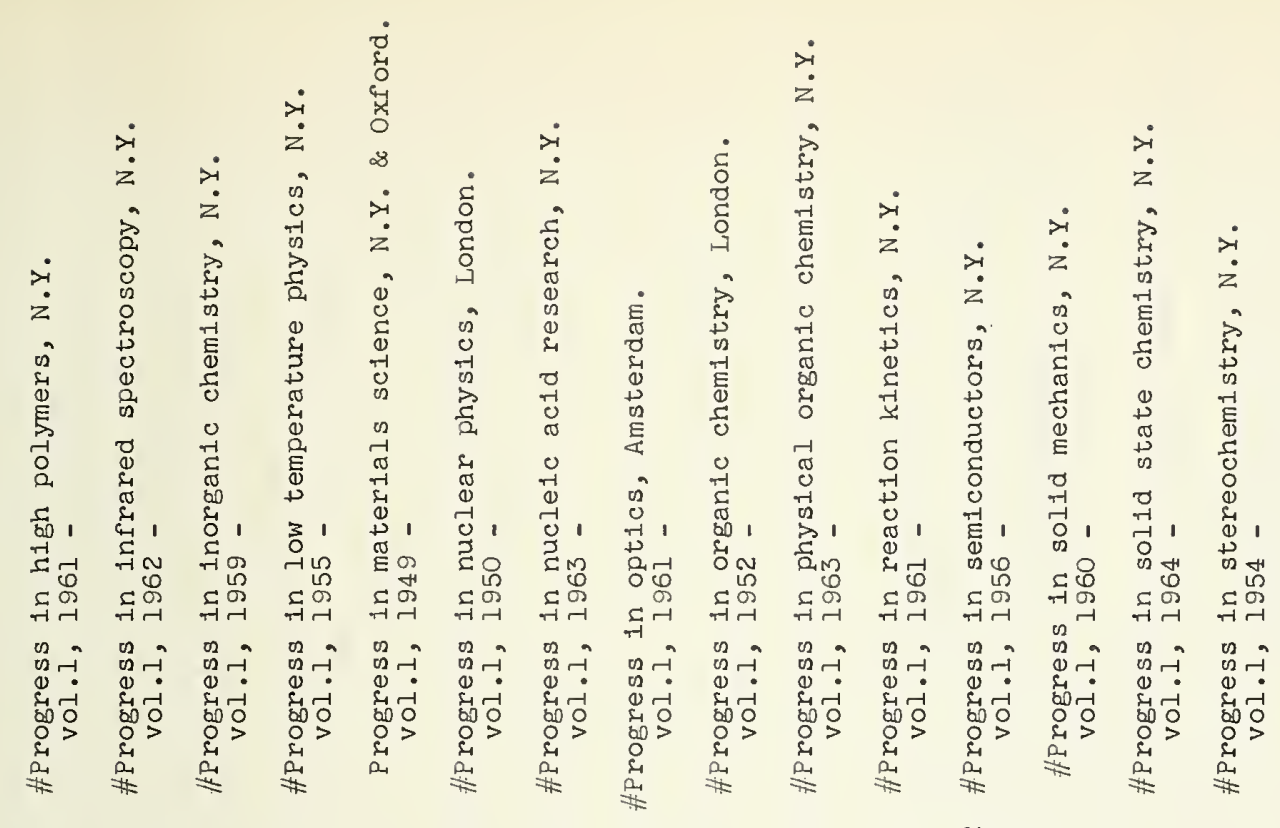

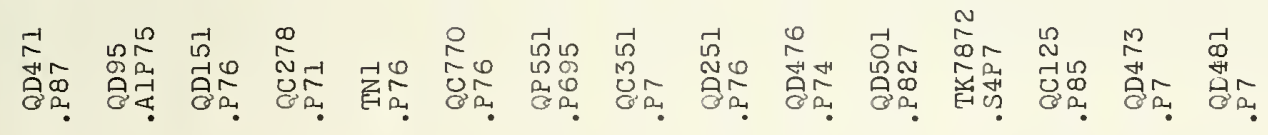
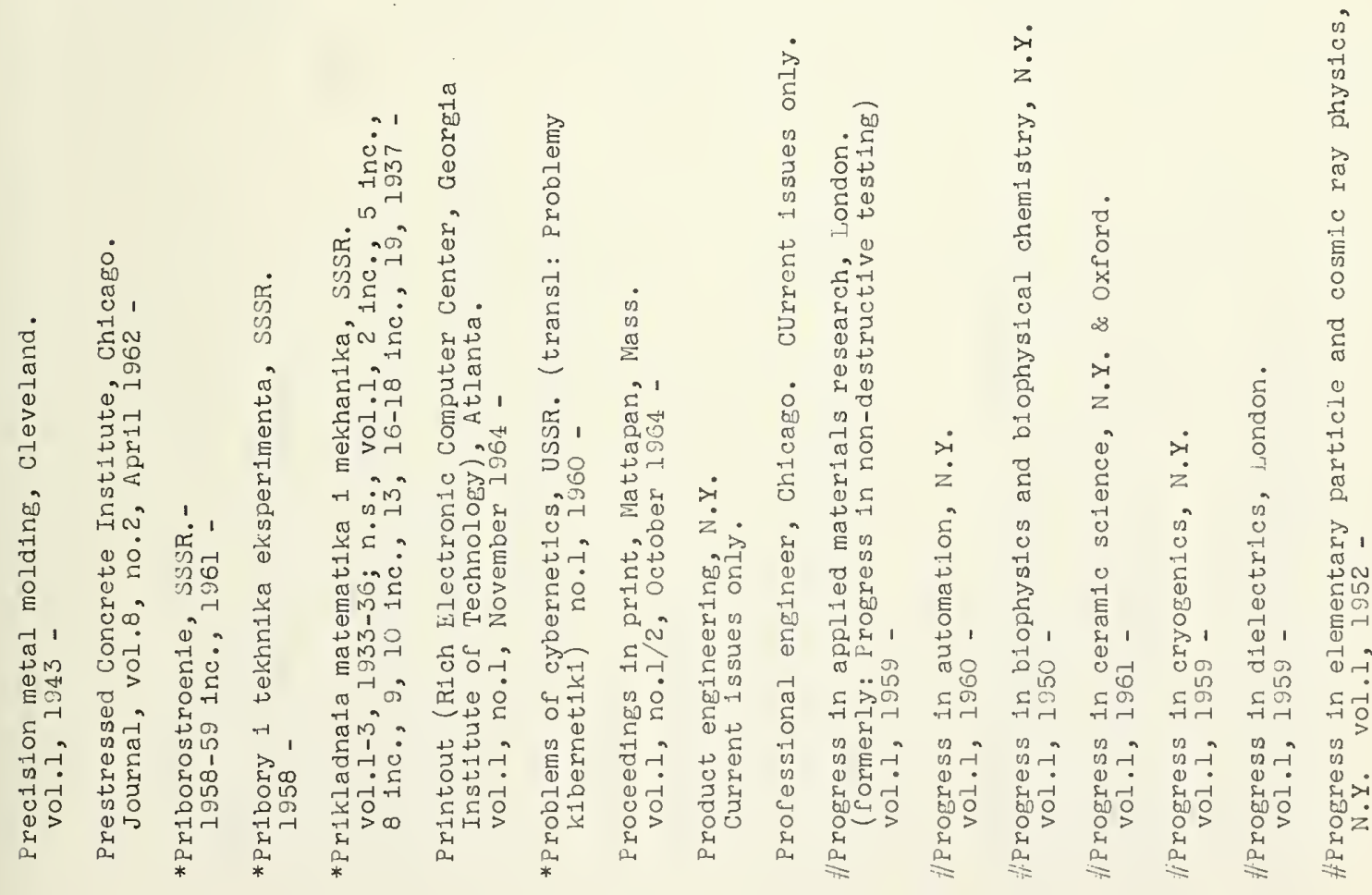

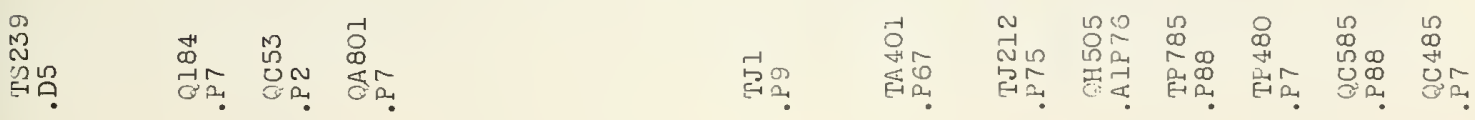




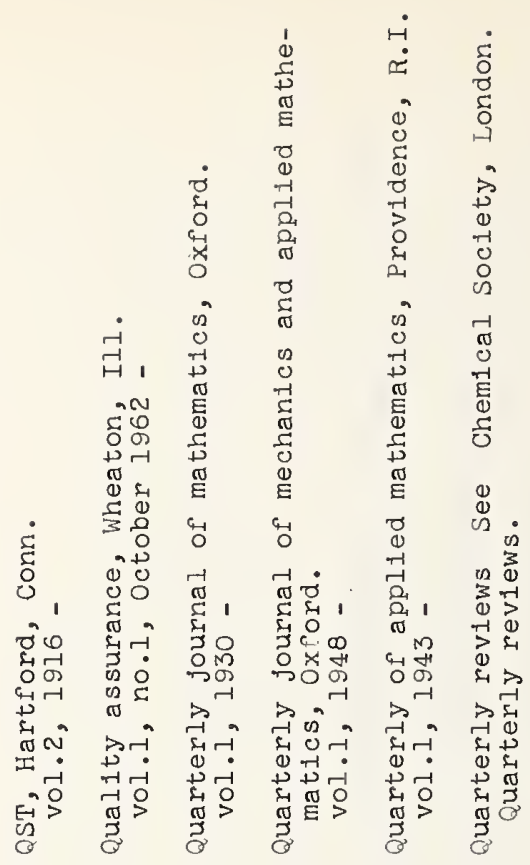

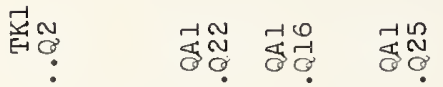

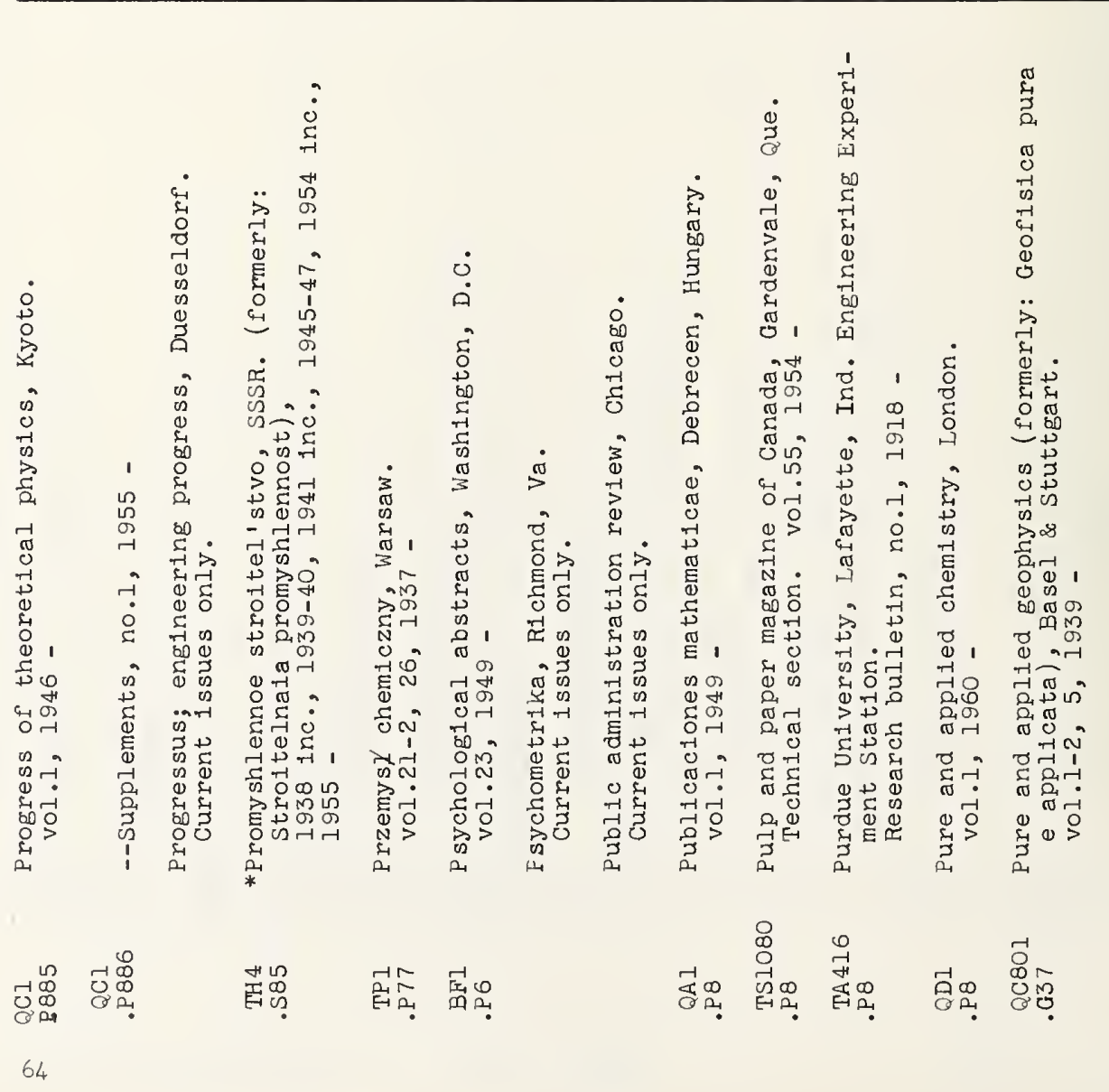




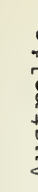

竎

옿

\%

s.

(a)

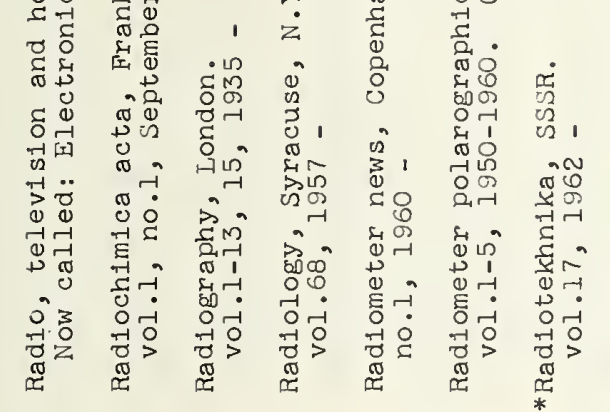

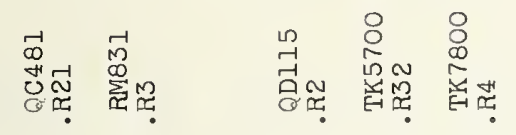

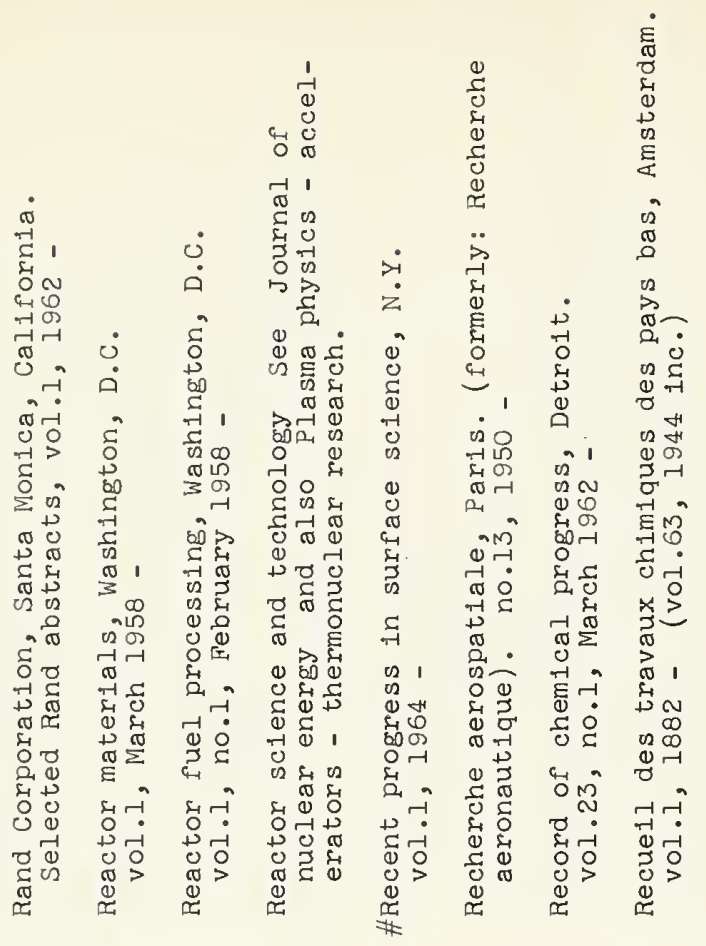

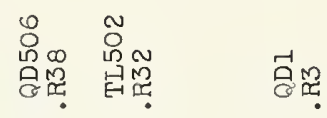

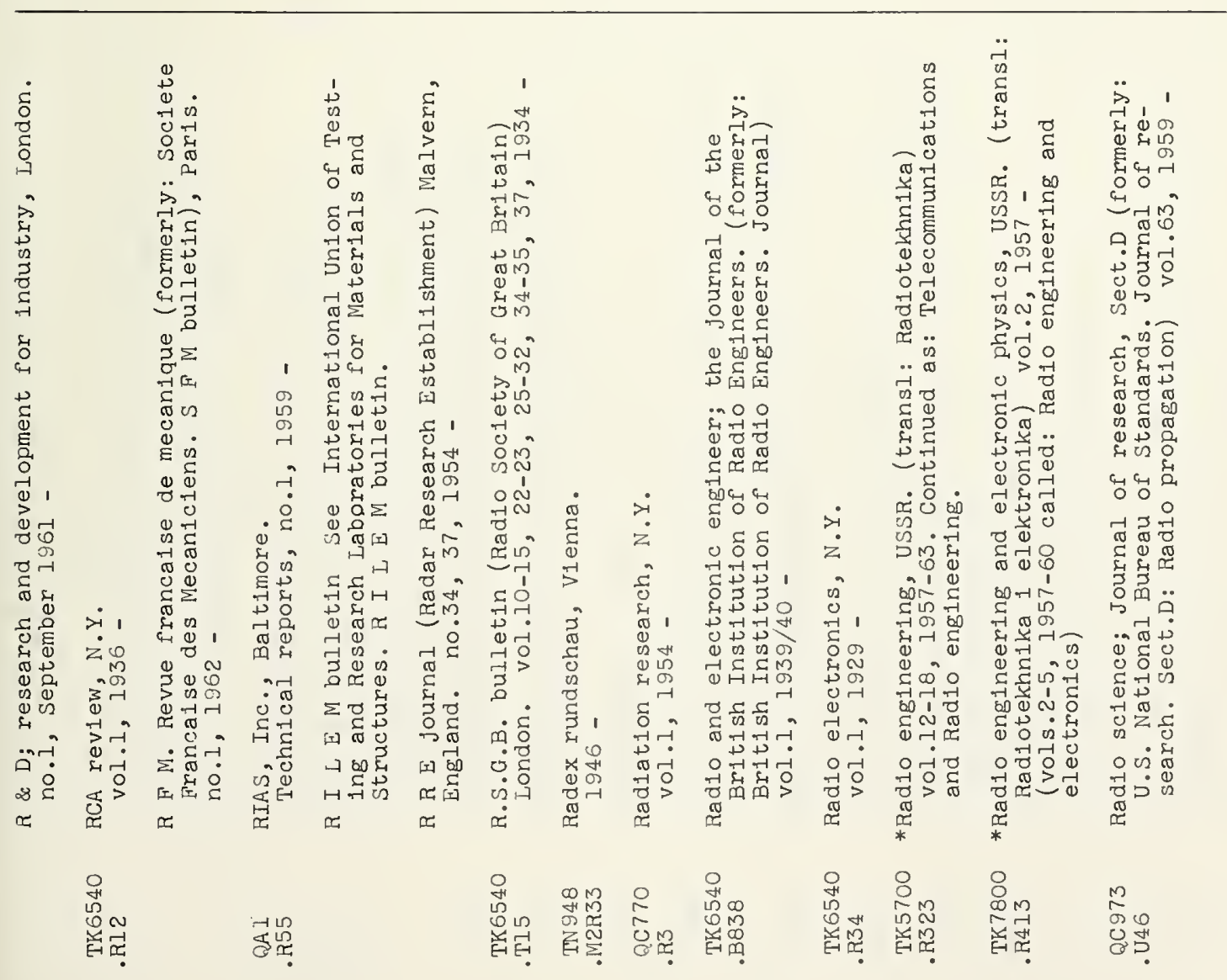




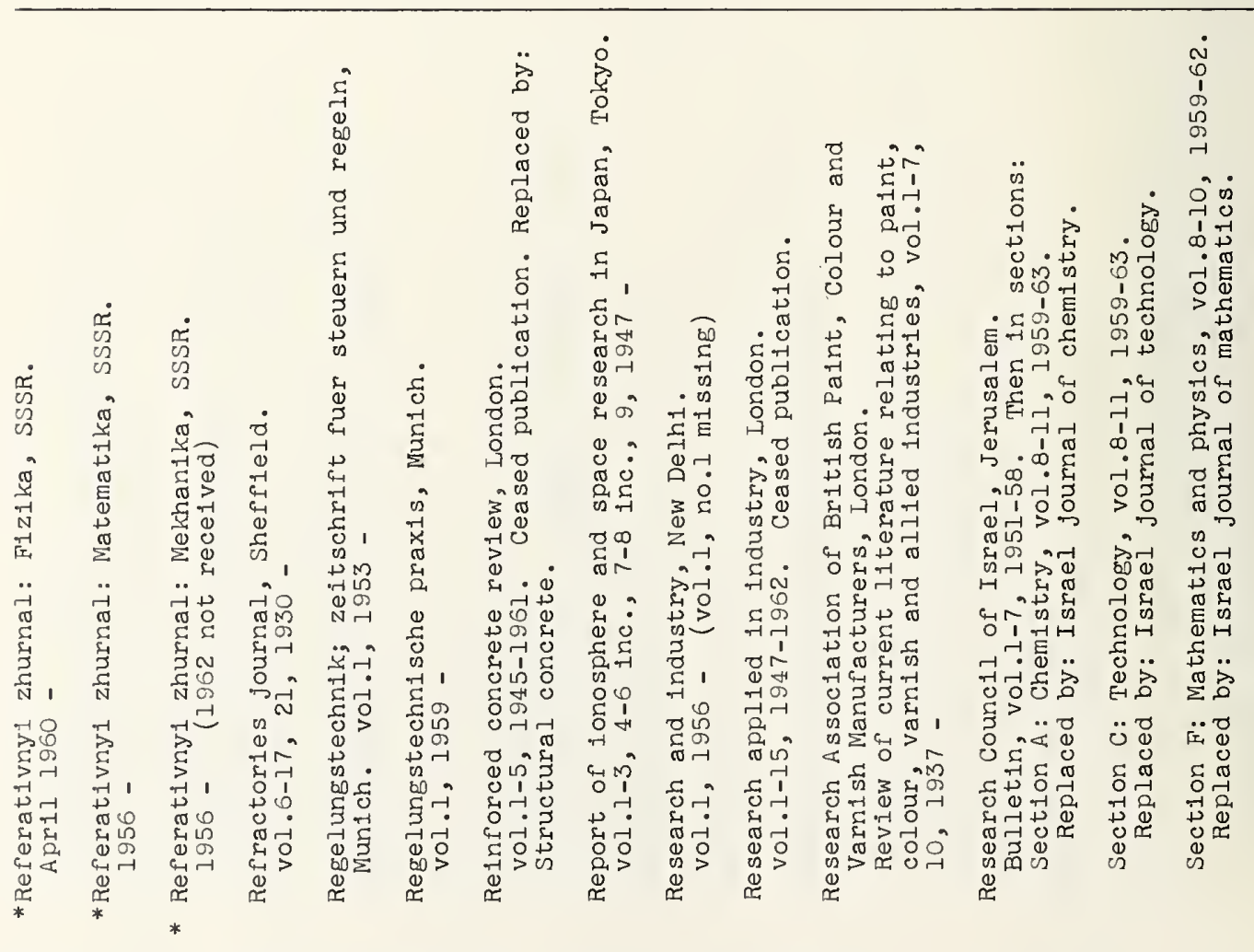

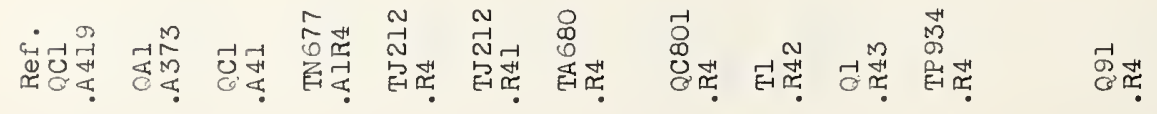


11

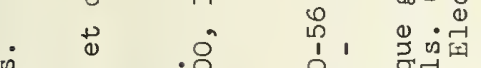

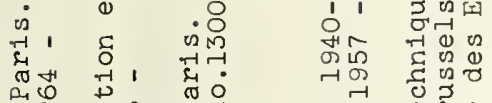

म.

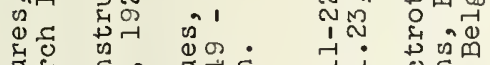

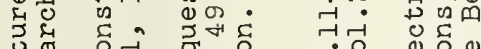

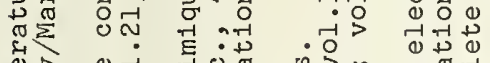

运

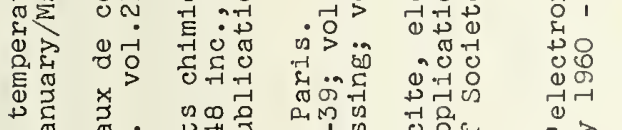

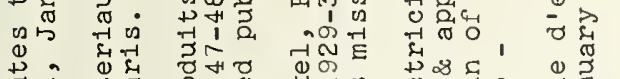

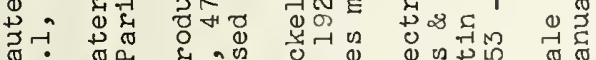

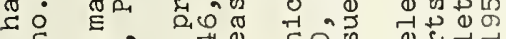

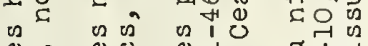

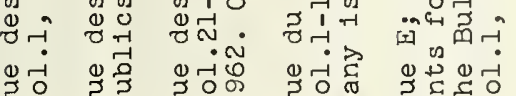

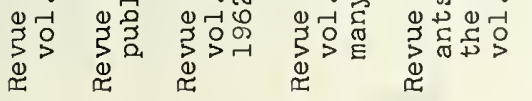

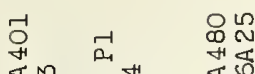

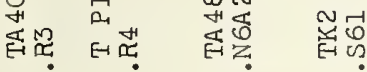

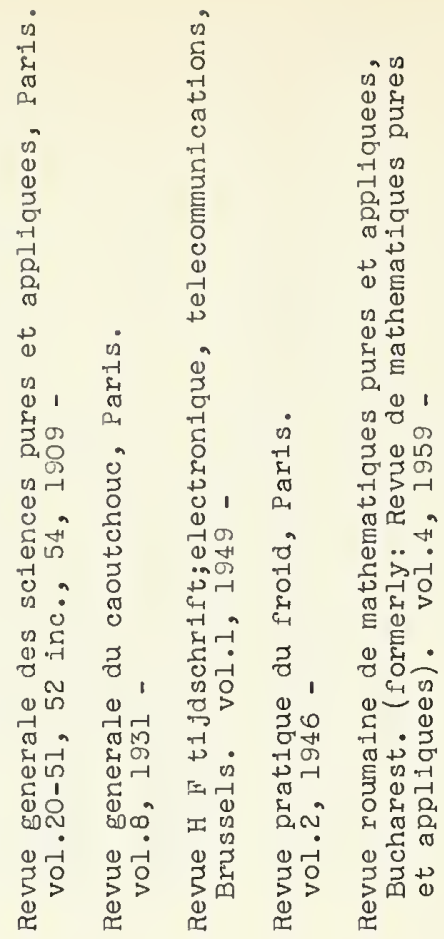

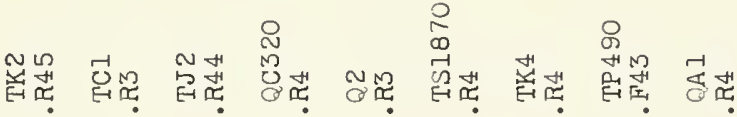

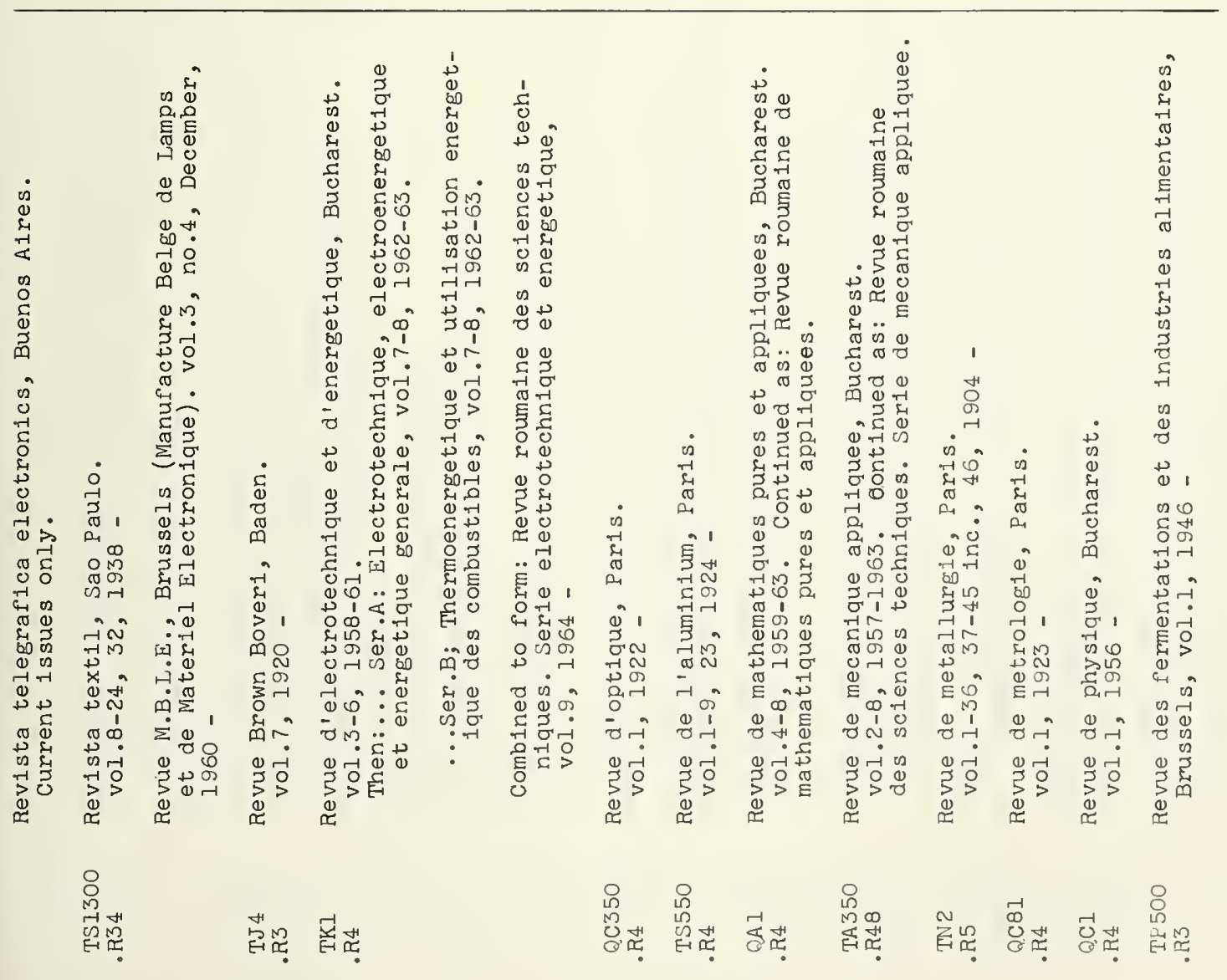




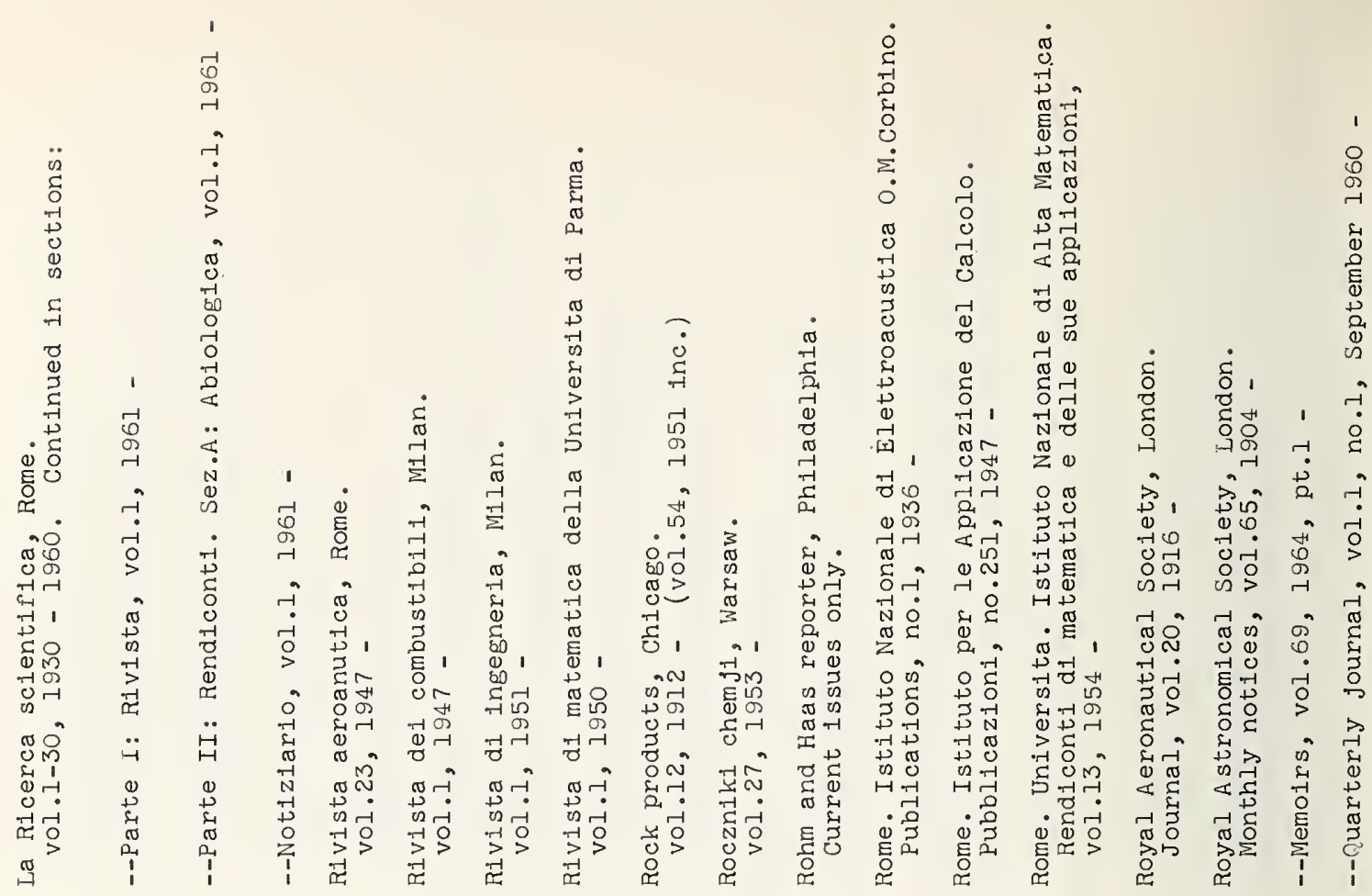

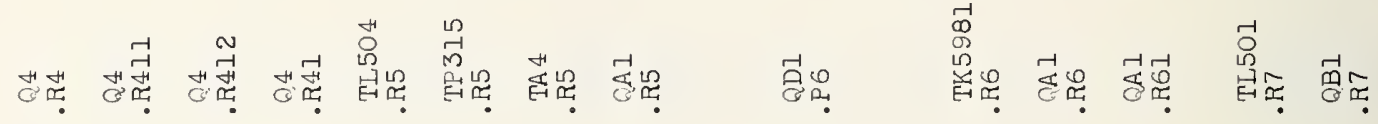

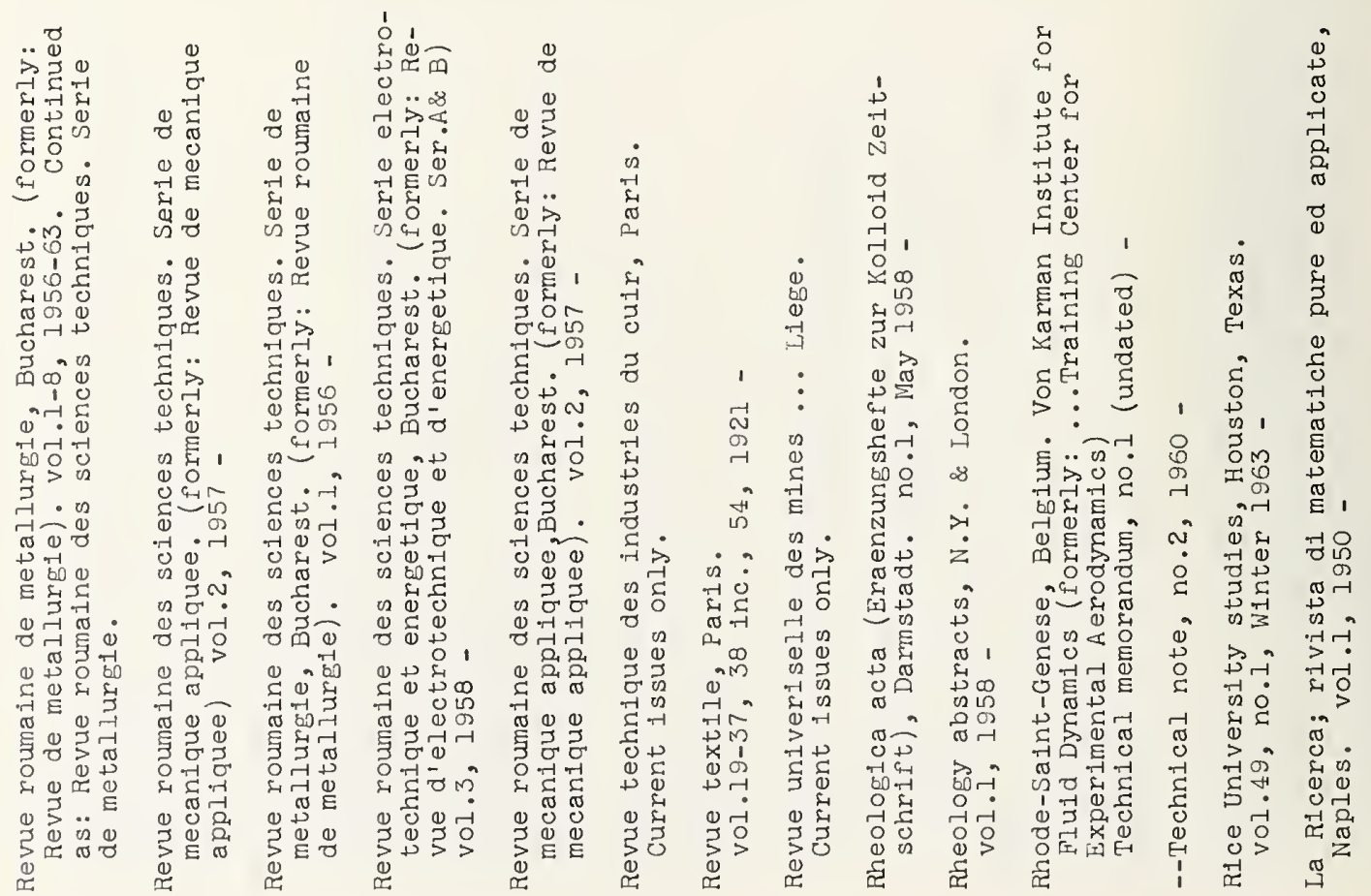

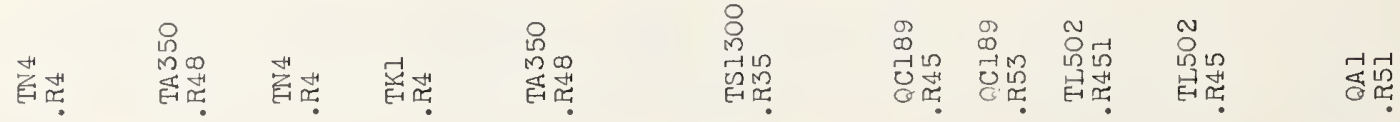




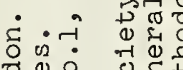

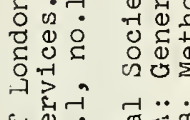
구료

1.

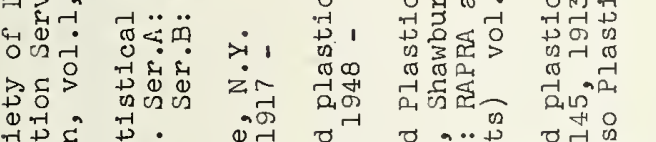

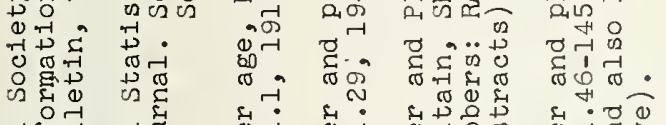

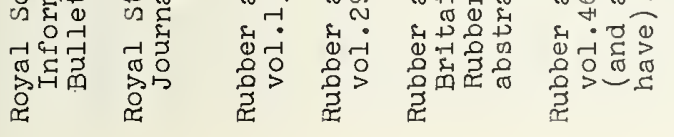

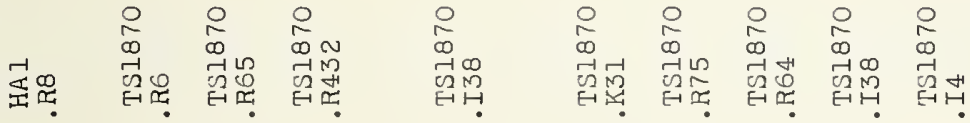

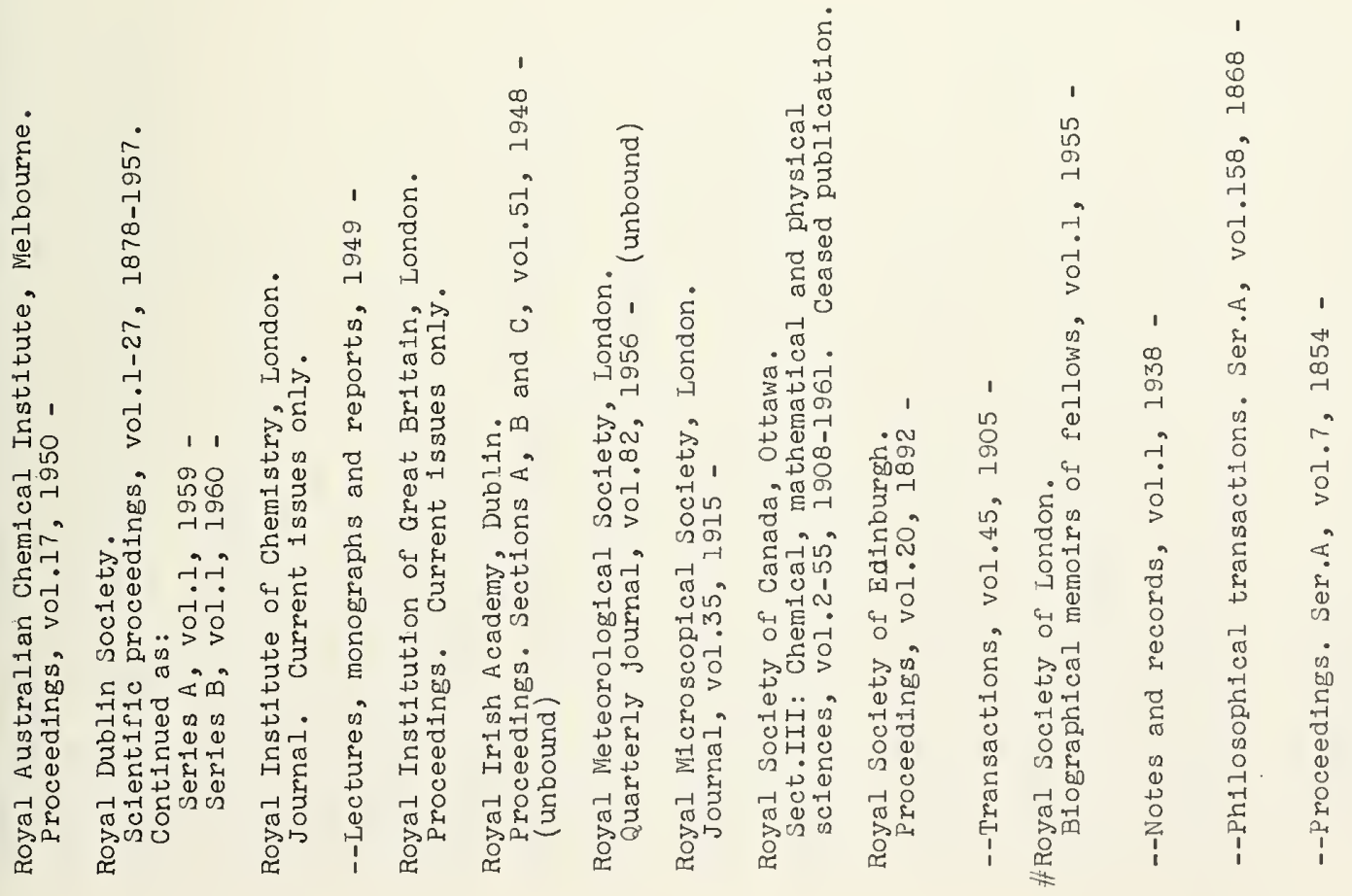

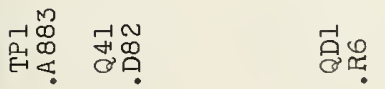

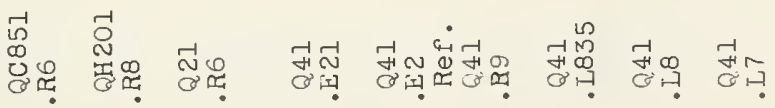




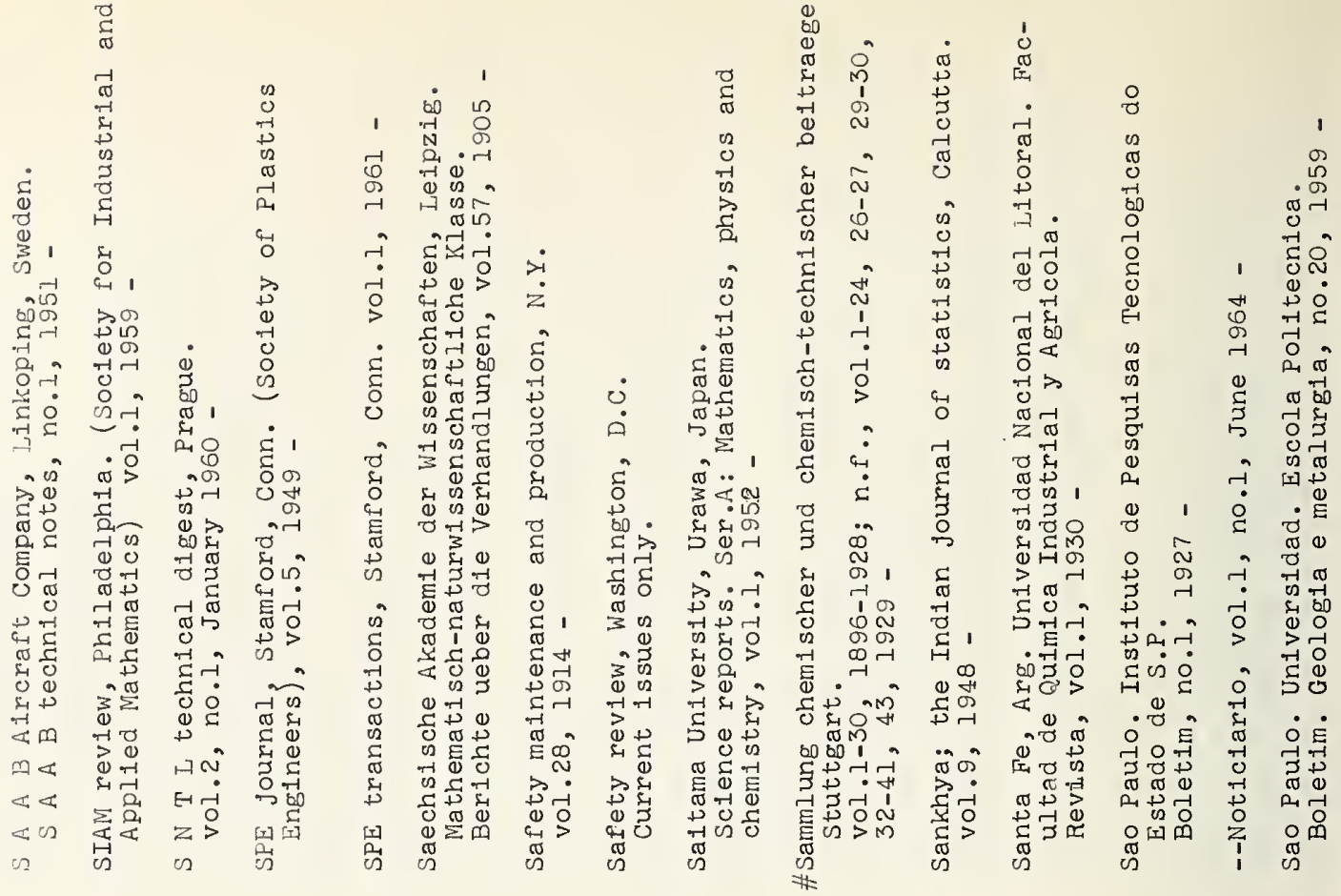

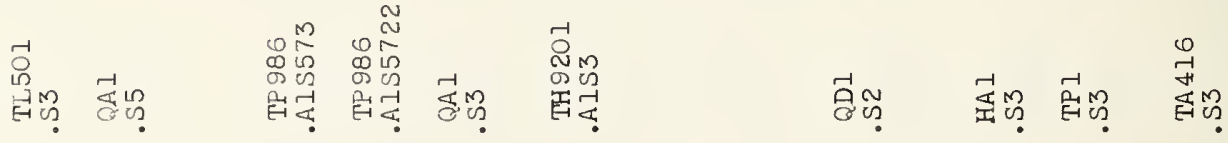

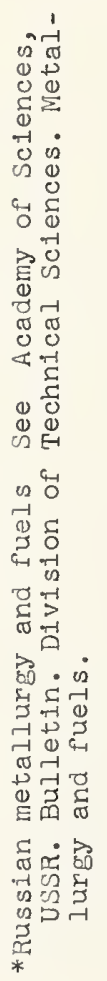




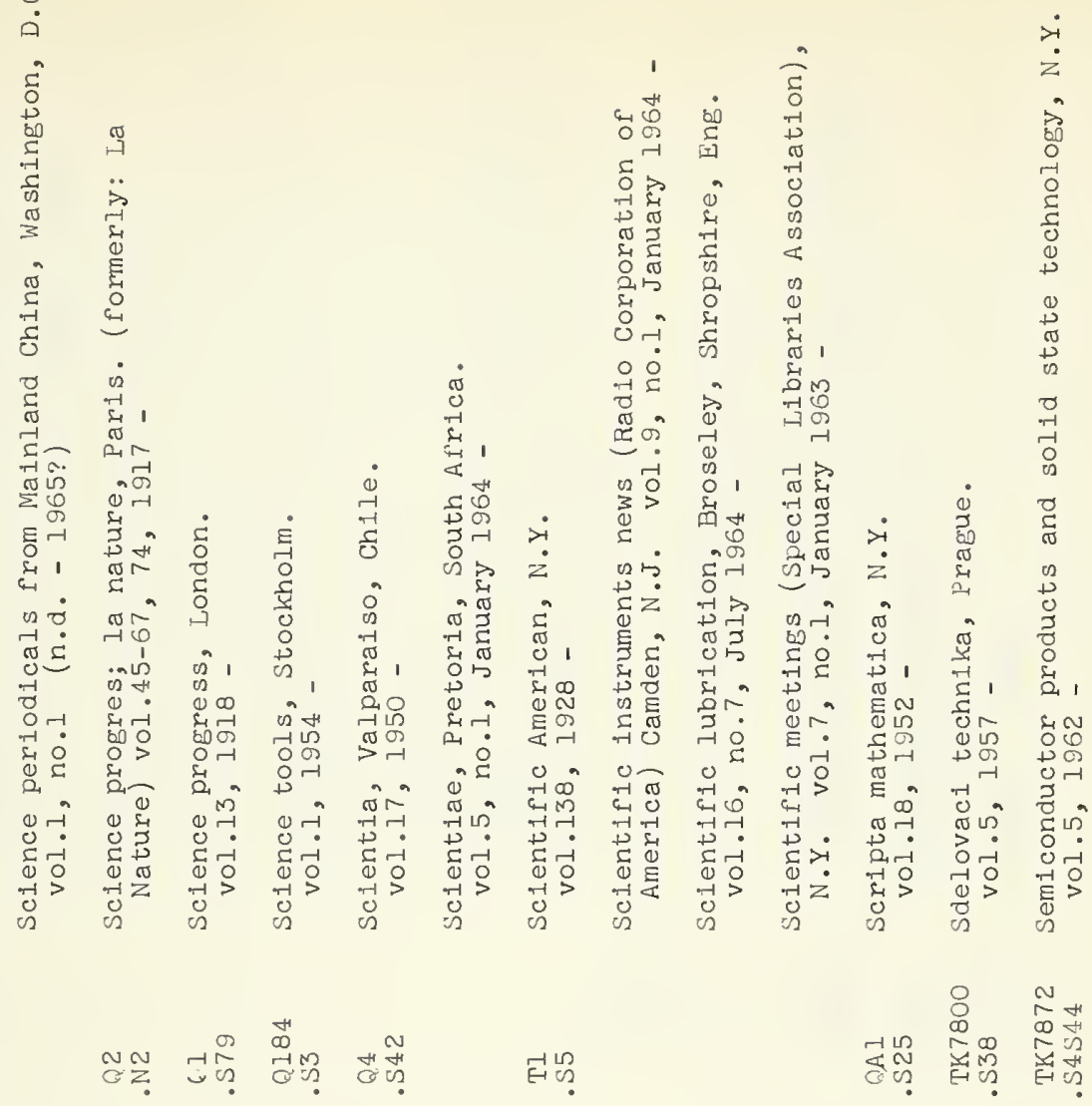

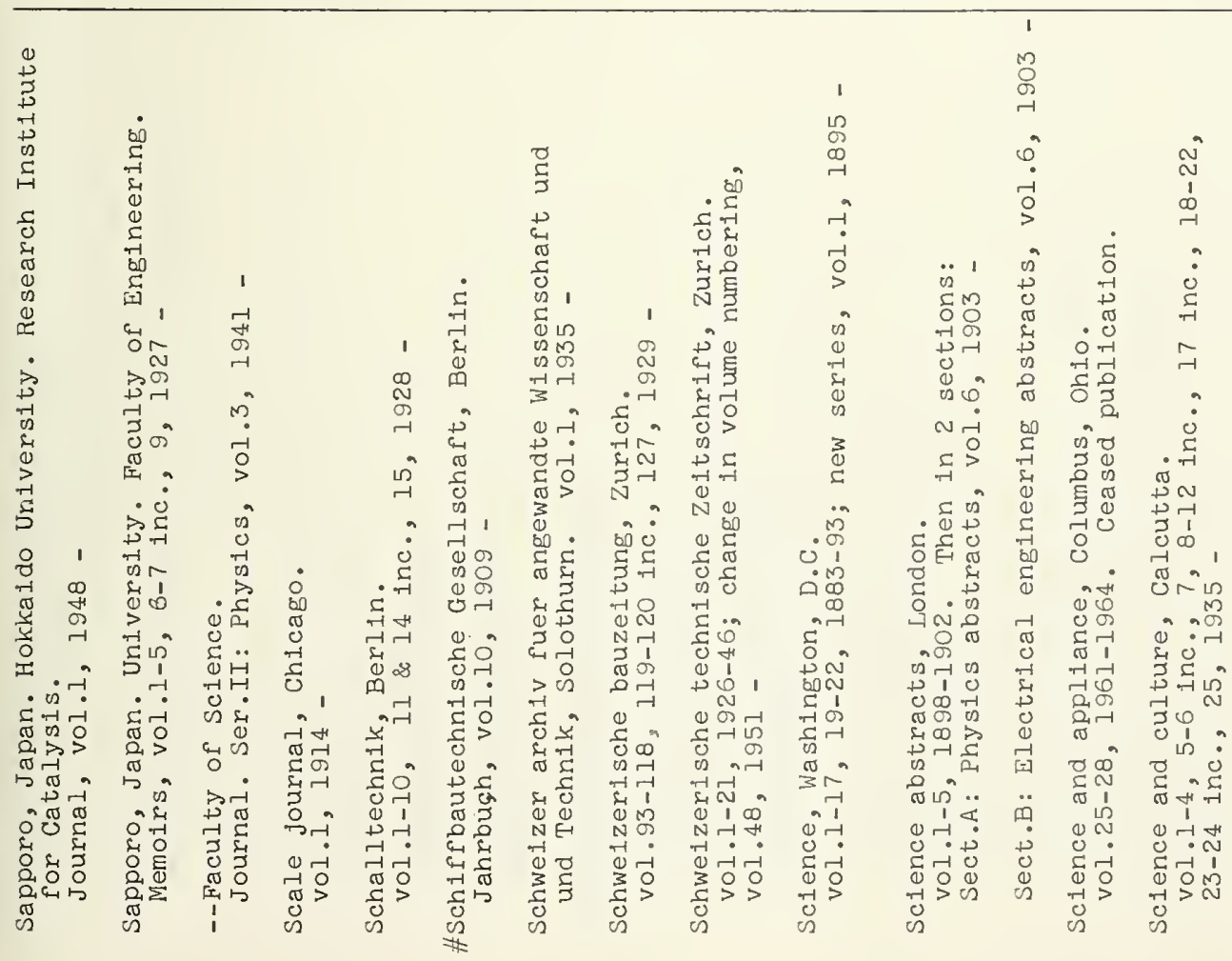

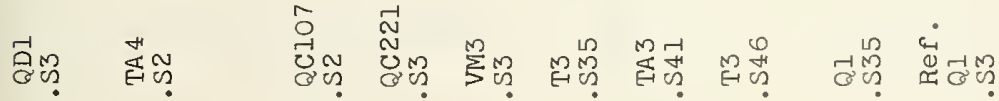

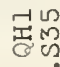




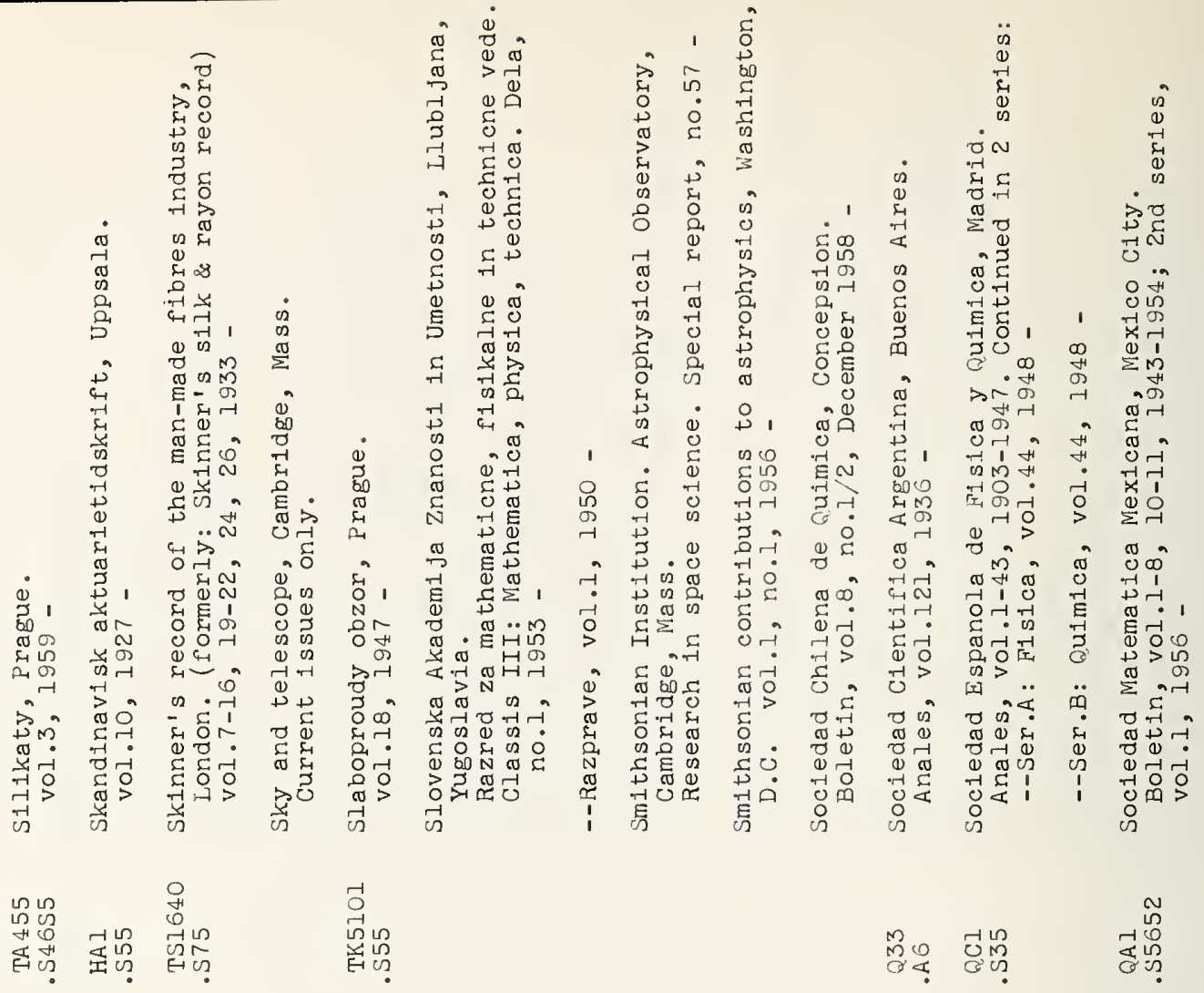

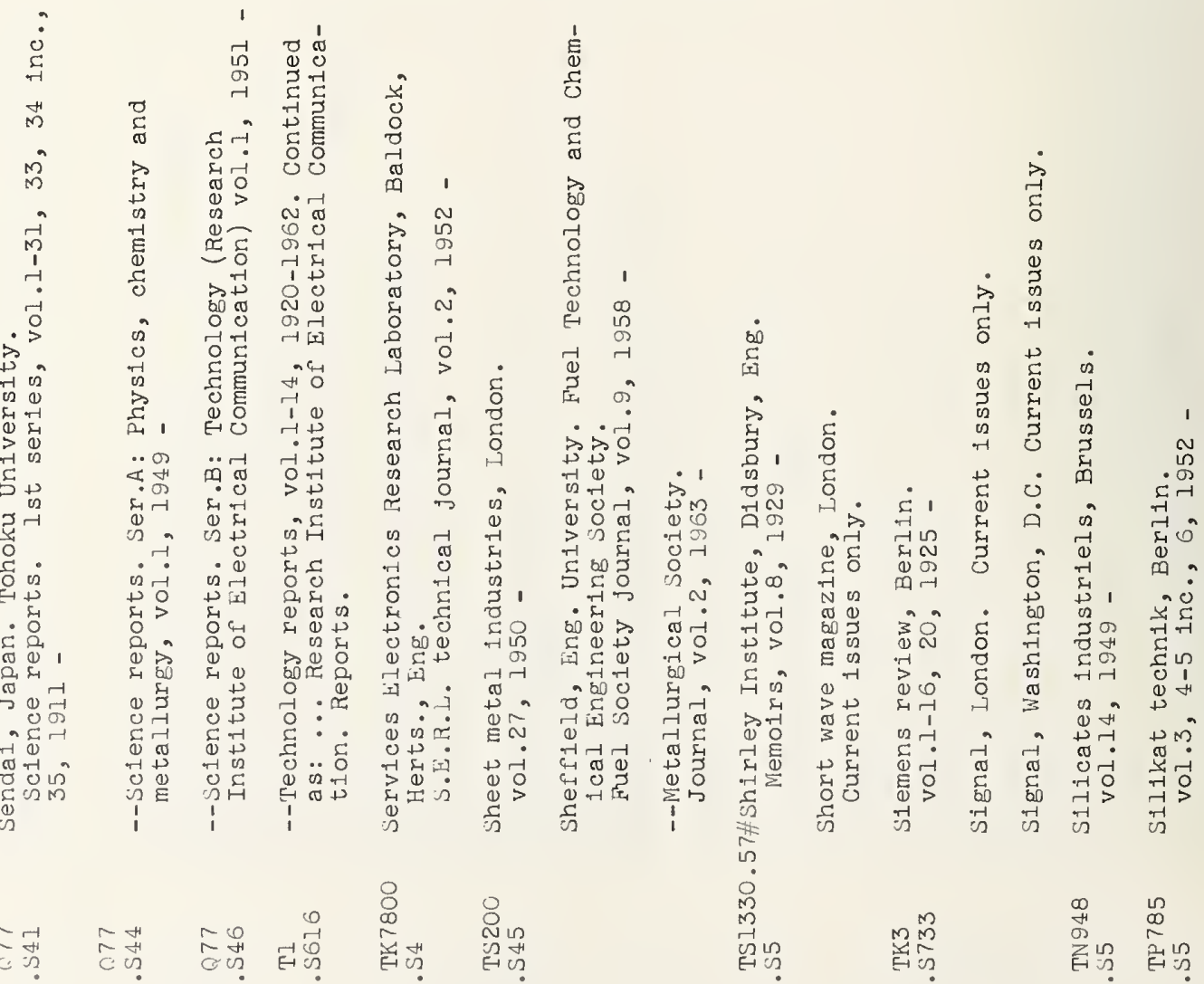




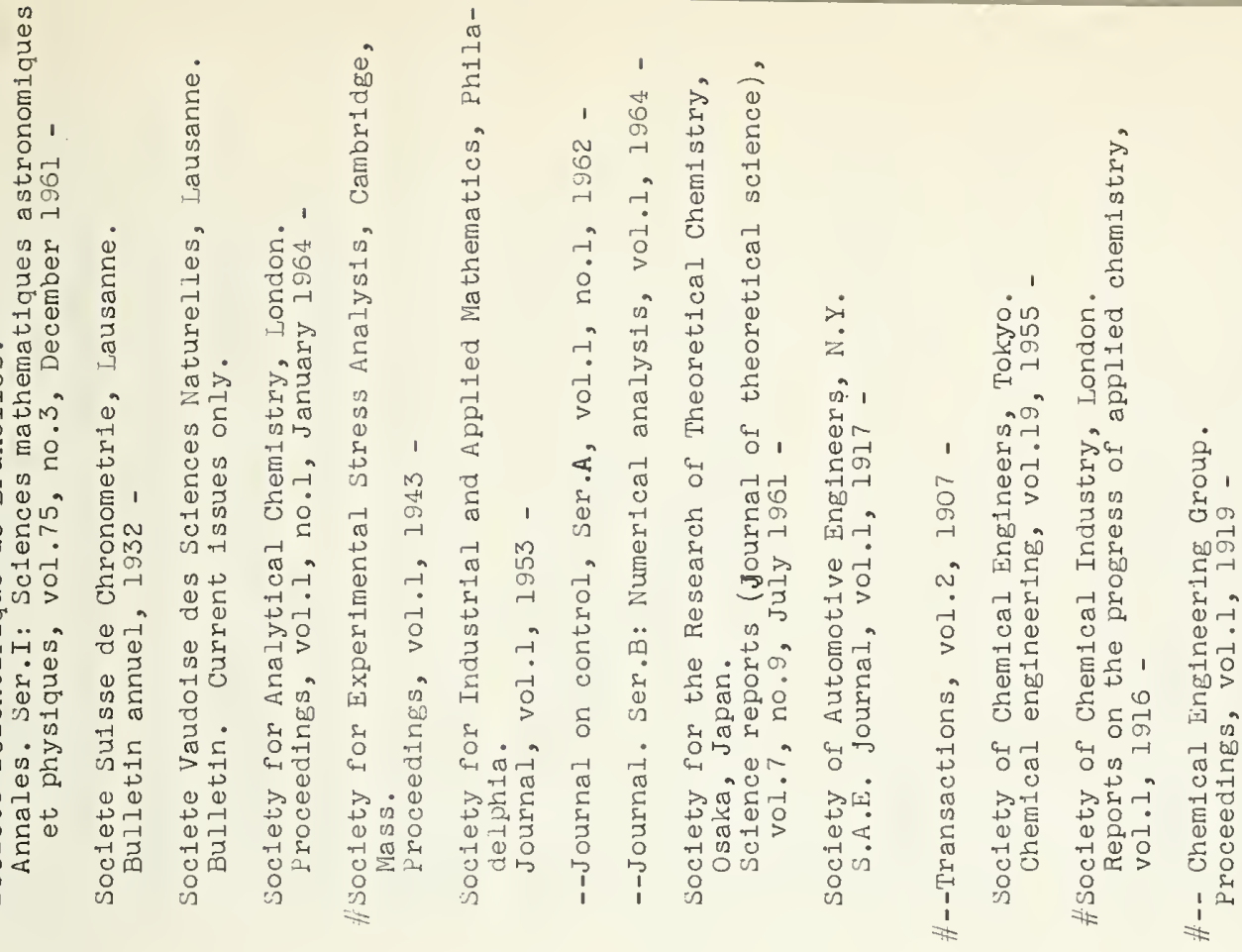
离最

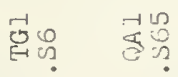

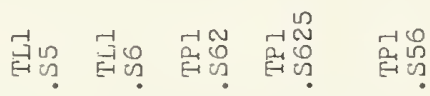

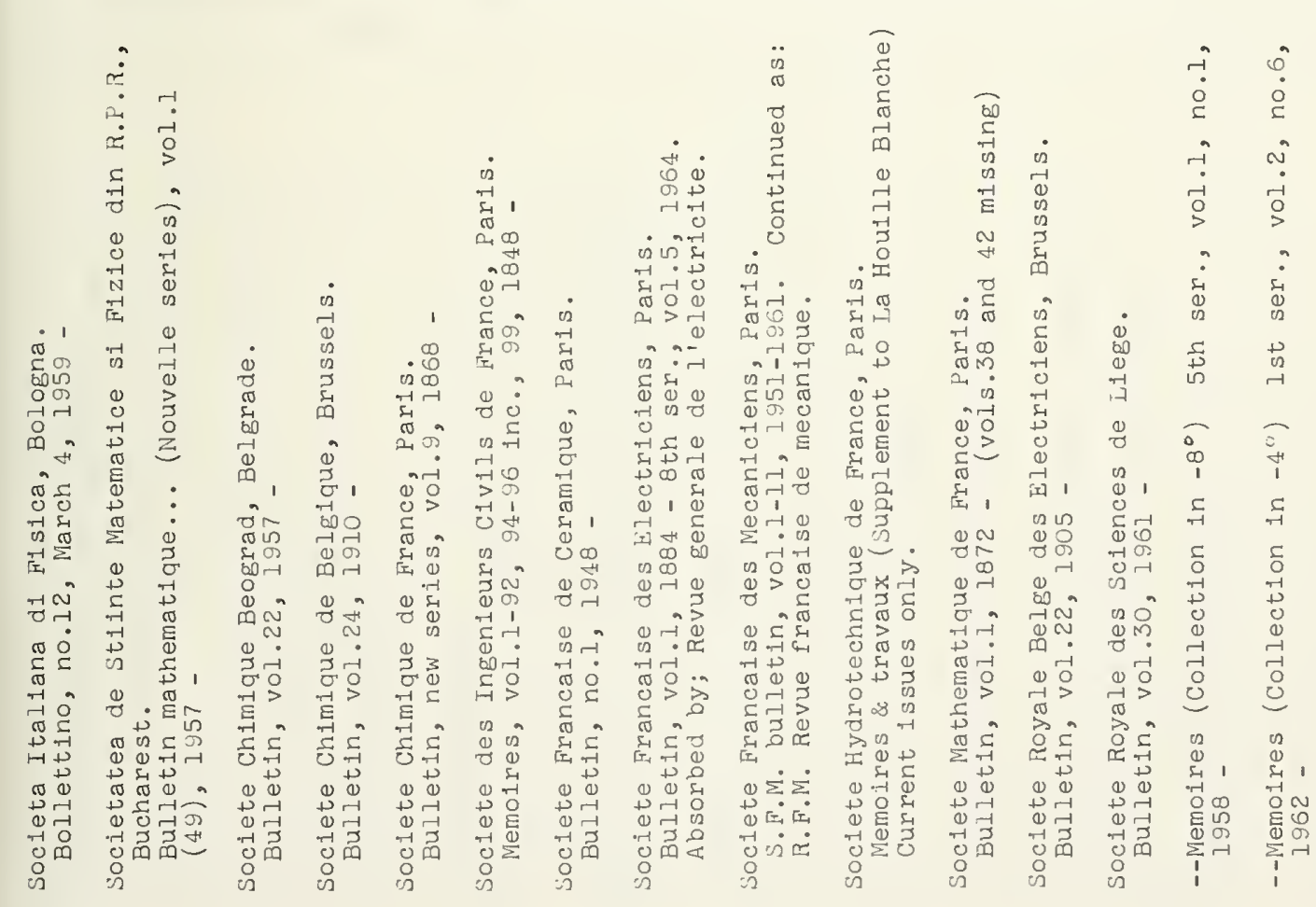

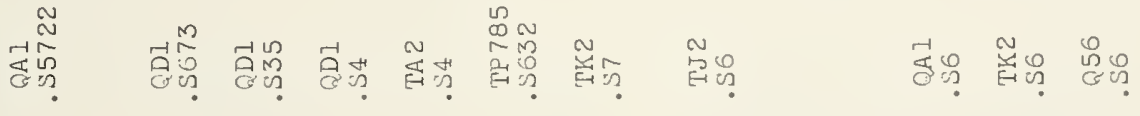




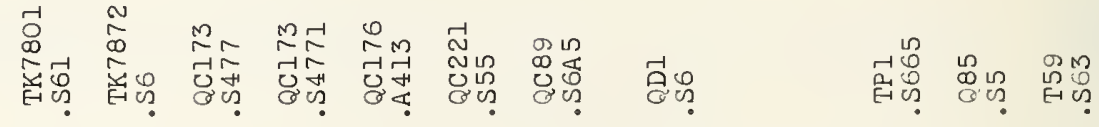

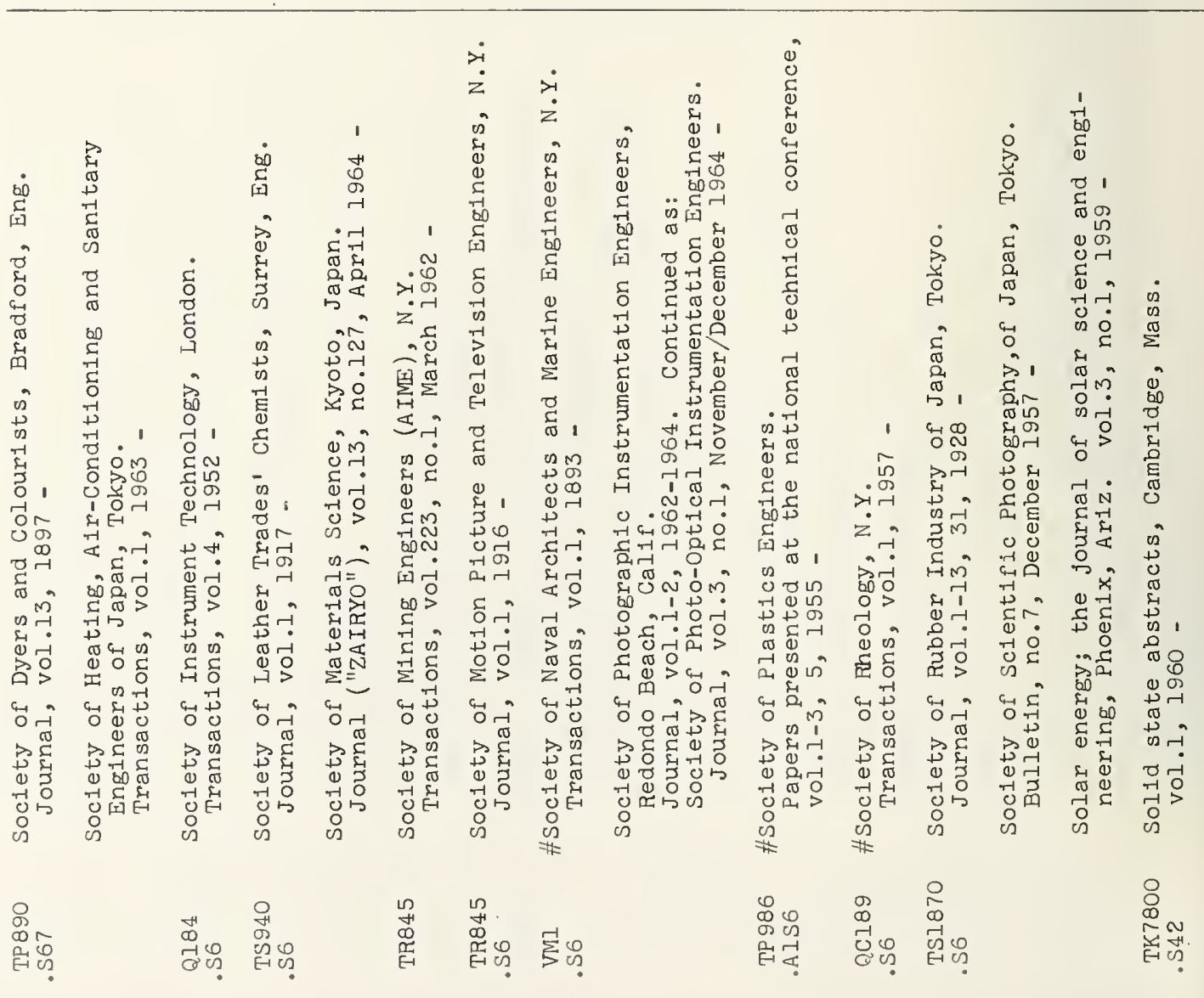




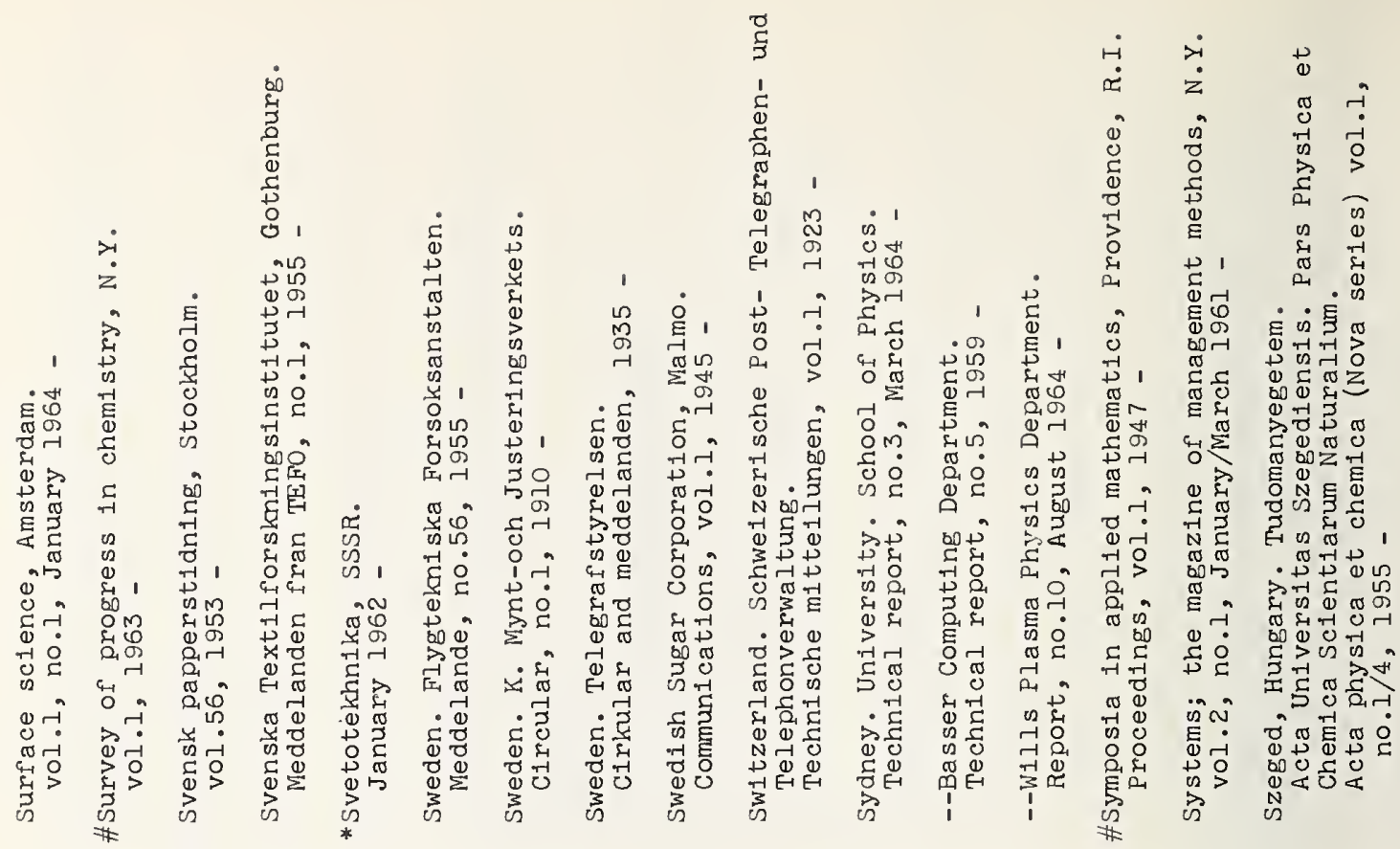

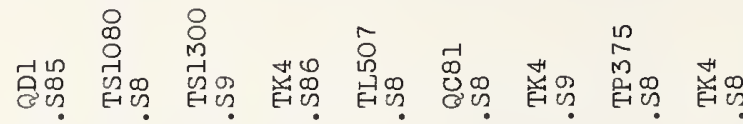

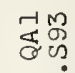

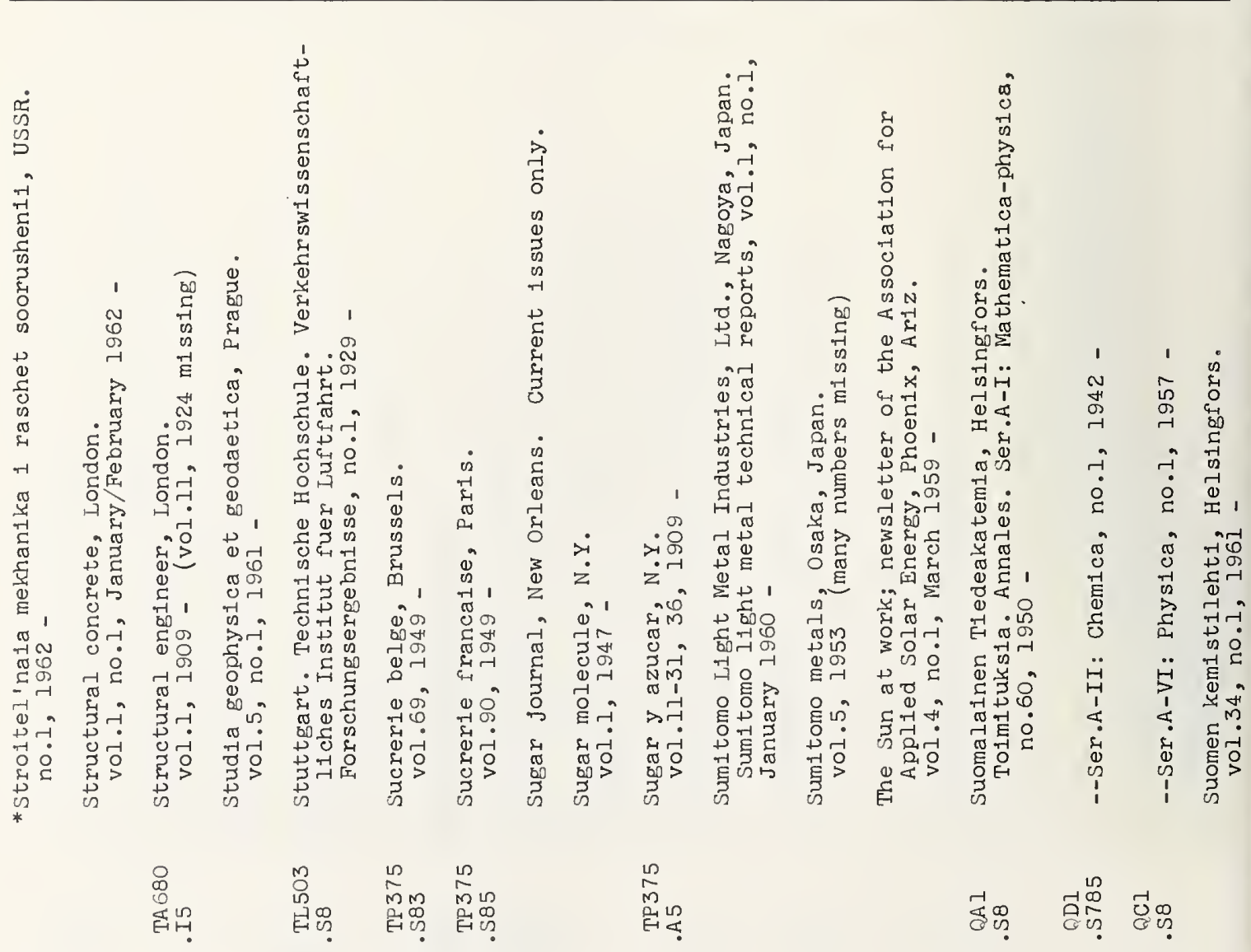




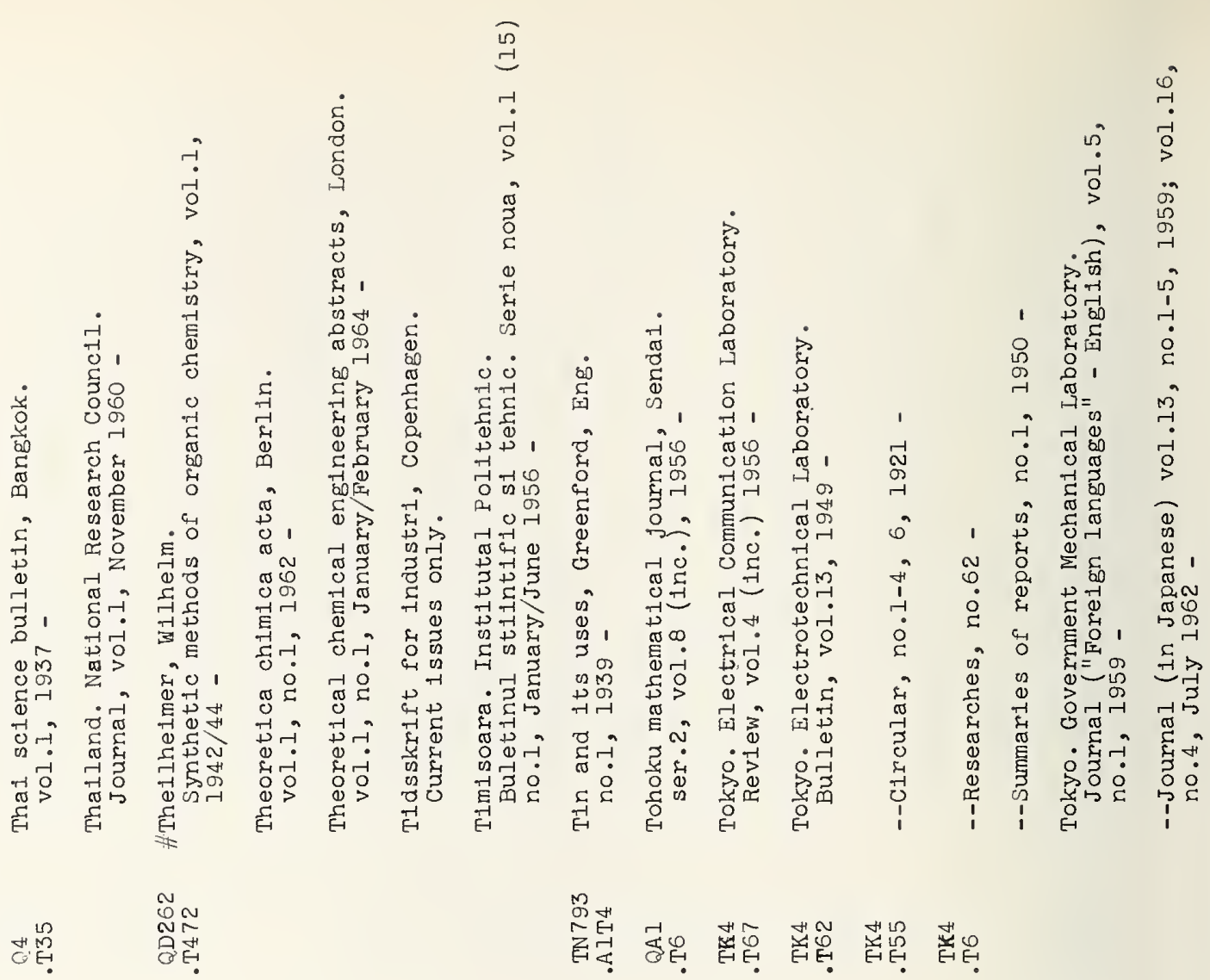




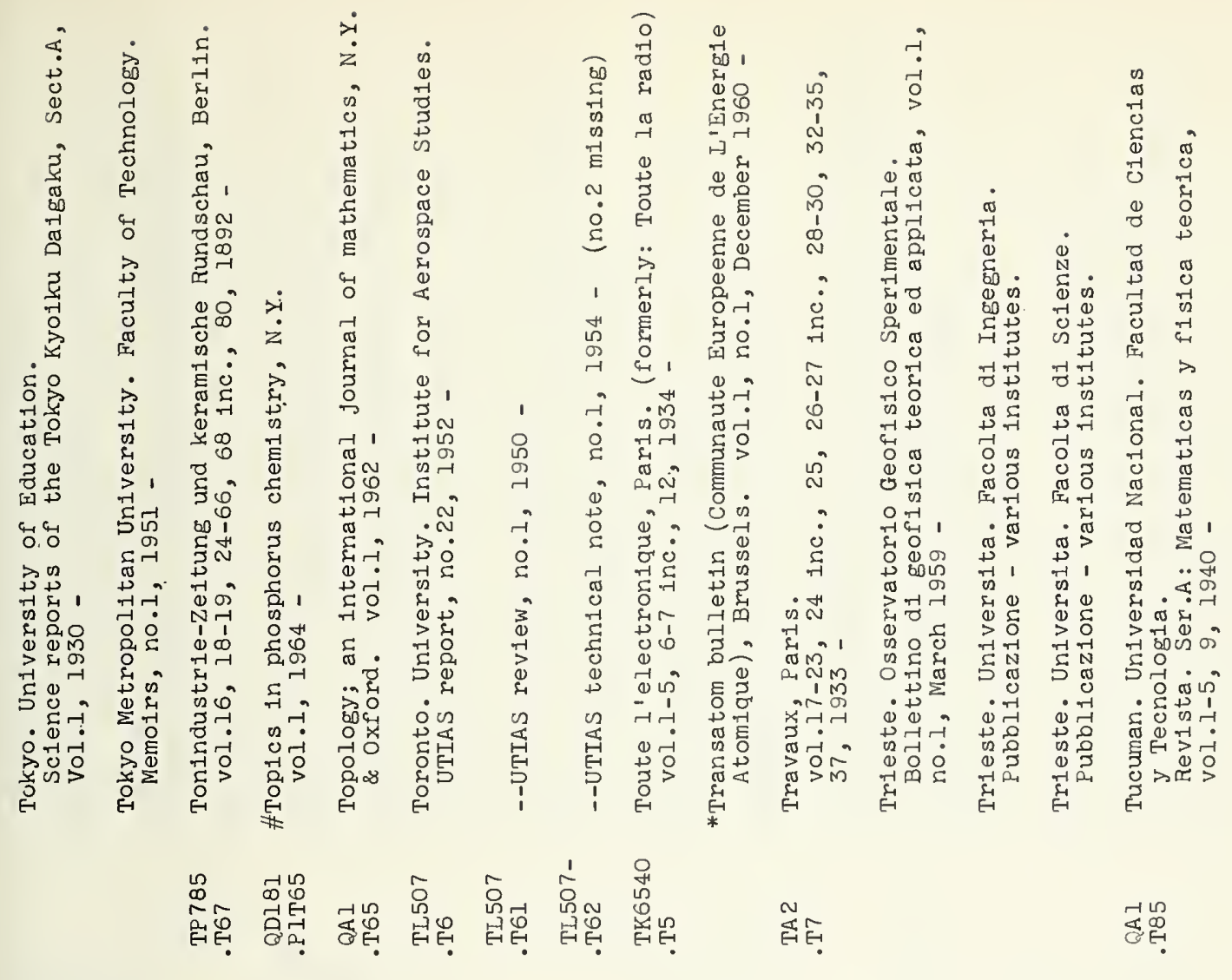

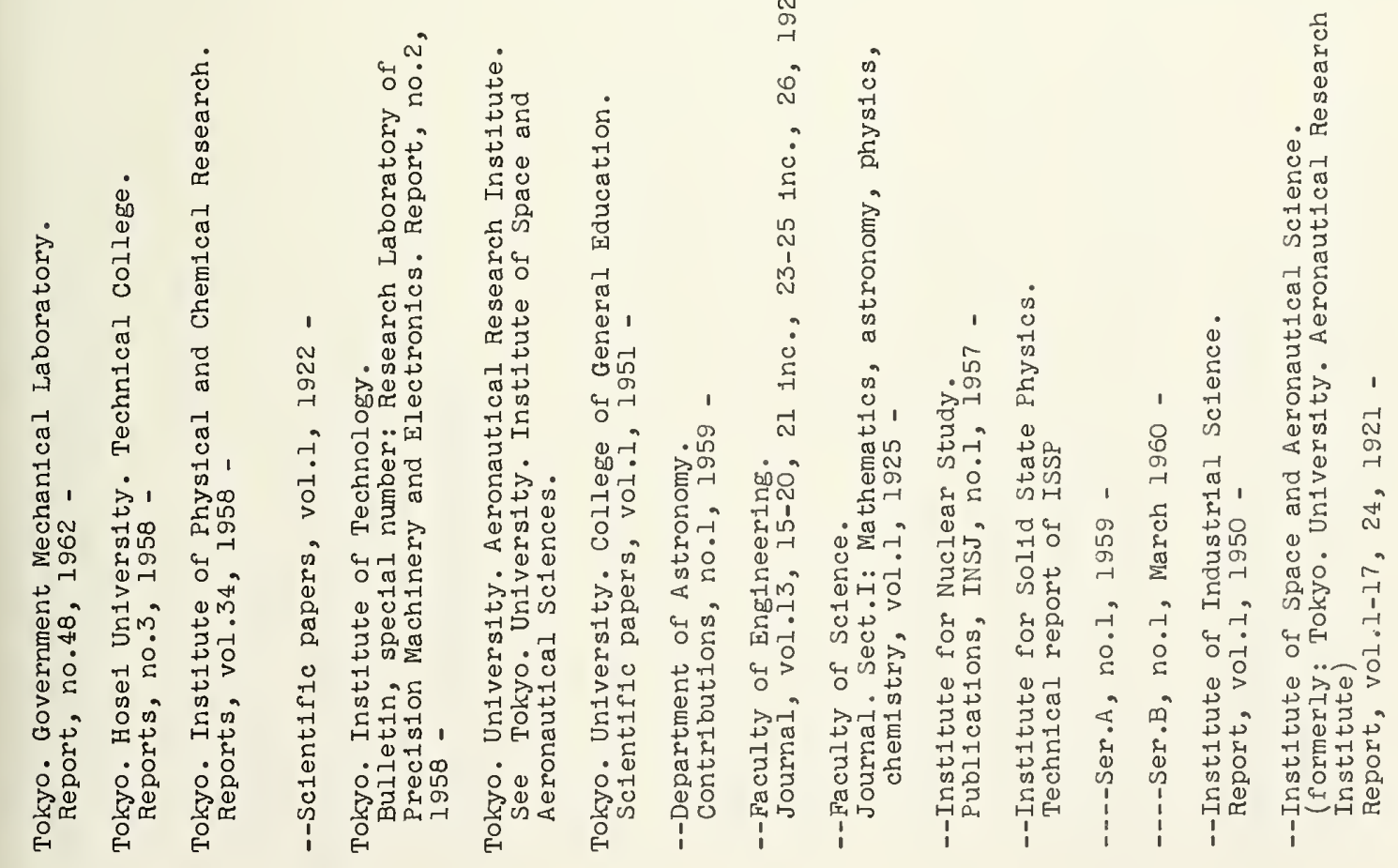

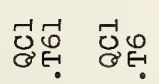



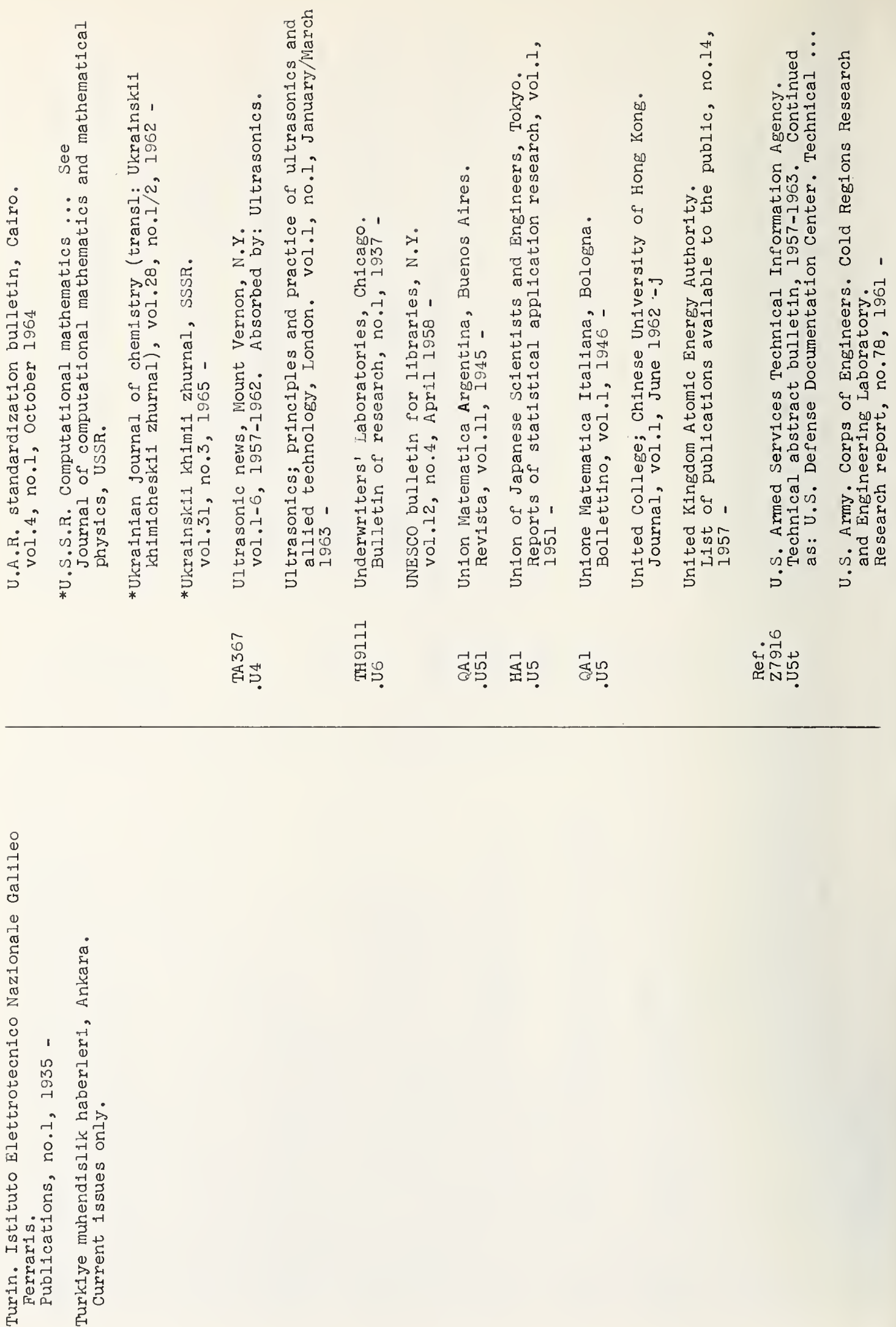

鼠思 
, .

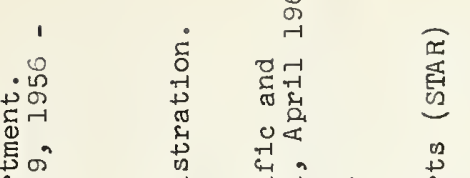

:

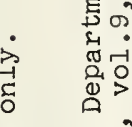

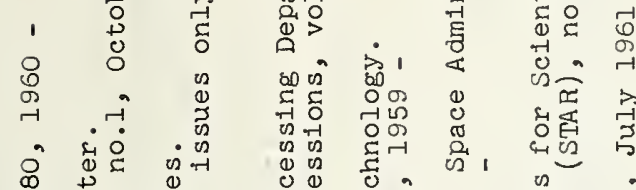

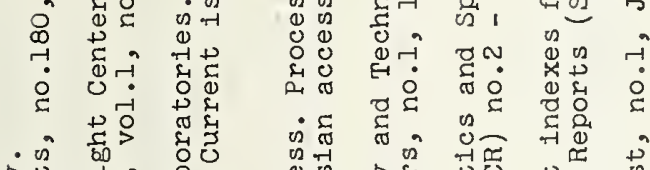

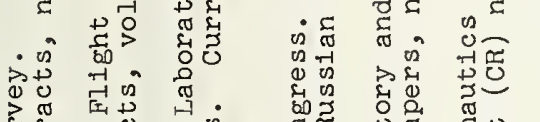

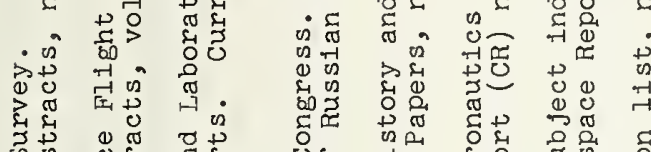

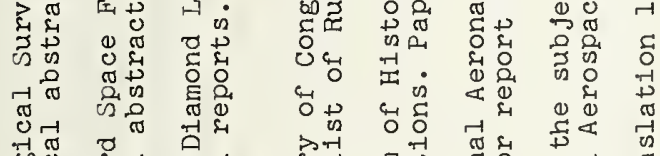

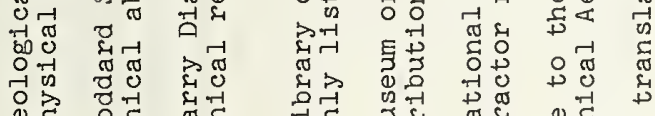

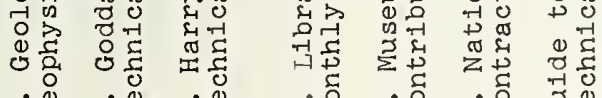

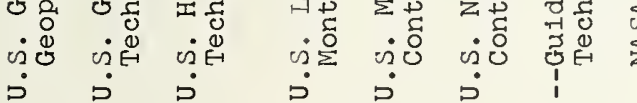

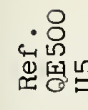

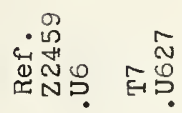

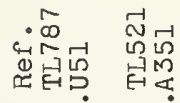

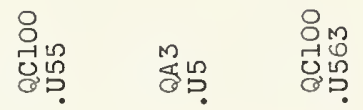

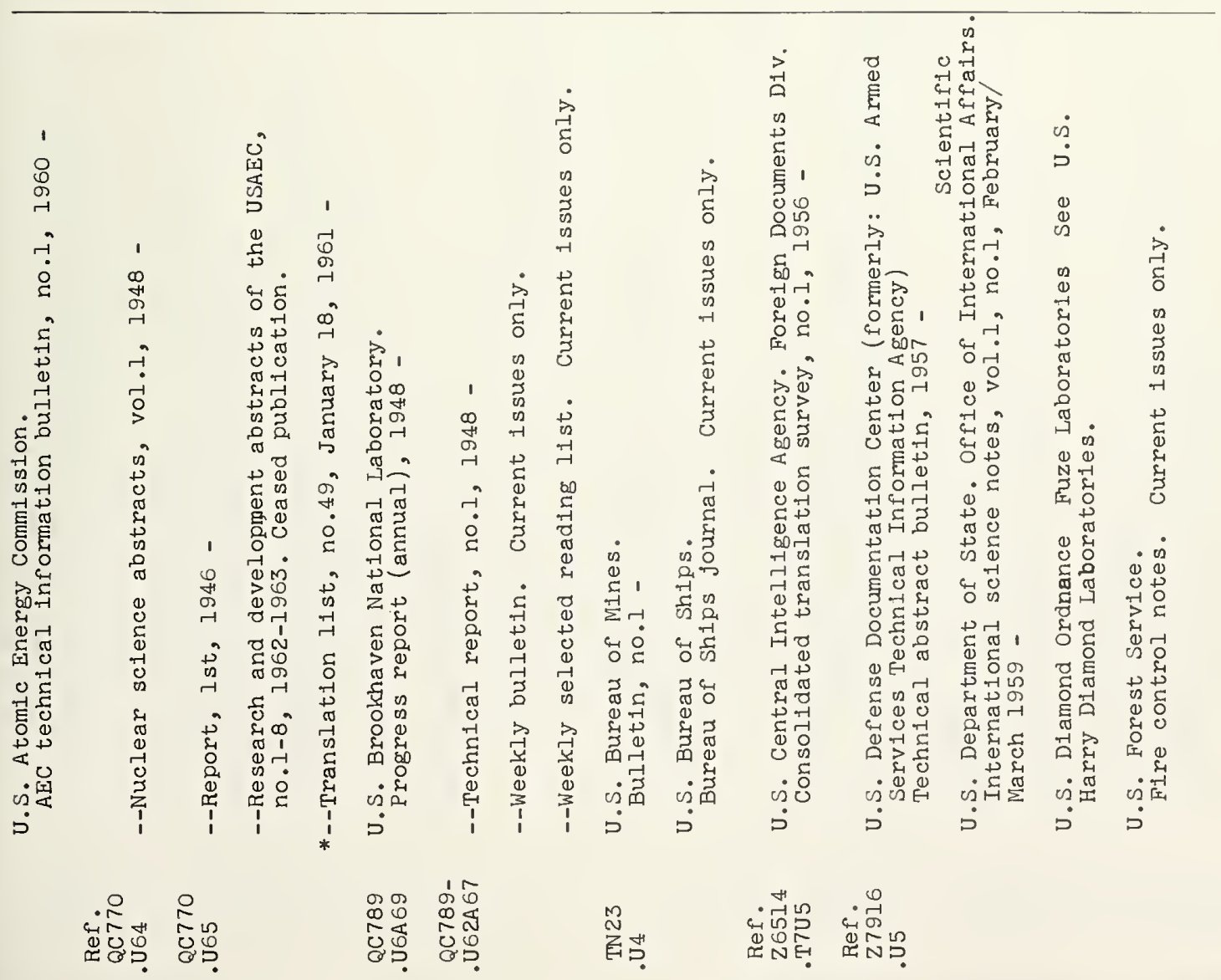




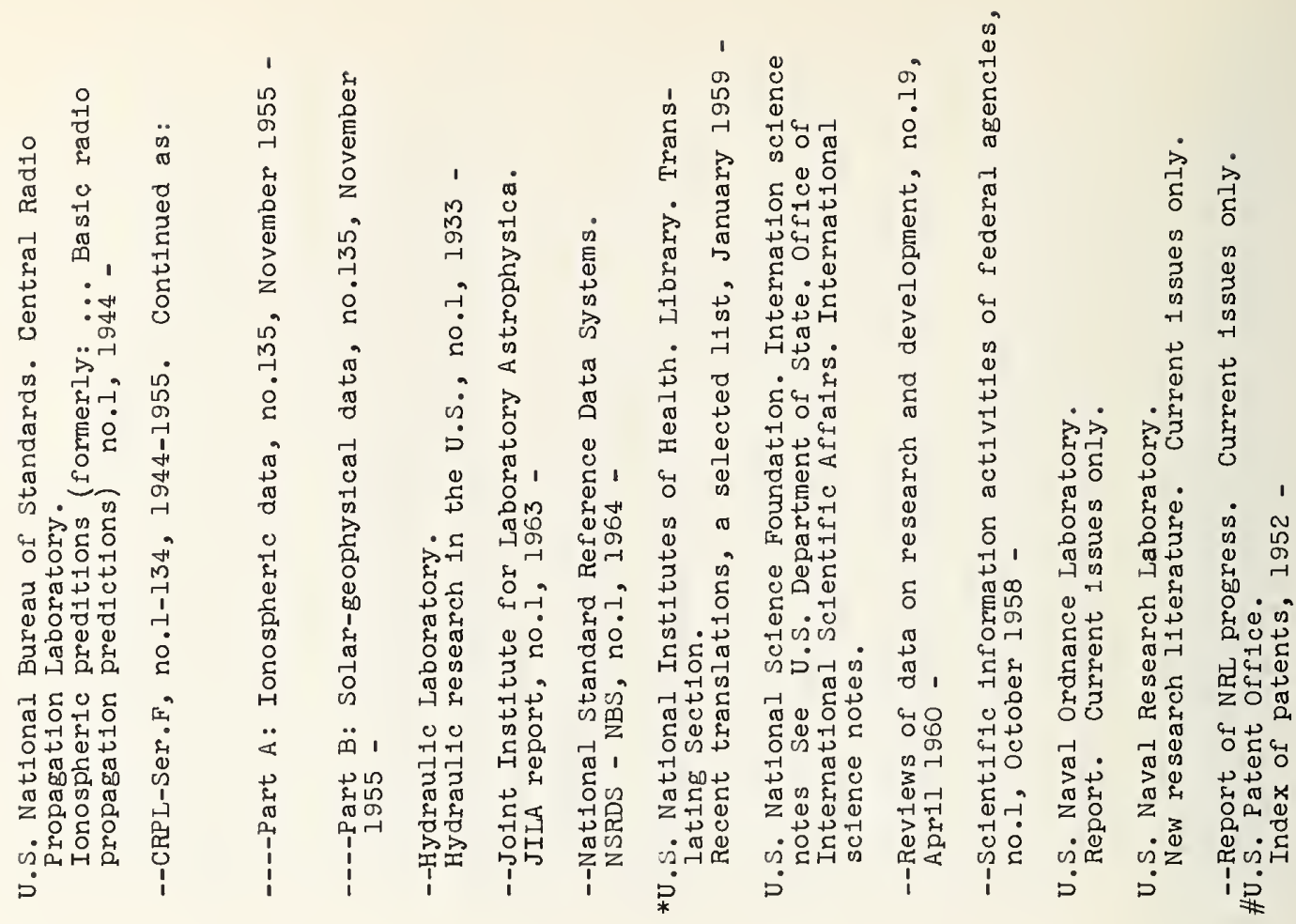

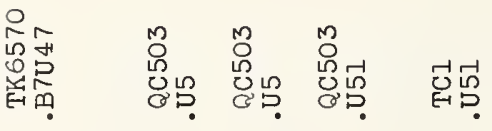

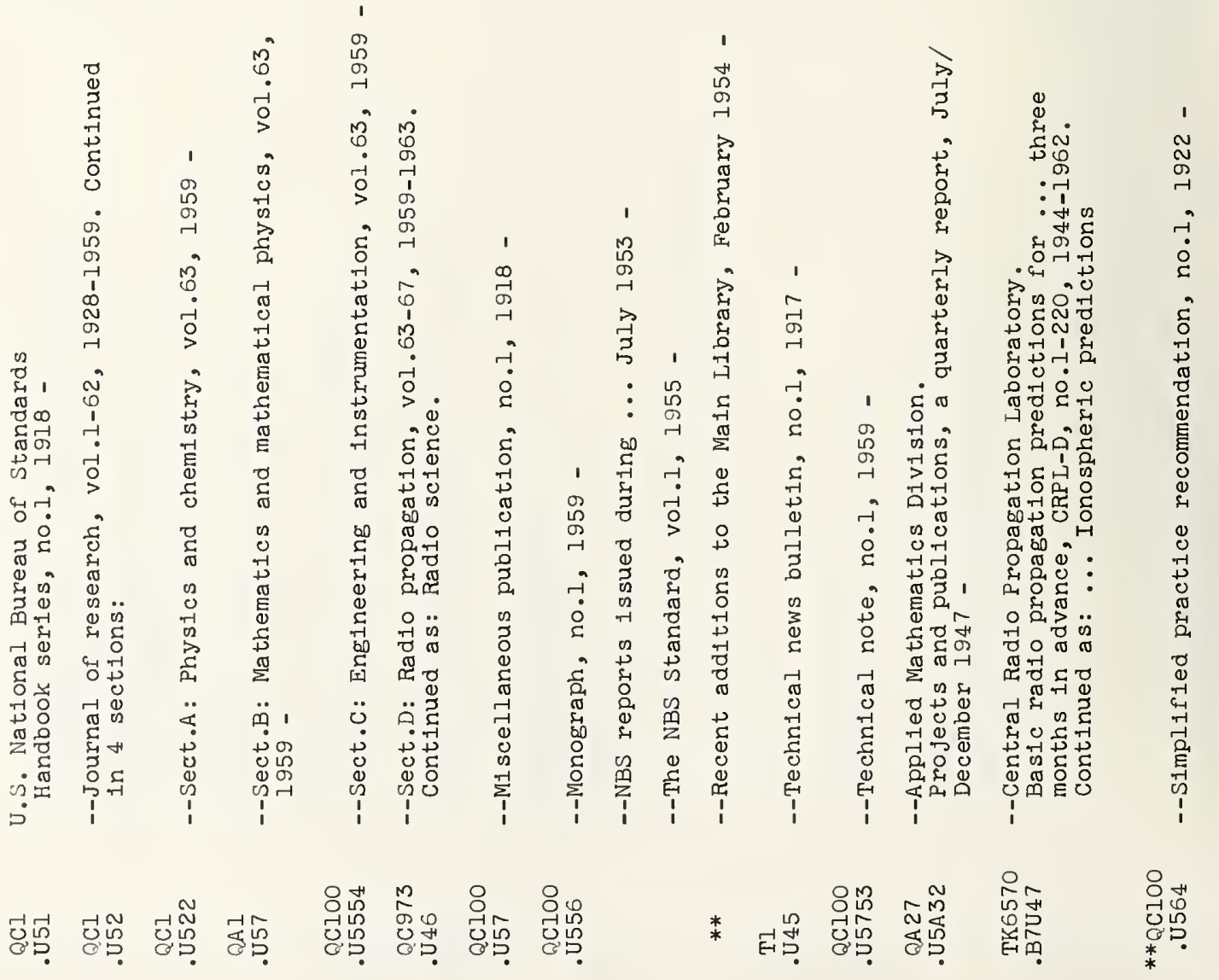




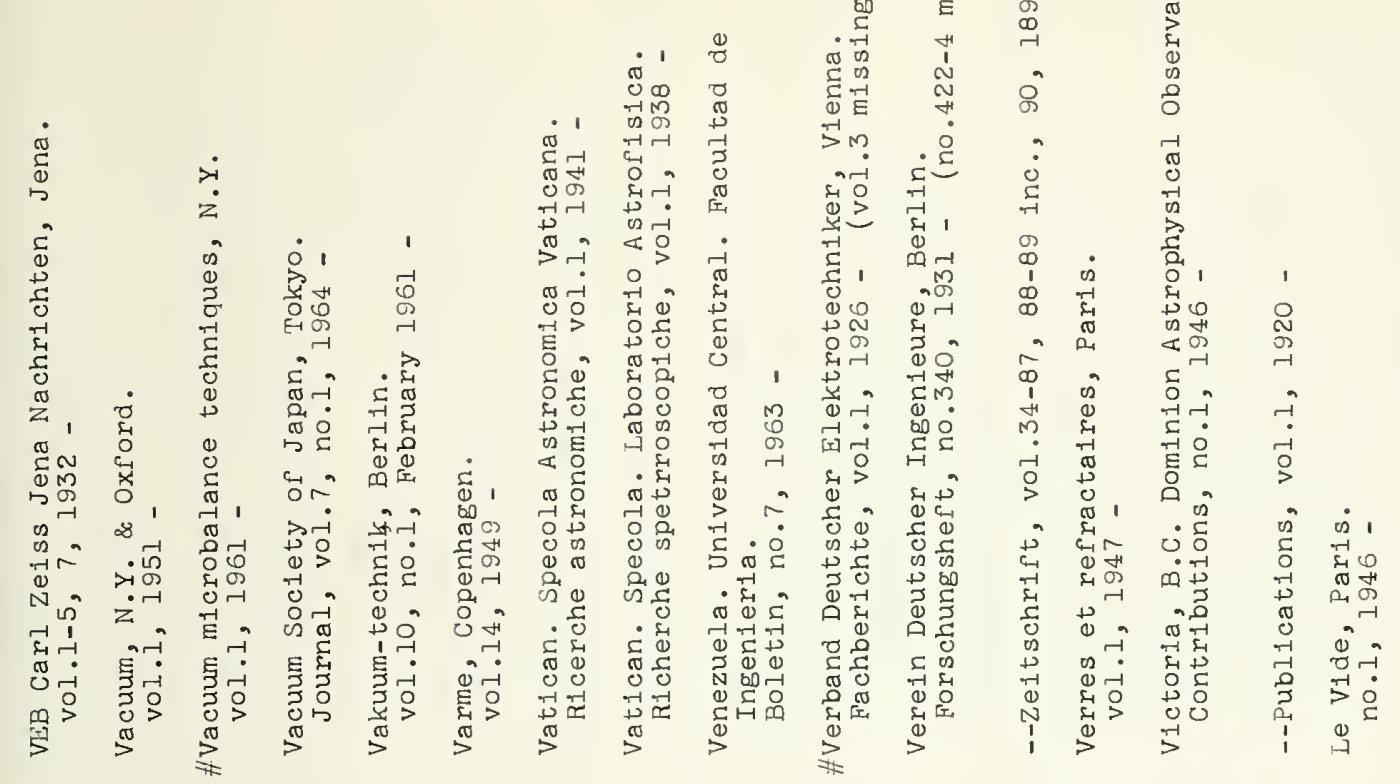

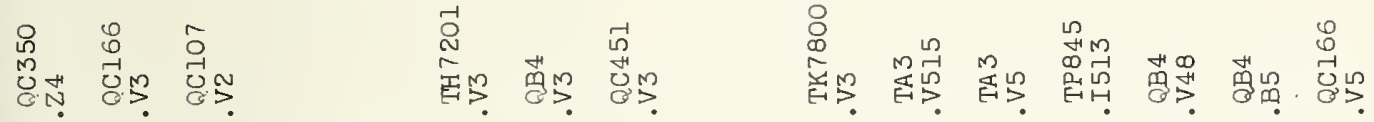

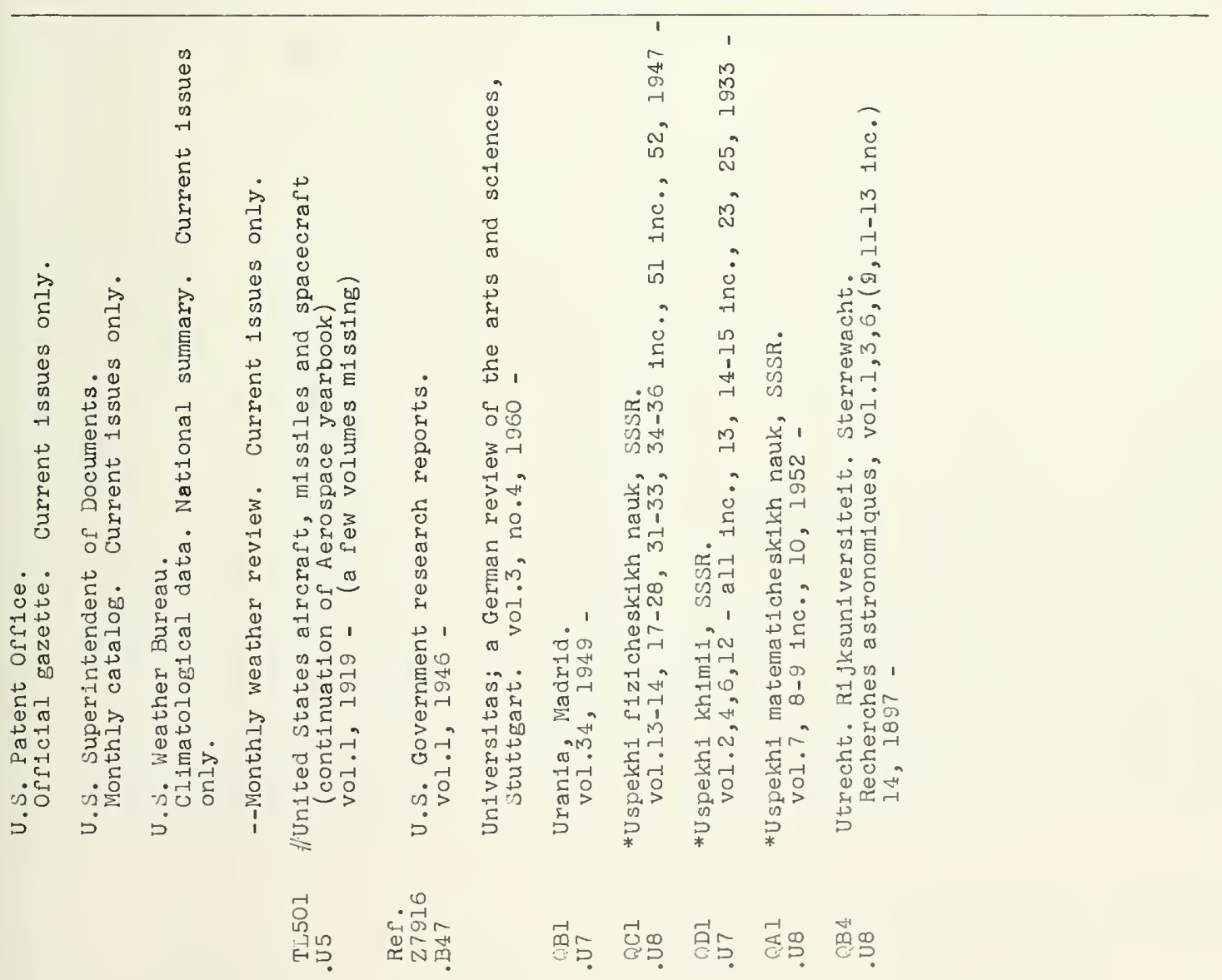




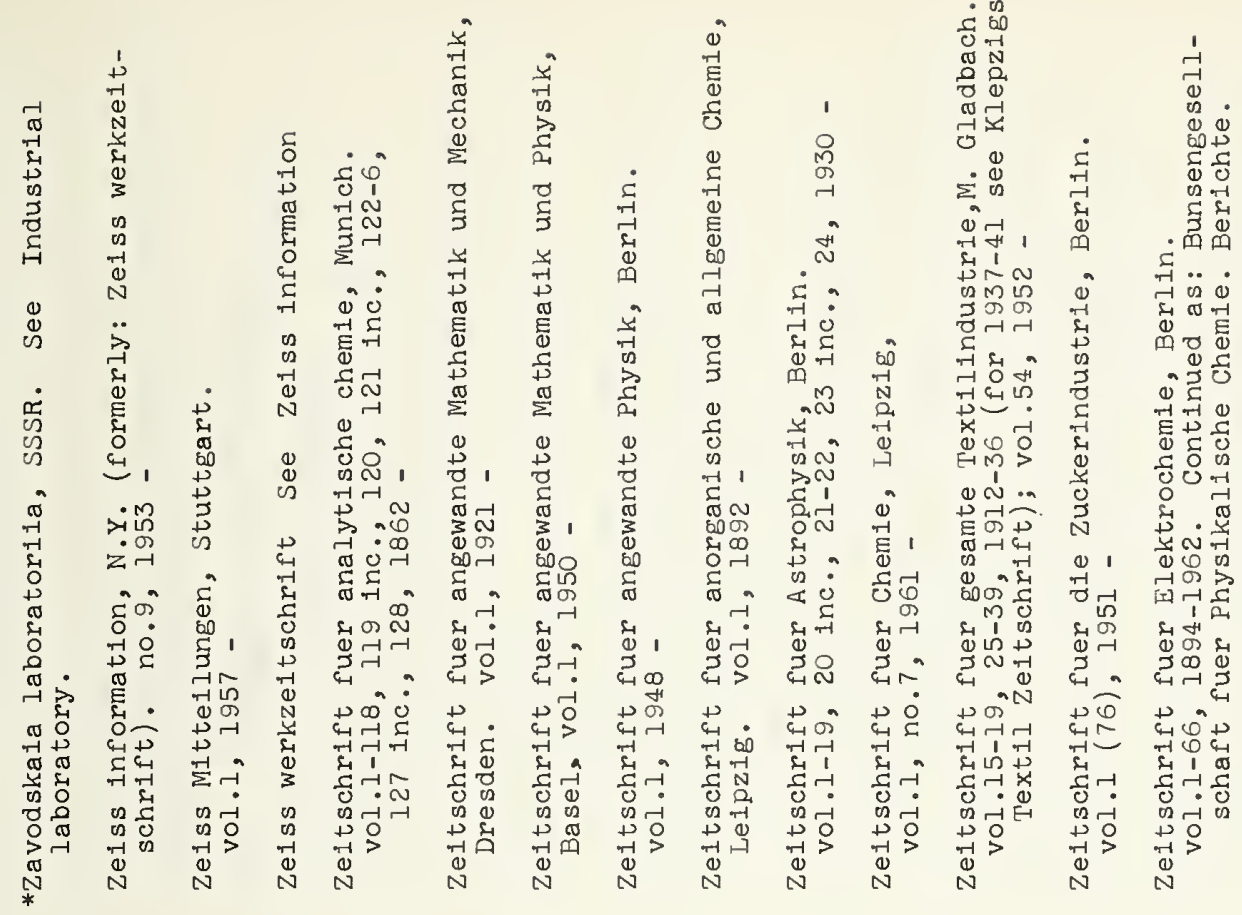

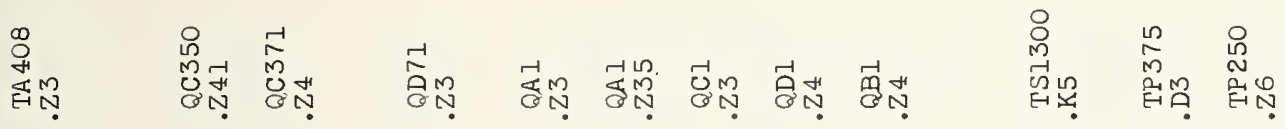

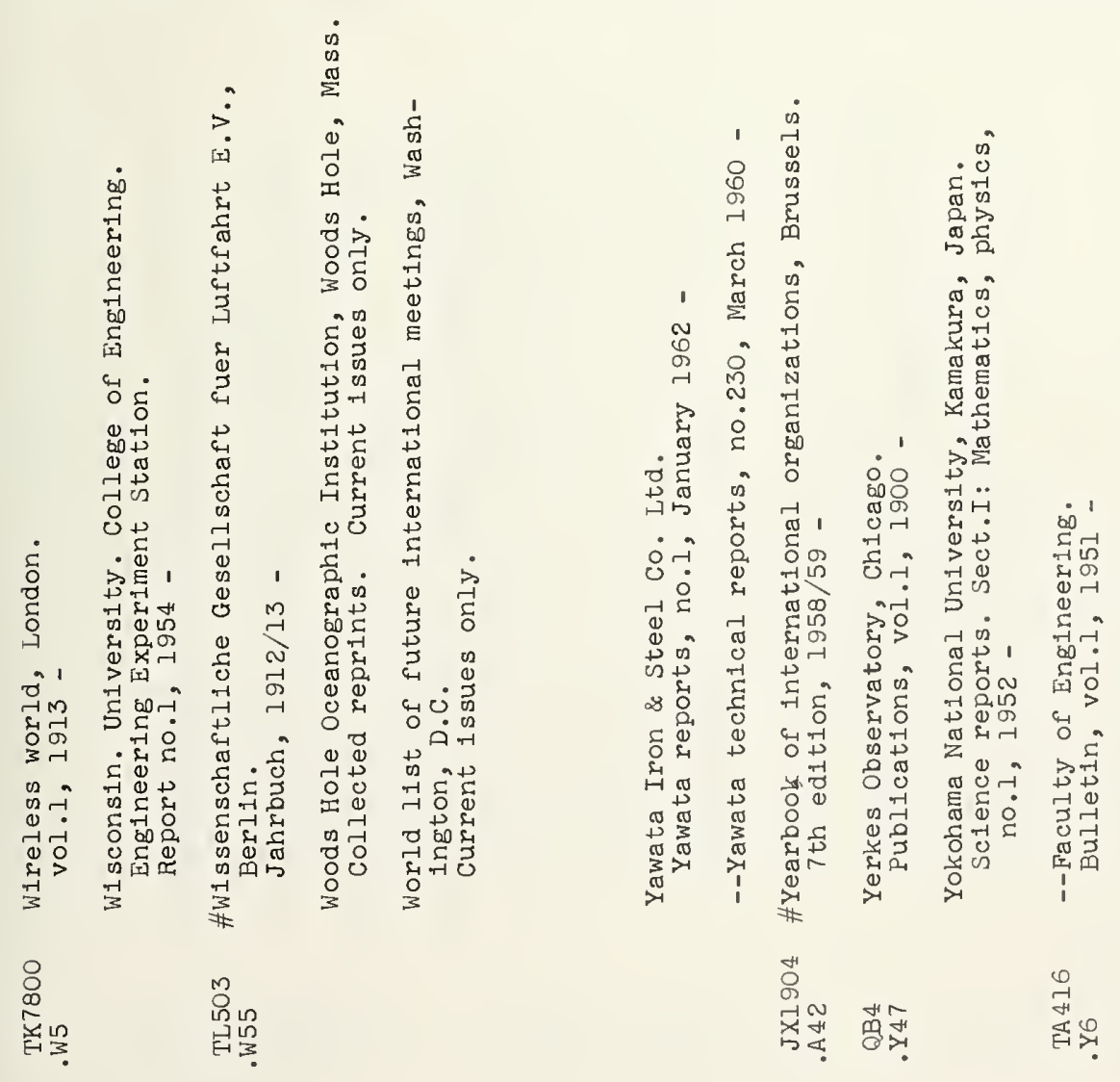




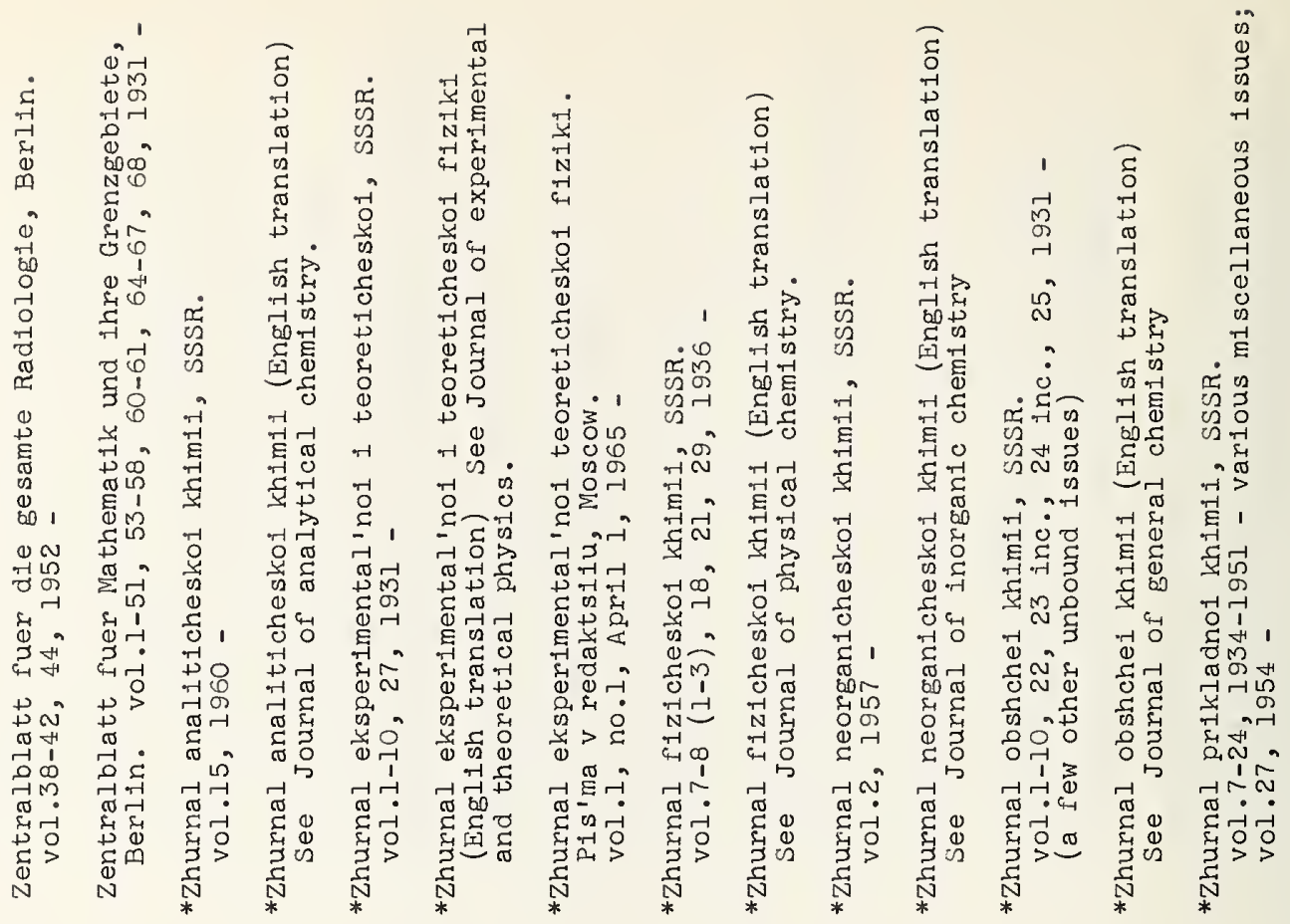

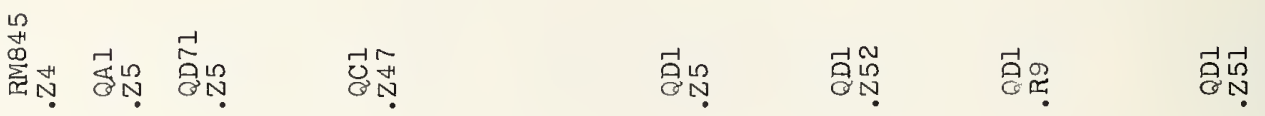

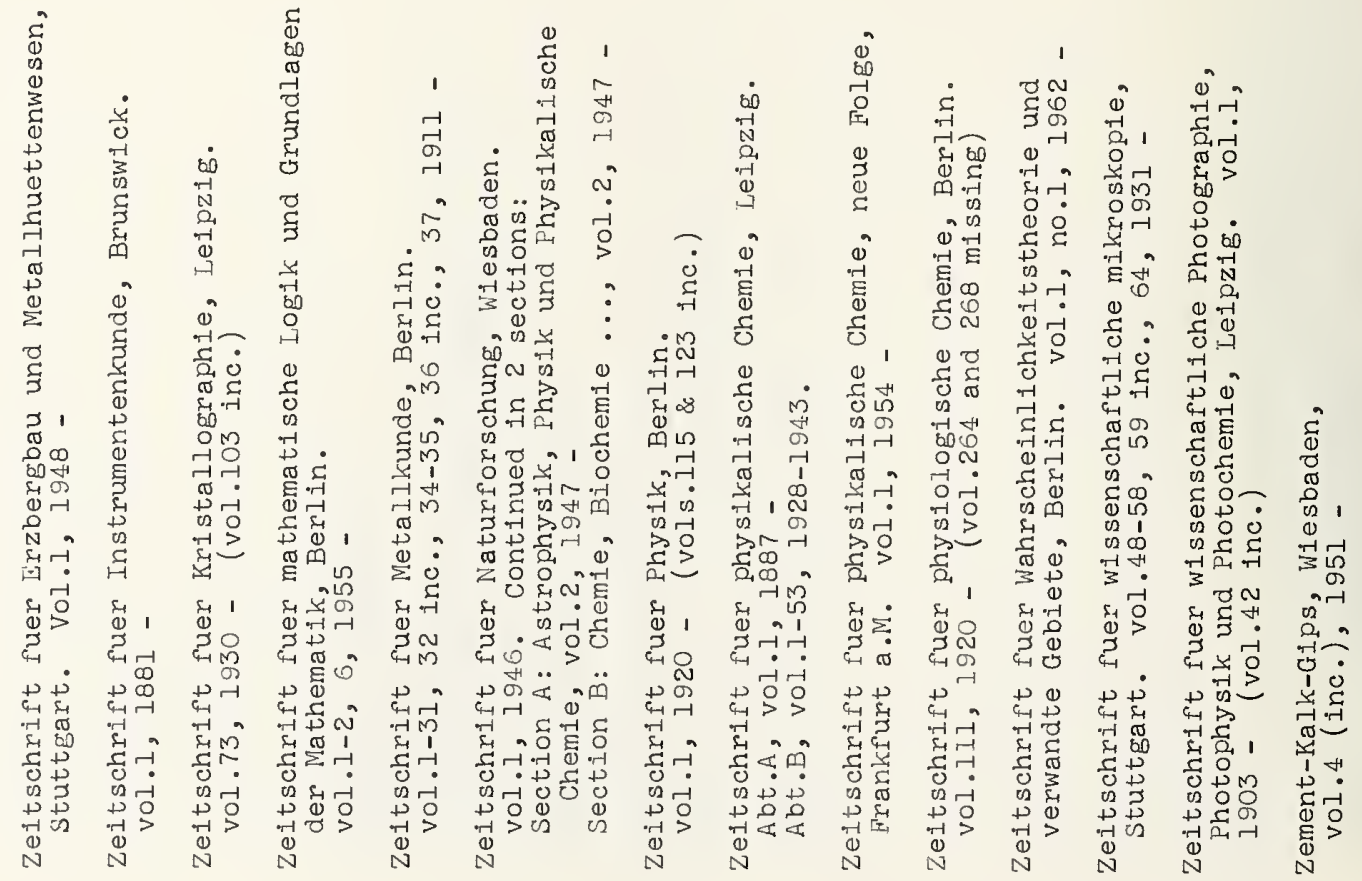

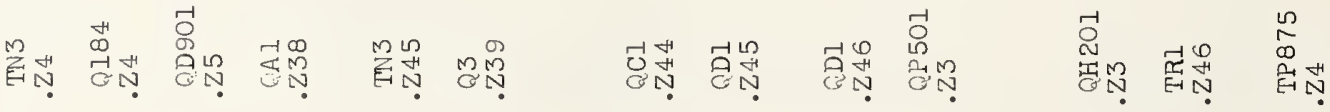




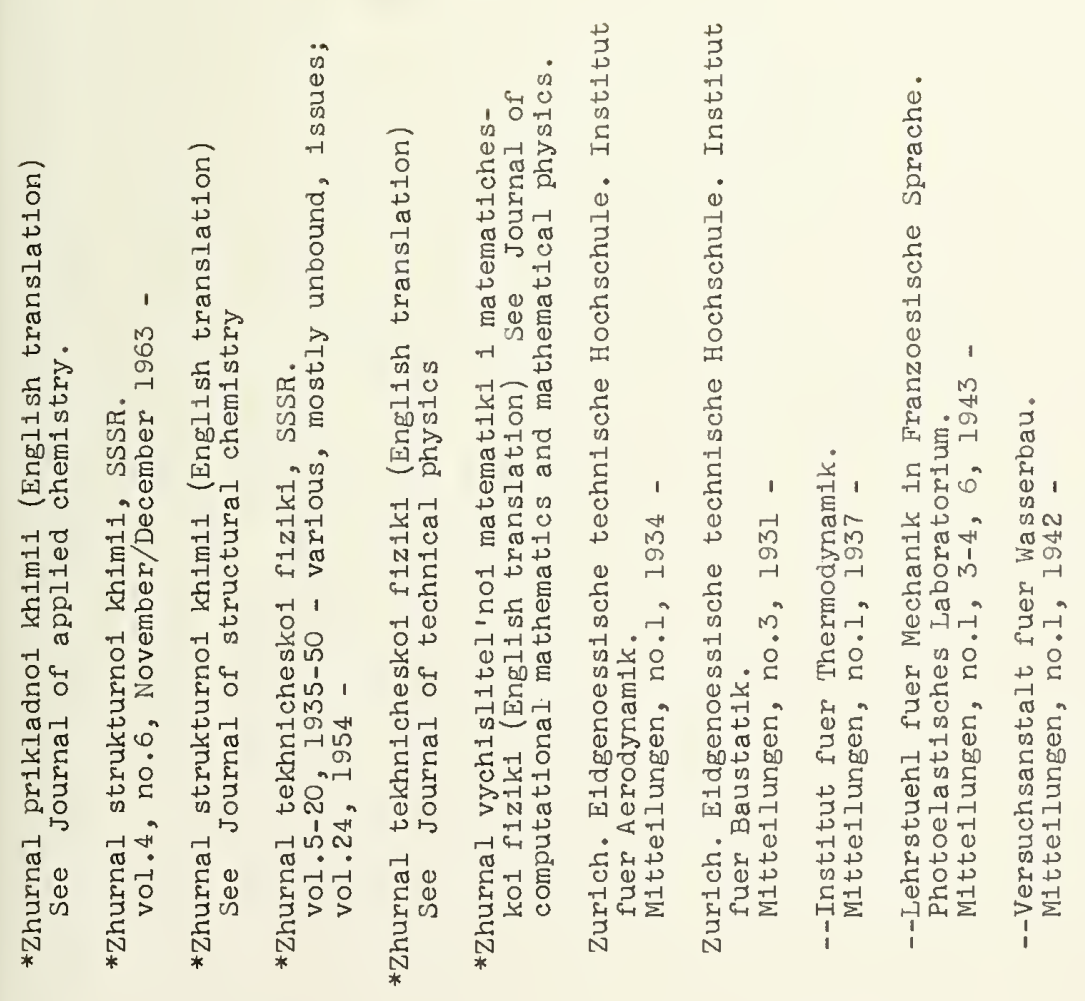

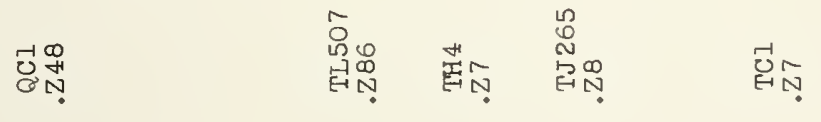






OFFICIAL BUSINESS 

